GIANCARLO BARBOSA MICHELI

ANÁLISE NUMÉRICO-EXPERIMENTAL DO IMPACTO EM CHAPAS DE ALUMÍNIO AERONÁUTICO

São Paulo

2008 

GIANCARLO BARBOSA MICHELI

\section{ANÁLISE NUMÉRICO-EXPERIMENTAL DO IMPACTO EM CHAPAS DE ALUMÍNIO AERONÁUTICO}

Tese apresentada à Escola Politécnica da

Universidade de São Paulo para obtenção do título de Doutor em Engenharia 

GIANCARLO BARBOSA MICHELI

\section{ANÁLISE NUMÉRICO-EXPERIMENTAL DO IMPACTO EM CHAPAS DE ALUMÍNIO AERONÁUTICO}

Tese apresentada à Escola Politécnica da

Universidade de São Paulo para obtenção do título de Doutor em Engenharia

Área de Concentração:

Engenharia Mecânica

Orientador: Prof. Associado

Marcílio Alves 


\section{FICHA CATALOGRÁFICA}

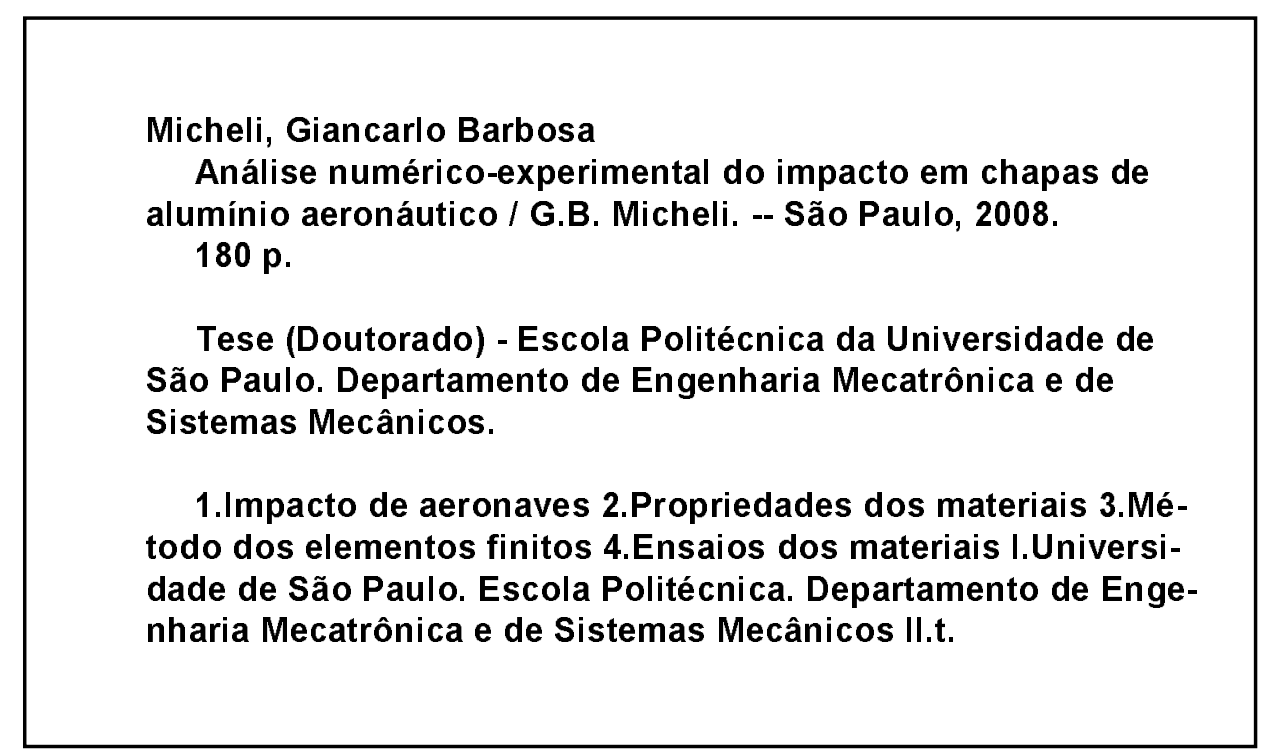

Autorizo a reprodução e/ou divulgação total ou parcial da presente obra, por qualquer meio convencional ou eletrônico, desde que citada a fonte. - $\mathrm{O}$ autor. 
Dedico aos meus queridos pais. 



\section{AGRADECIMENTOS}

A Deus.

Aos meus pais Reinaldo e Zilda, pelo carinho e apoio em minhas decisões.

Ao meu amigo e orientador Marcílio, pelo suporte, dedicação e, principalmente, pela paciência e crédito, demonstrados por diversas vezes.

À minha família, em especial, Lourdes, Lídia, Wanderley e meus irmãos Giu, Gui e Gu, pelo apoio dado em muitos momentos.

À Cris, pelo carinho e compreensão.

Aos meus companheiros e amigos que conheci na moradia estudantil, sempre dispostos a conversar e compartilhar risadas.

Aos colegas de trabalho e professores do GMSIE-USP, pela disposição em ajudar sempre que preciso.

Ao apoio fincanceiro da FAPESP (Projeto N. 02/11312-9) de 2003 a 2004, e da CAPES de 2005 a 2008. 

"A sabedoria é a coisa principal; adquire pois a sabedoria, emprega tudo o que possuis na aquisição de entendimento."

(Provérbios 4:7). 



\section{RESUMO}

A interação dinâmica resultante do impacto de esferas de aço contra chapas de alumínio é estudada através da representação numérica de testes experimentais, os quais imitam freqüentes colisões de pequenos fragmentos contra a fuselagem de aeronaves. Importância é dada à modelagem do comportamento visco-plástico do material da chapa, o que conduz à proposição de uma modificação no método de caracterização dinâmica mecânica de material, realizado através de um equipamento denominado Barra de Hopkinson. Adicionalmente, a influência de possíveis erros na seleção de parâmetros de simulação, relacionados ao contato, amortecimento estrutural e principalmente ao material, é discutida através de análises numéricas de sensibilidade. Testes de impacto foram conduzidos de forma a se obter a velocidade balística das chapas. O deslocamento máximo permanente das chapas a baixas velocidades também foi medido. O método de caracterização dinâmica de material proposto é então avaliado pela comparação dos resultados de simulações numéricas frente aos dados experimentais obtidos nos testes de impacto. As predições de deslocamento máximo permanente, para testes sem perfuração da chapa, e de velocidade balística, para testes de perfuração total, indicaram uma boa concordância numérico-experimental, respeitadas as observações realizadas acerca dos parâmetros envolvidos.

Palavras-chaves: impacto balístico, caracterização dinâmica do material, método dos elementos finitos, chapas finas, barra de Hopkinson. 



\begin{abstract}
Dynamic interaction present on impact of steel spheres against aluminum panels is studied through a numerical model of experimental tests, which reproduce common collisions of small debris against airplane fuselages. This thesis emphasizes the panel-material visco-plastic behaviour modeling, which leads to a modification of the material dynamic characterization method, based on a Split Hopkinson Pressure Bar. Influence of possible errors in some numerical simulations parameters, related to contact, structural damping and material behaviour is also discussed by sensitivity numerical analyses. Impact tests were conducted to obtain the ballistic velocity of the panels. Also, the final maximum plate deformation at low velocities was measured. The proposed dynamic characterization method is explored by comparing the numerical simulation and the impact tests. The predicted maximum impact point displacement, for no perforation cases, and the ballistic velocity, for total perforation tests, present a good numerical-experimental agreement, bearing in mind the observations about the various used parameters.
\end{abstract}

Keywords: ballistic impact, material dynamic characterization, finite element method, thin plates, Hopkinson's bar. 



\section{LISTA DE ILUSTRAÇÕES}

Figura 1.1 - Região danificada na aeronave da Delta Air Lines, devido ao impacto de fragmentos da turbina (NATIONAL TRANSPORTATION SAFETY BOARD, 1998). . . . . . . . . . . . . . . . . 36

Figura 1.2 - Incêndio no Concorde F-BTSC durante a decolagem devido ao impacto de fragmentos existentes na pista de decolagem (ROXBURGH, 2003). . . . . . . . . . . . . . . . . .

Figura 1.3 - Tanque de combustível da asa direita do boeing 737-800 perfurado por parafuso (MSNBC - Associated Press, 2007) . . . . . . . . . 38

Figura 1.4 - Dano causado pelo impacto de um pássaro (ALVES; CHAVES; BIRCH, 2003) . . . . . . . . . . . . . . . . . . 38

Figura 1.5 - Pára-brisa danificado pelo impacto de um urubu (O POPULAR, 2003).

Figura 1.6 - Estruturas complexas utilizadas para absorção de impacto: (a) honeycomb (DONGSHIN ENGINEERING CORP., 2008); (b) perfil extrudado (BORVIK et al., 2005). . . . . . . . . . . . . . . .

Figura 1.7 - Visualização dos resultados da simulação, em elementos finitos, do impacto de uma esfera numa chapa circular fina (fase de retorno da esfera após perfuração parcial da chapa - vista perfil em corte). . . . . . 41

Figura 3.1 - Corpo sujeito a forças externas. . . . . . . . . . . . . . . . . 47

Figura 3.2 - Geometria do corpo de prova usado nos testes de tração. Medidas em milímetros. . . . . . . . . . . . . . . . . . . . . . 54

Figura 3.3 - (a) Equipamento Instron utilizado nos testes estáticos. (b) Detalhe da montagem do sensor no teste de tração.

Figura 3.4 - corpos de prova antes e depois dos testes, indicando pouco estrangulamento na região de ruptura. . . . . . . . . . . . . .

Figura 3.5 - Curvas tensão versus deformação equivalentes do material M1, na direção de laminação (t1601N e t1602N) e a $90^{\circ}$ desta (t16901N e t16904N).

Figura 3.6 - Curvas tensão versus deformação equivalentes do material M2, na direção de laminação (t3201N, t3202N, t3203N e t3204N) e a $90^{\circ}$ desta $(\mathrm{t} 32901 \mathrm{~N}$ e $\mathrm{t} 32902 \mathrm{~N}) \ldots \ldots \ldots \ldots$. . . . . . . . . . 56 
Figura 3.7 - Ilustração do modo utilizado para cálculo da tensão de escoamento. O material M1 é utilizado neste exemplo. . . . . . . . . . . 58

Figura 3.8 - Curvas tensão versus deformação plástica equivalentes do material M1. . . . . . . . . . . . . . . . . . . . . . 58

Figura 3.9 - Curvas tensão versus deformação plástica equivalentes do material M2 . . . . . . . . . . . . . . . . . . . . . . 59

Figura 3.10 - Modelos para a curva tensão versus deformação plástica equivalentes do material M1. . . . . . . . . . . . . . . . . . . 61

Figura 3.11 - Modelos para a curva tensão versus deformação plástica equivalentes do material M2. . . . . . . . . . . . . . . . . . . . 62

Figura 3.12 - Detalhe (a) do corpo de prova e (b) da compressão pelos pratos da máquina Instron. . . . . . . . . . . . . . . . . . 65

Figura 3.13 - Parâmetros do corpo de prova no formato de anel. . . . . . . . . 65

Figura 3.14 - Método de medição do histórico de deslocamento no teste de compressão.

Figura 3.15 - Curva tensão versus deformação equivalentes do material M1, na direção perpendicular à de laminação.

Figura 3.16 - Curva tensão versus deformação equivalentes do material M2, na direção perpendicular à de laminação. . . . . . . . . . . . . . . . 68

Figura 3.17 - Comparação entre os modelos de Lemaitre e Swift e a curva experimental para o material M1 f . . . . . . . . . . 70

Figura 3.18 - Comparação entre os modelos de Lemaitre e Swift e a curva experimental para o material M2 . . . . . . . . . . . 70

Figura 3.19 - Comparação entre os modelos em tração e compressão do material M1 . . . . . . . . . . . . . . . . . . . . . . . . . 71

Figura 3.20 - Comparação entre os modelos em tração e compressão do material M2 . . . . . . . . . . . . . . . . . . . . . 71

Figura 4.1 - Princípio de funcionamento de uma BH clássica. . . . . . . . . . 74

Figura 4.2 - Foto da BH utilizada nos testes de caracterização dinâmica. Detalhes construtivos são apresentados em (GALLINA; BIRCH; ALVES, 2003). 76

Figura 4.3 - Esquema da cadeia de medição utilizada na BH. . . . . . . . . . 79

Figura 4.4 - Sinais da BH (a) antes e (b) após a aplicação de filtro digital passa baixa de 150kHz. Teste M1T3. Corpo de prova: disco. . . . . . . 82 
Figura 4.5 - Pulsos típicos de deformação elástica deslocados. Corpo de prova: disco. . . . . . . . . . . . . . . . . 83

Figura 4.6 - Equilíbrio de forças avaliado pela relação entre os pulsos de deformação na BH. Corpo de prova: disco. . . . . . . . . . . . . . . . 84

Figura 4.7 - Histórico de tensões de engenharia do corpo de prova em formato de disco. . . . . . . . . . . . . . . . . . . . . . . . 84

Figura 4.8 - Histórico de deformações de engenharia do corpo de prova em formato de disco. . . . . . . . . . . . . . . . . . . . 85

Figura 4.9 - Histórico de taxas de deformações de engenharia do corpo de prova em formato de disco. . . . . . . . . . . . . . 85

Figura 4.10 - Taxa de deformação média (M1T3). Corpo de prova: disco. . . . 86

Figura 4.11 - Comportamento quase-estático e dinâmico do material M1. Corpos de prova: discos. . . . . . . . . . . . . . . . . . 87

Figura 4.12 - Comportamento quase-estático e dinâmico do material M2. Corpos de prova: discos. . . . . . . . . . . . . . . 87

Figura 4.13 - Região selecionada das curvas dinâmicas para ajuste dos parâmetros do material M1. Corpos de prova: discos. . . . . . . . . . . . . 88

Figura 4.14 - Região selecionada das curvas dinâmicas para ajuste dos parâmetros do material M2. Corpos de prova: discos. . . . . . . . . . . . 88

Figura 4.15 - Ajuste das curvas dinâmicas com parâmetros do modelo estático do material M1. Corpos de prova: discos. . . . . . . . . . . . . . .

Figura 4.16 - Ajuste das curvas dinâmicas com parâmetros do modelo estático do material M2. Corpos de prova: discos. . . . . . . . . . . . . . . . 90

Figura 4.17 - Ajuste do parâmetro de JC para o material M1. Corpos de prova: discos. . . . . . . . . . . . . . . . . 91

Figura 4.18 - Ajuste do parâmetro de JC para o material M2. Corpos de prova: discos

Figura 4.19 - Ajuste dos parâmetros de CS para o material M1. Corpos de prova: discos.

Figura 4.20 - Ajuste dos parâmetros de CS para o material M2. Corpos de prova: discos.

Figura 4.21 - Curvas reconstruídas pelo modelo de JC para o material M1.

Corpos de prova: discos. . . . . . . . . . . . . . . . . . . . . . 94 
Figura 4.22 - Curvas reconstruídas pelo modelo de CS para o material M1. Corpos de prova: discos. . . . . . . . . . . . . . . . . . . . . . . . 94

Figura 4.23 - Curvas reconstruídas pelo modelo de JC para o material M2. Corpos de prova: discos. . . . . . . . . . . . . . . . . . 95

Figura 4.24 - Curvas reconstruídas pelo modelo de CS para o material M2. Corpos de prova: discos. . . . . . . . . . . . . . . 95

Figura 5.1 - Curva de entrada do material insensível à taxa de deformação. 101

Figura 5.2 - Curvas de entrada e reconstruídas de (a) discos e (b) anéis frente à variação do atrito. . . . . . . . . . . . . . . . . . . . . . . 102

Figura 5.3 - Erro no nível de tensão em função do diâmetro interno normalizado do corpo de prova. . . . . . . . . . . . . . . . . 103

Figura 5.4 - Erro na taxa de deformação em função do diâmetro interno normalizado do corpo de prova. . . . . . . . . . . . . . . . 103

Figura 5.5 - Sistema de coordenadas para um anel sob compressão (ALVES; KARAGIOZOVA, 2007). . . . . . . . . . . . . . . . . . 104

Figura 5.6 - Equilíbrio de forças avaliado pela relação entre os pulsos de deformação na BH. Corpo de prova: anel. . . . . . . . . . . . . . . . . 109

Figura 5.7 - Taxa de deformação média (teste M1T1A). Corpo de prova: anel. 110 Figura 5.8 - Comportamento quase-estático e dinâmico do material M1. Corpos de prova: anéis. . . . . . . . . . . . . . . . . 111

Figura 5.9 - Comportamento quase-estático e dinâmico do material M2. Corpos de prova: anéis.

Figura 5.10 - Região selecionada das curvas dinâmicas para ajuste dos parâmetros do material M1. Corpos de prova: anéis. . . . . . . . . . . . . 112

Figura 5.11 - Região selecionada das curvas dinâmicas para ajuste dos parâmetros do material M2. Corpos de prova: anéis. . . . . . . . . . . . 112

Figura 5.12 - Ajuste das curvas dinâmicas com parâmetros do modelo estático do material M1. Corpos de prova: anéis. . . . . . . . . . . . . . . 113

Figura 5.13 - Ajuste das curvas dinâmicas com parâmetros do modelo estático do material M2. Corpos de prova: anéis. . . . . . . . . . . . . . . . 113

Figura 5.14 - Ajuste do parâmetro de JC para o material M1. Corpos de prova: anéis. . . . . . . . . . . . . . . . . . . . . 114

Figura 5.15 - Ajuste do parâmetro de JC para o material M2. Corpos de prova: anéis. . . . . . . . . . . . . . . . . . . 114 
Figura 5.16 - Ajuste dos parâmetros de CS para o material M1. Corpos de prova: anéis. . . . . . . . . . . . . . . 115

Figura 5.17 - Ajuste dos parâmetros de CS para o material M2. Corpos de prova: anéis. . . . . . . . . . . . . . 115

Figura 5.18 - Curvas reconstruídas pelo modelo de JC para o material M1. Corpos de prova: anéis. . . . . . . . . . . . . . . . . . 116

Figura 5.19 - Curvas reconstruídas pelo modelo de CS para o material M1. Corpos de prova: anéis. . . . . . . . . . . . . . . . . 117

Figura 5.20 - Curvas reconstruídas pelo modelo de JC para o material M2. Corpos de prova: anéis.

Figura 5.21 - Curvas reconstruídas pelo modelo de CS para o material M2. Corpos de prova: anéis. . . . . . . . . . . . . . . . . . 118

Figura 6.1 - Curvas de velocidade residual para projéteis com diferentes tipos de ponta (BORVIK et al., 2002). . . . . . . . . . . . . . . . . 121

Figura 6.2 - Resposta impulsiva da chapa do material M1.

Figura 6.3 - Resposta impulsiva da chapa do material M2.

Figura 6.4 - Amplitude da vibração em função da frequiência para a chapa do material M1.

Figura 6.5 - Amplitude da vibração em função da freqüência para a chapa do material M2.

Figura 6.6 - Decaimento exponencial da amplitude de vibração de uma estrutura amortecida (THOMSON, 1993).

Figura 6.7 - (a) Lançador de projéteis (b) e anteparo-alvo pertencentes ao GMSIE-USP. . . . . . . . . . . . . . . . . . . . . . . . 130

Figura 6.8 - (a) Conjunto esfera e cartucho de disparo e (b) cronoscópio para medição da velocidade de impacto.

Figura 6.9 - Arranjo para fixação das chapas alvo.

Figura 6.10 - Faixa de velocidades para os três tipos de resposta estrutural, para o material M1.

Figura 6.11 - Faixa de velocidades para os três tipos de resposta estrutural, para o material M2.

Figura 6.12 - Detalhe da região de falha do material M1: falha sem perfuração a 116,0m/s, (a) vista anterior e (b) posterior; e perfuração total a $128,7 \mathrm{~m} / \mathrm{s}$, (c) vista anterior e (d) posterior. 
Figura 6.13 - Detalhe da região de falha do material M2: falha sem perfuração a $110,2 \mathrm{~m} / \mathrm{s}$, (a) vista anterior e (b) posterior ; e perfuração total a $140,0 \mathrm{~m} / \mathrm{s},(\mathrm{c})$ vista anterior e (d) posterior. . . . . . . . . . 135

Figura 6.14 - Detalhe da formação do tampão no material M1 a 127,5m/s com perfuração total, (a) vista anterior e (b) posterior. . . . . . . . . . . 136

Figura 6.15 - Chapa M1 testada a 80,81m/s: (a) visão geral e (b) detalhe da região impactada. . . . . . . . . . . . . . . . 136

Figura 6.16 - Chapa M2 testada a 83,47m/s: (a) visão geral e (b) detalhe da região impactada. . . . . . . . . . . . . . . . . 137

Figura 6.17 - Deslocamentos máximos obtidos nos testes sem perfuração do material M1. . . . . . . . . . . . . . . . . . . 137

Figura 6.18 - Deslocamentos máximos obtidos nos testes sem perfuração do material M2. . . . . . . . . . . . . . . . . . . . . 138

Figura 7.1 - Malhas de elementos quadriláteros (a) ref3 e (b) ref4. . . . . . . 141

Figura 7.2 - Variação da velocidade balística com o refinamento da malha. Material M1 com elementos (a) de casca e (b) sólido, e M2 com elementos (c) de casca e (d) sólido. . . . . . . . . . . . . . . . . . . 142

Figura 7.3 - Variação do deslocamento máximo permanente com o refinamento da malha. Material M1 com elementos (a) de casca e (b) sólido, e M2 com elementos (c) de casca e (d) sólido.

Figura 7.4 - Malhas de elementos axissimétricos para as chapas do material (a) M1 e (b) M2. 144

Figura 7.5 - Detalhe da malha de elementos de casca durante a penetração da esfera, utilizando as formulações: (a) Hughes-Liu; (b) BelytschkoTsay; (c) S/R Hughes-Liu; (d) Belytschko-Leviathan; (e) BelytschkoWong-Chiang; (f) integração total. . . . . . . . . . . . . . . . . 146

Figura 7.6 - Configuração da malha de elementos de casca (em vermelho) durante a penetração da esfera (azul) para diferentes valores de ordem de integração do contato: (a) 0; (b) 1; (c) 2; (d) 3; (e) 4; (f) $5 . \quad$. . . . . 148 
Figura 7.7 - Configuração da malha de elementos sólidos (em vermelho) durante a penetração da esfera (azul) para diferentes tipos de controle de modos espúrios: (a) padrão do LS-DYNA; (b) integração de Flanagan-Belytschko; (c) integração volumétrica exata de FlanaganBelytschko; (d) forma rígida da integração de Flanagan-Belytschko; (e) forma rígida da integração volumétrica exata de Flanagan-Belytschko; (f) forma rígida co-rotacional de Belytschko-Bindeman. . . . . . . . . 150

Figura 7.8 - Comparação dos valores de velocidades balísticas numéricas e experimentais. Caracterização mecânica do material M1 sem taxa de deformação (estático)

Figura 7.9 - Comparação dos valores de velocidades balísticas numéricas e experimentais. Caracterização mecânica do material M1 com a metodologia convencional.

Figura 7.10 - Comparação dos valores de velocidades balísticas numéricas e experimentais. Caracterização mecânica do material M1 com a nova metodologia.

Figura 7.11 - Comparação dos valores de velocidades balísticas numéricas e experimentais. Caracterização mecânica do material M2 sem taxa de deformação (estático).

Figura 7.12 - Comparação dos valores de velocidades balísticas numéricas e experimentais. Caracterização mecânica do material M2 com a nova metodologia. . . . . . . . . . . . . . . . . 155

Figura 7.13 - Diferença em relação à velocidade balística experimental, em função da metodologia de caracterização mecânica do material M1. . 156

Figura 7.14 - Diferença em relação à velocidade balística experimental, em função da metodologia de caracterização mecânica do material M2. 156

Figura 7.15 - Comparação da configuração após penetração total entre os casos real, casca e sólido, para o material M2 . . . . . . . . . . . . . 158

Figura 7.16 - Configuração final da malha de elementos axissimétricos, para o material M2. . . . . . . . . . . . . . . . . . . . 158

Figura 7.17 - Deslocamentos máximos encontrados com as diversas malhas, para o material M1.

Figura 7.18 - Deslocamentos máximos encontrados com as diversas malhas, para o material M2. 
Figura 7.19 - Diferença em relação ao deslocamento máximo permanente experimental, em função da metodologia de caracterização mecânica do material M1. . . . . . . . . . . . . . . . . . . . . . . . 162

Figura 7.20 - Diferença em relação ao deslocamento máximo permanente experimental, em função da metodologia de caracterização mecânica do material M2. . . . . . . . . . . . . . . . . . . . . 162 


\section{LISTA DE TABELAS}

Tabela 3.1 - Propriedades elasto-plásticas do material M1. . . . . . . . . . 57

Tabela 3.2 - Propriedades elasto-plásticas do material M2. . . . . . . . 57

Tabela 3.3 - Propriedades elasto-plásticas dos materiais M1 e M2. . . . . . 57

Tabela 3.4 - Parâmetros do modelo de Swift, obtidos a partir dos testes de tração dos materiais M1 e M2 . . . . . . . . . . . . . . . . . 60

Tabela 3.5 - Parâmetros de encruamento do modelo de Lemaitre, obtidos a partir dos testes de tração dos materiais M1 e M2. . . . . . . . . . 61

Tabela 3.6 - Parâmetros do modelo de dano de Lemaitre. . . . . . . . . . . . 64

Tabela 3.7 - Dados geométricos do corpo de prova em forma de anel. . . . . 65

Tabela 3.8 - Parâmetros do modelo de Swift, obtidos a partir dos testes de compressão quase-estática dos materiais M1 e M2 . . . . . . . . . . 69

Tabela 3.9 - Parâmetros de encruamento do modelo de Lemaitre, obtidos a partir dos testes de compressão dos materiais M1 e M2. . . . . . . . . 69

Tabela 4.1 - Propriedades da barra de Hopkinson. . . . . . . . . . . . . . . 77

Tabela 4.2 - Taxas de deformação utilizadas na caracterização dinâmica na BH. Corpos de prova: discos. . . . . . . . . . . . . . . 86

Tabela 4.3 - Parâmetros dos modelos de Johnson-Cook (JC) e CowperSymonds (CS). Corpos de prova: discos. . . . . . . . . . . . 93

Tabela 5.1 - Valores dos parâmetros utilizados nas simulações do teste de caracterização dinâmica. . . . . . . . . . . . . . . . . . . . 101

Tabela 5.2 - Taxas de deformação utilizadas na caracterização dinâmica na BH. Corpos de prova: anéis. . . . . . . . . . . . . . . . . . 110

Tabela 5.3 - Parâmetros dos modelos de Johnson-Cook (JC) e CowperSymonds (CS). Corpos de prova: anéis. . . . . . . . . . . . . 116

Tabela 6.1 - Velocidades balísticas experimentais. . . . . . . . . 133

Tabela 7.1 - Dados das malhas de elementos de casca usadas na modelagem das chapas. . . . . . . . . . . . . . . . . 141

Tabela 7.2 - Dados das malhas de elementos sólidos usadas na modelagem das chapas. . . . . . . . . . . . . . . . . . . 141

Tabela 7.3 - Dados da malha de elementos axissimétricos usada na modelagem das chapas. . . . . . . . . . . . . . . . . . . 144 
Tabela 7.4 - Avaliação da modelagem através da Análise Modal. Os valores percentuais representam a diferença em relação aos experimentos. . . . 151

Tabela 7.5 - Energia perdida na eliminação dos elementos em relação à energia total. . . . . . . . . . . . . . . . . . . 152

Tabela 7.6 - Diferenças percentuais entre as predições das velocidades balísticas dos refinamentos reft e ref5. . . . . . . . . . . . . . . . . 157

Tabela 7.7 - Tempo de processamento para predição da velocidade balística. . 159

Tabela 7.8 - Valores dos coeficientes angulares, lineares e de determinação das regressões lineares aplicadas nos resultados do material M1 . . . . 160

Tabela 7.9 - Valores dos coeficientes angulares, lineares e de determinação das regressões lineares aplicadas nos resultados do material M2. . . . . 161

Tabela 7.10 - Tempo de processamento para predição do deslocamento máximo permanente. . . . . . . . . . . . . . . 163 


\section{LISTA DE ABREVIATURAS E SIGLAS}

$M_{1} \quad$ Material que compõe a chapa de $1,6 \mathrm{~mm}$

$M_{2} \quad$ Material que compõe a chapa de 3,2mm

ARAIC Aircraft and Railway Accidents Investigation Commission

BEA Bureau d'Enquêtes et d'Analyses

FAA Federal Aviation Administration

LE $\quad$ Linear Encoders

NTSB National Transportation Safety Board

TNWF Tied-nodes-with-failure

BH Barra de Hopkinson

CS Cooper-Symonds

GMSIE Grupo de Mecânica dos Sólidos e Impacto em Estruturas

JC Johnson-Cook

USP Universidade de São Paulo 



\section{LISTA DE SÍMBOLOS}

\begin{tabular}{|c|c|}
\hline$\Sigma$ & Somatório \\
\hline$\alpha$ & Fator de proporcionalidade \\
\hline$\beta$ & $\begin{array}{l}\text { Fator de correção dos efeitos de atrito na caracterização dinâ- } \\
\text { mica com a BH }\end{array}$ \\
\hline$\delta$ & Decremento logarítmico do deslocamento da chapa \\
\hline $\boldsymbol{\varepsilon}$ & Tensor de deformações \\
\hline $\boldsymbol{\varepsilon}^{e}$ & Tensor de deformações elásticas \\
\hline $\boldsymbol{\varepsilon}^{p}$ & Tensor de deformações plásticas \\
\hline$\gamma$ & Parâmetro do modelo de material de Lemaitre \\
\hline$\kappa$ & Parâmetro do modelo de material de Lemaitre \\
\hline$\lambda$ & Razão geométrica ótima de Davies e Hunter \\
\hline$\mu$ & Coeficiente de atrito de Coulomb \\
\hline$v$ & Coeficiente de Poisson \\
\hline$v_{s}$ & Coeficiente de Poisson do corpo de prova \\
\hline$\omega_{d}$ & Primeira freqüência natural amortecida da chapa em rd/s \\
\hline$\omega_{n}$ & Primeira freqüência natural da chapa em rd/s \\
\hline$\phi$ & Ângulo de defasagem na vibração da chapa \\
\hline$\rho$ & Densidade \\
\hline$\rho_{b}$ & Densidade das barras da $\mathrm{BH}$ \\
\hline$\sigma$ & Tensão equivalente \\
\hline$\sigma_{0}$ & Tensão de escoamento \\
\hline$\sigma_{1}, \sigma_{2}, \sigma_{3}$ & Tensões principais máxima, média e mínima \\
\hline$\sigma_{E}$ & Tensão de engenharia uniaxial \\
\hline$\sigma_{E}^{\prime}$ & $\begin{array}{l}\text { Tensão de engenharia corrigida dos efeitos de atrito na } \mathrm{BH} \text { se- } \\
\text { gundo a metodologia proposta }\end{array}$ \\
\hline $\boldsymbol{\sigma}_{D}$ & Tensor de tensões desviador \\
\hline $\boldsymbol{\sigma}_{H}$ & Tensor de tensões hidrostático \\
\hline$\sigma_{T}$ & Tensão verdadeira uniaxial \\
\hline$\sigma_{Y}$ & Tensão equivalente estática \\
\hline$\sigma_{c}$ & $\begin{array}{l}\text { Tensão uniaxial corrigida para os efeitos de atrito segundo o } \\
\text { modelo de Malinowski e Klepaczko }\end{array}$ \\
\hline
\end{tabular}




\begin{tabular}{|c|c|}
\hline$\sigma_{m}$ & Tensão média ou hidrostática \\
\hline$\sigma_{p}$ & Pulso de tensão aplicado na BH \\
\hline$\sigma_{x}, \sigma_{y}, \sigma_{z}$ & Componentes normais do tensor de tensões \\
\hline$\sigma_{a v}$ & Tensão média no anel \\
\hline$\tau_{d}$ & Período de vibração \\
\hline$\tau_{r y}$ & Tensão cisalhante radial na interface do anel com as barras da \\
\hline & $\mathrm{BH}$, no sistema cilíndrico \\
\hline$\tau_{x y}, \tau_{x z}, \tau_{y z}$ & Componentes cisalhantes do tensor de tensões \\
\hline$\varepsilon$ & Deformação equivalente \\
\hline$\dot{\varepsilon}$ & Taxa de deformação equivalente \\
\hline$\dot{\varepsilon}_{0}^{p}$ & $\begin{array}{l}\text { Taxa de deformação plástica equivalente do teste quasi- } \\
\text { estático }\end{array}$ \\
\hline$\varepsilon_{D}$ & $\begin{array}{l}\text { Deformação plástica equivalente em que ocorre o início do } \\
\text { processo de danificação do material }\end{array}$ \\
\hline$\varepsilon_{E}$ & Deformação de engenharia uniaxial \\
\hline$\dot{\varepsilon_{E}}$ & Taxa de deformação de engenharia uniaxial \\
\hline$\varepsilon_{L}$ & Deformação logarítmica uniaxial \\
\hline$\varepsilon_{i}$ & Pulso incidente de deformação elástica da BH \\
\hline$\varepsilon_{p}$ ou $\varepsilon^{p}$ & Deformação plástica equivalente \\
\hline$\dot{\varepsilon}_{p}$ ou $\dot{\varepsilon}^{p}$ & Taxa de deformação plástica equivalente \\
\hline$\varepsilon_{r}$ & Pulso refletido de deformação elástica da $\mathrm{BH}$ \\
\hline$\varepsilon_{t}$ & Pulso transmitido de deformação elástica da $\mathrm{BH}$ \\
\hline$\varepsilon_{x}, \varepsilon_{y}, \varepsilon_{z}$ & Componentes normais do tensor de deformações \\
\hline$\dot{\varepsilon}_{r}, \dot{\varepsilon}_{y}, \dot{\varepsilon}_{\theta}, \dot{\varepsilon}_{r y}$ & Componentes das taxas de deformação no sistema cilíndrico \\
\hline$\varepsilon_{x y}, \varepsilon_{x z}, \varepsilon_{y z}$ & Componentes angulares do tensor de deformações \\
\hline$\zeta$ & razão de amortecimento \\
\hline$A$ & Parâmetro do modelo de material de Swift modificado \\
\hline$A_{0}$ & Área inicial da seção transversal do corpo de prova \\
\hline$A_{b}$ & Área da seção transversal das barras da BH \\
\hline$A_{s}$ & Área corrente da seção transversal do corpo de prova \\
\hline$b$ & parâmetro de abaulamento do anel \\
\hline$B$ & Parâmetro do modelo de material de Swift modificado \\
\hline$c$ & coeficiente de amortecimento \\
\hline
\end{tabular}


C Parâmetro da influência da taxa de deformação do modelo de Johnson-Cook

$C_{1}, C_{2} \quad$ Parâmetros do modelo de material de Lemaitre - nomenclatura

\section{LS-DYNA}

$c_{b} \quad$ Velocidade da onda elástica nas barras da $\mathrm{BH}$

$c_{c r i t} \quad$ coeficiente de amortecimento crítico

D Dano acumulado

$\dot{D} \quad$ Taxa de danificação

$D_{0} \quad$ Diâmetro externo inicial do corpo de prova-anel

$d_{0} \quad$ Diâmetro interno inicial do corpo de prova-anel

$D_{s} \quad$ Parâmetro numérico de amortecimento

$D_{\text {crit }} \quad$ Valor de dano crítico

E $\quad$ Módulo elástico

$\tilde{E} \quad$ Módulo elástico degradado

$E_{b} \quad$ Módulo elástico das barras da $\mathrm{BH}$

$f_{d} \quad$ Primeira freqüência natural amortecida da chapa em $\mathrm{Hz}$

$f_{n} \quad$ Primeira frequiência natural da chapa em $\mathrm{Hz}$

$f_{o b j} \quad$ Função objetivo da otimização

I Tensor identidade

$i \quad$ Índice numérico

$I_{1}, I_{2}, I_{3}$ Primeiro, Segundo e Terceiro invariantes do tensor de tensões

$J \quad$ Parâmetro do modelo de material de Swift

$J_{1}, J_{2}, J_{3}$ Primeiro, Segundo e Terceiro invariantes do tensor de tensões desviador

$K \quad$ Parâmetro do modelo de material de Swift

$K_{2} \quad$ Segundo invariante do tensor de deformação plástica

$L_{0} \quad$ Comprimento inicial do corpo de prova

$L_{S} \quad$ Comprimento corrente do corpo de prova

$m \quad$ Fator de atrito

$n \quad$ Parâmetro de encruamento do modelo de material de Swift

n Vetor normal ao plano

$P \quad$ Força axial

$p \quad$ Parâmetro da influência da taxa de deformação do modelo de Cooper-Symonds 
$P_{1}, P_{2} \quad$ Forças axiais nas interfaces do corpo de prova com as barras de entrada e de saída da BH

$P_{a v} \quad$ Tensão média na interface do anel com as barras

$Q \quad$ Parâmetro da influência da taxa de deformação do modelo de Cooper-Symonds

$Q_{1}, Q_{2} \quad$ Parâmetros do modelo de material de Lemaitre - nomenclatura LS-DYNA

$r \quad$ Eixo radial num sistema de coordenadas cilíndrico

$R^{2} \quad$ Coeficiente de determinação do ajuste linear

$R_{\infty} \quad$ Parâmetro do modelo de material de Lemaitre

$R_{b} \quad$ Raio das barras da $\mathrm{BH}$

$R_{n} \quad$ Raio onde a velocidade de expansão radial do anel é nula

$r_{p} \quad$ Raio da chapa

$R_{S} \quad$ Valor médio do raio externo do anel durante a compressão

$r_{s} \quad$ Valor médio do raio interno do anel durante a compressão

$R_{v} \quad$ Função triaxialidade

$S \quad$ Taxa de liberação de energia de deformação

$\boldsymbol{s} \quad$ Vetor tensão

$\boldsymbol{s}_{n} \quad$ Componente normal do vetor tensão

$\boldsymbol{s}_{t} \quad$ Componente tangente do vetor tensão

$T \quad$ Temperatura do material

$t \quad$ Tempo

$\boldsymbol{T} \quad$ Tensor de tensões

$T_{m} \quad$ Temperatura de fusão do material

$t_{p} \quad$ Espessura da chapa

$T_{a m b} \quad$ Temperatura ambiente

$u \quad$ Deslocamento axial

$\dot{u} \quad$ Velocidade de compressão do anel

$\dot{u}_{1}, \dot{u}_{2} \quad$ Velocidades das interfaces do corpo de prova com as barras de entrada e saída da BH

$u_{1}, u_{2} \quad$ Deslocamentos das interfaces do corpo de prova com as barras de entrada e saída da BH 
$V_{k} \quad$ Parâmetro da influência da taxa de deformação do modelo de Cooper-Symonds

$V_{m} \quad$ Parâmetro da influência da taxa de deformação do modelo de Cooper-Symonds

$V_{r} \quad$ Velocidade radial do anel

$V_{y} \quad$ Velocidade axial do anel

$\dot{W} \quad$ Potência externa

$w_{e} \quad$ Energia de deformação elástica específica

$\dot{W}_{f} \quad$ Potência dissipada pelo atrito

$\dot{W}_{i} \quad$ Potência interna de deformação

$X \quad$ Deslocamento máximo na vibração da chapa

$x, y, x$ Eixos do sistema de coordenadas cartesiano

$x_{1}, x_{2}$ Variáveis de projeto da otimização

$X_{\infty} \quad$ Parâmetro do modelo de material de Lemaitre

$Y \quad$ Densidade da taxa de liberação de energia de deformação 



\section{SUMÁRIO}

1 Introdução $\quad 35$

2 Objetivos $\quad 43$

3 Caracterização quase-estática dos materiais 45

3.1 Revisão Bibliográfica . . . . . . . . . . . . . . . . . . . . . . . . . 52

3.2 Teste de tração . . . . . . . . . . . . . . . . . . . . . . . 54

3.2.1 Identificação dos parâmetros do modelo de Swift - tração . . . . . 59

3.2.2 Identificação dos parâmetros do modelo de Lemaitre - tração . . . 60

3.3 Teste de Compressão . . . . . . . . . . . . . . . . . . . . . . . . . 64

3.3.1 Identificação dos parâmetros do modelo de Swift - compressão . 69

3.3.2 Identificação dos parâmetros do modelo de Lemaitre - compressão 69

4 Caracterização dinâmica convencional dos materiais 73

4.1 Revisão Bibliográfica . . . . . . . . . . . . . . . . . . . . . . . 77

4.2 Testes experimentais . . . . . . . . . . . . . . . . . 79

4.3 Identificação do parâmetro do modelo de Johnson-Cook (JC) . . . . . . . 89

4.4 Identificação dos parâmetros do modelo de Cowper-Symonds (CS) . . . . 92

4.5 Comparação entre os modelos dinâmicos . . . . . . . . . . . . . . . . . . 92

5 Caracterização dinâmica modificada dos materiais 97

5.1 Revisão Bibliográfica . . . . . . . . . . . . . . . . . . . . . . . . 97

5.2 Correção dos efeitos de atrito nos testes dinâmicos . . . . . . . . . . . . . 99

5.2.1 Análise numérica inicial . . . . . . . . . . . . 100

5.2.2 Modelagem analítica . . . . . . . . . . . . . 103

5.3 Testes Experimentais _ . . . . . . . . . . . . . . . . . 108

5.4 Identificação dos parâmetros do modelo de Johnson-Cook (JC) . . . . . . 113

5.5 Identificação dos parâmetros do modelo de Cowper-Symonds (CS) . . . . 114

5.6 Comparação entre os modelos dinâmicos . . . . . . . . . . . . . . 116

6 Impacto em chapas $\quad 119$

6.1 Revisão Bibliográfica . . . . . . . . . . . . . . . . . . 120

6.2 Análise modal e transiente . . . . . . . . . . . . . . . . . 126 
6.3 Testes de Impacto . . . . . . . . . . . . . . . . . . . . . . . 130

7 Simulações Numéricas $\quad 139$

7.1 Modelagem em elementos finitos . . . . . . . . . . . . . . . . . . 139

7.1 .1 Malha ...................... 139

7.1.2 Definição de parâmetros . . . . . . . . . . . . . . 145

7.2 Resultados . . . . . . . . . . . . . . . . . . . 150

7.2.1 Análise modal . . . . . . . . . . . . . . . . . . 150

7.2.2 Velocidade balística . . . . . . . . . . . . . . . 152

7.2.3 Deslocamento máximo permanente . . . . . . . . . . . . 159

7.3 Discussão dos Resultados . . . . . . . . . . . . . . . . . 163

7.3.1 Influência da malha . . . . . . . . . . . . . . . 163

7.3.2 Efeitos dinâmicos . . . . . . . . . . . . . . 166

8 Conclusão 169

$\begin{array}{ll}\text { Referências Bibliográficas } & 173\end{array}$ 


\section{INTRODUÇÃO}

Painéis metálicos fazem parte de diversas estruturas presentes em nosso cotidiano e projetadas para nos proporcionar maior mobilidade, conforto e segurança, tais como a carenagem de automóveis, o casco de navios e a fuselagem e asas de aviões. A motivação em se estudar o comportamento de chapas finas, quando sujeitas ao impacto de pequenos objetos, segue da necessidade da engenharia de controlar possíveis danos causados nessas estruturas, os quais podem ser catastróficos.

Normalmente dispostos em várias camadas, painéis também são empregados em aeronaves espaciais, revestindo e protegendo suas estruturas. Estas finas chapas, geralmente metálicas, sofrem a ação de uma grande variedade de agentes impactantes, desde gotas de chuvas (ADLER, 1999), granizo (JOHNSON; HOLZAPFEL, 2003), até meteoritos e fragmentos orbitais (PALMIERI et al., 2001). Os danos causados num veículo espacial podem ser classificados, de acordo com a gravidade e o mecanismo de agressão, em (LANDGRAF et al., 2004):

- degradação da superfície, causada principalmente por pequenos objetos impactantes, da ordem de micrometros, porém capazes de alterar as propriedades térmicas e ópticas da camada de proteção mais externa;

- penetração, trata-se da perfuração das camadas de proteção, atingindo câmaras pressurizadas da aeronave e podendo causar desde um simples vazamento a uma falha desastrosa;

- descarga de plasma, onde íons, criados localmente pela interação do impactador com a estrutura impactada, geram zonas mais condutivas que podem interferir nos mecanismos eletrônicos de medição e controle da aeronave.

No âmbito militar, os estudos relacionados à perfuração de painéis, aplicados na blindagem de coletes e dos diversos tipos de veículos, se intensificaram durante a Segunda Guerra Mundial (GOLDSMITH, 1999). Porém, é de se entender que, pela exigência de um grande sigilo tecnológico, à época, poucos trabalhos foram disponibilizados para livre acesso. Atualmente, são publicadas pesquisas nesta área, justificadas pela necessidade de proteção de equipamentos e tropas pertencentes a forças de paz (JOVICIC; ZAVALIANGOS; KO, 2000), como, por exemplo, pesquisas a respeito da blindagem de veícu- 
los terrestres (KURTARAN; BUYUK; ESKANDARIAN, 2003) e helicópteros militares (HORSFALL; AUSTIN; BISHOP, 2000).

$\mathrm{Na}$ aviação civil, existe uma preocupação grande com os fragmentos que se desprendem do rotor da turbina da aeronave (SCIUVA; FROLA; SALVANO, 2003), quando esta falha durante o vôo. Estes fragmentos necessitam ser retidos pela câmara do rotor de modo a não perfurarem completamente a turbina e atingir outras estruturas, como compartimentos de combustíveis e a fuselagem que protege os passageiros. Exatamente uma falha deste tipo foi apontada pela agência norte-americana National Transportation Safety Board (NTSB) como causadora do acidente com o vôo 1288 da Delta Air Lines, na Flórida em 1996 (NATIONAL TRANSPORTATION SAFETY BOARD, 1998). Durante a decolagem, uma falha na parte frontal da turbina liberou estilhaços que atravessaram a fuselagem, ferindo gravemente dois passageiros e levando outros dois a falecer. A intensidade do dano causado pode ser avaliada na foto da Figura 1.1.

Acidentes como este induzem órgãos, como o $N T S B$, a sugerir às agências reguladoras, no caso a Federal Aviation Administration (FAA) nos Estados Unidos, modificações nos projetos e processos de fabricação e manutenção dos componentes envolvidos nos diversos tipos de falhas. Este tipo de necessidade de aperfeiçoamento, associado a exigentes critérios de validação e certificação, abrem caminho a pesquisas nas áreas de impacto e perfuração de materiais.

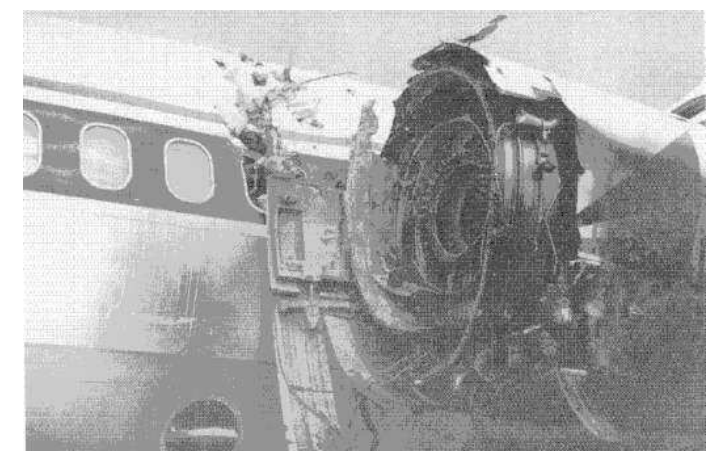

Figura 1.1: Região danificada na aeronave da Delta Air Lines, devido ao impacto de fragmentos da turbina (NATIONAL TRANSPORTATION SAFETY BOARD, 1998).

Uma segunda fonte de danos consideráveis na aviação é o impacto de objetos encontrados na pista, como pequenas peças ou pedaços de pneus deixados por outras aeronaves. Estes fragmentos são arremessados pelos próprios pneus da aeronave, quando do pouso ou 
decolagem, contra as partes inferiores da fuselagem e asas, podendo causar estragos semelhantes aos de fragmentos expelidos em falhas de turbinas. Um exemplo trágico deste tipo de falha foi o acidente com o concorde da Air France na cidade de Gonesse, em junho de 2000, que culminou na morte de 113 pessoas. Segundo relatório do Bureau d'Enquêtes et d'Analyses (BEA) (MINISTERE de L'EQUIPEMENT DES TRANSPORTS ET DU LOGEMENT. Bureau d'Enquêtes et d'Analyses, 2001), órgão oficial francês de investigação de acidentes na aviação civil, fragmentos metálicos deixados na pista foram lançados por um dos pneus contra a asa esquerda, rompendo um dos tanques de combustível e causando um incêndio que implicou na queda da aeronave, Figura 1.2.

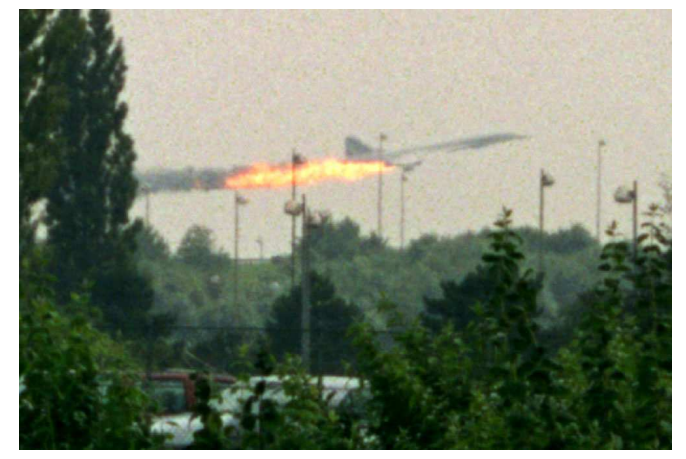

(a)

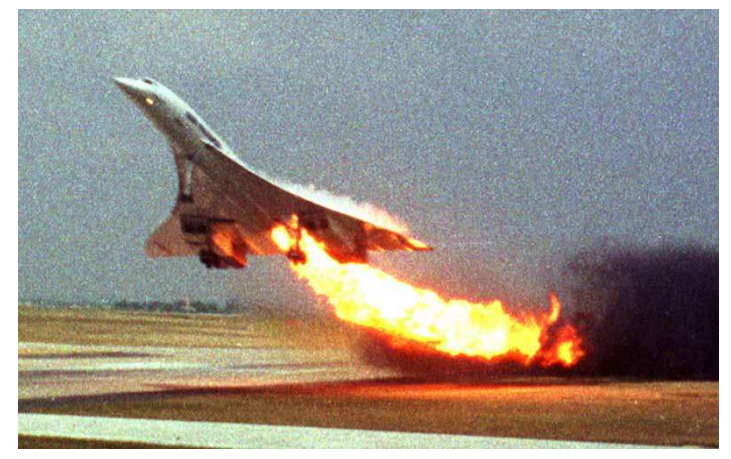

(b)

Figura 1.2: Incêndio no Concorde F-BTSC durante a decolagem devido ao impacto de fragmentos existentes na pista de decolagem (ROXBURGH, 2003).

Um acidente bem menos trágico, ocorreu em agosto de 2007 em Okinawa no Japão, onde um boeing 737-800 da China Airlines explodiu logo após sua aterrissagem (ASITEVEO.COM, 2007). Os 156 passageiros e os 8 tripulantes escaparam ilesos. Resultados preliminares da investigação do orgão japonês Aircraft and Railway Accidents Investigation Commission (ARAIC) creditou o incêndio a um parafuso que penetrou na parede do tanque de combustível no interior de uma das asas (MSNBC - Associated Press, 2007), como mostra a Figura 1.3.

Avarias de alta gravidade em aeronaves também ocorrem devido ao impacto de pássaros, como pode ser observado na foto da Figura 1.4. No Brasil, especial atenção é dada à presença de urubus nas regiões próximas a aeroportos. Em abril de 2003, logo após ter decolado, um Boeing 737 da Varig com 63 passageiros teve um pára-brisa danificado ao se chocar contra um urubu, Figura 1.5, fazendo com que a aeronave tivesse que retornar ao aeroporto de Santa Genoveva, em Goiânia (O POPULAR, 2003). Dependendo da região 


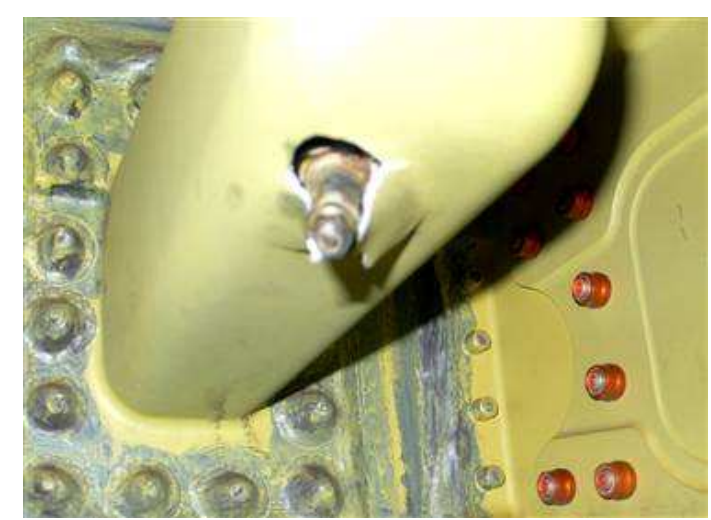

Figura 1.3: Tanque de combustível da asa direita do boeing 737-800 perfurado por parafuso (MSNBC - Associated Press, 2007).

atingida, as consequiências do impacto de um pássaro podem assumir grandes proporções e causar graves acidentes, o que faz com que esse tema assuma papel de significativa relevância entre os pesquisadores (JOHNSON; HOLZAPFEL, 2003; ALVES; CHAVES; BIRCH, 2003; AIROLDI; CACCHIONE, 2006).

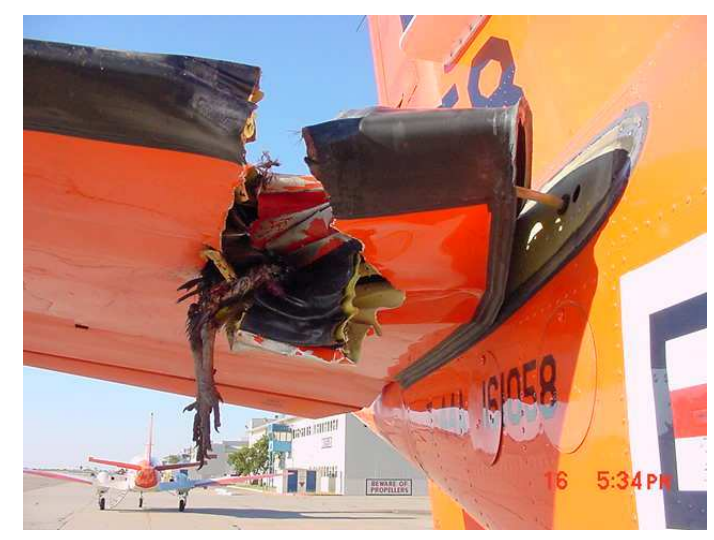

Figura 1.4: Dano causado pelo impacto de um pássaro (ALVES; CHAVES; BIRCH, 2003).

Uma maneira de se avaliar relativamente os diversos tipos de estruturas quanto à eficiência na proteção contra o impacto de pequenos objetos é relacionar a capacidade de proteção com a razão peso/área (densidade), e o custo (ARIAS et al., 2003). Dependendo do tipo de aplicação, alguns destes parâmetros assumem uma importância maior, e.g., na aviação é sempre importante a minimização da massa, no caso de veículos terrestres talvez o custo seja preponderante. 


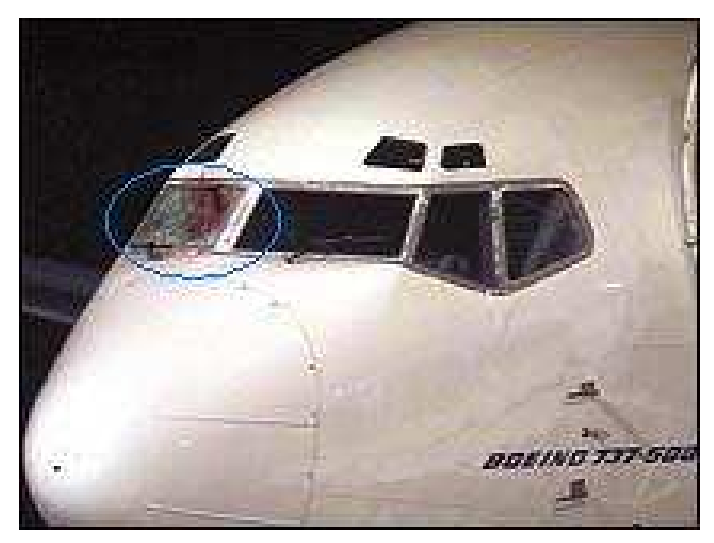

Figura 1.5: Pára-brisa danificado pelo impacto de um urubu (O POPULAR, 2003).

Nesse contexto, é evidente a influência das características do material do qual é feita a estrutura. Os metais, provavelmente escolhidos para compor as primeiras estruturas de proteção pela alta rigidez apresentada, possuem propriedades bem definidas e amplamente conhecidas e, por isso, são os mais utilizados atualmente. Em particular, o interesse nas ligas de alumínio tem sido grande, principalmente em estruturas de proteção de baixo peso, devido a sua baixa densidade, alta capacidade de absorção de energia específica, boa resistência à corrosão, boa condutividade térmica (menos sensível às bandas de cisalhamento e instabilidades termoplásticas que o aço) e maleabilidade (possibilidade de extrusão em estruturas complexas) (BORVIK et al., 2004).

Existem limitações quando, através da adição de elementos de liga, se deseja manipular as propriedades de um metal com o objetivo de melhor adequá-lo às exigências de determinada aplicação. Neste sentido, a possibilidade de se criar um novo material, composto pela união de dois ou mais materiais (normalmente uma fibra e uma resina), tem se mostrado uma alternativa eficiente e viável, despertando o interesse de diversos pesquisadores e da indústria automotiva, naval e aeroespacial (OKAFOR et al., 2001; JOHNSON; PICKETT; ROZYCKI, 2001).

Uma outra opção dentro do objetivo de proteção de peças ou compartimentos contra perfuração é utilizar outras estruturas que não uma única chapa, como placas dispostas em várias camadas (PALMIERI et al., 2001; HAYHURST et al., 2001), ou revestidas de material composto (ARIAS et al., 2003; HORSFALL; AUSTIN; BISHOP, 2000), e até estruturas mais complexas, como compostos de matrizes metálicas (CADY; GRAY, 2001), estruturas honeycomb (POTEET; BLOSSER, 2002; MEO et al., 2003; HAZIZAN; CANTWELL, 2003) ou os perfis extrudados (BORVIK et al., 2005), vide Figura 1.6. 
Essas estruturas contém ou derivam de uma chapa plana simples e o entendimento do comportamento desta deve ser o mais completo possível, de modo a facilitar a análise e o projeto de variações na geometria, na forma, nas condições de contorno, etc. Neste ponto se insere o tema desta tese. Trata-se da análise de uma chapa, uma estrutura aparentemente simples, mas que, quando submetida ao impacto de outro corpo, passa a englobar ramos não-triviais de diversas áreas da mecânica dos sólidos, como dinâmica, visco-plasticidade, contato e dano.

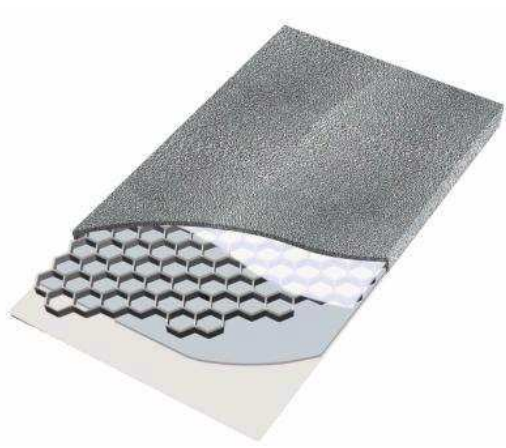

(a)

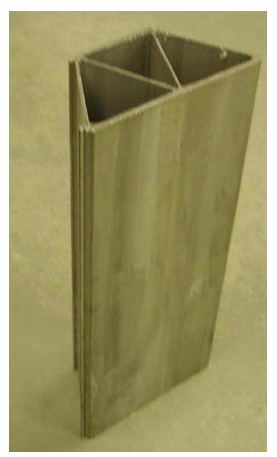

(b)

Figura 1.6: Estruturas complexas utilizadas para absorção de impacto: (a) honeycomb (DONGSHIN ENGINEERING CORP., 2008); (b) perfil extrudado (BORVIK et al., 2005).

Estudos analíticos acerca da perfuração de painéis por projéteis relativamente pequenos, denominada perfuração balística, surgiram nas décadas de 50 e 60, na tentativa de se entender e representar os fenômenos observados experimentalmente (IPSON, 1963). A obtenção de equações, e.g. para velocidades residuais (velocidade do projétil após perfuração da chapa), que resultassem em boas correlações com dados coletados continuaram a despertar a atenção de pesquisadores ao longo desses anos (FORRESTAL; OKAJIMA; LUK, 1988; WIERZBICKI, 1999). Estruturas mais complexas, contudo, são impraticáveis de serem analisadas por métodos analíticos, os quais são específicos para algumas geometrias básicas e empregam simplificações significativas na representação do comportamento do material.

O método mais eficaz de se avaliar e comparar diversas estruturas e materiais, quanto à capacidade de proteção ao impacto, é a realização de um experimento físico. Tanto que, para uma aeronave poder operar, são necessárias certificações que somente são obtidas por testes de campo. Porém, nas etapas de desenvolvimento e projeto, é inviável a execução de testes experimentais para as variações propostas, pois o custo dessas operações é muito 
elevado (JOHNSON; HOLZAPFEL, 2003). A solução desse problema surge, então, a partir da utilização de métodos computacionais, que cada vez mais se afirmam como uma ferramenta essencial de análise, propiciando postergar os testes físicos para etapas mais avançadas de projeto.

Inicialmente restrita a instituições que dispunham de supercomputadores (KNIGHT et al., 2000), a utilização de métodos computacionais se disseminou quando do surgimento e difusão dos microcomputadores e hoje está presente em diversas áreas da Engenharia. Sendo aplicada principalmente na resolução de problemas complexos, a análise numérica permite vincular múltiplos aspectos que estão envolvidos na representação dos fenômenos, além de proporcionar a visualização dos resultados (e.g. tensões e deformações) diretamente num modelo geométrico da estrutura, como exemplificado na Figura 1.7. Atualmente, o avançado poder computacional dos microprocessadores possibilita, em uma máquina de relativo baixo custo, a execução da simulação de um evento dinâmico e repleto de não-linearidades, como encruamento por deformação e por taxa de deformação, amolecimento por temperatura, contato e falha.

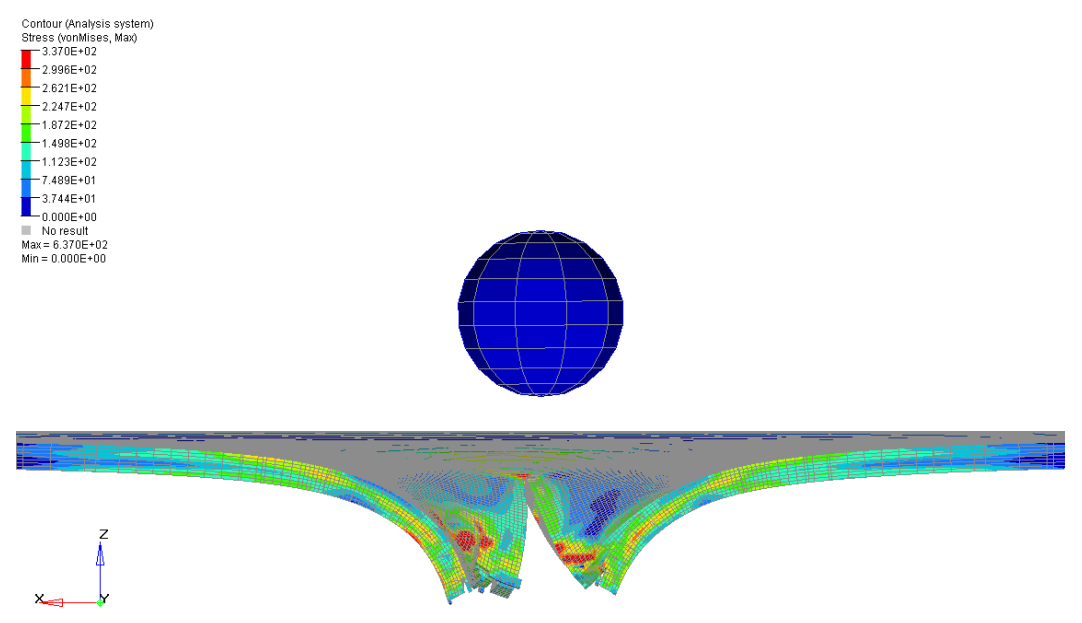

Figura 1.7: Visualização dos resultados da simulação, em elementos finitos, do impacto de uma esfera numa chapa circular fina (fase de retorno da esfera após perfuração parcial da chapa - vista perfil em corte).

Um dos métodos computacionais mais utilizados na análise estrutural é o método dos elementos finitos. Baseada na discretização de um corpo em diversos elementos geométricos interligados, a solução das equações diferenciais de equilíbrio da mecânica do contínuo é feita de modo aproximado, a partir de um número finito de variáveis-incógnitas definidas normalmente nas junções (nós) dos elementos. Em geral, a solução se aproxima mais da exata quanto maior o número de elementos utilizados, i.e. quanto mais graus 
de liberdade compõem o modelo, além de estar condicionada à adequada aplicação de condições iniciais e de contorno. Naturalmente que a qualidade e validade dos resultados de uma simulação numérica dependem muito do modo como é feita a representação, ou modelagem, do problema.

Um fator importante na eficácia da representação de uma estrutura por elementos finitos é a modelagem do comportamento de seu material. Anisotropia, fratura, encruamento cinemático e outras não-linearidades na curva tensão versus deformação, como efeitos da taxa de deformação e da temperatura, fazem com que haja um grande dispêndio de tempo na calibração das constantes que compõem as equações do modelo constitutivo. Quanto mais complexo é o modelo, escolhido na tentativa de se aumentar a fidelidade da representação, maior é o esforço na obtenção dos seus parâmetros. A correta caracterização do material é essencial nos casos onde se busca a previsão do comportamento de novas estruturas a partir da original estudada.

A transformação de um sistema real em números e algoritmos matemáticos está longe de ser um procedimento simples, estando limitada, a princípio, pelo potencial dos tipos de modelos existentes; e num âmbito maior, à capacidade humana de entender os fenômenos da natureza. Assim, na utilização de programas computacionais, é necessário avaliar se o código é capaz de modelar as propriedades encontradas. Outro fator a considerar é qual grau de complexidade do fenômeno é viável representar, dependendo do tempo computacional disponível e tendo-se em mente que a solução provém de um modelo, que sempre é uma simplificação da realidade. A partir deste panorama, definem-se a seguir os objetivos da pesquisa aqui documentada. 


\section{OBJETIVOS}

O motivo deste trabalho se enquadra na necessidade de realização de simulações numéricas para representação dos fenômenos envolvidos no impacto de uma esfera de aço contra uma chapa circular de alumínio. Neste contexto, o objetivo principal é estudar a influência da modelagem do comportamento dinâmico do material da chapa, a partir da proposição de uma modificação no seu método de caracterização, utilizando-se uma Barra de Hopkinson (BH) de compressão. O método convencional de caracterização do material neste equipamento sugere certas proporções geométricas para os corpos de prova, as quais não podem ser respeitadas quando se utiliza corpos de prova retirados de chapas finas. Propõe-se então um método de caracterização dinâmica de chapas finas através da BH de compressão.

A modelagem do comportamento do material é então tratada como um fator determinante para a correta representação numérica dos testes experimentais. A partir da mudança proposta no método convencional de caracterização dinâmica pretende-se mostrar que os efeitos de atrito, responsáveis por erros na modelagem do ensaio da $\mathrm{BH}$, são minimizados. Objetiva-se explorar também a sensibilidade dos resultados numéricos frente a vários parâmetros associados à representação dos testes de impacto pelo método dos elementos finitos. Pretende-se com isto identificar quais parâmetros, principalmente aqueles relacionados ao contato, material, malha, vibração estrutural e formulação do elemento finito, influenciam de modo mais significativo as predições numéricas. Os modelos dinâmicos de Cowper-Symonds (CS) e Johnson-Cook (JC) foram escolhidos para representação do comportamento dos materiais e serão avaliados quanto a sua adequação aos dados experimentais.

Um amplo conhecimento acerca dos fenômenos envolvidos no impacto da esfera contra a chapa torna-se necessário para avaliação dos resultados numéricos. Desta forma, uma série de experimentos físicos deve ser cuidadosamente realizada, a fim de se capturar com fidelidade os mais diferentes detalhes presentes na interação dos dois corpos metálicos. Estes testes envolvem desde a obtenção dos deslocamentos sofridos pelas chapas em impactos de baixa velocidade até a determinação das velocidades balísticas das mesmas.

Na busca dessas metas, apresenta-se no Capítulo 3 a caracterização quase-estática do material da chapa e a calibração de parâmetros dos modelos envolvidos. A caracterização dinâmica segundo a metodologia tradicional é apresentada no Capítulo 4. As causas da 
necessidade de uma modificação no método convencional para representação do material de chapas finas e como é feita essa modificação são explicitadas no Capítulo 5. Em seguida, os testes experimentais são apresentados em detalhes com os resultados obtidos. A avaliação do novo método de caracterização dinâmica do material e de toda a modelagem do fenômeno de impacto proposta ocorre no Capítulo 7, onde são confrontados os dados experimentais e os numéricos, obtidos tanto sem os efeitos dinâmicos quanto com a inclusão destes a partir das duas metodologias. Finalizando, o Capítulo 8 reúne as principais conclusões deste trabalho. 


\section{CARACTERIZAÇÃO QUASE-ESTÁTICA DOS MATERIAIS}

A caracterização mecânica estática ou quase-estática compreende a determinação do comportamento do material, representado principalmente pela curva tensão, $\sigma$, versus deformação, $\varepsilon$, sob carregamentos que variam muito lentamente no tempo, implicando em taxas de deformação, $\dot{\varepsilon}$, da ordem de $10^{-5} \mathrm{~s}^{-1}$ a $10^{-2} \mathrm{~s}^{-1}$. O teste quase-estático mais empregado é o de tração unidimensional, onde o corpo de prova é submetido a uma carga que atua na direção do seu comprimento. Além deste, outros ensaios, como o de cisalhamento puro, o de compressão e o de flexão de três pontos também são utilizados na determinação do módulo elástico, tensão de escoamento, tensão máxima e de ruptura dos corpos de prova.

Num teste quase-estático convencional de tração, as grandezas medidas são a força atuante, $P$, obtida indiretamente através de uma célula de carga, e o deslocamento axial aplicado, $u$, mensurado com sensores compostos geralmente de extensômetros. Contudo, é mais viável se trabalhar com grandezas que não dependem das dimensões do corpo de prova, como tensões e deformações para, por exemplo, comparar a eficiência de materiais ou obter dados para cálculos estruturais analíticos ou computacionais. A partir das duas medições, calcula-se, então, o histórico de tensões axiais de engenharia, $\sigma_{E}(t)$, pela relação

$$
\sigma_{E}(t)=\frac{P(t)}{A_{0}},
$$

sendo $A_{0}$ a área da seção transversal do corpo de prova no início do teste e $t$ a variável tempo. O histórico de deformações axiais de engenharia, $\varepsilon_{E}$, por sua vez, é obtido por

$$
\varepsilon_{E}(t)=\frac{u(t)}{L_{0}}
$$

sendo $L_{0}$ o comprimento inicial do corpo de prova, determinado normalmente pela distância entre os dois pontos de contato do sensor de deslocamento.

Apesar de largamente utilizada em análises elásticas, a tensão de engenharia é pouco empregada para grandes deformações, pois, neste caso, a área transversal do corpo pode mudar sensivelmente. Isto faz com que seja necessária a utilização de uma medida mais real do esforço interno, a tensão verdadeira, $\sigma_{T}$, expressa pela relação 


$$
\sigma_{T}(t)=\frac{P(t)}{A_{s}(t)}
$$

onde $A_{s}$ é a área corrente da seção transversal do corpo de prova, i.e. a área que realmente suporta os esforços naquele instante.

A deformação de engenharia também é substituída por uma medida mais coerente, a deformação logarítmica (BORESI; SCHMIDT; SIDEBOTTOM, 1993). Esta é anti-simétrica para deslocamentos compressivos ou trativos (ASHBY; JONES, 1996), i.e. apresenta valores de mesmo módulo, porém de sinais opostos, para uma deformação obtida diminuindo ou aumentando o comprimento do corpo de prova de uma mesma proporção. Exemplificando, valores aproximados de $-70 \%$ e $70 \%$ de deformação logarítmica são obtidos para um comprimento final do corpo de prova igual à metade $\left(L_{0} / 2\right)$ ou ao dobro $\left(2 L_{0}\right)$ do inicial, respectivamente.

Tornando implícita a variação no tempo, a deformação logarítmica, também chamada de verdadeira, $\varepsilon_{L}$, é obtida por

$$
\varepsilon_{L}=\int_{L_{0}}^{L_{s}} d \varepsilon_{L}=\int_{L_{0}}^{L_{s}} \frac{d L}{L}=\ln \left(\frac{L_{s}}{L_{0}}\right),
$$

onde $L_{S}$ é o comprimento corrente da região do corpo de prova que fica livre para se deformar (normalmente esta distância é delimitada pelo sensor de deslocamento). A Equação (3.4) pode ser manipulada, de forma a relacionar as duas medidas de deformação já vistas,

$$
\varepsilon_{L}=\ln \left(\frac{L_{s}}{L_{0}}\right)=\ln \left(\frac{L_{0}+u}{L_{0}}\right)=\ln \left(1+\varepsilon_{E}\right)
$$

A área corrente utilizada no cálculo de $\sigma_{T}$, Equação (3.3), não é facilmente medida num teste de tração ou compressão. No regime elástico, esta área é praticamente igual à área inicial, porém, no regime plástico, pode se diferenciar muito. Neste caso, utilizase a hipótese de conservação de volume do corpo (escoamento plástico incompressível), $A_{0} L_{0}=A_{s} L_{s}$, para relacionar a área corrente com a deformação de engenharia,

$$
A_{s}=A_{0} \frac{L_{0}}{L_{s}}=A_{0} \frac{L_{0}}{L_{0}+u}=\frac{A_{0}}{1+\varepsilon_{E}} .
$$

Substituindo a Equação (3.6) na Equação (3.3), obtém-se uma relação mais prática para o cálculo da tensão verdadeira

$$
\sigma_{T}=\frac{P}{A_{0}}\left(1+\varepsilon_{E}\right)=\sigma_{E}\left(1+\varepsilon_{E}\right)
$$


É importante notar que as tensões e deformações apresentadas até o momento são grandezas uniaxiais, próprias de um teste simples de tração (corpos de prova de seção constante).

No caso geral, tensões e deformações dependem do ponto considerado e da direção utilizada. Tomando-se um corpo sob carregamento externo num sistema cartesiano tridimensional, e escolhendo-se um ponto no interior do mesmo, existem infinitos planos que passam por este ponto, interceptando o corpo e dividindo-o em duas partes. A interação entre estas duas partes, no ponto selecionado, pode ser representada por um vetor tensão, $\boldsymbol{s}$, que tem componentes tanto no plano escolhido, $\boldsymbol{s}_{t}$, como no eixo perpendicular a este, $\boldsymbol{s}_{n}$, vide Figura 3.1 .
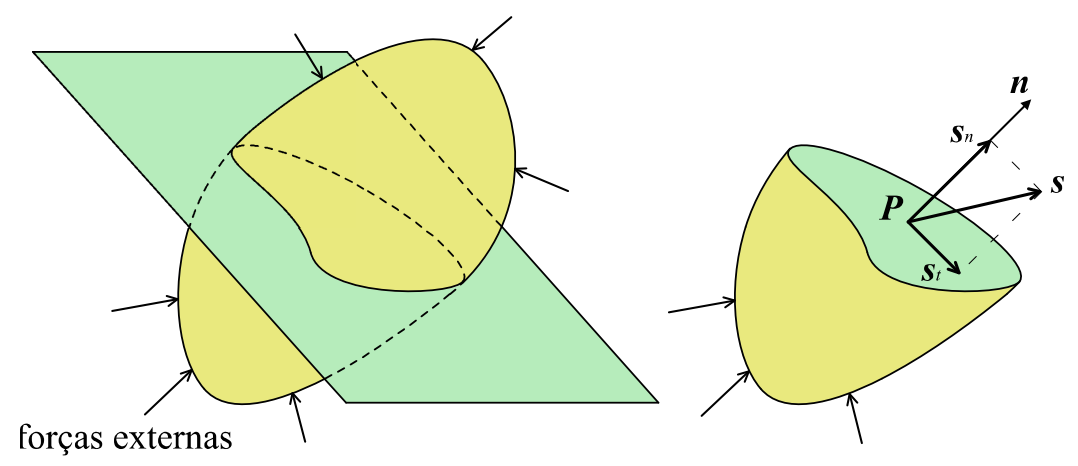

Figura 3.1: Corpo sujeito a forças externas.

Dependendo da escolha do ponto do corpo e do plano que o intercepta, os valores destas componentes são diferentes. Porém, ao se determinar os vetores de tensão em três planos perpendiculares é possível representar todo o estado de tensões neste ponto e também obter as componentes de tensão para qualquer plano que o interceptar.

Considerando os três planos perpendiculares às três direções de um sistema cartesiano tridimensional $x y z$, é possível exprimir o estado de tensões de um ponto do corpo isotrópico através de seis valores de tensão - normais $\left(\sigma_{x}, \sigma_{y}\right.$ e $\left.\sigma_{z}\right)$ e de cisalhamento $\left(\tau_{x y}, \tau_{x z}\right.$ e $\left.\tau_{y z}\right)$ - que podem ser agrupadas matematicamente num tensor de tensões simétrico, $\boldsymbol{T}$, como segue

$$
\boldsymbol{T}=\left\{\begin{array}{ccc}
\sigma_{x} & \tau_{x y} & \tau_{x z} \\
\tau_{x y} & \sigma_{y} & \tau_{y z} \\
\tau_{x z} & \tau_{y z} & \sigma_{z}
\end{array}\right\}
$$


A partir do tensor de tensões, pode-se calcular o vetor tensão de um plano qualquer definido pelo seu vetor normal $\boldsymbol{n}$, como segue

$$
s=T n
$$

Para cada sistema de eixos $x y z$ escolhidos, ou seja, para cada conjunto de três planos perpendiculares, as componentes do tensor de tensões assumem valores diferentes. Particularmente, existem três direções, chamadas de principais, nas quais os valores de tensão de cisalhamento são nulos. Esta configuração pode ser obtida matematicamente forçando-se o paralelismo entre o vetor tensão e o vetor normal de cada plano, ou seja,

$$
\boldsymbol{T} n=\alpha \boldsymbol{n} \Rightarrow[\boldsymbol{T}-\alpha \boldsymbol{I}] \boldsymbol{n}=0
$$

onde $\alpha$ é um fator de proporcionalidade e $\boldsymbol{I}$ é o tensor identidade. A solução não trivial para a Equação (3.10) requer que

$$
|\boldsymbol{T}-\alpha \boldsymbol{I}|=0 .
$$

Expandindo o determinante obtém-se a seguinte equação cúbica

$$
\begin{gathered}
\alpha^{3}-\left(\sigma_{x}+\sigma_{y}+\sigma_{z}\right) \alpha^{2} \\
+\left(\sigma_{x} \sigma_{y}+\sigma_{x} \sigma_{z}+\sigma_{y} \sigma_{z}-\tau_{x y}^{2}-\tau_{x z}^{2}-\tau_{y z}^{2}\right) \alpha \\
-\left(2 \tau_{x y} \tau_{x z} \tau_{y z}+\sigma_{x} \sigma_{y} \sigma_{z}-\sigma_{x} \tau_{y z}^{2}-\sigma_{y} \tau_{x z}^{2}-\sigma_{z} \tau_{x y}^{2}\right)=0 .
\end{gathered}
$$

A Equação (3.12) apresenta três raízes reais (BORESI; SCHMIDT; SIDEBOTTOM, 1993) chamadas de tensões principais, $\sigma_{1}, \sigma_{2}$ e $\sigma_{3}$, que são as tensões normais nos planos onde as tensões de cisalhamento são nulas. Estes valores não dependem do sistema de eixos $x y z$ adotado, de modo que os coeficientes da Equação (3.12), definidos como

$$
\begin{gathered}
I_{1} \equiv \sigma_{x}+\sigma_{y}+\sigma_{z}=\sigma_{1}+\sigma_{2}+\sigma_{3} \\
I_{2} \equiv \sigma_{x} \sigma_{y}+\sigma_{x} \sigma_{z}+\sigma_{y} \sigma_{z}-\tau_{x y}^{2}-\tau_{x z}^{2}-\tau_{y z}^{2} \mathrm{e} \\
I_{3} \equiv 2 \tau_{x y} \tau_{x z} \tau_{y z}+\sigma_{x} \sigma_{y} \sigma_{z}-\sigma_{x} \tau_{y z}^{2}-\sigma_{y} \tau_{x z}^{2}-\sigma_{z} \tau_{x y}^{2}
\end{gathered}
$$

são invariantes quanto à rotação no ponto.

A maioria das teorias de plasticidade assumem (BORESI; SCHMIDT; SIDEBOTTOM, 
1993), baseadas em dados experimentais, que o escoamento num ponto do material é independente da tensão média atuante no mesmo, $\sigma_{m}$, dada por

$$
\sigma_{m}=\frac{\sigma_{1}+\sigma_{2}+\sigma_{3}}{3}=\frac{\sigma_{x}+\sigma_{y}+\sigma_{z}}{3}=\frac{1}{3} I_{1}
$$

também chamada de tensão normal octaédrica ou ainda tensão hidrostática. Desta forma, assume-se que o invariante $I_{1}$ somente exerce influência no processo de deformação elástica, responsável pela mudança de volume do sólido. O tensor de tensão $\boldsymbol{T}$ pode então ser desmembrado em uma parte relacionada à deformação elástica, $\boldsymbol{\sigma}_{H}$, dada por

$$
\boldsymbol{\sigma}_{H}=\left\{\begin{array}{ccc}
\sigma_{m} & 0 & 0 \\
0 & \sigma_{m} & 0 \\
0 & 0 & \sigma_{m}
\end{array}\right\}
$$

e uma associada à deformação plástica, $\boldsymbol{\sigma}_{D}$,

$$
\boldsymbol{\sigma}_{D}=\boldsymbol{T}-\boldsymbol{\sigma}_{H}=\left\{\begin{array}{ccc}
\sigma_{x}-\sigma_{m} & \tau_{x y} & \tau_{x z} \\
\tau_{x y} & \sigma_{y}-\sigma_{m} & \tau_{y z} \\
\tau_{x z} & \tau_{y z} & \sigma_{z}-\sigma_{m}
\end{array}\right\}
$$

O tensor $\boldsymbol{\sigma}_{H}$ é chamado de tensor hidrostático pois representa um estado onde as tensões são iguais nas três direções, como no equilíbrio hidrostático de um fluido ideal. O tensor $\boldsymbol{\sigma}_{D}$ é chamado de tensor desviador (desvio em relação ao estado hidrostático), o qual está associado com a mudança de forma do sólido, e portanto, segundo as teorias clássicas de plasticidade, rege o processo de deformação plástica. Devido a essa sua importância, ao tensor desviador também são associados invariantes, obtidos de maneira análoga aos do tensor de tensões,

$$
\begin{gathered}
J_{1}=0 \quad \text { (cisalhamento puro) } \\
\left.J_{2}=I_{2}+\frac{1}{3} I_{1}^{2}=\frac{1}{6}\left[\left(\sigma_{1}-\sigma_{2}\right)^{2}+\left(\sigma_{2}-\sigma_{3}\right)^{2}+\left(\sigma_{3}-\sigma_{1}\right)^{2}\right)\right] \quad \mathrm{e} \\
J_{3}=I_{3}+\frac{1}{3} I_{1} I_{2}+\frac{2}{27} I_{1}^{3} .
\end{gathered}
$$

O objetivo de se utilizar esses invariantes e as próprias três tensões (normais) principais, $\sigma_{1}, \sigma_{2}$ e $\sigma_{3}$, é relacionar o estado de tensões a um único valor que indique o nível de solicitação interna naquele ponto. Este valor de tensão, chamada de tensão equivalente, pode então ser comparado com um valor limite para identificar a ocorrência ou não de es- 
coamento. Uma das relações mais utilizadas para materiais dúcteis é a tensão equivalente de von Mises (BICKFORD, 1998), $\sigma$, definida como

$$
\sigma \equiv \sqrt{3 J_{2}}
$$

que pode ser escrita em função das tensões principais,

$$
\sigma=\sqrt{\frac{\left(\sigma_{1}-\sigma_{2}\right)^{2}+\left(\sigma_{2}-\sigma_{3}\right)^{2}+\left(\sigma_{3}-\sigma_{1}\right)^{2}}{2}}
$$

Da mesma forma que para as tensões, as deformações num ponto também possuem valores principais, direções principais, invariantes e um valor equivalente. Neste caso, o tensor de deformações $\boldsymbol{\varepsilon}$ é desmembrado numa parte elástica, $\boldsymbol{\varepsilon}^{e}$, e em outra plástica, $\boldsymbol{\varepsilon}^{p}$, de tal modo que

$$
\boldsymbol{\varepsilon}=\boldsymbol{\varepsilon}^{e}+\boldsymbol{\varepsilon}^{p}
$$

Os valores de deformação equivalente ao longo do tempo em conjunto com o histórico de tensão equivalente compõem uma curva de escoamento que equivale a um estado uniaxial de tensão, facilitando o entendimento e a modelagem do comportamento multiaxial do material. Pode-se definir a deformação equivalente de von Mises, $\varepsilon$, como (SHAMES; COZZARELLI, 1992)

$$
\begin{gathered}
\varepsilon \equiv \frac{2}{3} \sqrt{3 K_{2}} \\
=\frac{\sqrt{2}}{3} \sqrt{\left(\varepsilon_{x}^{p}-\varepsilon_{y}^{p}\right)^{2}+\left(\varepsilon_{y}^{p}-\varepsilon_{z}^{p}\right)^{2}+\left(\varepsilon_{z}^{p}-\varepsilon_{x}^{p}\right)^{2}+6\left[\left(\varepsilon_{x y}^{p}\right)^{2}+\left(\varepsilon_{y z}^{p}\right)^{2}+\left(\varepsilon_{z x}^{p}\right)^{2}\right]},
\end{gathered}
$$

onde $K_{2}$ é o segundo invariante do tensor $\boldsymbol{\varepsilon}^{p}$.

Grandezas equivalentes de von Mises, $\sigma$ e $\varepsilon$, são então empregadas neste trabalho, permitindo identificar os níveis de tensão e os graus de plastificação de cada ponto do corpo. No caso de um teste de tração ou compressão de corpos de prova sem entalhes, considerando a região onde o corpo de prova possui seção transversal constante e concêntrica em relação ao eixo de aplicação do carregamento, a tensão e a deformação equivalentes são os próprios valores axiais, 


$$
\begin{gathered}
\sigma=\sqrt{\frac{\left(\sigma_{1}-0\right)^{2}+(0-0)^{2}+\left(0-\sigma_{1}\right)^{2}}{2}}=\left|\sigma_{1}\right|=\left|\sigma_{T}\right| \quad \mathrm{e} \\
\varepsilon=\frac{\sqrt{2}}{3} \sqrt{\left(\varepsilon_{x}^{p}+\frac{1}{2} \varepsilon_{x}^{p}\right)^{2}+\left(-\frac{1}{2} \varepsilon_{x}^{p}+\frac{1}{2} \varepsilon_{x}^{p}\right)^{2}+\left(-\frac{1}{2} \varepsilon_{x}^{p}-\varepsilon_{x}^{p}\right)^{2}} \\
=\frac{\sqrt{2}}{3} \sqrt{2\left(\frac{3}{2} \varepsilon_{x}^{p}\right)^{2}}=\left|\varepsilon_{x}^{p}\right|=\left|\varepsilon_{L}^{p}\right|
\end{gathered}
$$

os quais são obtidos com as Equações (3.4) e (3.7) a partir do escoamento e admitindose plasticidade com conservação de volume, i.e. coeficiente de Poisson, $v$, igual a $1 / 2$. Considera-se então que, nestes tipos de testes, as tensões e deformações são uniformes em todos os pontos do corpo delimitado por $L_{s}$. Isto é válido até o instante em que ocorre a chamada estricção, no caso do teste de tração, e o chamado abaulamento, na compressão. A partir deste instante, o cálculo das deformações e tensões equivalentes é mais complexo.

Além da curva que descreve o nível de tensão em função da plastificação ocorrida, as teorias de plasticidade também tratam da representação da falha ou ruptura do material. Dependendo do modelo matemático escolhido para essas modelagens, a obtenção dos parâmetros envolvidos, a partir dos dados experimentais, processo esse também chamado de calibração, pode exigir a realização de ensaios muito específicos.

Neste trabalho, testes de tração em corpos de prova planos sem entalhes foram conduzidos em conjunto com testes de compressão em anéis, ambos retirados de chapas laminadas. Da curva tensão versus deformação em tração, o módulo elástico e a tensão de escoamento foram obtidos diretamente, e parâmetros de dois modelos de escoamento com encruamento foram ajustados: o de Swift e o de Lemaitre. Este último modelo engloba a representação da danificação e falha do material, essenciais na determinação do limite balístico. Os parâmetros associados a este modelo foram retirados da literatura, especificamente de um projeto realizado pelo GMSIE-USP, onde foram utilizadas simulações numéricas do próprio teste de tração, buscando-se a minimização de erros entre as curvas força versus deslocamento, numéricas e experimentais. Os testes estáticos de compressão foram conduzidos, de modo a servirem como referência para a determinação da influência do carregamento dinâmico no comportamento do material, etapa esta descrita nos próximos capítulos. Somente o modelo de Swift foi utilizado neste caso, em conjunto com os termos dinâmicos dos modelos de Johnson-Cook (JC) e Cowper-Symonds (CS). 
Duas ligas de alumínio aeronáutico, denominadas M1 e M2, compondo chapas de 1,6mm e 3,2mm de espessura, respectivamente, foram caracterizadas de modo estático, através de ensaios de tração e compressão, à temperatura ambiente. Realizados numa máquina universal Instron de 50kN de capacidade, estes testes de caracterização são descritos neste capítulo, juntamente com o método usado na calibração dos parâmetros necessários para o modelo constitutivo escolhido.

\subsection{REVISÃO BIBLIOGRÁFICA}

A importância de uma correta caracterização quase-estática do material está no fato de que a curva obtida não só representa o comportamento do material a uma baixa taxa de deformação como torna-se referência para avaliação da sensibilidade do material a esta grandeza, quando da caracterização dinâmica. O conhecimento desta propriedade possibilita o emprego de materiais adequados em estruturas sob carregamentos que variam rapidamente no tempo, como no caso de impacto estrutural.

Diversos modelos constitutivos, representados por equações analíticas, foram propostos para relacionar o nível de tensão com a deformação plástica, a taxa de deformação e a temperatura, que são os principais fatores que influenciam o comportamento mecânico do material. Alguns destes modelos podem ser extremamente precisos, envolvendo um grande número de parâmetros a serem determinados por testes no material, porém são difíceis de calibrar, principalmente se forem compostos de parâmetros sem significado físico macroscópico. De acordo com Clausen et al. (2004), esta é a causa primordial que faz com que o modelo de material de JC (JOHNSON; COOK, 1983) seja muito usado. Este modelo utiliza como curva estática uma modificação da equação de Swift, que possui encruamento por deformação, variando de forma exponencial. Na caracterização da liga de alumínio AA5083-H116, Clausen et al. (2004) utilizaram este modelo que possibilita ainda a inclusão de modo independente dos efeitos de temperatura e taxa de deformação. Importância também foi dada à influência da triaxialidade, através do ensaio de corpos de prova com entalhes de vários raios, e da anisotropia, com ensaios em direções ortogonais.

Utilizado também em outros trabalhos (KURTARAN; BUYUK; ESKANDARIAN, 2003; EL-MAGD; ABOURIDOUANE, 2006; HADDADI et al., 2006), o modelo de Swift estabelece a seguinte relação entre a tensão equivalente estática, $\sigma_{Y}$, e a deformação plástica equivalente, $\varepsilon_{p}$,

$$
\sigma_{y}=K\left(J+\varepsilon_{p}\right)^{n}
$$


onde $K, J$ e $n$ são parametros do material. O índice 'p' é subscrito para melhor visualização, $\varepsilon_{p} \equiv \varepsilon^{p}$.

O modelo de JC, utilizado neste trabalho, apresenta uma modificação na Equação (3.24), resultando em

$$
\sigma_{y}=A+B\left(\varepsilon_{p}\right)^{n}
$$

$\operatorname{com} A, B$ e $n$ sendo os parâmetros do material. Neste caso, a tensão de escoamento, $\sigma_{0}$, é diretamente representada pelo parâmetro $A$.

Uma ampla caracterização mecânica de três ligas forjadas - alumínio (AA7075), magnésio (AZ80) e Titânio (Ti-6Al-4V) - foi realizada por El-Magd e Abouridouane (2006), em conjunto com a calibração de modelos numéricos. Testes de tração, compressão e cisalhamento puro foram conduzidos com o intuito de se criar um banco de dados com parâmetros para posteriores análises numéricas. Simulações computacionais dos testes no programa ABAQUS auxiliaram nessa calibração, principalmente nos parâmetros associados a critérios de falha. O modelo constitutivo escolhido para representação estática também foi o de Swift, o qual se mostrou adequado à modelagem do encruamento por deformação encontrado nos resultados experimentais.

Atualmente, os testes estáticos são muito utilizados na calibração de modelos de falha do material, que estão implementados em códigos de cálculo estrutural (BORVIK et al., 2001a). O interesse da indústria automotiva e aeroespacial na consideração da fratura em modelos numéricos tem aumentado sensivelmente, principalmente na análise de testes de impacto globais, que envolvem toda a estrutura, e.g. crash tests.

A falta de informações claras e acessíveis, quanto à capacidade dos critérios de falha implementados em programas comerciais e quanto à metodologia de calibração das constantes envolvidas, motivaram o trabalho de Wierzbicki et al. (2005), que avalia sete modelos de falha presentes em códigos comerciais. Interessante citar que o critério mais funcional, considerando o custo e a performance, foi o simples critério da máxima tensão cisalhante, por ser computacionalmente rápido, necessitar de apenas um teste e se adequar bem a uma ampla faixa de valores de triaxialidade.

A mecânica do dano associa a falha do material ao resultado de um processo de fragilização que ocorre, em geral, devido à interação dos defeitos existentes no material com a 
ação do carregamento externo. Um dos modelos de dano mais utilizados é o de Lemaitre (LEMAITRE, 1992). Neste modelo, o encruamento é modelado segundo a equação

$$
\sigma_{y}=\sigma_{0}+R_{\infty}\left[1-\exp \left(-\kappa \varepsilon_{p}\right)\right]+X_{\infty}\left[1-\exp \left(-\gamma \varepsilon_{p}\right)\right]
$$

que separa o encruamento isotrópico (primeiro termo do lado direito da igualdade) do cinemático (o segundo termo do lado direito da igualdade). Os valores de $\kappa$ e $\gamma$ se referem à taxa de encruamento, $R_{\infty}$ e $X_{\infty}$ são valores de tensão de retas assintóticas paralelas ao eixo das deformações e $\sigma_{0}$ é a tensão de escoamento.

\subsection{TESTE DE TRAÇÃO}

Os corpos de prova utilizados nos ensaios trativos seguem a forma e as dimensões apresentadas na Figura 3.2, com a espessura variando de acordo com o material. Foram confeccionados a partir de chapas planas de alumínio, segundo as direções paralela e perpendicular, em relação à direção de laminação, de modo que se pode avaliar o grau de anisotropia existente.

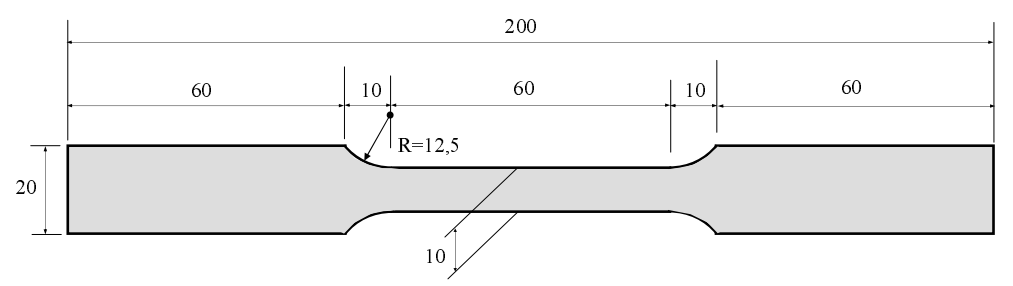

Figura 3.2: Geometria do corpo de prova usado nos testes de tração. Medidas em milímetros.

A montagem do corpo de prova na máquina foi feita através de mordentes, de acordo com o apresentado na Figura 3.3(a). O detalhe do posicionamento do sensor de deslocamento, de $25 \mathrm{~mm}$ de abertura, pode ser visto na Figura 3.3(b). A uma velocidade de $5 \mathrm{~mm} / \mathrm{min}$, os corpos de prova foram tracionados até seu rompimento.

Observando a região onde ocorreu o rompimento, verificou-se que a estricção formada foi pequena, Figura 3.4. Isto possibilita a consideração de um estado uniaxial de tensões no corpo de prova, na região entre os clipes do sensor de deslocamento, até momentos antes da falha do material. Desta forma, é possível assumir que a tensão equivalente de von Mises é a própria tensão axial, valendo a mesma igualdade para a deformação axial e a equivalente. 


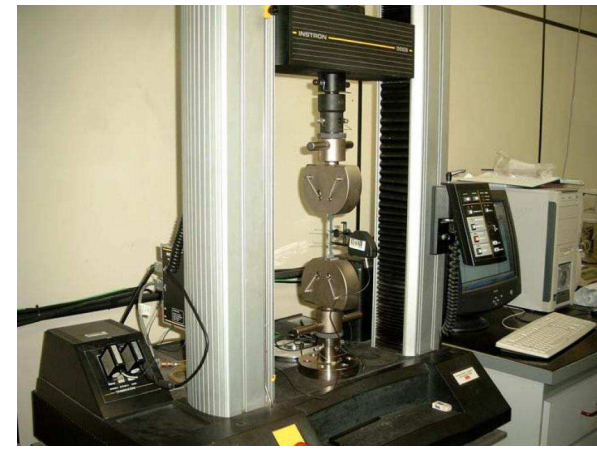

(a)

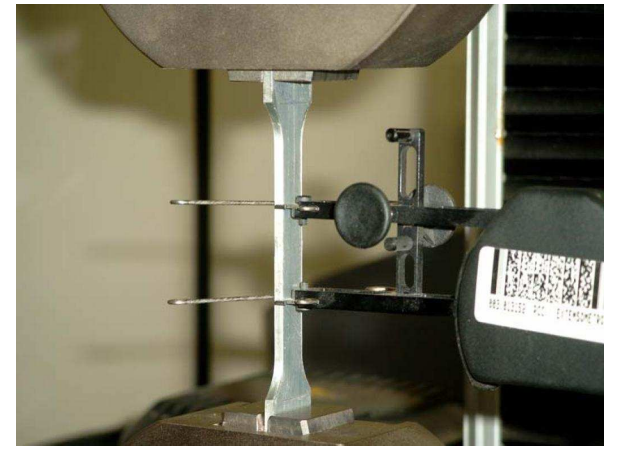

(b)

Figura 3.3: (a) Equipamento Instron utilizado nos testes estáticos. (b) Detalhe da montagem do sensor no teste de tração.

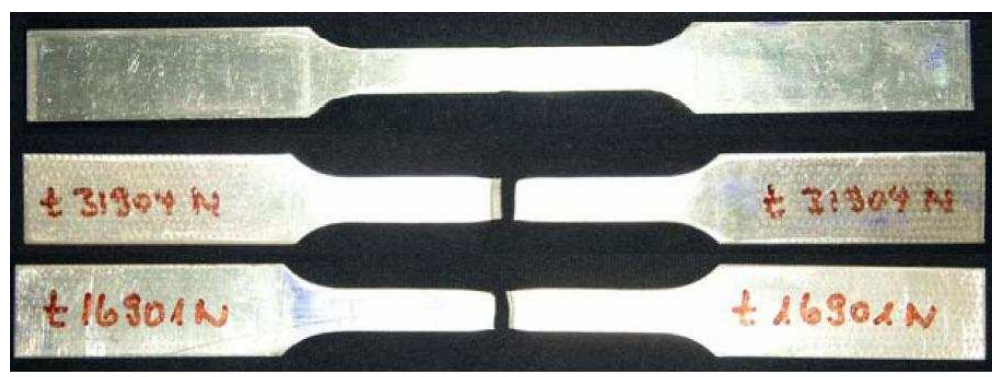

Figura 3.4: corpos de prova antes e depois dos testes, indicando pouco estrangulamento na região de ruptura.

A partir das Equações (3.3) e (3.4), as curvas do comportamento do material foram construídas para ambos os materiais e direções.

Quatro curvas, duas de corpos de prova retirados a $0^{\circ}$ (identificados como t1601N e t1602N) e outras duas de corpos de prova a $90^{\circ}$ da direção de laminação (t16901N e t16904N), foram selecionadas para representar o material M1, conforme apresentado na Figura 3.5. Observa-se nesta figura uma curva típica para metais, com pequena e delimitada região elástica, encruamento ao longo da deformação e posterior amolecimento seguido de falha. Comparando-se as propriedades nas duas direções, a menos da deformação de ruptura, as curvas são bem próximas. Isto possibilita a consideração de um material isotrópico, conduzindo à utilização de modelos mais simples e bem estabelecidos. Os descarregamentos presentes na Figura 3.5 foram usados em Alves, Driemeier e Micheli (2006) para medição da variação do módulo elástico com a deformação, necessário para calibração do modelo de dano, descrito mais à frente. 


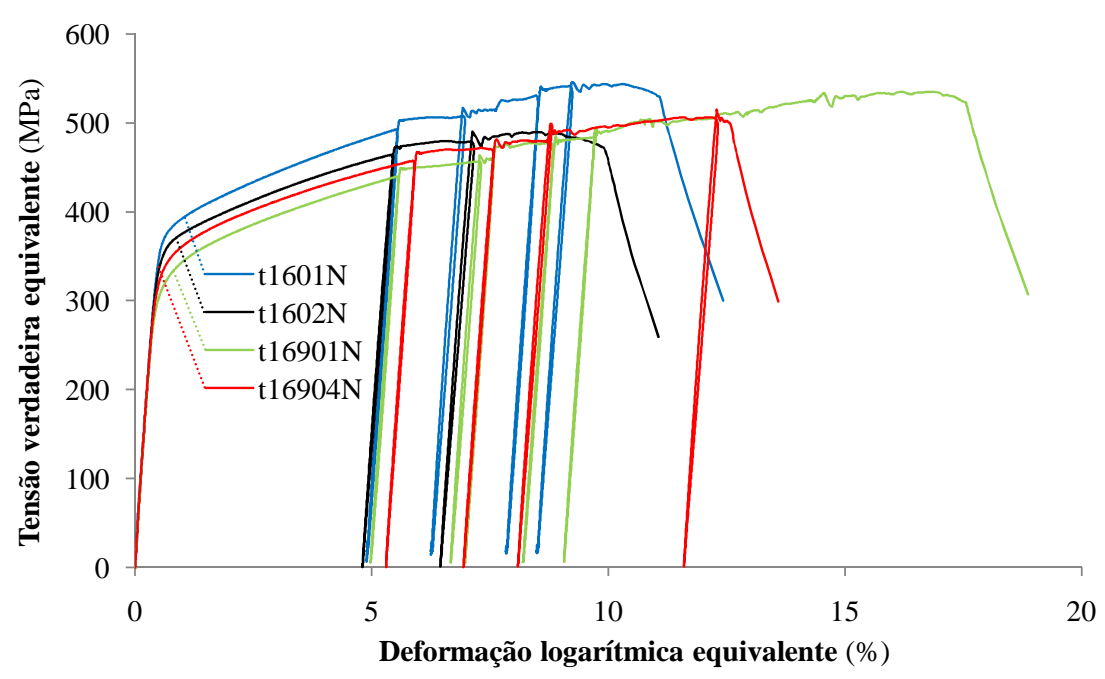

Figura 3.5: Curvas tensão versus deformação equivalentes do material M1, na direção de laminação $\left(\mathrm{t} 1601 \mathrm{~N}\right.$ e t1602N) e a $90^{\circ}$ desta (t16901N e t16904N).

Na representação do material M2 foram selecionadas seis curvas, três para cada direção no plano da chapa, de acordo com o apresentado na Figura 3.6. Do mesmo modo que para o material M1, em aspectos gerais, as curvas representam bem um material dúctil. Neste caso, porém, à $90^{\circ}$ da direção de laminação, o material é um pouco menos resistente que a $0^{\circ}$, indicando uma característica anisotrópica. Entretanto, em virtude da simplicidade dos modelos matemáticos isotrópicos e pela coerência de se aplicar a mesma metodologia nos dois materiais, essa diferença foi desconsiderada. Um maior número de testes seria necessário para calibração de um modelo anisotrópico.

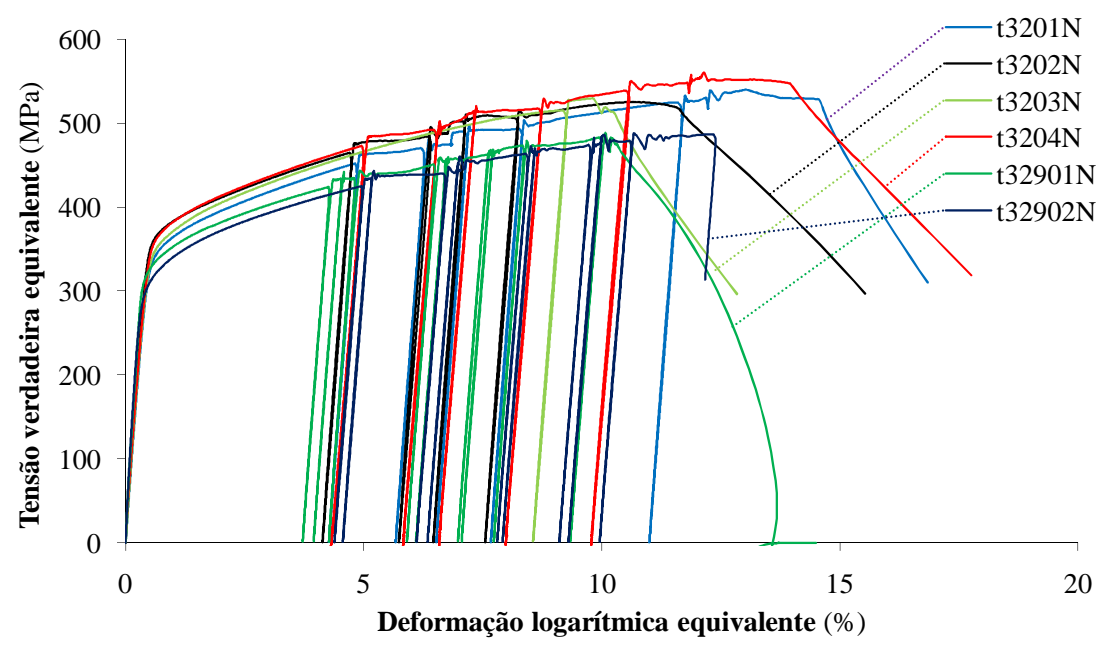

Figura 3.6: Curvas tensão versus deformação equivalentes do material M2, na direção de laminação (t3201N, t3202N, t3203N e t3204N) e a $90^{\circ}$ desta (t32901N e t32902N). 
A partir dos resultados desses testes de tração, foram obtidos os valores para o módulo elástico, $E$, e tensão de escoamento, $\sigma_{0}$. O módulo elástico de cada curva foi calculado por regressão linear realizada entre as deformações de $0,05 \%$ e $0,35 \%$. Os valores dos coeficientes angulares obtidos são apresentados nas Tabelas 3.1 e 3.2.

Tabela 3.1: Propriedades elasto-plásticas do material M1.

\begin{tabular}{|c||cccc|}
\hline Teste & $\mathrm{t} 1601 \mathrm{~N}$ & $\mathrm{t} 1602 \mathrm{~N}$ & $\mathrm{t} 16901 \mathrm{~N}$ & $\mathrm{t} 16904 \mathrm{~N}$ \\
\hline $\boldsymbol{E}(\mathrm{MPa})$ & 73336,3 & 73694,4 & 72575,7 & 73452,7 \\
$\boldsymbol{\sigma}_{0}(\mathrm{MPa})$ & 379,2 & 361,7 & 321,1 & 341,7 \\
\hline
\end{tabular}

Para cada um dos materiais, uma reta foi traçada com inclinação igual ao valor mediano dos módulos, a partir de uma deformação de 0,2\%, e, como ilustra a Figura 3.7, a interceptação desta reta com as curvas definiu as tensões de escoamento de cada teste, as quais são listadas nas Tabelas 3.1 e 3.2. A definição de valores únicos destes dois parâmetros para cada material foi feita por meio do cálculo da mediana dos valores obtidos em cada teste. A Tabela 3.3 apresenta os resultados encontrados, os quais estão próximos a valores típicos de ligas de alumínio. Observa-se nesta tabela que valores comuns do coeficiente de Poisson, $v$, e densidade, $\rho$, de ligas de alumínio foram empregados (MATWEB, 2008).

Tabela 3.2: Propriedades elasto-plásticas do material M2.

\begin{tabular}{|c||cccccc|}
\hline Teste & $\mathrm{t} 3201 \mathrm{~N}$ & $\mathrm{t} 3202 \mathrm{~N}$ & $\mathrm{t} 3203 \mathrm{~N}$ & $\mathrm{t} 3204 \mathrm{~N}$ & $\mathrm{t} 32901 \mathrm{~N}$ & $\mathrm{t} 32902 \mathrm{~N}$ \\
\hline $\boldsymbol{E}(\mathrm{MPa})$ & 71822,0 & 78019,6 & 73205,1 & 72070,9 & 85671,1 & 79698,0 \\
$\boldsymbol{\sigma}_{0}(\mathrm{MPa})$ & 343,7 & 367,5 & 351,3 & 364,3 & 335,5 & 319,2 \\
\hline
\end{tabular}

Tabela 3.3: Propriedades elasto-plásticas dos materiais M1 e M2.

\begin{tabular}{|c|ccccc|}
\hline Material & $\boldsymbol{E}(\mathrm{MPa})$ & $\boldsymbol{v}$ & $\boldsymbol{\rho}\left(\mathrm{kg} / \mathrm{m}^{3}\right)$ & $\boldsymbol{\sigma}_{0}(\mathrm{MPa})$ & $\boldsymbol{\varepsilon}_{0}^{p}\left(\mathrm{~s}^{-1}\right)$ \\
\hline \hline M1 & 73394,5 & 0,31 & 2700 & 351,70 & $3,22 \cdot 10^{-03}$ \\
M2 & 75612,4 & 0,31 & 2700 & 347,50 & $2,38 \cdot 10^{-03}$ \\
\hline
\end{tabular}

Na calibração das equações que definem o encruamento, a região elástica perde a importância e se faz necessário um ajuste nas curvas para obtenção dos parâmetros envolvidos. Elimina-se a região anterior à tensão de escoamento, de modo a se construir relações tensão equivalente versus deformação plástica equivalente, como apresentado nas Figuras 3.8 


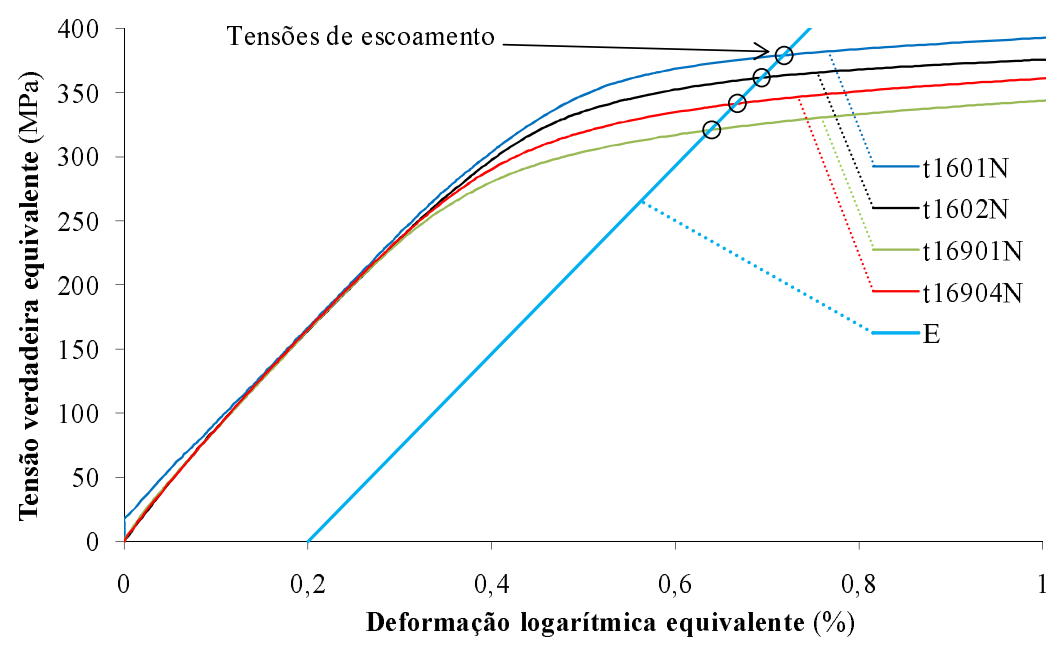

Figura 3.7: Ilustração do modo utilizado para cálculo da tensão de escoamento. O material M1 é utilizado neste exemplo.

e 3.9. Com a utilização de modelo isotrópicos, apenas uma curva deve ser escolhida para representar o comportamento do material em todas as direções de carregamento. Isto foi realizado com o cálculo, para alguns valores de deformação plástica, da mediana dos valores de tensão de todas as curvas, resultando numa curva central base, também apresentada nas Figuras 3.8 e 3.9.

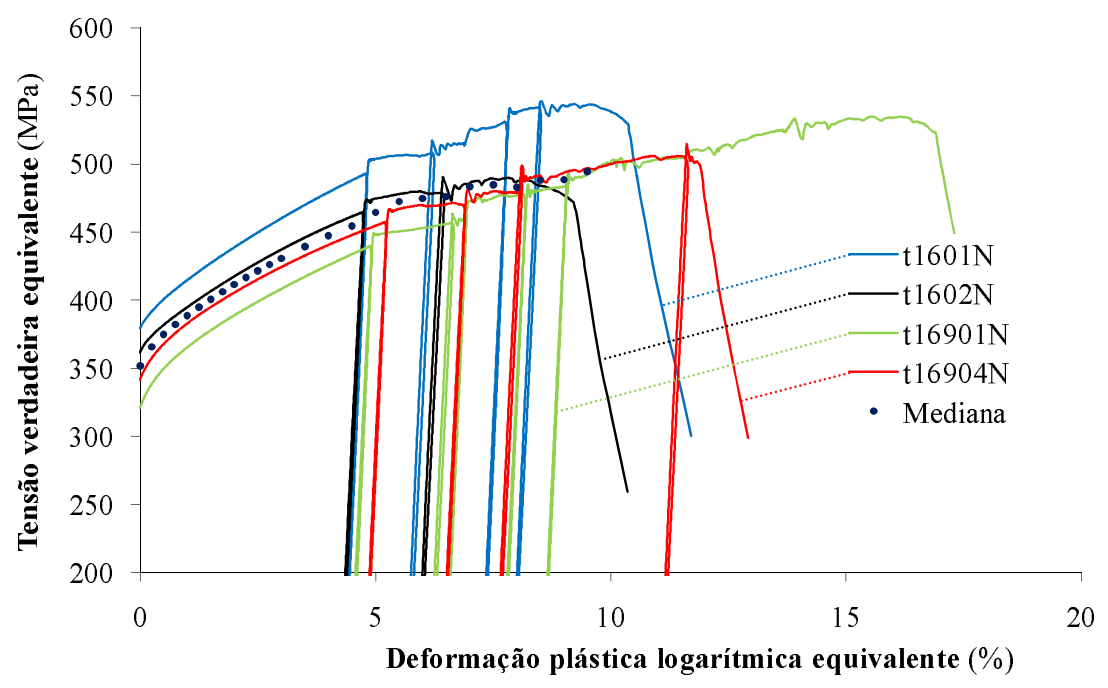

Figura 3.8: Curvas tensão versus deformação plástica equivalentes do material M1.

Através de uma rotina de otimização (fminsearch) do programa Matlab, foi possível ajustar os parâmetros dos dois modelos de encruamento selecionados. Trata-se de uma rotina 


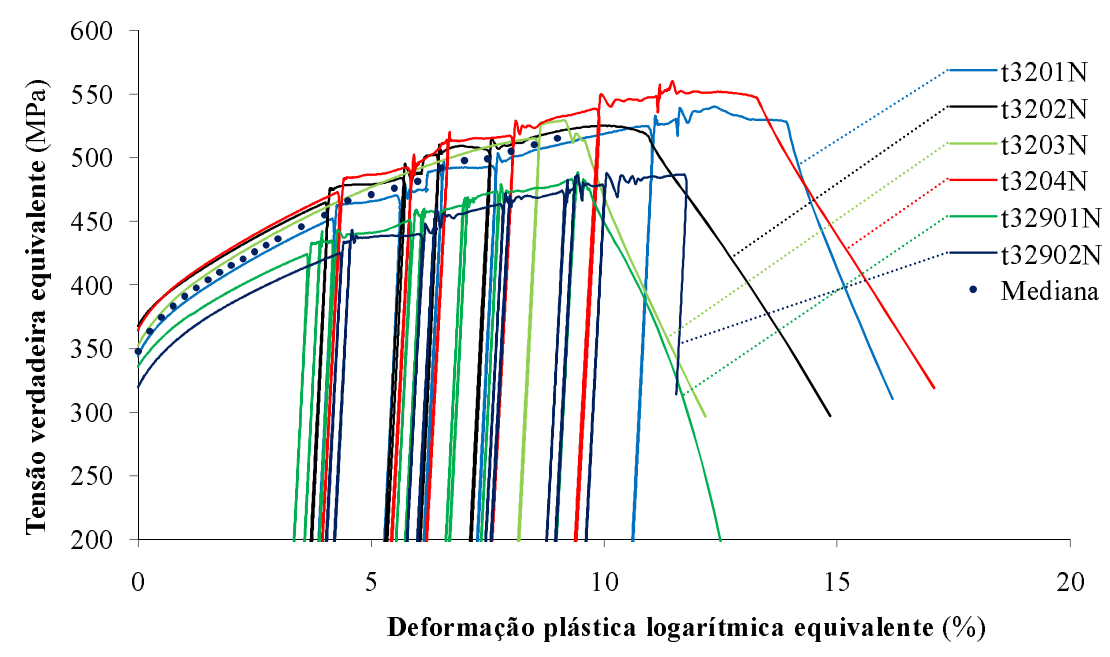

Figura 3.9: Curvas tensão versus deformação plástica equivalentes do material M2.

de otimização que utiliza o método simplex de Nelder-Mead para a busca do valor mínimo de uma função.

A taxa de deformação sofrida pelo material durante o teste, apesar de relativamente pequena, é utilizada quando da avaliação do comportamento dinâmico, tendo sido, portanto, calculada de modo análogo ao módulo elástico. Através de uma regressão linear aplicada na curva deformação plástica equivalente versus tempo, seguida do cálculo da mediana dos coeficiente angulares, foi possível encontrar os valores da taxa de deformação plástica equivalente dos testes quase-estáticos, $\dot{\varepsilon}_{0}^{p}$. Os resultados de cada material estão presentes na Tabela 3.3. Considerando a taxa nominal, de $3,3 \cdot 10^{-03} \mathrm{~s}^{-1}$, calculada a partir da velocidade inposta na máquina de tração, os valores não se distanciaram muito deste, principalmente para o material M1, de menor espessura e que, portanto, exige uma força menor da máquina, a qual tem sua precisão diminuída com o aumento da força que aplica.

\subsubsection{Identificação dos parâmetros do modelo de Swift - tração}

Este modelo, como descrito na Equação (3.25), apresenta apenas dois parâmetros a se determinar, pois o parâmetro $A$ é a própria tensão de escoamento, $\sigma_{0}$. Deste modo, definiuse a função objetivo, $f_{o b j}$, que se deseja minimizar, como

$$
f_{o b j}=\sum_{i}\left(\sigma_{0}+x_{1}\left(\varepsilon_{p(i)}\right)^{x_{2}}-\sigma_{y(i)}\right)^{2}
$$

onde $\varepsilon_{p(i)}$ e $\sigma_{y(i)}$ referem-se aos pontos da curva mediana calculados a partir dos dados experimentais e apresentados nas Figuras 3.8 e 3.9, e $x_{1}$ e $x_{2}$ são as variáveis de projeto, 
cujos valores ótimos definem os parâmetros $B$ e $n$ da Equação (3.25).

A Tabela 3.4 apresenta o número de iterações realizadas pela rotina de otimização e os valores dos parâmetros do modelo de Swift. As curvas de representação numérica do comportamento quase-estático do material, construídas com esses parâmetros, são apresentadas nas Figuras 3.10 e 3.11. Diversos conjuntos de valores iniciais das variáveis de projeto foram utilizados na rotina de otimização de forma a tentar evitar a obtenção de pontos de mínimo local. Variou-se o valor inicial do parâmetro $B$ de 200 a 1000 MPa e o valor inicial do parâmetro $n$ de 0,01 a 10,0, para ambos os materiais, obtendo-se, em todos os testes, os resultados apresentados na Tabela 3.4.

Tabela 3.4: Parâmetros do modelo de Swift, obtidos a partir dos testes de tração dos materiais M1 e M2.

\begin{tabular}{|c|cccc|}
\hline Material & $\begin{array}{c}\text { Número de } \\
\text { iterações }\end{array}$ & $\boldsymbol{A}(\mathrm{MPa})$ & $\boldsymbol{B}(\mathrm{MPa})$ & $\boldsymbol{n}$ \\
\hline \hline M1 & $<120$ & 351,70 & 582,29 & 0,5740 \\
M2 & $<110$ & 347,50 & 748,94 & 0,6113 \\
\hline
\end{tabular}

\subsubsection{Identificação dos parâmetros do modelo de Lemaitre - tração}

\section{Parâmetros de encruamento}

Aplicando-se a nomenclatura utilizada pelo programa de análise numérica LS-DYNA, a Equação (3.26), que modela o encruamento segundo a lei constitutiva de Lemaitre, tornase

$$
\sigma_{y}=\sigma_{0}+Q_{1}\left[1-\exp \left(-C_{1} \varepsilon_{p}\right)\right]
$$

A rotina de otimização do programa Matlab foi empregada na função objetivo

$$
f_{o b j}=\sum_{i}\left(\sigma_{0}+x_{1}\left[1-\exp \left(-x_{2} \varepsilon_{p(i)}\right)\right]-\sigma_{y(i)}\right)^{2}
$$

com os valores ótimos das variáveis de projeto $x_{1}$ e $x_{2}$ sendo $Q_{1}$ e $C_{1}$, respectivamente. É interessante notar que o programa LS-DYNA utiliza ainda outros dois parâmetros isotrópicos, $Q_{2}$ e $C_{2}$, repetindo o segundo termo do lado direito da Equação (3.28). A utilização destes dois parâmetros adicionais foi considerada irrelevante e a ambos foi estabelecido o valor zero. Os valores de $Q_{1}$ e $C_{1}$ encontrados estão na Tabela 3.5. Do mesmo modo que 
no modelo de Swift, estes parâmetros foram obtidos a partir de diferentes valores iniciais, variando de 50 a 1000 o valor de $Q_{1}$ e de 1 a 50 o de $C_{1}$.

Tabela 3.5: Parâmetros de encruamento do modelo de Lemaitre, obtidos a partir dos testes de tração dos materiais M1 e M2.

\begin{tabular}{|c|ccc|}
\hline Material & $\begin{array}{c}\text { Número de } \\
\text { iterações }\end{array}$ & $\boldsymbol{Q}_{1}(\mathrm{MPa})$ & $\boldsymbol{C}_{1}$ \\
\hline \hline M1 & $<150$ & 156,48 & 24,59 \\
M2 & $<140$ & 189,81 & 21,77 \\
\hline
\end{tabular}

As Figuras 3.10 e 3.11 apresentam as curvas geradas com os parâmetros do modelo de Lemaitre para os materiais M1 e M2, respectivamente. Nestas figuras também estão presentes os dados experimentais e as curvas de Swift. A princípio, os dois modelos representam bem o comportamento de ambos os materiais. A lei de encruamento de Lemaitre possui uma melhor adaptação aos pontos da curva experimental, principalmente para deformações acima de $8 \%$, porém não houve grandes discrepâncias que indicassem a não utilização do modelo de Swift. Deste modo, os dois modelos serão empregados na representação da curva quase-estática, o de Lemaitre com o modelo dinâmico de CS e o de Swift com o modelo de JC, conforme está implementado no programa LS-DYNA.

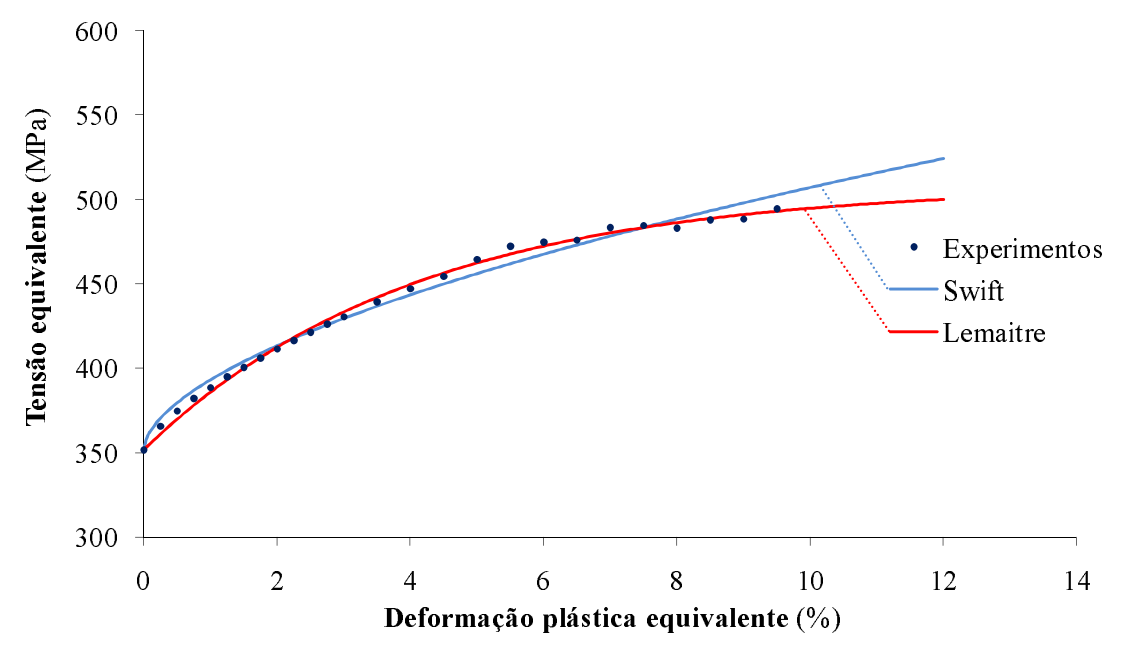

Figura 3.10: Modelos para a curva tensão versus deformação plástica equivalentes do material M1. 


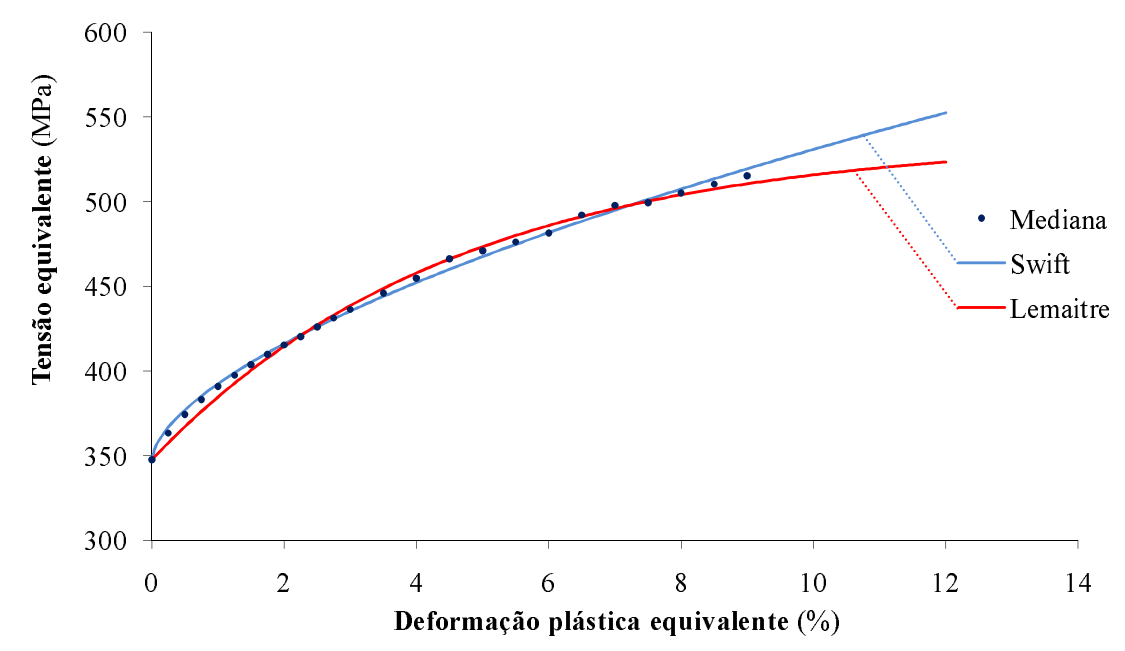

Figura 3.11: Modelos para a curva tensão versus deformação plástica equivalentes do material M2.

Parâmetros de dano

O modelo de Lemaitre (LEMAITRE, 1992), baseado na mecânica do dano contínuo, é implementado no LS-DYNA sob a denominação MAT_DAMAGE_1 (LSTC, 2003). Neste modelo, a tensão equivalente, $\sigma$, é escrita segundo a Equação (3.28) até o momento em que se inicia o processo de danificação do material, definido pela deformação plástica equivalente $\varepsilon_{D}^{p}$. A partir deste ponto, a tensão equivalente passa a valer

$$
\sigma=\sigma_{y}(1-D)
$$

onde $\sigma_{y}$ é dado pela Equação (3.26) e $D$ representa a variável dano que segue a lei de evolução

$$
\dot{D}=\left\{\begin{array}{ll}
0 & \text { se } \varepsilon^{p} \leq \varepsilon_{D}^{p} \\
\frac{Y}{S(1-D)} \dot{\varepsilon} & \text { se } \varepsilon^{p}>\varepsilon_{D}^{p} \text { e } \sigma_{1}>0
\end{array},\right.
$$

O termo $\sigma_{1}$ representa a máxima tensão principal e $S$ é o parâmetro do material que representa a taxa de liberação de energia de deformação, cuja densidade é dada por

$$
Y=\frac{w_{e}}{1-D}
$$

onde $w_{e}$ é a energia de deformação elástica específica, definida por

$$
w_{e}=\int \sigma_{i j} d \varepsilon_{i j}^{e}
$$


sendo $\sigma_{i j}$ e $\varepsilon_{i j}^{e}$ as componentes do tensor de tensão e de deformação elástica, respectivamente. Decompondo estes tensores em componentes hidrostáticas e desviadoras, é possível mostrar (LEMAITRE, 1992) que a Equação (3.33) pode ser reescrita como

$$
w_{e}=\frac{\sigma^{2}}{2 E(1-D)}\left[\frac{2}{3}(1+v)+3(1-2 v)\left(\frac{\sigma_{H}}{\sigma}\right)^{2}\right]
$$

ou, ainda, como

$$
w_{e}=\frac{\sigma^{2} R_{v}}{2 E(1-D)},
$$

a partir da definição da função triaxialidade, $R_{v}$,

$$
R_{v}=\frac{2}{3}(1+v)+3(1-2 v)\left(\frac{\sigma_{m}}{\sigma}\right)^{2}
$$

Substituindo a Equação (3.35) na Equação (3.32), obtém-se

$$
Y=\frac{\sigma^{2} R_{v}}{2 E(1-D)^{2}}
$$

Utilizando a Equação (3.37) pode-se reescrever a lei de evolução do dano, Equação (3.31), para $\varepsilon^{p}>\varepsilon_{D}^{p}$, como

$$
\dot{D}=\frac{\sigma^{2} R_{v}}{2 E S(1-D)^{2}} \dot{\varepsilon_{p}}
$$

Segundo esta representação, o material falha quando a variável dano atinge um valor crítico,

$$
D=D_{\text {crit }}
$$

Desta forma, além das variáveis elásticas, os parâmetros necessários para a modelagem do dano são três: $\varepsilon_{D}^{p}$, $S$ e $D_{c r i t}$. Faixas aceitáveis para os valores destes três parâmetros foram levantadas a partir da medição da variação do módulo elástico com a deformação equivalente (ALVES; DRIEMEIER; MICHELI, 2006), obtida aplicando ciclos de carregamento e descarregamento, apresentados nas Figuras 3.5 e 3.6, dada por

$$
\tilde{E}=E(1-D)
$$

onde $\tilde{E}$ é o módulo elástico atual, degradado pelo dano e obtido pelo descarregamento elástico na região plástica. 
O detalhamento da obtenção desses parâmetros do modelo de dano está presente em Alves, Driemeier e Micheli (2006). A supressão desses detalhes ocorre pois o objetivo deste trabalho não foca no modelo de falha e sim no comportamento dinâmico do material e no modo de caracterização deste. Em resumo, a determinação de um valor único para cada parâmetro dentro dos intervalos estabelecidos foi realizada através de simulações numéricas do teste de tração. Num processo iterativo, os parâmetros compondo o modelo de material do corpo de prova eram ajustados, a simulação executada até o rompimento e a curva numérica de carga versus deslocamento comparada com a experimental. A partir dos resultados, modificações nos valores dos parâmetros eram feitas e o processo se repetia com novas simulações. Obtidos quando encontrada uma boa correlação entre essas curvas, os parâmetros finais são apresentados na Tabela 3.6 para ambos os materiais.

Tabela 3.6: Parâmetros do modelo de dano de Lemaitre.

\begin{tabular}{|c|ccc|}
\hline Material & $\boldsymbol{S}(\mathrm{MPa})$ & $\boldsymbol{\varepsilon}_{D}^{p}$ & $\boldsymbol{D}_{c}$ \\
\hline \hline M1 & 3,3 & 0,05 & 0,19 \\
M2 & 2,8 & 0,07 & 0,14 \\
\hline
\end{tabular}

\subsection{TESTE DE COMPRESSÃO}

Testes de compressão foram realizados em corpos de prova na forma de anéis, como o da Figura 3.12(a), no mesmo equipamento Instron dos testes de tração, através da utilização de pratos de alta rigidez, apresentados na Figura 3.12(b). O material M1 foi comprimido a uma velocidade de $0,05 \mathrm{~mm} / \mathrm{min}$ e o material $\mathrm{M} 2$ a $0,45 \mathrm{~mm} / \mathrm{min}$, resultando numa taxa de deformação nominal de $5,2 \cdot 10^{-4} \mathrm{~s}^{-1}$ e $2,3 \cdot 10^{-3} \mathrm{~s}^{-1}$, respectivamente.

A geometria utilizada provém da metodologia adotada para a caracterização dinâmica, apresentada no Capítulo 5. Trata-se de anéis cuja direção axial é perpendicular ao plano das chapas de alumínio, o que levou à caracterização do material numa terceira direção, ortogonal às outras duas testadas em tração. Os valores do diâmetro interno, $d_{0}$, do externo, $D_{0}$, e da largura dos anéis (aqui chamada de comprimento), $L_{0}$, Figura 3.13 , são apresentados na Tabela 3.7.

O carregamento neste teste quase-estático de compressão é paralelo à direção axial dos anéis, do mesmo modo que nos testes de caracterização dinâmica. O objetivo de se realizar este ensaio, nestas condições, é determinar uma curva tensão versus deformação de referência para as curvas dinâmicas, visto que a BH disponível para determinação destas 


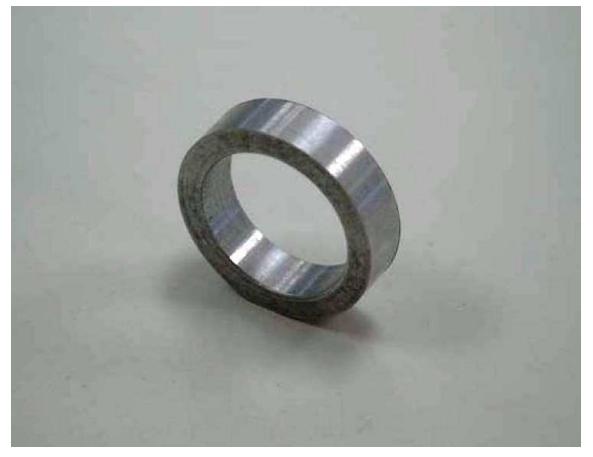

(a)

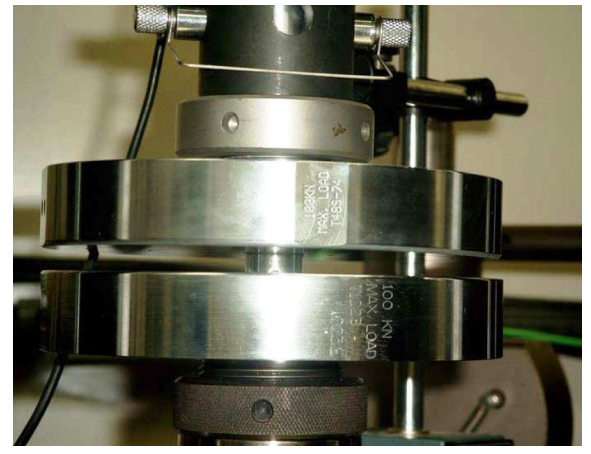

(b)

Figura 3.12: Detalhe (a) do corpo de prova e (b) da compressão pelos pratos da máquina Instron.

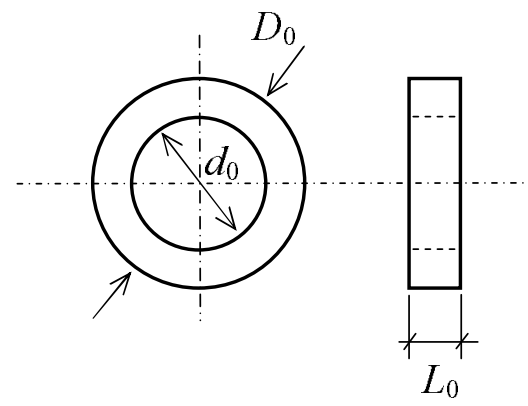

Figura 3.13: Parâmetros do corpo de prova no formato de anel.

Tabela 3.7: Dados geométricos do corpo de prova em forma de anel.

\begin{tabular}{|c|ccc|}
\hline Material & $\begin{array}{c}\text { Comprimento } \\
\boldsymbol{L}_{0}(\mathrm{~mm})\end{array}$ & $\begin{array}{c}\text { Diâmetro } \\
\text { interno } \\
\boldsymbol{d}_{0}(\mathrm{~mm})\end{array}$ & $\begin{array}{l}\text { Diâmetro } \\
\text { externo } \\
\boldsymbol{D}_{0}(\mathrm{~mm})\end{array}$ \\
\hline \hline M1 & 1,60 & 18,4 & 20,0 \\
M2 & 3,20 & 16,8 & 20,0 \\
\hline
\end{tabular}

opera em compressão. A partir desta curva de referência e dos dados dinâmicos é possível calcular os coeficientes dos modelos constitutivos que consideram o efeito da taxa de deformação na resistência mecânica do material. É importante notar que esses parâmetros se referem à direção perpendicular ao plano de laminação de uma chapa fina, que, normalmente, difere razoavelmente das propriedades nas outras direções, as quais se acredita serem as mais importantes no impacto balístico em questão. A solução encontrada foi não utilizar as curvas de compressão diretamente no modelo do encruamento aplicado nas simulações numéricas do teste de impacto (os parâmetros das curvas em tração são usa- 
dos neste caso), e sim, obter os coeficientes que caracterizam o comportamento dinâmico do material a partir da curva em compressão e assumir que são os mesmos em todas as direções. Ou seja, é considerado que o endurecimento causado pelo aumento na taxa de deformação é o mesmo em todas as direções da chapa.

Algumas complicações que não ocorrem num teste de tração, dificultam a obtenção de dados válidos num teste de compressão. Neste tipo de teste, existe contato, e portanto, atrito entre as superfícies dos discos da máquina e do corpo de prova, normalmente cilíndrico, de modo que este não tem total liberdade para se expandir radialmente quando comprimido. Um efeito disto é o abaulamento causado no perfil externo do corpo, o que implica na perda do estado uniaxial e uniforme de tensão e deformação. Atenção também deve ser dada ao fenômeno de flambagem, agravada por outra característica da compressão, que é a alta resistência à falha do material, que faz com que seja necessária uma força de magnitude bem superior em relação a um teste trativo. Outro efeito problemático desta elevada carga é a inclinação do prato superior da máquina (o que se desloca na compressão), que dificulta a medição do histórico de deslocamento e pode também interferir na uniformidade do carregamento.

Vários testes foram realizados até a obtenção de uma curva válida para cada material. Utilizou-se o lubrificante MOLIKOTE BR-2 (Bissulfeto de Molibdênio) entre os corpos de prova e os pratos de forma a minimizar o atrito. Os testes que apresentaram grande abaulamento foram desconsiderados. O fenômeno de flambagem não ocorreu, devido ao pequeno comprimento dos corpos de prova, resultado da fina espessura das chapas. Em contrapartida, esse pequeno comprimento dos corpos de prova fez com que o deslocamento máximo na compressão fosse pequeno: 0,2mm para o material M1 e $1 \mathrm{~mm}$ para o M2. Isto também dificulta a medição do histórico de deformações, pois o erro na precisão da medição do deslocamento pela máquina é proporcional à força aplicada, e por isso, se torna da mesma ordem de grandeza dos deslocamentos medidos devido ao valor da força alcançado. Além disso, uma pequena inclinação do prato superior já implica numa variação de deslocamento relativamente alto perto destes deslocamentos obtidos. A solução encontrada foi usar a média dos deslocamentos de dois transdutores lineares ( $L E$ - linear encoders) da Solartron, de precisão $1 \mu \mathrm{m}$, posicionados diametralmente opostos nos discos, de modo a eliminar a inclinação do prato, conforme mostra a Figura 3.14.

As tensões verdadeiras e deformações logarítmicas são calculadas da mesma maneira que no teste de tração, porém possuem sinal negativo. Aplicando-se o módulo, têm-se as tensões e deformações equivalentes, conforme as Equações (3.22) e (3.23). As Figuras 


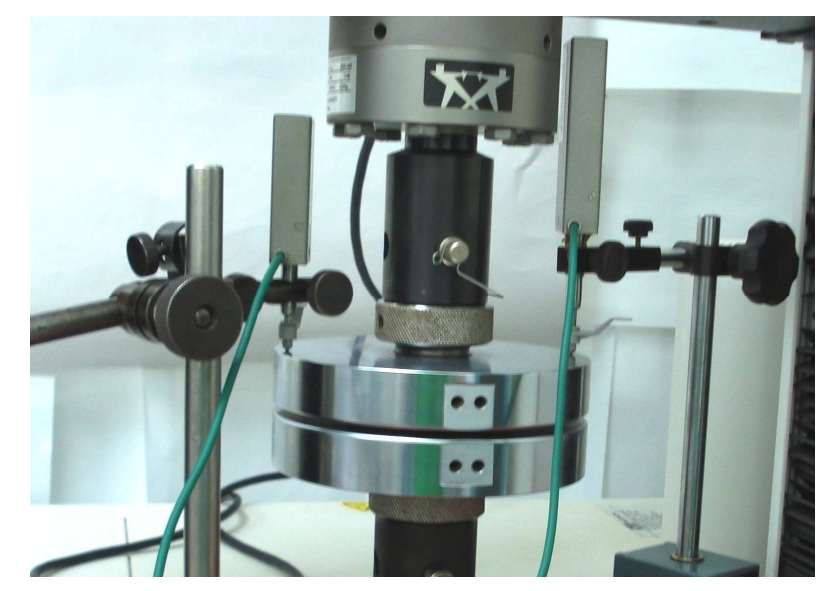

Figura 3.14: Método de medição do histórico de deslocamento no teste de compressão.

3.15 e 3.16 apresentam as curvas para os materiais M1 e M2, respectivamente.

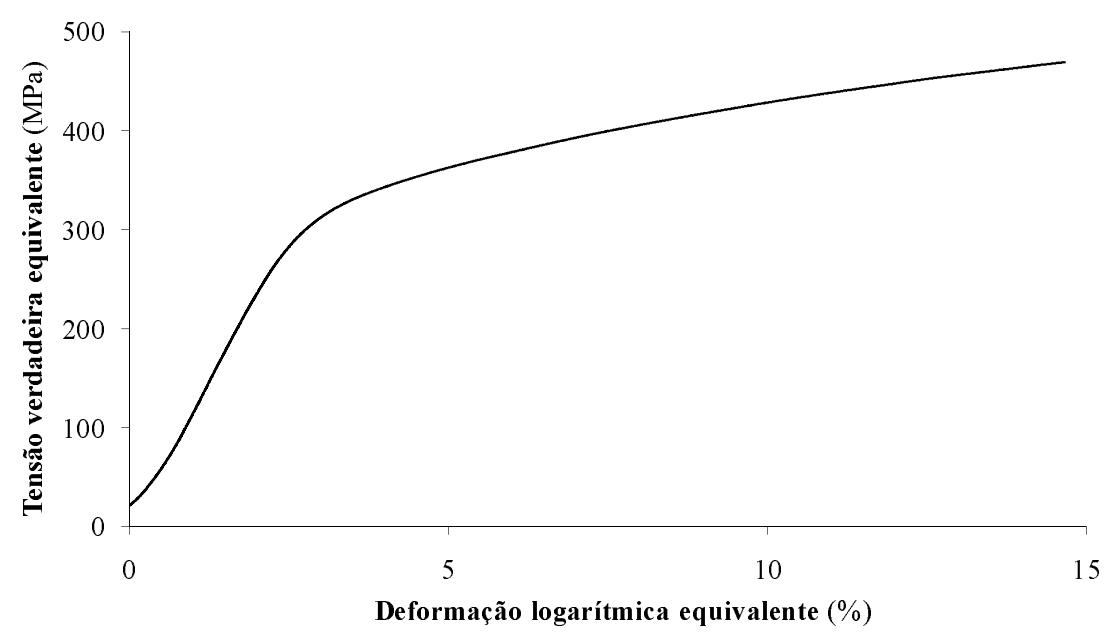

Figura 3.15: Curva tensão versus deformação equivalentes do material M1, na direção perpendicular à de laminação.

Observa-se nas curvas das Figuras 3.15 e 3.16 que a resposta obtida de ambos os materiais no início do teste não corresponde ao que se esperava baseado no teste de tração, como linearidade e mesma inclinação (módulo elástico). Isto se deve, em parte, aos ajustes iniciais no contato entre os pratos e o corpo de prova, e, em uma maior parte, à dificuldade de medição, com precisão e acurácia, dos pequenos deslocamentos envolvidos, visto que não se podem utilizar os extensômetros do teste de tração devido à forma dos corpos de prova. Considerando que a importância destas curvas, neste trabalho, é sua região plástica, que serve como referência para os testes dinâmicos, as curvas foram admitidas válidas. 


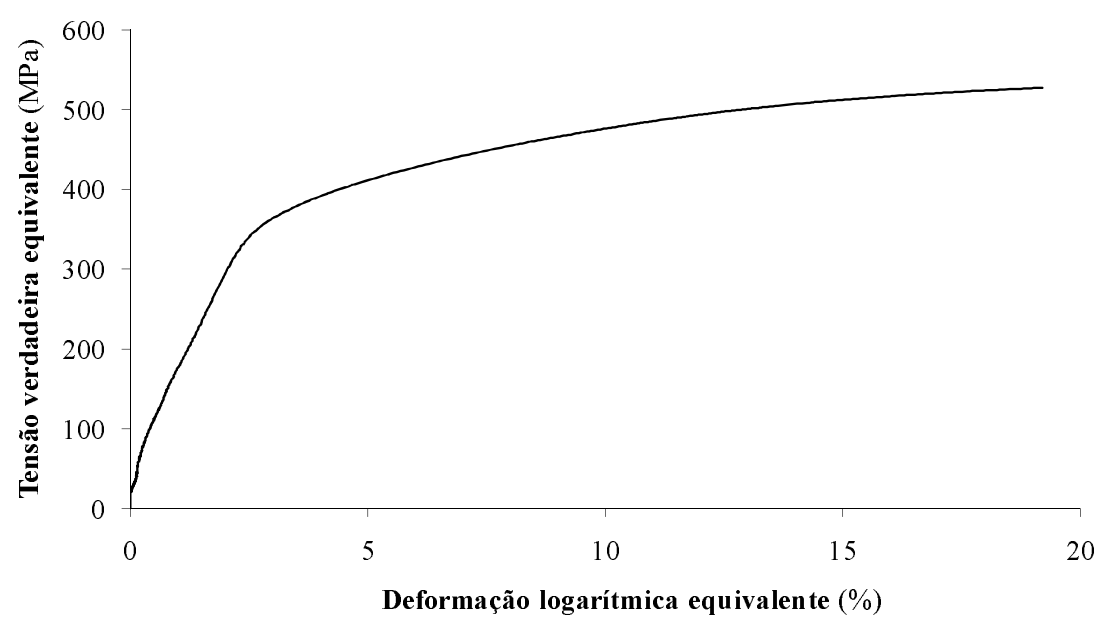

Figura 3.16: Curva tensão versus deformação equivalentes do material M2, na direção perpendicular à de laminação.

A definição da região plástica foi feita pela tensão de escoamento encontrada no teste de tração, Tabela 3.3. Deste modo, eliminou-se o que poderia ser considerado deformação elástica do teste, obtendo-se pontos para ajuste do modelo de Swift. Interessante notar que o final das curvas não foi definido pela falha do material e sim pela máxima carga da máquina, no caso $50 \mathrm{kN}$ para o material M1 e $60 \mathrm{kN}$ para o material M2, caso este realizado numa máquina EMIC de maior capacidade.

As taxas de deformação reais dos testes foram medidas por regressão linear aplicada nas curvas deformação logarítmica versus tempo, do mesmo modo que nos testes de tração. O material M1 apresentou taxa de deformação de $2,3 \cdot 10^{-4} \mathrm{~s}^{-1}$ e o material M2 de 2,6 . $10^{-3} \mathrm{~s}^{-1}$. Comparando estes resultados com as taxas nominais, observa-se que a maior discrepância ocorre com a chapa de menor espessura, onde os deslocamentos são menores e os erros em relação à precisão de aplicação da velocidade pela máquina são maiores. Estes valores medidos pelas curvas do histórico de deformação logarítmica equivalente é que foram utilizados para representação da taxa de deformação de cada curva na obtenção dos parâmetros dinâmicos.

Nos testes de compressão, os dois modelos, de Swift e de Lemaitre, foram calibrados, possibilitando a escolha do melhor ajuste para a curva de referência tanto no caso do encruamento por taxa de deformação de CS quanto no de JC. Neste caso, não se tem a limitação do vínculo entre modelos (existente no programa LS-SYNA), pois a rotina empregada para cálculo dos coeficientes foi desenvolvidas pelo autor a partir da rotina de otimização do programa MATLAB. 


\subsubsection{Identificação dos parâmetros do modelo de Swift - compressão}

A Equação (3.25) foi ajustada como função objetivo idêntica à apresentada na Equação (3.27). De modo a garantir a obtenção de mínimos globais e não locais da função objetivo, os valores iniciais empregados no algoritmo de otimização foram variados. Ao parâmetro inicial $B$ foram atribuídos valores iniciais de 100 a $1000 \mathrm{MPa}$, e ao parâmetro $n$, de 0,05 a 10, para ambos os materiais. O número máximo de interações necessárias dentro destes intervalos é apresentado na Tabela 3.8, que também contém os parâmetros do modelo de Swift obtidos em todos os casos.

Tabela 3.8: Parâmetros do modelo de Swift, obtidos a partir dos testes de compressão quase-estática dos materiais M1 e M2.

\begin{tabular}{|c|ccccc|}
\hline Material & $\begin{array}{c}\text { Número de } \\
\text { iterações }\end{array}$ & $\boldsymbol{A}(\mathrm{MPa})$ & $\boldsymbol{B}(\mathrm{MPa})$ & $\boldsymbol{n}$ & $\boldsymbol{\varepsilon}_{0}^{p}\left(\mathrm{~s}^{-1}\right)$ \\
\hline \hline $\mathrm{M} 1$ & $<95$ & 351,70 & 699,45 & 0,7725 & $2,3 \cdot 10^{-4}$ \\
$\mathrm{M} 2$ & $<95$ & 347,50 & 507,70 & 0,5406 & $2,6 \cdot 10^{-3}$ \\
\hline
\end{tabular}

A partir destes parâmetros, as curvas foram reconstruídas e podem ser comparadas com os dados experimentais através das Figuras 3.17 e 3.18. Observa-se nestas figuras que o comportamento do material foi bem representado pelo modelo de Swift com os parâmetros encontrados, dentro da região de $10 \%$ de deformação plástica. Esta faixa de deformação compreende toda a resposta do material em tração, inclusive a falha, tornando-se suficiente para representação de uma curva quase-estática.

\subsubsection{Identificação dos parâmetros do modelo de Lemaitre - compressão}

A rotina de otimização utilizada em tração em conjunto com a função objetivo definida na Equação (3.29) foram empregadas nos dados experimentais obtidos por compressão, de modo a ajustá-los à Equação (3.28). Os parâmetros ótimos são expressos na Tabela 3.9.

Tabela 3.9: Parâmetros de encruamento do modelo de Lemaitre, obtidos a partir dos testes de compressão dos materiais M1 e M2.

\begin{tabular}{|c|ccc|}
\hline Material & $\begin{array}{c}\text { Número de } \\
\text { iterações }\end{array}$ & $\boldsymbol{Q}_{1}(\mathrm{MPa})$ & $\boldsymbol{C}_{1}$ \\
\hline \hline M1 & $<140$ & 188,67 & 9,41 \\
M2 & $<140$ & 192,11 & 15,74 \\
\hline
\end{tabular}


A seleção do melhor modelo foi feita pela observação das curvas presentes nas Figuras 3.17 e 3.18, onde estão expostas os resultados dos modelos de Lemaitre e Swift e os dados experimentais dos materiais M1 e M2, respectivamente. Até 10\% de deformação plástica do material M1 e até $15 \%$ do material M2, as curvas se assemelham muito. Porém, analisando deformações maiores e a extrapolação dos modelos, o de Lemaitre tende a uma assíntota mais próxima a dos dados experimentais, principalmente para o material M2. Optou-se, deste modo, pelo modelo de Lemaitre para representação da curva quaseestática de compressão que será utilizada na obtenção dos parâmetros dinâmicos.

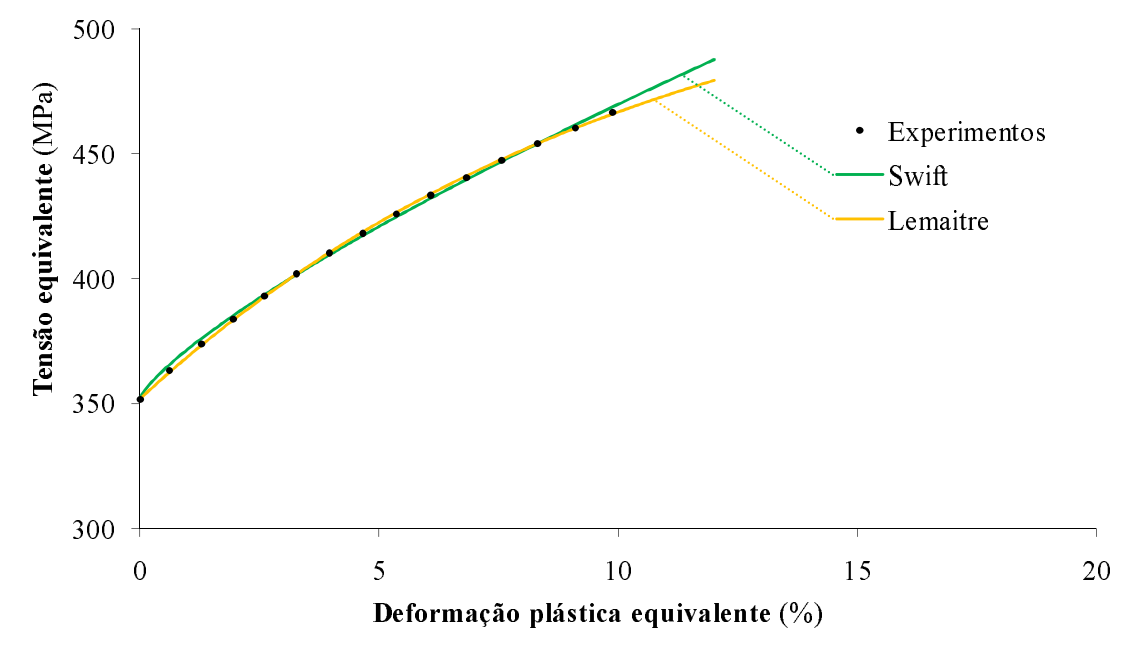

Figura 3.17: Comparação entre os modelos de Lemaitre e Swift e a curva experimental para o material M1

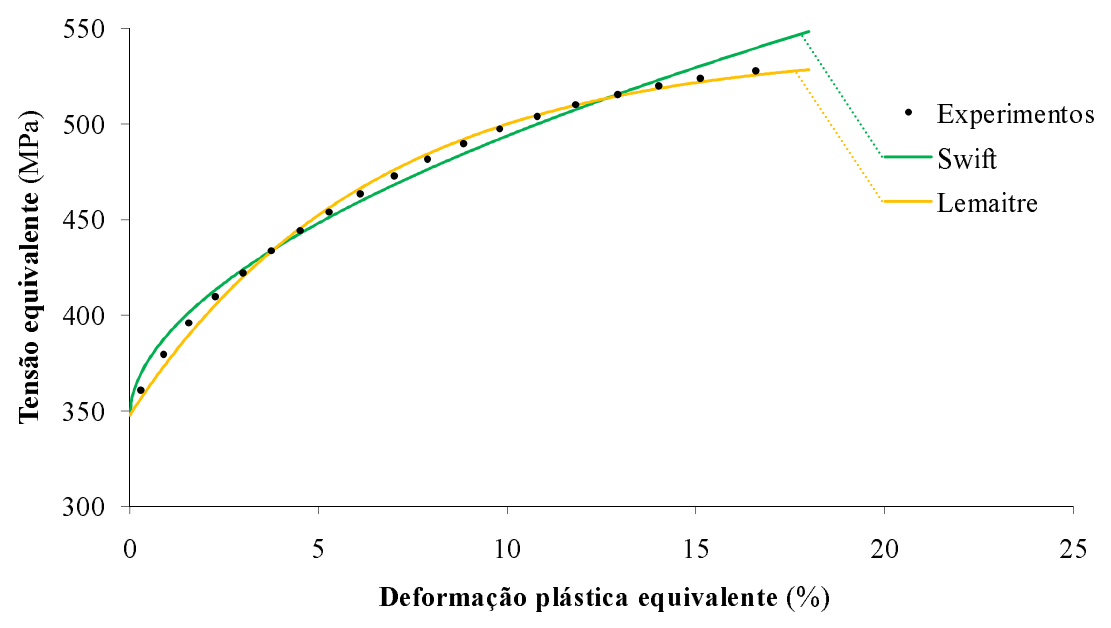

Figura 3.18: Comparação entre os modelos de Lemaitre e Swift e a curva experimental para o material M2 
Uma comparação com as curvas dos modelos em tração é apresentada nas Figuras 3.19 e 3.20 para os dois materiais. Observa-se que o nível de tensão dos materiais em compressão é menor que nos testes em tração. Isto se deve principalmente à mudança da direção testada. É coerente que a direção perpendicular de uma chapa laminada tenha resistência menor que uma direção no plano da chapa, principalmente devido à reorientação dos grãos durante a laminação. Esta diferença é maior quanto menor a espessura da chapa, como pode ser observado ao comparar-se a diferença do nível de tensão entre tração e compressão, maior no material M1 (chapa mais fina) em relação ao M2.

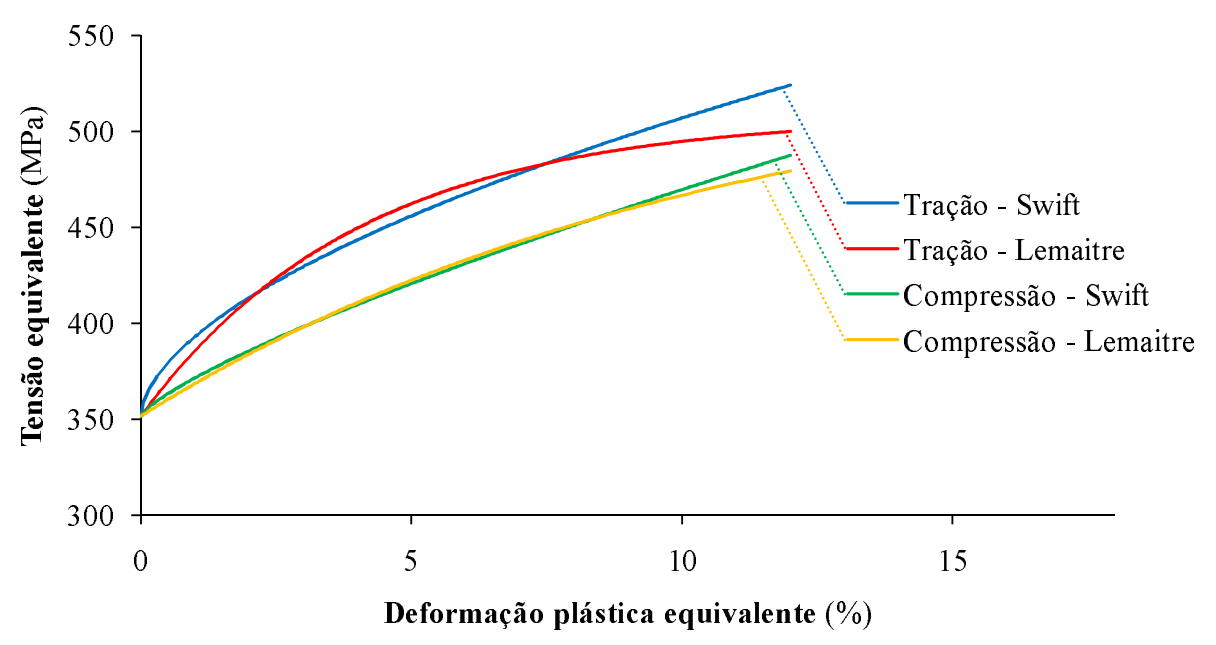

Figura 3.19: Comparação entre os modelos em tração e compressão do material M1.

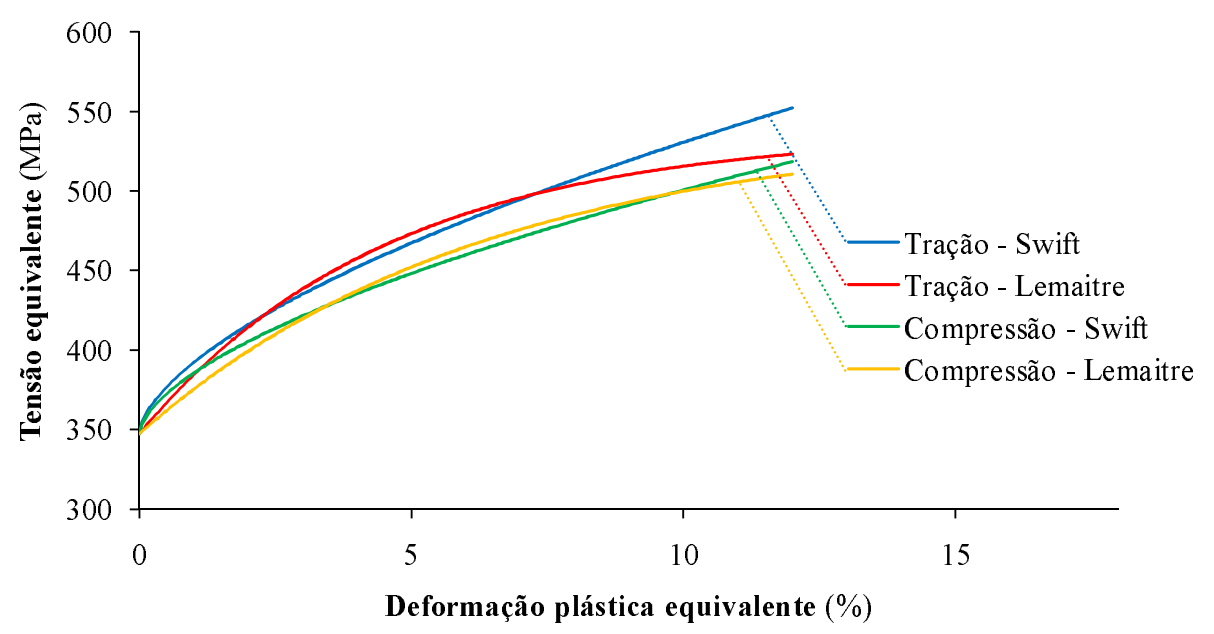

Figura 3.20: Comparação entre os modelos em tração e compressão do material M2. 



\section{CARACTERIZAÇÃO DINÂMICA CONVENCIONAL DOS MATERIAIS}

Os materiais, em geral, respondem diferentemente quando solicitados de maneira estática e dinâmica. A quantificação desta mudança de comportamento é realizada em função da taxa de deformação a qual o material é submetido. Valores de taxa da ordem de $10^{2}$ a $10^{4}$ são comumente encontrados em testes de impacto e o conhecimento da sensibilidade do material a esse parâmetro é de extrema importância na análise dos fenômenos envolvidos.

Uma parcela dessa variação de comportamento, principalmente relacionada ao endurecimento do material com o aumento da taxa de deformação, pode ser entendida através da teoria das discordâncias (DIETER, 1986). Segundo esta teoria, deformações plásticas ocorreriam pela movimentação de discordâncias na rede cristalina dos materiais. Estes seriam mais maleáveis quanto mais facilmente as discordâncias se movimentassem, ultrapassando barreiras como contornos de grãos, maclação, elementos de liga ou impurezas. Deste modo, a aplicação mais rápida do carregamento implicaria na necessidade das discordâncias encontrarem mais rapidamente um caminho para sua propagação. Isto dificultaria a realização de desvios nas barreiras existentes, travando as discordâncias, o que, por sua vez, implicaria na exigência de uma maior carga para transposição destas barreiras. A tensão que o material apresenta sob determinadas deformação e taxa de deformação depende, então da microestrutura que o compõe, no nível das discordâncias (LEE; SHYU; CHIOU, 2000), o que explica a variabilidade na resposta de diferentes materiais.

Em testes quase-estáticos, o material se deforma lentamente, de maneira que é possível considerar a plastificação um processo isotérmico. Quando este material é deformado a altas taxas, entretanto, o tempo existente para a transferência do calor gerado na plastificação do material, para o meio que o envolve, é reduzido. Assim, a temperatura local aumenta, tornando mais coerente a assunção de um processo adiabático (KAPOOR; NEMAT-NASSER, 1998). É conhecido que, na maioria dos metais, o aumento da temperatura causa amolecimento do material (EL-MAGD; ABOURIDOUANE, 2006), o que vem a formar uma segunda parcela de contribuição na mudança do comportamento deste devido ao aumento da taxa de deformação.

A obtenção de parâmetros da sensibilidade do material à taxa de deformação para análises numéricas é realizada testando-o dinamicamente, a diferentes temperaturas, e calibrando modelos constitutivos que destinam um ou mais parâmetros à representação dessa carac- 
terística. Ao contrário dos testes quase-estáticos, máquinas de ensaios dinâmicos comerciais são menos comuns. Isto justifica a existência de uma grande bibliografia sobre o projeto de novos equipamentos ou de modificações em máquinas existentes, objetivando a realização dos mais variados tipos de teste a altas taxas de deformação.

O aumento de temperatura devido ao processo de deformação adiabático não será considerado neste trabalho. Erros devido a esta simplificação não devem interferir de maneira significativa na resposta das chapas ao impacto, pois os níveis de deformação crítica obtidos são relativamente pequenos. Esta afirmação está de acordo com o obtido por Seo, Min e Yang (2005), que avaliou o comportamento da liga Ti-6Al-4V sob altas temperaturas e taxas de deformação.

Um dos equipamentos mais utilizados para caracterização dinâmica, pelo seu baixo custo de fabricação e facilidade de operação, é a barra de Hopkinson (BH). O princípio estudado por Hopkinson e, posteriormente concretizado no equipamento criado por Kolsky (ZHAO; GARY, 1996), baseia-se na teoria de propagação de ondas mecânicas em sólidos elásticos e plásticos. Uma BH convencional consiste de duas barras longas de mesmo comprimento - chamadas de barra de entrada e barra de saída - que comprimem entre elas um corpo de prova que possui a forma de um cilindro regular, Figura 4.1. Uma terceira barra, mais curta e chamada de striker ou impactador, é acelerada contra a barra de entrada, normalmente por ar comprimido, dando início ao processo que resultará na plastificação do corpo de prova.

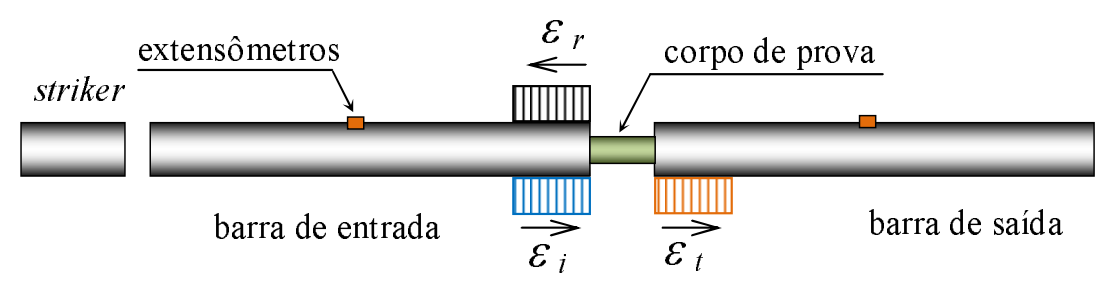

Figura 4.1: Princípio de funcionamento de uma BH clássica.

Uma onda de compressão elástica é gerada na barra de entrada pelo impactador e se propaga até a interface com o corpo de prova. Neste ponto, parte da onda é refletida e parte é transmitida ao corpo de prova que, por possuir uma tensão de escoamento menor que a do pulso gerado, se deforma plasticamente. A onda transmitida alcança a barra de saída, enquanto reflexões elasto-plásticas se interagem no corpo de prova, conduzindo-o a um estado uniforme de tensão e deformação. A partir da medição, na barra de entrada, 
dos pulsos incidente, $\varepsilon_{i}(t)$, e refletido, $\varepsilon_{r}(t)$, e na barra de saída, do pulso transmitido, $\varepsilon_{t}(t)$, é possível determinar os históricos de tensão e deformação no corpo de prova. Essa medição é realizada com a fixação de extensômetros no meio das duas barras, assumindose que não há dispersão na propagação das ondas ao longo das mesmas e nas interfaces com o corpo de prova.

No equacionamento do teste, assume-se que a propagação de ondas é unidimensional. Analisando-se o processo de deformação do corpo de prova, sabe-se que a variação de seu comprimento resulta da diferença entre os deslocamentos das suas extremidades, dados por (GALLINA; BIRCH; ALVES, 2003)

$$
u_{1}(t)=\int_{0}^{t} c_{b} \varepsilon_{1}(t) d t=c_{b} \int_{0}^{t}\left[\varepsilon_{i}(t)-\varepsilon_{r}(t)\right] d t
$$

e

$$
u_{2}(t)=\int_{0}^{t} c_{b} \varepsilon_{2}(t) d t=c_{b} \int_{0}^{t} \varepsilon_{t}(t) d t
$$

onde $c_{b}=\sqrt{E_{b} / \rho_{b}}$ é a velocidade da onda elástica nas barras de módulo elástico $E_{b} \mathrm{e}$ densidade $\rho_{b}$, e os índices 1 e 2 se referem às extremidades do corpo de prova em contato com a barra de entrada e de saída, respectivamente. Nota-se que, por convenção, os pulsos compressivos, $\varepsilon_{i}(t)$ e $\varepsilon_{t}(t)$, são representados com valores negativos e o pulso trativo, $\varepsilon_{r}(t)$, possui valores positivos, de modo que tanto $u_{1}(t)$ quanto $u_{2}(t)$ são deslocamentos negativos. A deformação de engenharia, $\varepsilon_{E}$, do corpo de prova é calculada por

$$
\varepsilon_{E}(t)=\frac{u_{1}(t)-u_{2}(t)}{L_{0}}
$$

Substituindo as Equações (4.1) e (4.2) na Equação (4.3), obtém-se o histórico de deformação do corpo de prova em função dos pulsos medidos,

$$
\varepsilon_{E}(t)=\frac{c_{b}}{L_{0}} \int_{0}^{t}\left[\varepsilon_{i}(t)-\varepsilon_{r}(t)-\varepsilon_{t}(t)\right] d t
$$

A taxa de deformação é então obtida pela diferenciação no tempo da Equação (4.4), resultando em

$$
\dot{\varepsilon}_{E}(t)=\frac{c_{b}}{L_{0}}\left[\varepsilon_{i}(t)-\varepsilon_{r}(t)-\varepsilon_{t}(t)\right]
$$

Admitindo-se um estado uniaxial de tensões, as forças atuando nas interfaces barra-corpo de prova são dadas por

$$
P_{1}(t)=E_{b} A_{b}\left[\varepsilon_{i}(t)+\varepsilon_{r}(t)\right]
$$


e

$$
P_{2}(t)=E_{b} A_{b} \varepsilon_{t}(t)
$$

onde $A_{b}$ é a área da seção transversal das barras, supostas idênticas. A tensão no corpo de prova leva alguns instantes (algumas reflexões das ondas) para se uniformizar, de modo que Lindholm (1964) propôs o uso da média das forças para seu cálculo,

$$
\sigma_{E}(t)=\frac{P_{1}(t)+P_{2}(t)}{2 A_{0}}
$$

Substituindo as Equações (4.6) e (4.7), obtém-se o histórico de tensões de engenharia médias no corpo de prova,

$$
\sigma_{E}(t)=E_{b} \frac{A_{b}}{2 A_{0}}\left[\varepsilon_{i}(t)+\varepsilon_{r}(t)+\varepsilon_{t}(t)\right] .
$$

Deste modo, o comportamento do material do corpo de prova, expresso pela curva tensão versus deformação equivalentes, pode ser determinado a partir das tensões e deformações de engenharia calculadas, considerando um estado uniaxial de tensões.

A BH utilizada neste trabalho, vide Figura 4.2, possui as propriedades apresentadas na Tabela 4.1. O impactador é acelerado por ar comprimido e, através da variação da pressão no reservatório, é possível obter diferentes taxas de deformação no corpo de prova.

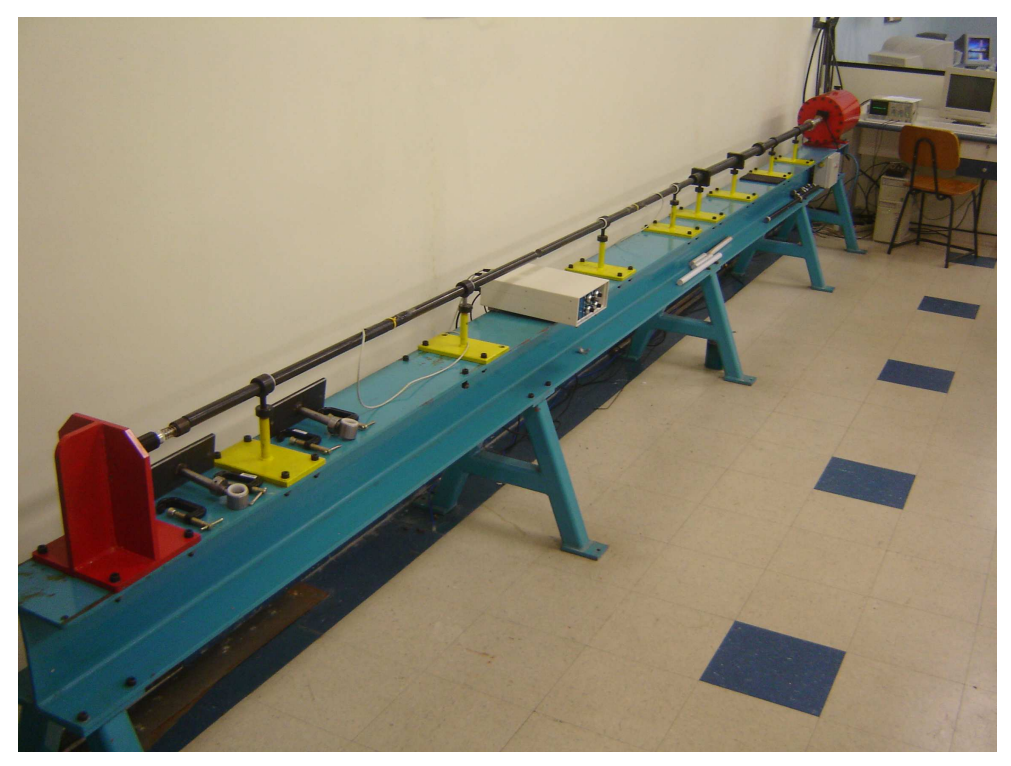

Figura 4.2: Foto da BH utilizada nos testes de caracterização dinâmica. Detalhes construtivos são apresentados em (GALLINA; BIRCH; ALVES, 2003). 
Tabela 4.1: Propriedades da barra de Hopkinson.

\begin{tabular}{|ccccc|}
\hline $\begin{array}{c}\text { Diâmetro } \\
(\mathrm{mm})\end{array}$ & $\begin{array}{c}\text { Comprimento } \\
\text { de cada barra } \\
(\mathrm{mm})\end{array}$ & $\begin{array}{c}\text { Comprimento } \\
\text { do impactador } \\
(\mathrm{mm})\end{array}$ & $\boldsymbol{E}_{b}(\mathrm{GPa})$ & $\boldsymbol{A}_{b}\left(\mathrm{~mm}^{2}\right)$ \\
\hline \hline 25,4 & 1400,0 & 400,0 & 205,0 & 506,7 \\
\hline
\end{tabular}

\subsection{REVISÃO BIBLIOGRÁFICA}

Desde sua criação em 1949, modificações foram acrescentadas à BH de modo a adequá-la às mais variadas formas de ensaio, como teste de tração (HARDING; WOOD; CAMPBELL, 1960), torção (DUFFY; CAMPBELL; HAWLEY, 1971), efeito Bauschinger (NEMATNASSER; ISAACS; STARRETT, 1991), teste de avaliação de atrito (ESPINOSA; PATANELLA; FISCHER, 2000), testes de materiais não-metálicos (CASEM; FOURNEY; CHANG, 2003; TRAUTMANN et al., 2005; BOIS et al., 2006; JUE; SHISHENG; LILI, 2006) e utilização de barras curtas (MENG; LI, 2003b).

O procedimento de caracterização de materiais na $\mathrm{BH}$, cuja modelagem é sintetizada nas Equações (4.4), (4.5) e (4.9), aparenta ser um método de fácil aplicação, porém, as suposições utilizadas na sua concepção não são completamente satisfeitas num teste real. Efeitos causados pelas inércias radial e axial do corpo de prova e pelo atrito deste com as barras podem invalidar a hipótese do estado uniforme de tensão-uniaxial e deformação (YANG; SHIM, 2005; MENG; LI, 2003b). Adicionalmente, dependendo da geometria e do material das barras, a atenuação e a dispersão das ondas mecânicas podem levar a erros consideráveis no processo de obtenção dos pulsos atuantes na interface com o corpo de prova (ZHAO; GARY, 1996; GORHAM, 1983).

A modelagem matemática do teste com a $\mathrm{BH}$ se inicia com a comparação dos deslocamentos das extremidades do corpo de prova, os quais se relacionam com os três pulsos de deformação atuantes no local. Os pulsos, entretanto, são medidos a certa distância das interfaces (de modo a se ter uma medição sem sobreposição), podendo não representar exatamente o que ocorre nessa região de contato com o corpo de prova, uma vez que é sabido que ondas mecânicas se propagando em corpos elásticos sofrem dispersão e atenuação (MENG; LI, 2003b). Esta dispersão é conseqüência de que componentes de alta freqüência se propagam com velocidades menores que componentes de baixa frequiência, de modo que há uma alteração na forma do pulso em decorrência das defasagens geradas. A atenuação está relacionada à perda de energia da onda devido à propagação não-uniaxial, a efeitos inerciais e ao amortecimento intrínseco presente nos materiais. Por 
outro lado, segundo Vales et al. (1996), efeitos tridimensionais na teoria de propagação unidimensional são negligenciáveis depois que a onda atinge uma distância de cinco vezes o diâmetro do cilindro no qual se propaga.

O método utilizado para registro dos pulsos também possui um papel importante na acurácia dos sinais medidos e, conseqüentemente, na validade da curva do material obtida. A resposta em freqüência de extensômetros de diversos comprimentos foi avaliada por Ueda e Umeda (1998), numa faixa de até $300 \mathrm{kHz}$. Através de experimentos físicos, os autores evidenciaram que o comprimento de um extensômetro é o fator que determina sua resposta em frequiência e indicaram o uso de extensômetros de $3 \mathrm{~mm}$ para realização de medições dinâmicas.

A diminuição do tempo para que o corpo de prova atinja o equilíbrio também é motivo de estudos pelos pesquisadores que lidam com a BH (FREW; FORRESTAL; CHEN, 2005; CHEN et al., 2003; ELLWOOD; GRIFFITHS; PARRY, 1982). Estes trabalhos, entre outros, indicam a utilização de um "formatador de pulso", composto por um disco fino, cujo material varia dependendo do caso, colocado entre o impactador e a barra de entrada. Este formatador tem a finalidade de gerar um pulso com um tempo de subida maior, o que conduziria o corpo de prova a uma transição mais suave, e portanto mais rápida, até o equilíbrio. Este procedimento produziria também uma taxa de deformação mais constante durante o teste (ELLWOOD; GRIFFITHS; PARRY, 1982; CHEN et al., 2003) e levaria à diminuição da dispersão, uma vez que componentes de mais alta freqüência não seriam geradas (FREW; FORRESTAL; CHEN, 2005).

A compressão axial do corpo de prova entre as barras implica na sua expansão radial. Esta expansão é dificultada pelo atrito entre as superfícies em contato que gera tensões cisalhantes no sentido de restringir o movimento (ALVES; KARAGIOZOVA, 2007). Isto implica na mudança do estado uniaxial de tensões, invalidando a modelagem utilizada. Este efeito é visível quando causa um abaulamento na superfície lateral do corpo de prova. A solução mais simples adotada é o uso de lubrificante na interface barras-corpo de prova (SEO; MIN; YANG, 2005; TRAUTMANN et al., 2005).

A influência destes efeitos, isolada ou em conjunto, na precisão da modelagem do comportamento do material a altas taxas de deformação pode parecer insignificante. Entretanto, na análise de um material que é pouco sensível a taxa de deformação, como as ligas de alumínio, estes erros se tornam de igual grandeza a desta sensibilidade (HALL; GUDEN, 2003). Esta representação imprecisa terá implicações na comparação final das análises numéricas e experimentais de estruturas compostas deste material. 


\subsection{TESTES EXPERIMENTAIS}

Trabalhando-se com chapas laminadas, o único modo de se extrair cilindros - seguindo-se a metodologia clássica - é usinar discos cujo comprimento segue a direção da espessura da chapa. Deste modo, discos de diâmetro de $20 \mathrm{~mm}$ e comprimento (espessura) de $1,6 \mathrm{~mm}$ e 3,2mm foram retirados das chapas dos materiais M1 e M2, respectivamente. O diâmetro dos discos foi selecionado de maneira a ser o maior possível, para diminuir a dispersão dos pulsos na interface com as barras, e garantir que a expansão em compressão não ultrapassasse o diâmetro destas de 25,4mm.

A medição dos pulsos de deformação nas barras exigiu a montagem de sistema de medição com os extensômetros numa ponta da cadeia e um microcomputador com uma placa de aquisição em outra. A Figura 4.3 apresenta esquematicamente os componentes deste sistema. Cada uma das barras possui dois extensômetros de $3 \mathrm{~mm}$ de comprimento diametralmente opostos, de modo a eliminar o efeito de flexão nas medições. Um módulo FYLDE FE-H359-TA, trandutor-amplificador de alta resposta em freqüência, desempenha o papel de condicionador, amplificador e filtro analógico.

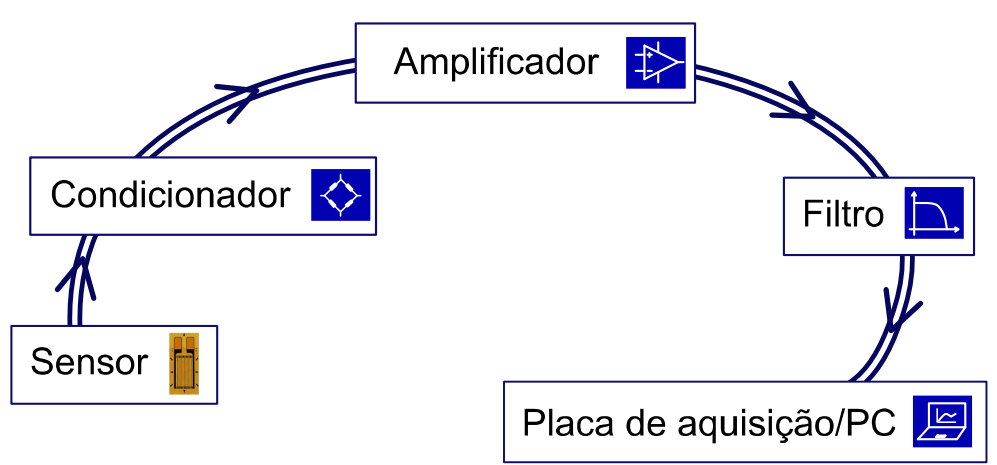

Figura 4.3: Esquema da cadeia de medição utilizada na BH.

Na função de condicionador, o módulo é responsável por transformar a variação das dimensões do extensômetro em um sinal de tensão elétrica. Isto foi feito através do ajuste do mesmo, na configuração de "meia ponte", onde os dois extensômetros se adicionam a duas resistências internas formando uma ponte de Wheatstone. Trata-se de um circuito passivo, formado de resistências elétricas, onde a diferença de potencial elétrico entre dois pontos determinados é diretamente proporcional à variação da resistência de um de seus componentes. Após um balanceamento, executado antes de cada teste com uma resistência variável do módulo, a deformação do extensômetro pode então ser determinada 
pela medição da tensão elétrica resultante e aplicação de um fator de proporcionalidade. Este fator é obtido adicionando uma deformação fictícia na ponte, através de uma função do módulo (duas resistências opostas na ponte), e medindo o sinal amplificado no microcomputador.

A tensão gerada na ponte de Wheatstone é muito baixa para ser registrada numa placa de aquisição de dados. Possuindo um ganho máximo de 1000 até $500 \mathrm{kHz}$, o módulo foi ajustado para amplificar o sinal de forma a adequá-lo à faixa de tensão elétrica da placa $(-10 \mathrm{~V}$ a $+10 \mathrm{~V})$ e garantindo a melhor resolução possível na digitalização. A resposta em frequiência do módulo foi medida de forma a avaliar a variação do ganho e da fase. Verificou-se que até aproximadamente $180 \mathrm{kHz}$, a defasagem é desprezível. O ganho, porém, se mantém constante até cerca de $800 \mathrm{kHz}$ e, em cerca de $1,8 \mathrm{MHz}$, tem seu valor diminuído de $90 \%$. Estes valores foram importantes para se utilizar o módulo como filtro analógico.

Numa cadeia de medição, o filtro analógico passa-baixa desempenha um papel importante, limitando a maior frequiência do sinal. Para uma correta aquisição dos dados, o teorema de Nyquist estabelece que a freqüência de aquisição deve ser, no mínimo, maior que o dobro da freqüência do sinal a ser digitalizado. Não respeitado este teorema, componentes do sinal que possuem freqüência maior que a de aquisição são deslocados para frequiências menores, fictícias e desconhecidas, sendo impossível identificá-las no sinal digital, o qual acaba por não representar o sinal real. Desta forma, utilizou-se o módulo como um filtro analógico de freqüência de corte de $1,8 \mathrm{MHz}$ e a aquisição de dados foi realizada a $5 \mathrm{MHz}$, respeitando-se o teorema de aquisição.

A placa de aquisição utilizada foi uma NI-6110 PCI da NATIONAL INSTRUMENTS de 12 bits de resolução e $5 \mathrm{MHz}$ de taxa máxima de aquisição, operada por uma rotina criada no programa MATLAB. Apesar de a aquisição ser realizada na máxima taxa, o que implicaria na possibilidade de um sinal com maior freqüência de $2,5 \mathrm{MHz}$, o filtro limitou esse máximo a 1,8MHz. Entretanto, segundo Ueda e Umeda (1998), os extensômetros possuem resposta linear somente até aproximadamente $300 \mathrm{kHz}$, o que limitaria a validade do sinal até este ponto. O problema é que testes preliminares de compressão dos discos indicaram componentes do sinal de até $350 \mathrm{kHz}$. A solução encontrada foi utilizar o formatador de pulso, que eliminou componentes de alta freqüência do sinal, além de trazer outros benefícios já citados, como a diminuição da dispersão das ondas na barra e o auxílio na obtenção de um estado uniforme de tensão e deformação no corpo de prova. Os novos sinais tiveram suas frequiências máximas reduzidas, de forma que foi possível 
utilizar um filtro digital passa baixa em $150 \mathrm{kHz}$ e manter toda a informação presente no sinal, além de eliminar o ruído adquirido ao longo da cadeia. Este filtro digital auxiliou também na eliminação da distorção de fase causado pelo módulo, que ocorre a partir de $180 \mathrm{kHz}$, como medido nos testes preliminares.

Um disco de papelão foi utilizado como formatador de pulso, colocado entre o impactador e a barra de entrada, de forma a suavizar o pulso incidente, facilitando a uniformização dos estados de tensão e deformação do corpo de prova. Entre o corpo de prova e as barras foi aplicado o lubrificante MOLIKOTE BR-2 no intuito de minimizar os efeitos danosos do atrito. Um algoritmo proposto por Gorham (1983) foi implementado para correção da dispersão inerente à propagação das ondas nas barras, porém os resultados não indicaram grandes mudanças nas curvas. Esta dispersão é tanto maior quanto maior a relação diâmetro por comprimento da barra, e foi constatado então que as barras da BH utilizada são esbeltas o suficiente para não interferirem no processo de propagação unidimensional dos pulsos.

O procedimento na utilização da $\mathrm{BH}$ da Figura 4.2 consiste em posicionar o corpo de prova entre as duas barras, pressurizar a câmara com ar comprimido até a pressão desejada, balancear a ponte no módulo FYLDE, calibrar o fator de proporcionalidade entre a deformação e a tensão lida, acionar o trigger na rotina do programa MATLAB e, então, disparar o impactador através do acionamento de uma válvula de descarga. Os sinais, após passarem por todos os elementos da cadeia de medição, são armazenados no computador, onde são filtrados digitalmente, tornando-se dados aptos ao cálculo das curvas do material do corpo de prova.

A Figura 4.4 apresenta sinais típicos da BH com corpo de prova em forma de disco, antes e depois da aplicação do filtro digital. Estes sinais correspondem a um teste com o material M1 e serão utilizados para demonstração do procedimento dos cálculos da curva do material do corpo de prova. O filtro digital aplicado consiste simplesmente da anulação (colocação de zeros) da amplitude de componentes com freqüência maior que $150 \mathrm{kHz}$ no espaço freqüencial e retornar o sinal ao espaço temporal. Observa-se que o ruído, gerado ao longo da cadeia de medição, principalmente em cabos, é eliminado do sinal, assim como uma parte inicial e final dos pulsos, de forma a separar a região que contém a informação do sinal.

A aplicação do equacionamento da BH, Equações (4.4), (4.5) e (5.34), exige a soma e subtração dos pulsos. Para isso, deve-se separá-los, definindo-se os inícios de cada um. 


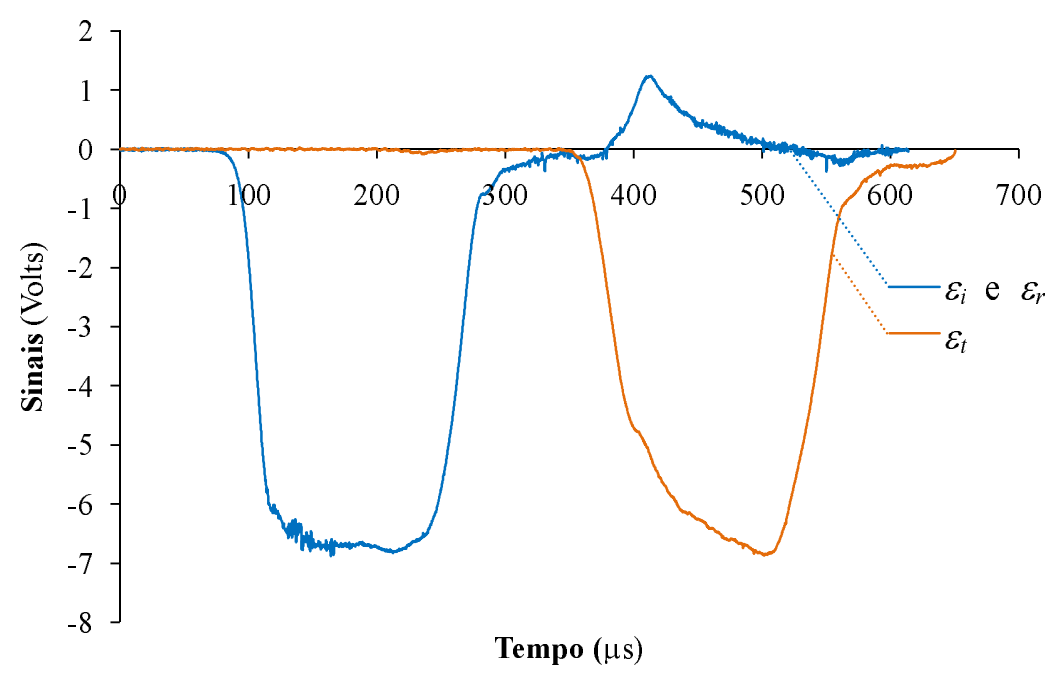

(a)

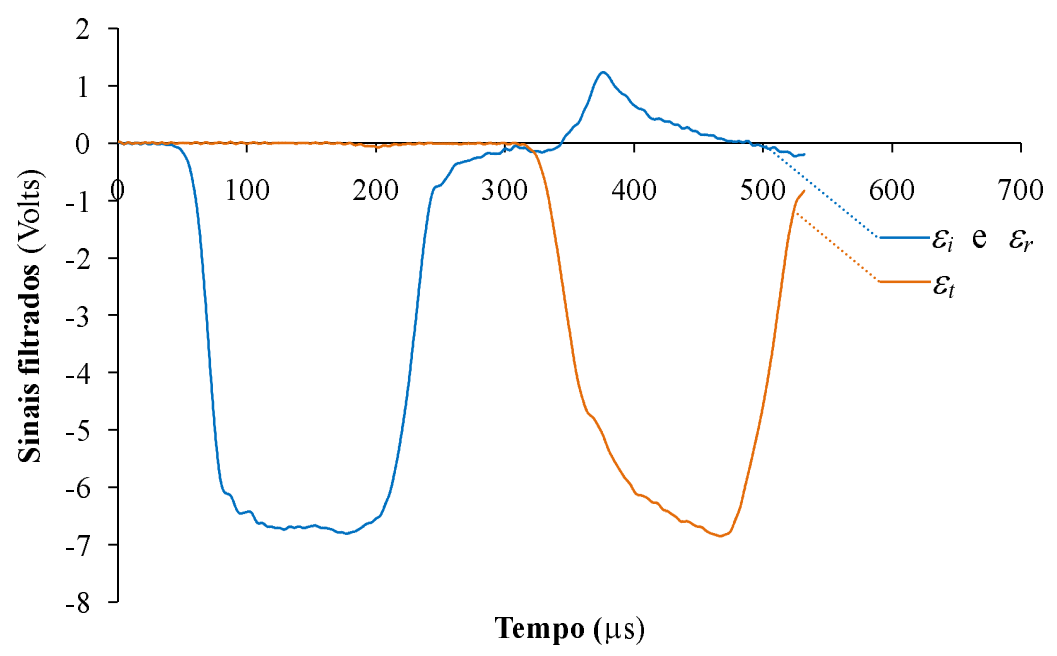

(b)

Figura 4.4: Sinais da BH (a) antes e (b) após a aplicação de filtro digital passa baixa de 150kHz. Teste M1T3. Corpo de prova: disco.

Admitindo um instante inicial para o pulso incidente, o início do outros dois pulsos pode ser calculado sabendo-se a distância percorrida pelo pulso e a velocidade da onda na barra, $c_{b}$. Para o pulso refletido têm-se o percurso de duas vezes a distância do extensômetro da barra de entrada à interface com o corpo de prova, e para o pulso transmitido uma vez esta distância somada ao comprimento do corpo de prova e à distância da outra interface até o extensômetro da barra de saída. Os pulsos são então deslocados conforme apresenta a Figura 4.5. Percebe-se nesta figura que já houve a aplicação do fator de proporcionalidade, transformando o sinal de tensão elétrica em pulso de deformação elástica das barras.

Após este deslocamento dos pulsos no tempo, é interessante averiguar a condição de equi- 


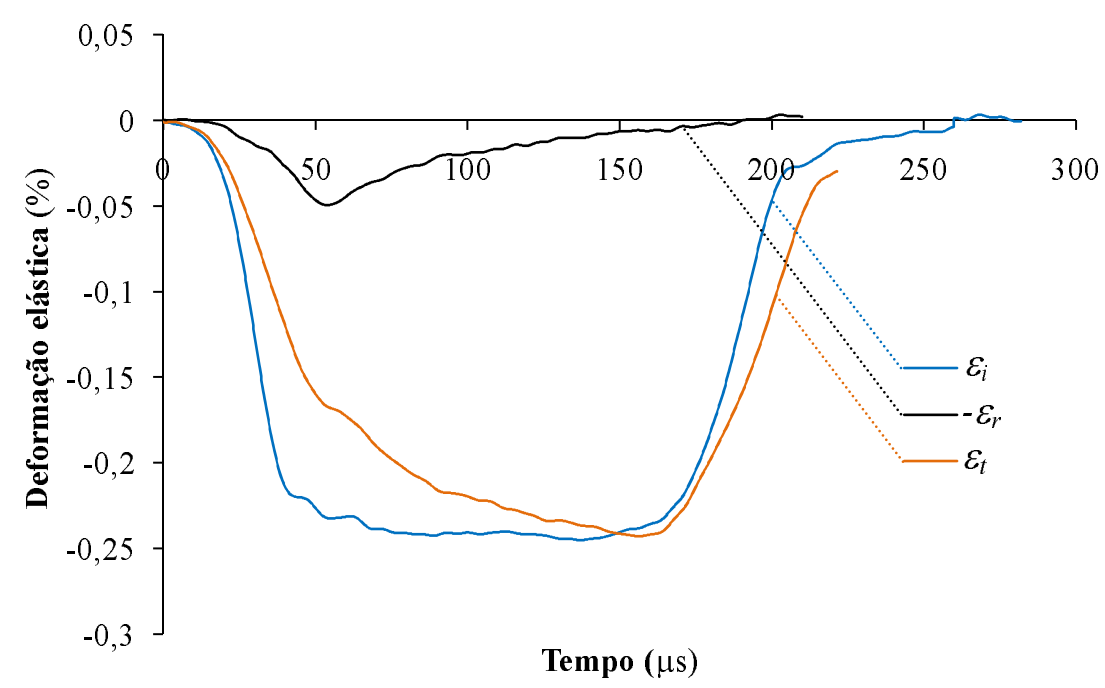

Figura 4.5: Pulsos típicos de deformação elástica deslocados. Corpo de prova: disco.

líbrio entre as extremidades do corpo de prova, $P_{1}=P_{2}$, que, com o auxílio das Equações (4.6) e (4.7), pode ser escrita como

$$
\varepsilon_{i}(t)+\varepsilon_{r}(t)=\varepsilon_{r}(t)
$$

Comparando-se as curvas $\varepsilon_{i}(t)+\varepsilon_{r}(t)$ e $\varepsilon_{t}(t)$, como exemplificado na Figura 4.6, verificase a sobreposição e valida-se ou não o teste. Percebe-se que, como comentado anteriormente, há uma região transiente, na qual não ocorre equilíbrio, pois, nestes instantes, poucas reflexões de ondas ocorreram no corpo de prova. A sobreposição encontrada em quase todos os testes com corpos de prova em forma de discos foi considerada apenas satisfatória, porém suficiente para considerar a ocorrência do equilíbrio.

Após a aplicação dessa verificação, para cada um dos testes, os históricos de tensão, Figura 4.7, de deformação de engenharia, Figura 4.8 e de taxa de deformação de engenharia, Figura 4.9, são calculados. A obtenção de valores equivalentes de tensão e deformação e a posterior curva de representação do material é realizada da mesma maneira que a exposta no Capítulo 3.

Observa-se na Figuras 4.8 e 4.9 uma característica que é encontrada em todas as curvas obtidas com os corpos de prova em forma de disco: a deformação não progride linearmente no tempo, ou seja, a taxa de deformação não é constante ao longo do teste. Isto implica na não ocorrência de um estado de tensões e deformações uniforme no corpo de prova durante o carregamento. A causa está associada principalmente à relação en- 


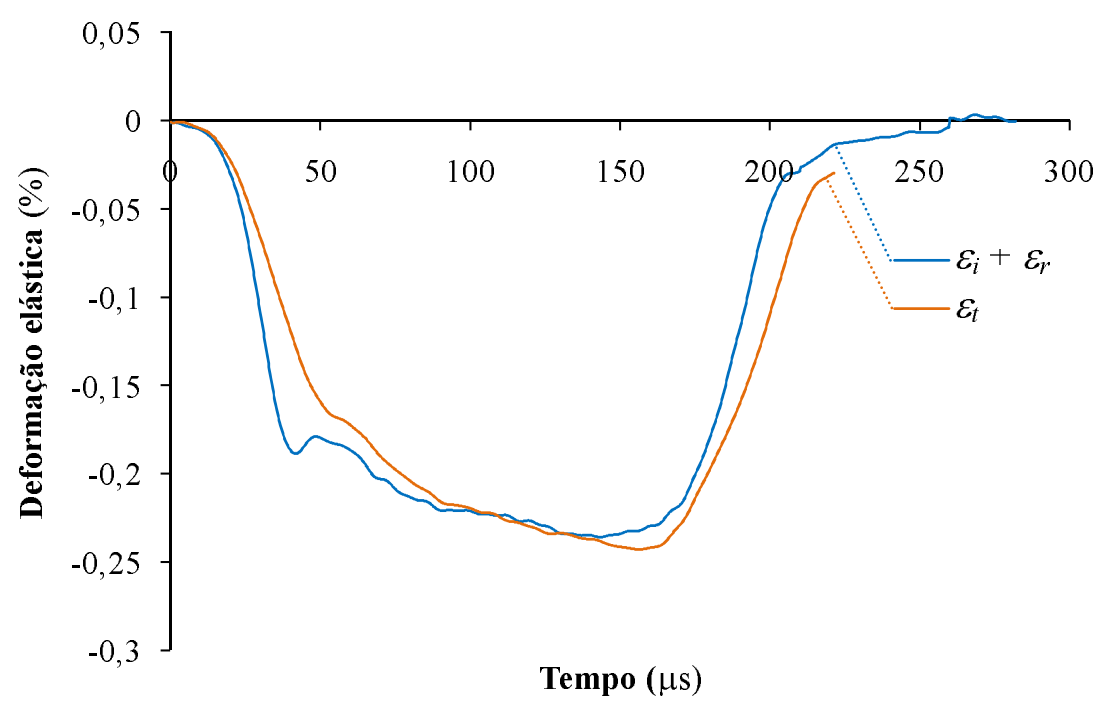

Figura 4.6: Equilíbrio de forças avaliado pela relação entre os pulsos de deformação na BH. Corpo de prova: disco.

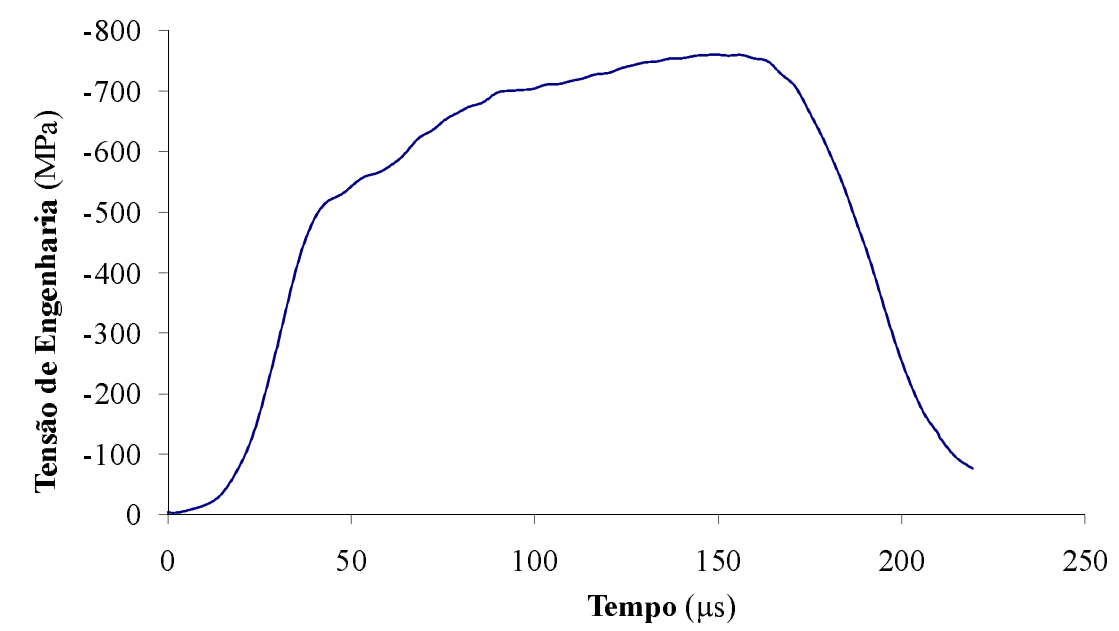

Figura 4.7: Histórico de tensões de engenharia do corpo de prova em formato de disco.

tre as inércias radias e axiais do corpo de prova, que, neste caso, difere muito da faixa de valores válidos apresentados por Davies e Hunter (1963), i.e. o corpo de prova cilíndrico empregado (disco) tem um comprimento (espessura) muito pequeno em relação ao seu diâmetro. Salienta-se, porém, que empregando a metodologia clássica, a geometria utilizada é a única possível de ser extraída a partir de chapas finas.

Apesar de ser matematicamente possível prever a taxa de deformação pela velocidade do impactador, o procedimento contém inúmeras aproximações. Assim, tornou-se mais prático e preciso utilizar diversas pressões no reservatório de ar e, somente depois de 


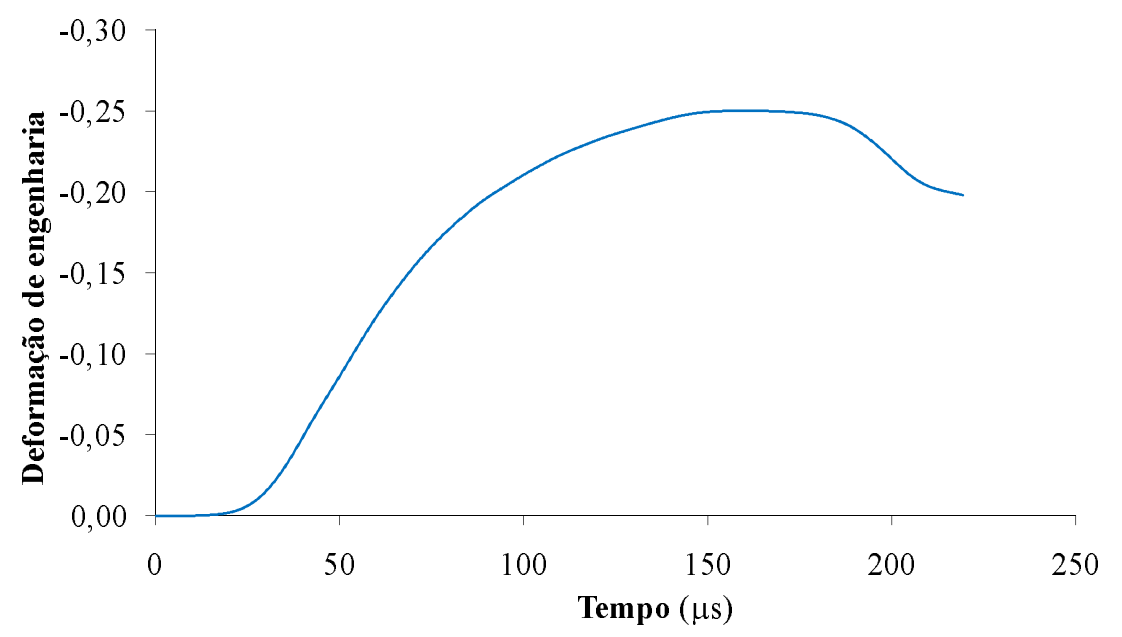

Figura 4.8: Histórico de deformações de engenharia do corpo de prova em formato de disco.

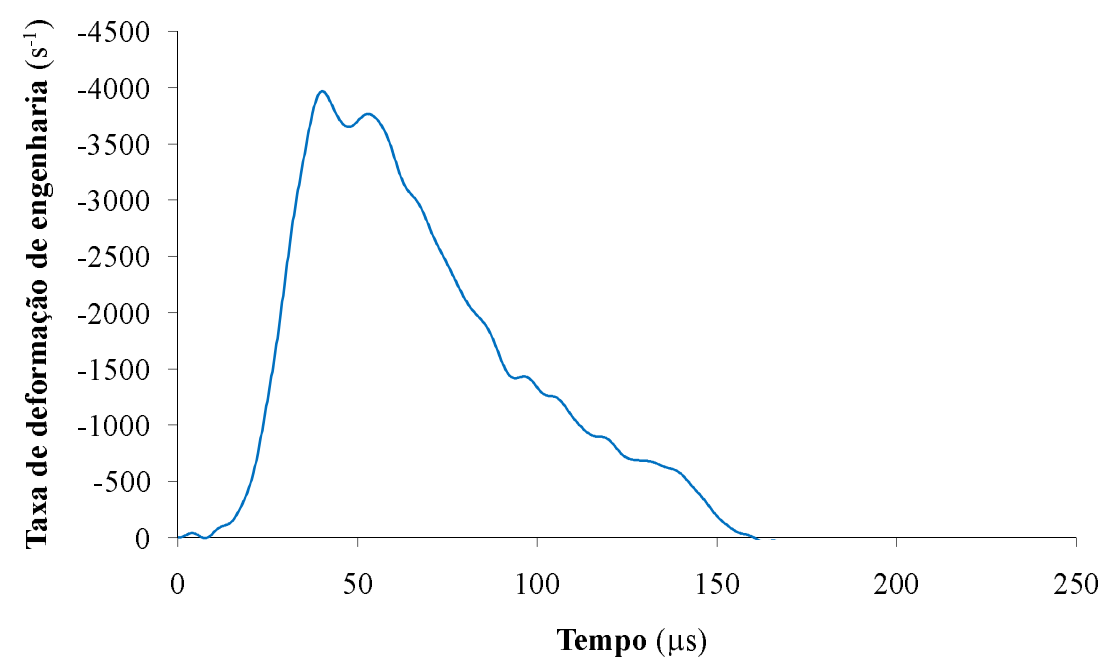

Figura 4.9: Histórico de taxas de deformações de engenharia do corpo de prova em formato de disco.

processados os sinais, obter a taxa real em que o corpo de prova foi comprimido. A determinação de um valor médio de taxa de deformação do teste a partir da Equação (4.5) não é muito prática, como pode ser observado na Figura 4.9. Utilizou-se então o coeficiente angular de uma regressão linear, aplicada na região de interesse de deformação plástica, a partir da curva do histórico de deformação equivalente do corpo de prova no tempo, como exemplifica a Figura 4.10, resultante do teste de maior taxa de deformação do material M1.

O procedimento apresentado para obtenção da curva equivalente do material foi repetido 


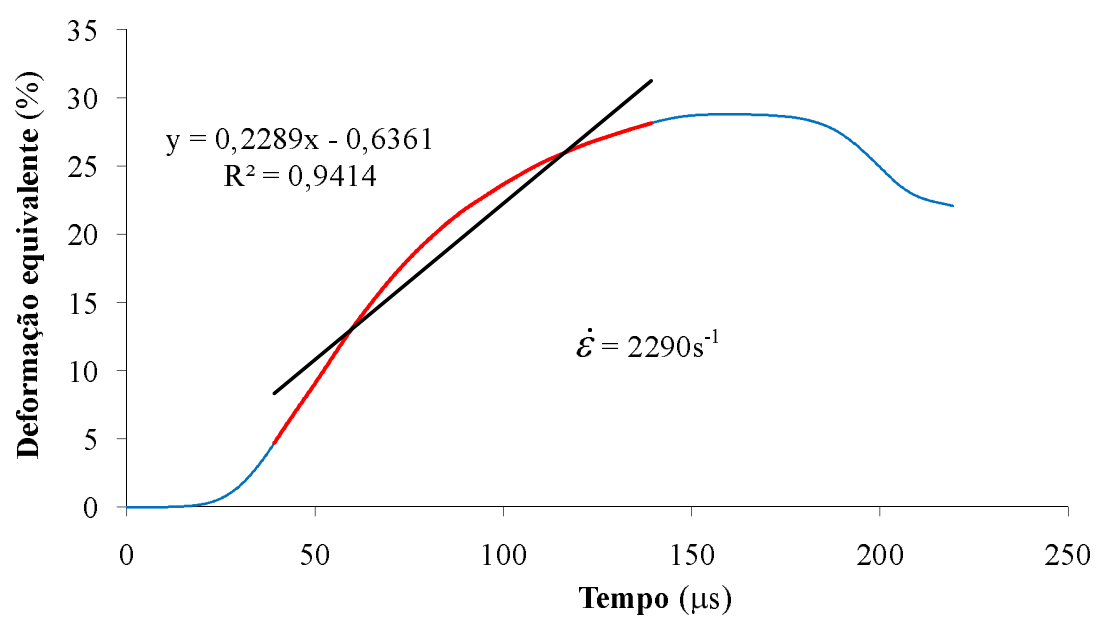

Figura 4.10: Taxa de deformação média (M1T3). Corpo de prova: disco.

para todos os testes realizados. Baseado na verificação do equilíbrio e na comparação entre as curvas dinâmicas, admitindo que o aumento da taxa de deformação provocasse o endurecimento do material, três curvas dinâmicas foram selecionadas para cada material. A Tabela 4.2 reúne os valores médios de taxas de deformação a que os corpos de prova foram submetidos durante os testes de caracterização na BH. Os testes são identificados pela sigla formada pelo tipo de material seguido da letra "T"e da ordem do teste.

Tabela 4.2: Taxas de deformação utilizadas na caracterização dinâmica na BH. Corpos de prova: discos.

\begin{tabular}{|c|c|c|}
\hline Material & Teste & Taxa de deformação $\left(\mathbf{s}^{-1}\right)$ \\
\hline \hline \multirow{3}{*}{ M1 } & $M 1 T 1$ & 1980 \\
& $M 1 T 2$ & 2080 \\
& $M 1 T 3$ & 2290 \\
\hline \multirow{3}{*}{ M2 } & $M 2 T 1$ & 1470 \\
& $M 2 T 2$ & 1730 \\
& $M 2 T 3$ & 1775 \\
\hline
\end{tabular}

A partir dos históricos obtidos, as curvas tensão verdadeira versus deformação logarítmica equivalente puderam ser construídas, para cada um dos materiais, como mostram as Figuras 4.11 e 4.12. Nestas figuras, as curvas dinâmicas são plotadas juntamente com as curvas quase-estáticas, para facilitar a visualização e avaliação da influência da taxa de deformação no comportamento das duas ligas de alumínio.

Observa-se nas Figuras 4.11 e 4.12 que os testes de compressão não são muito indicados para medir o comportamento dos materiais em pequenas deformações. Somente a partir 


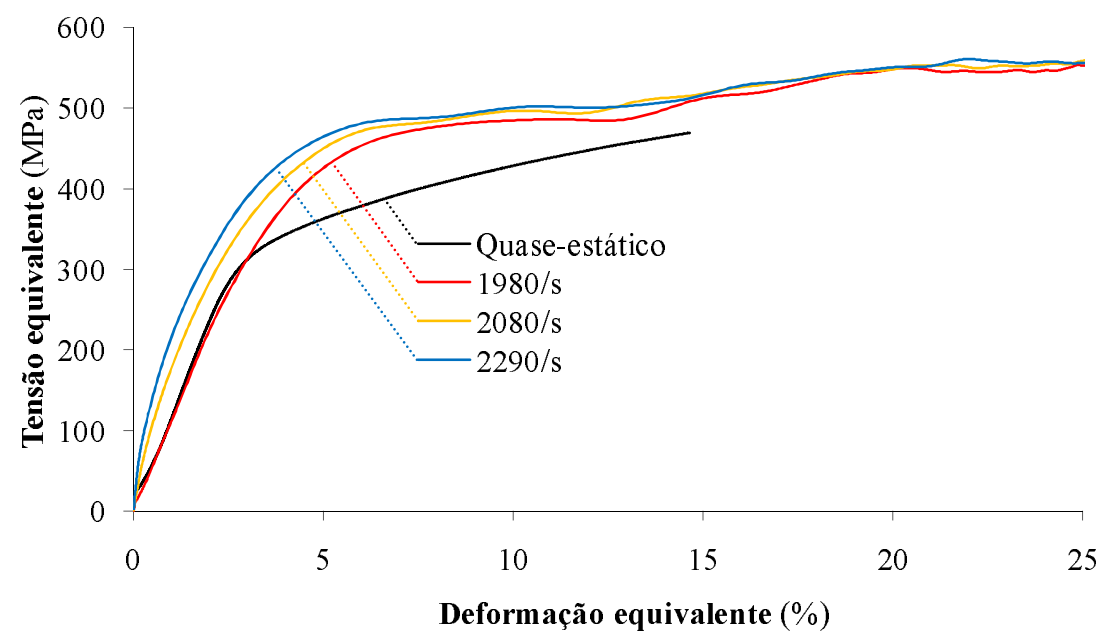

Figura 4.11: Comportamento quase-estático e dinâmico do material M1. Corpos de prova: discos.

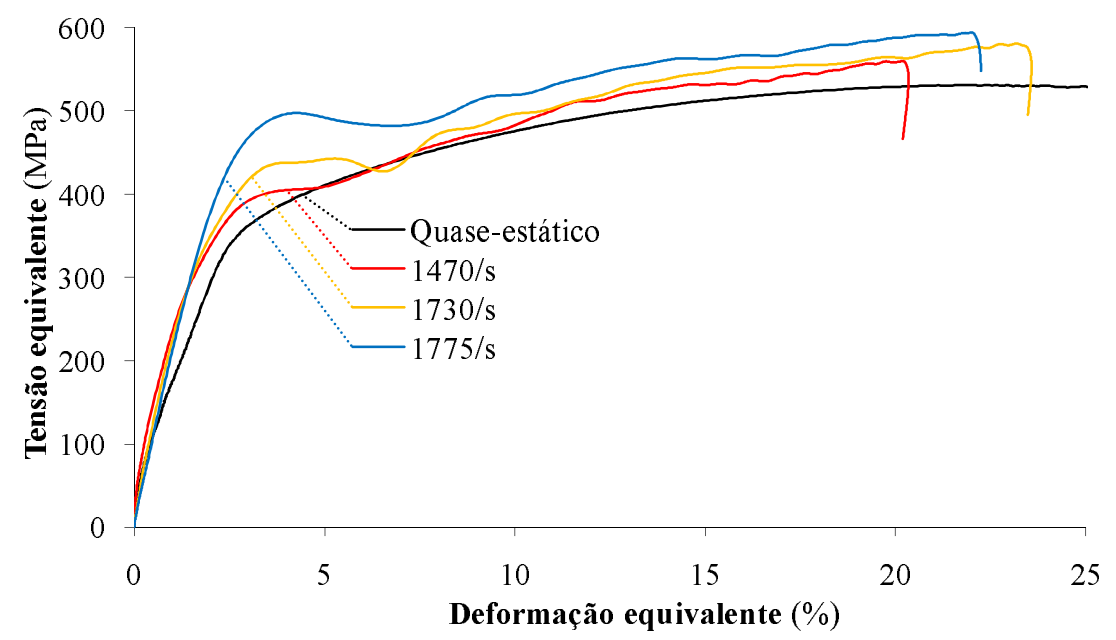

Figura 4.12: Comportamento quase-estático e dinâmico do material M2. Corpos de prova: discos.

de cerca de $5 \%$ a $10 \%$ de deformação é que as curvas se mostram mais coerentes, com menor oscilação de seu nível de tensão. Em relação à sensibilidade à taxa de deformação, o material M1 apresentou uma sensibilidade significativa, enquanto o material M2 se mostrou pouco sensível. Verificou-se em ambos, porém, o endurecimento com o aumento da deformação e de sua taxa (aumento do nível de tensão para uma mesma deformação), resultado este comum à maioria dos metais.

Admitindo que o escoamento nas curvas dinâmicas ocorra na mesma deformação que na curva quase-estática, pode-se restringir as curvas à região plástica, de modo a adequá- 
las ao cálculo dos coeficientes dos modelos de JC e CS. Na obtenção destes parâmetros costuma-se fixar um valor de deformação plástica e relacionar os níveis de tensão dinâmica e estática neste ponto. De forma a aumentar a quantidade de informação das curvas no ajuste desses parâmetros, neste trabalho, optou-se por selecionar uma faixa de valores de deformação, ou seja, escolher uma região das curvas de cada material, como mostram as Figuras 4.13 e 4.14, para os materiais M1 e M2, respectivamente. O modelo de Lemaitre para a curva quase-estática de compressão é utilizado nestas figuras ao invés dos dados experimentais, porém respeitando-se os valores de deformação máxima obtidos em cada caso.

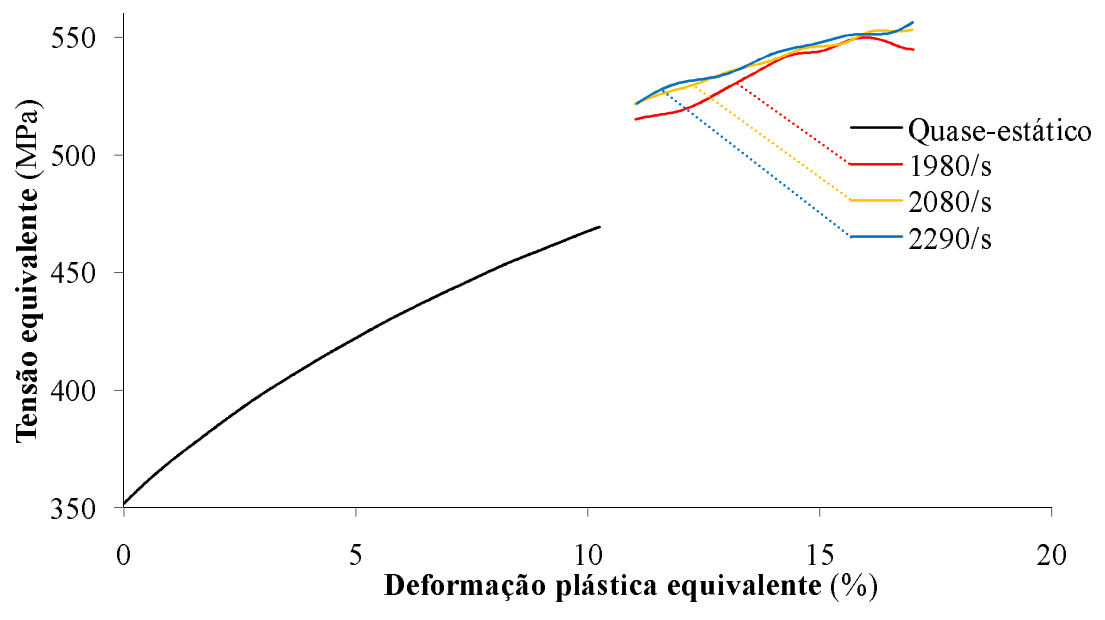

Figura 4.13: Região selecionada das curvas dinâmicas para ajuste dos parâmetros do material M1. Corpos de prova: discos.

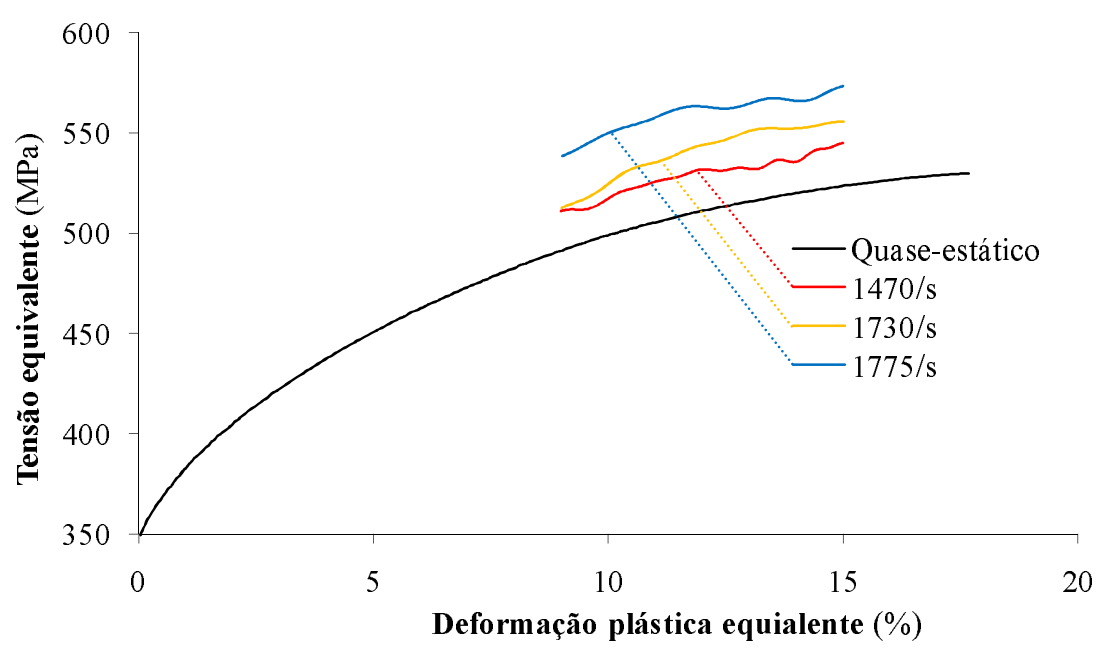

Figura 4.14: Região selecionada das curvas dinâmicas para ajuste dos parâmetros do material M2. Corpos de prova: discos. 
O procedimento consistiu em ajustar uma curva para cada teste segundo o modelo estático de Lemaitre, com os mesmos parâmetros usados neste, a menos da tensão de escoamento. Desta maneira, eliminaram-se oscilações nos níveis de tensão, comuns em testes dinâmicos, diminuindo a importância da escolha do ponto de deformação na obtenção dos resultados. As Figuras 4.15 e 4.16 apresentam as curvas experimentais e os modelos ajustados, para os materiais M1 e M2, respectivamente. Percebe-se, no caso do material M1, que devido a extrapolação do modelo, é possível avaliar os efeitos dinâmicos em pontos fora da região testada.

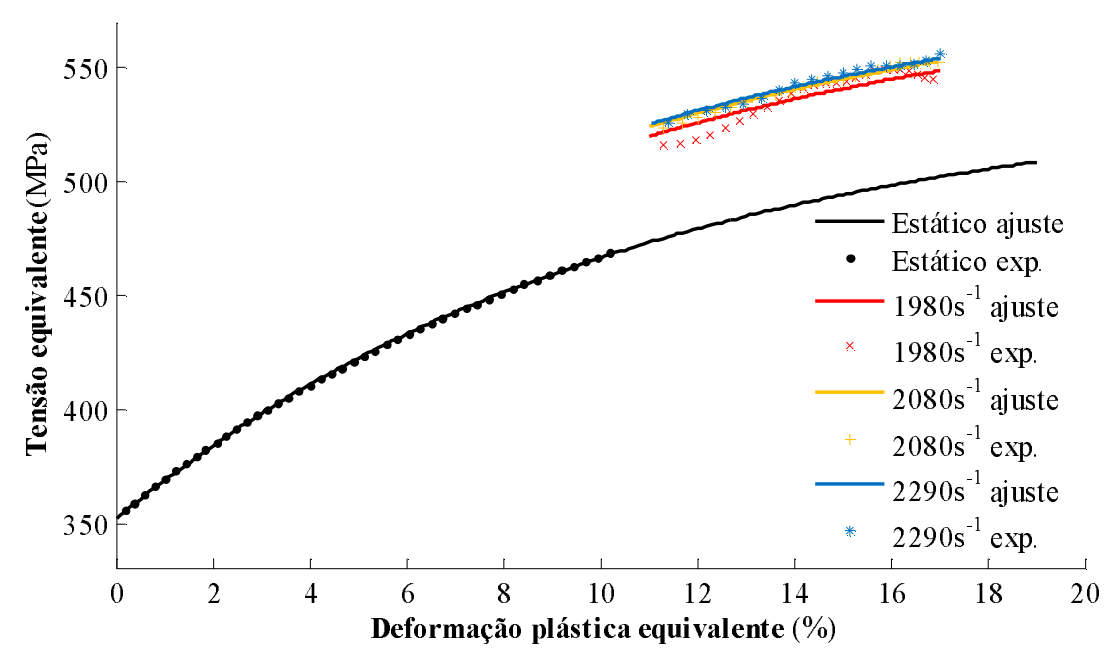

Figura 4.15: Ajuste das curvas dinâmicas com parâmetros do modelo estático do material M1. Corpos de prova: discos.

\subsection{IDENTIFICAÇÃO DO PARÂMETRO DO MODELO DE JOHNSON-COOK (JC)}

A equação de JC (JOHNSON; COOK, 1983) para a representação do comportamento de materiais visco-plásticos é dada por

$$
\sigma=\left(\sigma_{0}+B \varepsilon_{p}^{n}\right)\left(1+C \ln \frac{\dot{\varepsilon}^{p}}{\dot{\varepsilon}_{0}^{p}}\right)\left[1-\left(\frac{T-T_{a m b}}{T_{m}-T_{a m b}}\right)^{m}\right],
$$

onde os termos no primeiro parênteses representam a curva estática, $\sigma_{y}$, definida pelo modelo de Swift. A variável $\varepsilon_{0}^{p}$ é a taxa de deformação do teste de referência quaseestático, ambos presentes na Tabela 3.8 do Capítulo 3. $T$ é a temperatura do material a cada instante, $T_{a m b}$ é a temperatura ambiente durante o teste e $T_{m}$ é a temperatura de fusão do material. A intensidade da sensibilidade à taxa de deformação é representada pelo constante $C$, e a influência da temperatura pelo fator $m$. Neste modelo, as representações dos efeitos de taxa de deformação e de temperatura são independentes. 


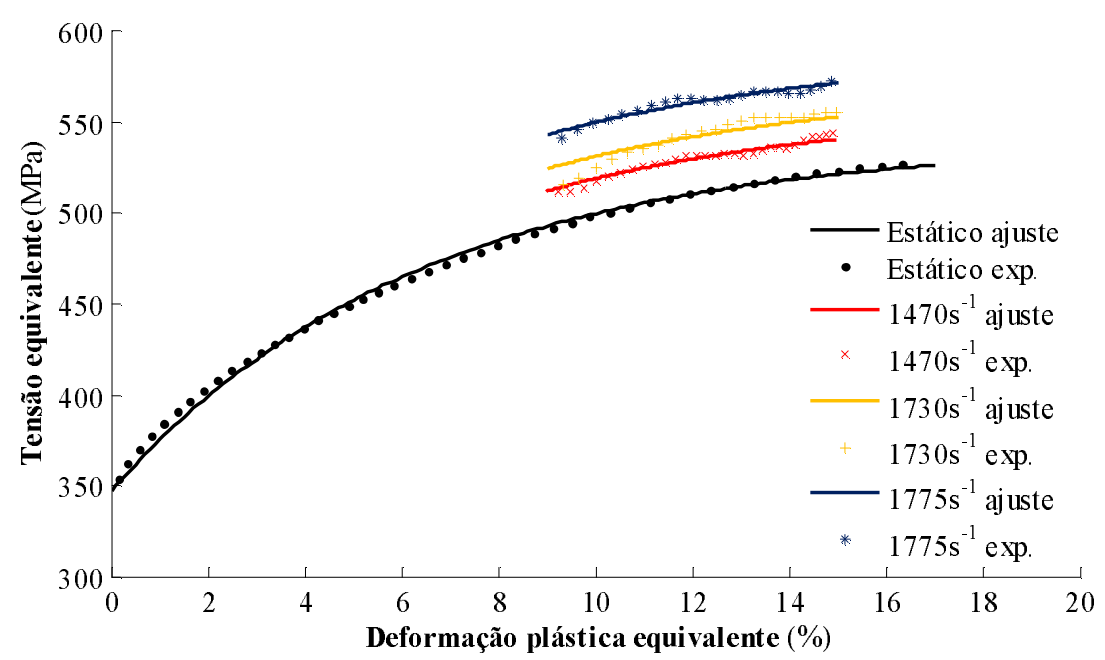

Figura 4.16: Ajuste das curvas dinâmicas com parâmetros do modelo estático do material M2. Corpos de prova: discos.

Desprezando-se os efeitos de temperatura, a Equação (4.11) se reduz a

$$
\sigma=\sigma_{y}\left(1+C \ln \frac{\dot{\varepsilon}^{p}}{\dot{\varepsilon}_{0}^{p}}\right) .
$$

No Capítulo 3, a busca por uma equação para $\sigma_{y}$ indicou como melhor ajuste a lei de escoamento de Lemaitre, Equação (3.28). Deste modo, a calibração do parâmetro $C$ de JC foi baseado na seguinte equação

$$
\sigma=\sigma_{0}+Q_{1}\left[1-\exp \left(-C_{1} \varepsilon^{p}\right)\right]\left(1+C \ln \frac{\dot{\varepsilon}^{p}}{\dot{\varepsilon}_{0}^{p}}\right)
$$

Manipulando-se a Equação (4.13), através da fixação de um valor de $\sigma_{y}$, ou seja, definindo um valor de deformação plástica, pode-se chegar à equação de uma reta que cruza a origem dos eixos,

$$
\left(\frac{\sigma-\sigma_{y}}{\sigma_{y}}\right)=C \ln \left(\frac{\dot{\varepsilon}^{p}}{\dot{\varepsilon}_{0}^{p}}\right),
$$

onde $C$ torna-se o coeficiente angular, cujo cálculo é realizado através dos três pontos $\left(\sigma, \dot{\varepsilon}^{p}\right)$ correspondentes às três taxas de deformação. Salienta-se que a reta obtida deve passar obrigatoriamente pela origem do sistema de coordenadas, não havendo coeficiente linear neste caso. Para o cálculo de $\sigma_{y}$, um valor de deformação arbitrário foi escolhido dentro da região selecionada, visto que sua definição não é relevante devido ao procedimento adotado, como já descrito. As Figuras 4.17 e 4.18 apresentam, para os materiais M1 e M2, respectivamente, os pontos $\left(\sigma, \dot{\varepsilon}^{p}\right)$ e as retas ajustadas com suas equações e 
coeficientes de determinação. Os valores de $C$ são listados na Tabela 4.3.

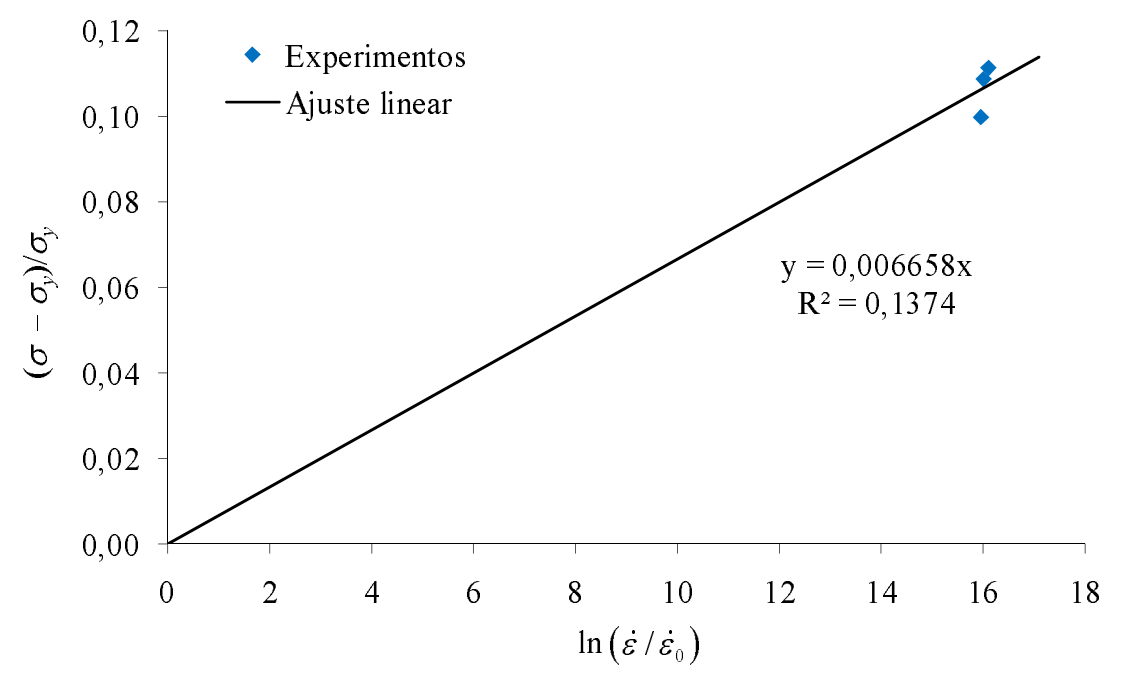

Figura 4.17: Ajuste do parâmetro de JC para o material M1. Corpos de prova: discos.

Estes valores de $C$ representam uma média do encruamento apresentado pelas curvas experimentais nas diversas taxas de deformação, como pode se observar pela diferença dos pontos e das retas ajustadas, nas Figuras 4.17 e 4.18. Quanto mais próximo os pontos da reta, melhor é a representação dos dados pelo modelo.

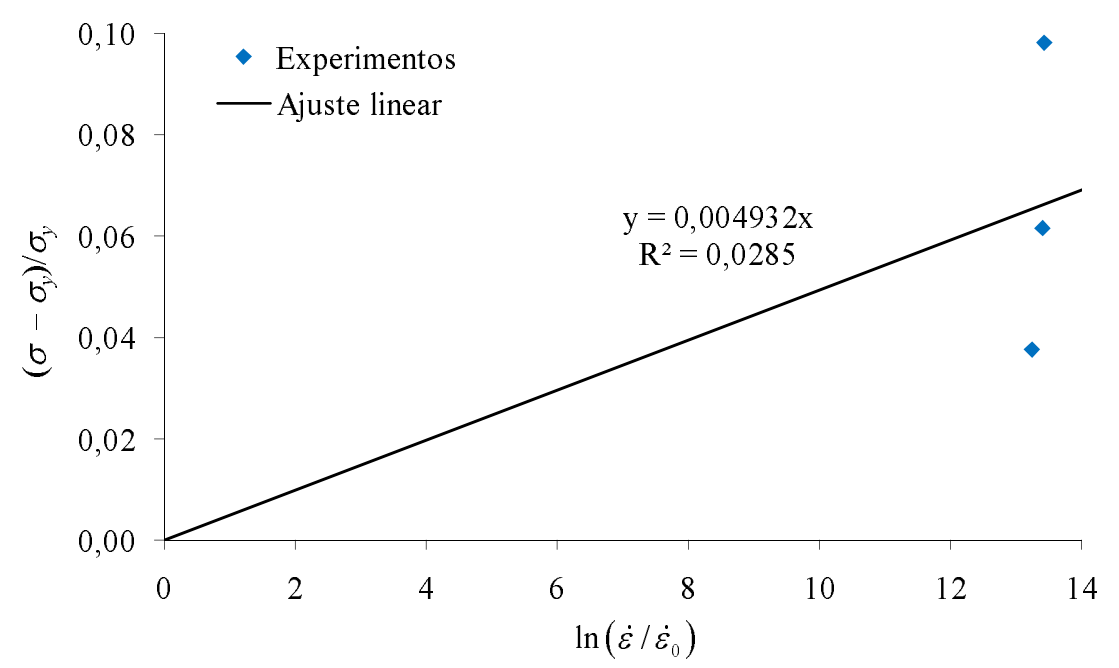

Figura 4.18: Ajuste do parâmetro de JC para o material M2. Corpos de prova: discos. 


\subsection{IDENTIFICAÇÃO DOS PARÂMETROS DO MODELO DE COWPER-SYMONDS (CS)}

O modelo de CS representa o comportamento do material frente à taxa de deformação pela relação

$$
\sigma=\sigma_{y}\left[1+\left(\frac{\dot{\varepsilon}_{p}}{Q}\right)^{1 / p}\right],
$$

onde $Q$ e $p$ são as constantes do modelo. Manipulando-se a Equação (4.15) é possível explicitar os parâmetros $V_{k}=\sigma_{y}(1 / Q)^{1 / p}$ e $V_{m}=1 / p$, utilizados pelo programa LS-DYNA,

$$
\sigma=\sigma_{y}+\sigma_{y}\left(\frac{1}{Q}\right)^{1 / p}\left(\dot{\varepsilon}_{p}\right)^{1 / p}
$$

ou

$$
\sigma=\sigma_{y}+V_{k} \dot{\varepsilon}_{p}^{V_{m}},
$$

que é outra forma de representação do modelo de CS.

Para obtenção dos parâmetros, aplica-se a função logarítmica em cada membro da Equação (4.17), como segue

$$
\ln \left(\sigma-\sigma_{y}\right)=\ln \left(V_{k} \dot{\varepsilon}_{p}^{V_{m}}\right) \Rightarrow \ln \left(\sigma-\sigma_{y}\right)=\ln \left(V_{k}\right)+V_{m} \ln \left(\dot{\varepsilon}_{p}\right),
$$

que representa a equação de uma reta cujo coeficiente linear é $\ln \left(V_{k}\right)$ e o angular $V_{m}$. Deste modo, plotando-se os pares de pontos dados pelo logaritmo neperiano da diferença entre os níveis de tensão dinâmica e estática para uma determinada deformação e pelo logaritmo neperiano da taxa de deformação, obtém-se $V_{k}$ e $V_{m}$. Uma rotina no programa MATLAB foi construída com esta finalidade e o ajuste dos pontos pela reta pode ser visto nas Figuras 4.19 e 4.20, para os materiais M1 e M2.

Os valores dos coeficientes $V_{k}$ e $V_{m}$ e do coeficiente $C$ de JC são apresentados na Tabela 4.3, para cada um dos materiais. Observando-se isoladamente o valor de $V_{k}$, pode-se precipitadamente indicá-lo como nulo, porém, ao se fazer a multiplicação pela taxa de deformação elevada à potência $V_{m}$, obtém-se um valor percentualmente relevante frente ao nível de tensão estática.

\subsection{COMPARAÇÃO ENTRE OS MODELOS DINÂMICOS}

Uma verificação dos parâmetros obtidos para os modelos e a comparação entre estes é possível se as curvas do material forem reconstruídas pelas equações correspondentes, 


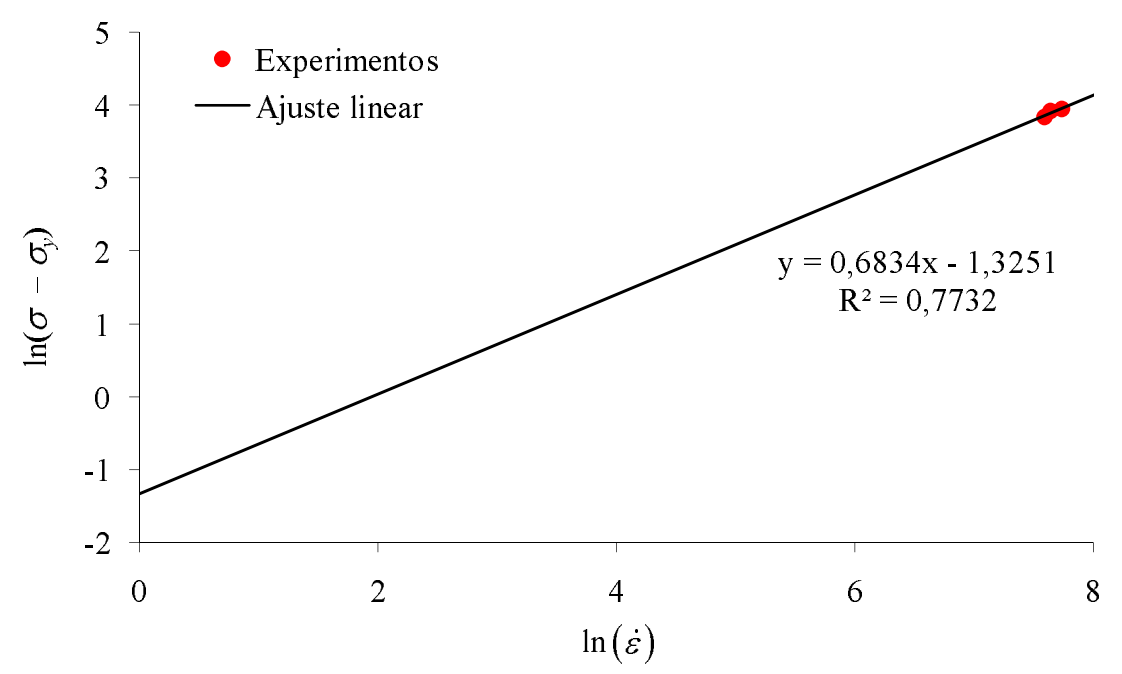

Figura 4.19: Ajuste dos parâmetros de CS para o material M1. Corpos de prova: discos.

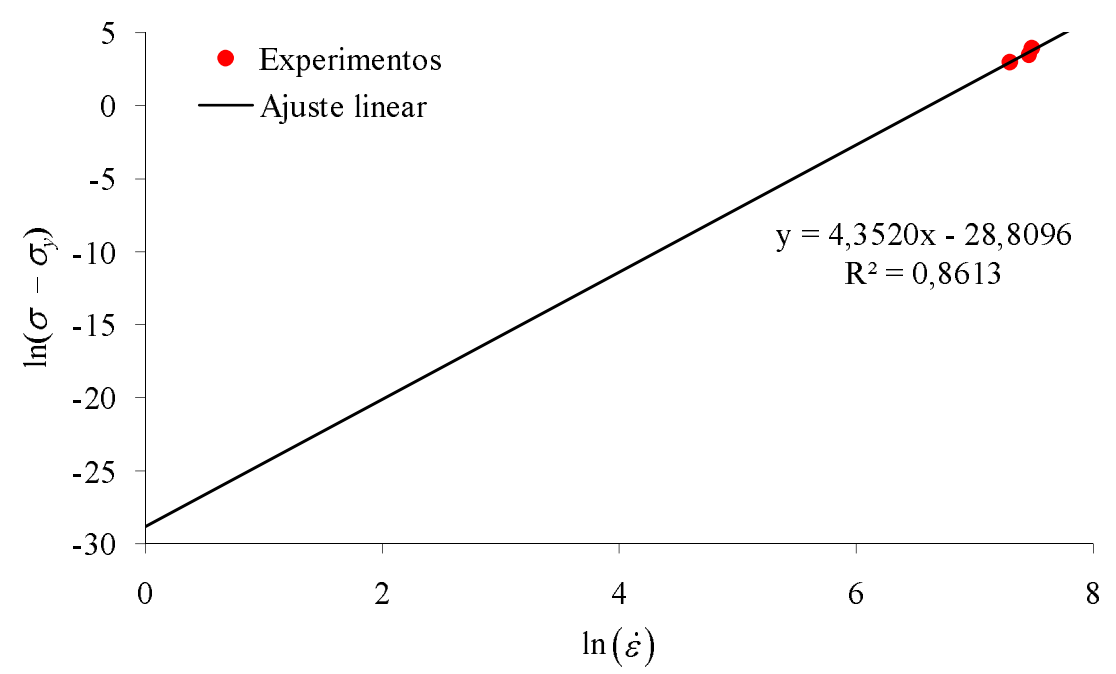

Figura 4.20: Ajuste dos parâmetros de CS para o material M2. Corpos de prova: discos.

Tabela 4.3: Parâmetros dos modelos de Johnson-Cook (JC) e Cowper-Symonds (CS). Corpos de prova: discos.

\begin{tabular}{|c|c|cccc|}
\hline Material & JC & \multicolumn{4}{|c|}{ CS } \\
& $\boldsymbol{C}$ & $\boldsymbol{V}_{k}(\mathrm{MPa} \cdot \mathrm{s})$ & $\boldsymbol{V}_{m}$ & $\boldsymbol{Q}\left(\mathrm{s}^{-1}\right)$ & $\boldsymbol{p}$ \\
\hline \hline $\mathrm{M} 1$ & 0,006658 & 0,2658 & 0,6834 & $5,5976 \cdot 10^{4}$ & 1,4634 \\
$\mathrm{M} 2$ & 0,004932 & $3,0779 \cdot 10^{-13}$ & 4,3519 & $3,1423 \cdot 10^{3}$ & 0,2298 \\
\hline
\end{tabular}

para cada uma das taxas de deformação experimentais. Isto é feito nas Figuras 4.21 e 4.22 para o material M1 e nas Figuras 4.23 e 4.24 para o material M2. 


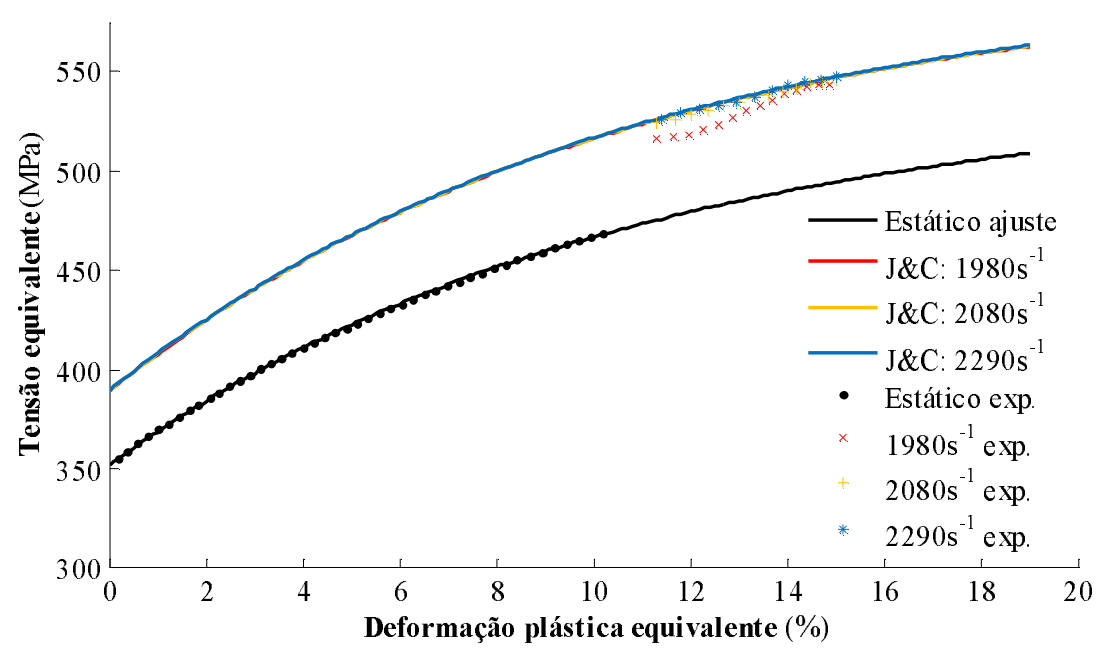

Figura 4.21: Curvas reconstruídas pelo modelo de JC para o material M1. Corpos de prova: discos.

Nas curvas experimentais do material M1 (Figuras 4.21 e 4.22), percebe-se que há pouca variação no nível de tensão entre as taxas de deformação testadas. Neste caso, os dois modelos de representação, JC e CS, se adequaram de maneira satisfatória aos dados experimentais, com um ajuste ligeiramente melhor apresentado pelo modelo de CS. Essa pequena vantagem se torna mais pronunciada na representação do material M2 (Figuras 4.23 e 4.24), onde observa-se que a equação de JC não se adequou bem aos experimentos físicos.

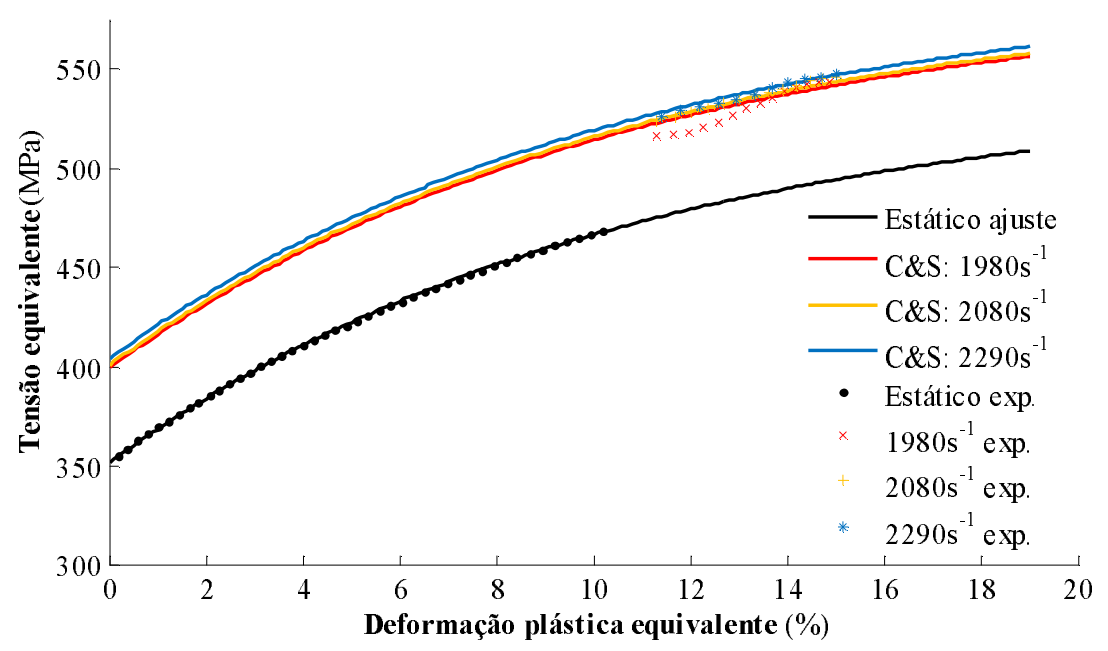

Figura 4.22: Curvas reconstruídas pelo modelo de CS para o material M1. Corpos de prova: discos. 


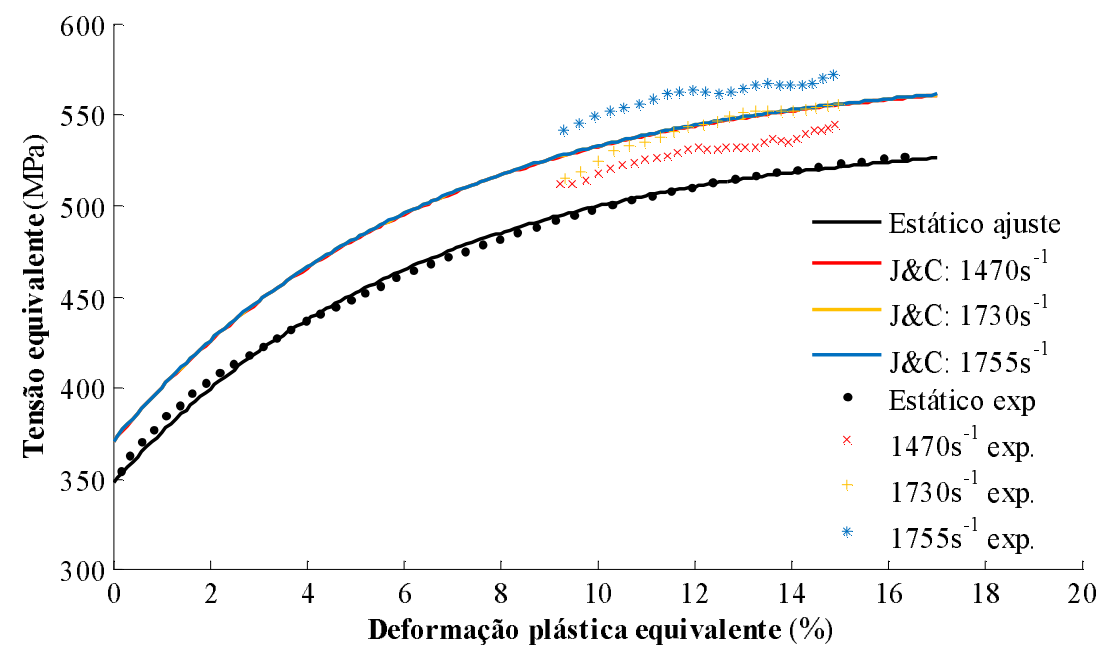

Figura 4.23: Curvas reconstruídas pelo modelo de JC para o material M2. Corpos de prova: discos.

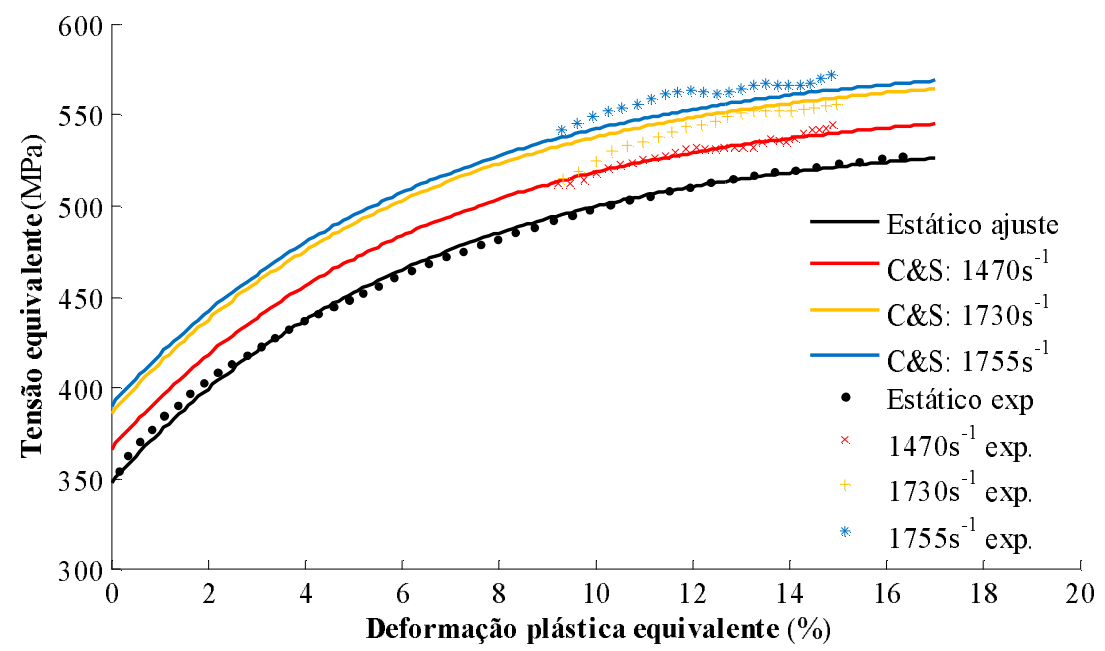

Figura 4.24: Curvas reconstruídas pelo modelo de CS para o material M2. Corpos de prova: discos. 



\section{CARACTERIZAÇÃO DINÂMICA MODIFICADA DOS MATERIAIS}

No Capítulo 4, foi apresentada a caracterização dinâmica das duas ligas de alumínio utilizadas neste trabalho, segundo a metodologia clássica, mais precisamente com o uso de um corpo de prova cilíndrico na BH. Apontou-se, a partir de pesquisa bibliográfica, a utilização de lubrificante como solução aos erros na modelagem matemática da $\mathrm{BH}$, relacionados ao atrito entre o corpo de prova e as barras. Contudo, este artifício não foi suficiente para garantir uma taxa constante de deformação do corpo de prova, outra hipótese importante adotada na modelagem (ELLWOOD; GRIFFITHS; PARRY, 1982; BRAGOV; LOMUNOV, 1995; CADY; GRAY, 2001; CHEN et al., 2003; FREW; FORRESTAL; CHEN, 2005).

Este capítulo inicia-se com uma revisão bibliográfica que aponta incertezas com relação à utilização de lubrificantes na BH. A faixa de valores ótima da razão comprimento por diâmetro do corpo de prova cilíndrico, do trabalho de Davies e Hunter (1963), é apresentada. Pode-se então verificar que os valores desta razão nos discos estão distantes da região pretendida.

Baseado nesta relação geométrica, um estudo numérico do teste de compressão dinâmico foi realizado. Buscou-se averiguar a influência nas curvas do material obtidas com uma $\mathrm{BH}$ virtual, variando-se o coeficiente de atrito de Coulomb e inserindo um novo corpo de prova de formato anelar. Devido à relevância dos resultados obtidos neste estudo, partiuse para uma análise analítica que pudesse comprová-los, validando-os para o emprego das modificações na metodologia do teste com a BH.

Apresenta-se, no final do capítulo, a caracterização dinâmica na BH com a nova metodologia, i.e. utilizando anéis como corpos de prova e aplicando-se o fator de correção encontrado no estudo analítico. As diferenças em relação à metodologia convencional são então apontadas e discutidas e os novos parâmetros de JC e CS são obtidos para os materiais estudados.

\subsection{REVISÃO BIBLIOGRÁFICA}

Trabalhos que tratam da caracterização dinâmica numa BH de compressão (SEO; MIN; YANG, 2005; TRAUTMANN et al., 2005) indicam a utilização de lubrificante como 
fator essencial na diminuição do atrito na interface do corpo de prova com as barras e na conseqüente obtenção de dados válidos.

Entretanto, o nível de tensão obtido pode variar com o tipo de lubrificante utilizado, chegando a 8\% de diferença em ligas de alumínio, como mostrado em Hall e Guden (2003). Utilizando seis tipos de lubrificação na $\mathrm{BH}$, os pesquisadores concluíram que os lubrificantes são imprescindíveis, porém há a necessidade de mais estudos para se avaliar a correta utilização dos mesmos. É indicado ainda, neste estudo, que lubrificantes líquidos agem de uma melhor forma que os sólidos. Outra dificuldade na aplicação de lubrificantes é apontada no trabalho de Seo, Min e Yang (2005), onde testes a altas temperaturas foram fortemente influenciados pelo atrito devido à degradação das propriedades do lubrificante.

Malinowski e Klepaczko (1986) sugeriram uma correção no nível de tensão médio para os erros devido à influência do atrito. Trata-se de uma relação entre a tensão real corrigida, $\sigma_{c}$, e a medida no teste, $\sigma$, em função do coeficiente de atrito de Coulomb, $\mu$, do diâmetro do corpo de prova, $D_{0}$, de seu comprimento, $L_{0}$, e da deformação sofrida, $\varepsilon$,

$$
\sigma_{c}=\left[1-\frac{\mu D_{0}}{L_{0}}(1-\varepsilon)^{-3 / 2}\right] \sigma
$$

Esta correção, entretanto, foi aplicada por Seo, Min e Yang (2005) e mínimas diferenças foram encontradas. Outra desvantagem é a necessidade de se conhecer o valor do coeficiente de Coulomb, o que não é trivial.

A não ocorrência de um estado uniforme de tensão também tem sua causa nos efeitos de inércia radiais e axiais. Forças inerciais, agindo no sentido de tentar dificultar a deformação causada pela passagem dos pulsos através do corpo de prova, podem não ser negligenciáveis. Davies e Hunter (1963) estudaram a influência da inércia em cilindros submetidos à compressão na BH. Foi descoberto que os efeitos radial e axial são opostos e que existe uma relação geométrica ótima, na qual esses efeitos são minimizados, dada por

$$
\lambda=\frac{L_{0}}{D_{0}}=\frac{1}{2} \sqrt{3 v_{s}}
$$

onde $v_{s}$ é o coeficiente de Poisson do corpo de prova. Como $v_{s}$ varia normalmente de 0,3 a 0,5, têm-se uma razão ótima de 0,47 a 0,61 entre o comprimento e o diâmetro de um corpo de prova cilíndrico.

Outro método de correção para a influência do atrito e dos efeitos de inércia foi proposto por Meng e Li (2003a). Trata-se da inclusão de dois coeficientes de correção para a não- 
uniformidade axial e radial das tensões. Análises numéricas foram realizadas de modo a se comparar curvas com e sem correção com a curva correta. Os resultados indicaram a validade do método. A desvantagem é que, no cálculo destes coeficientes, se faz necessária a realização de simulações numéricas para ajuste de cada caso.

Mesmo considerando todos os fatores comentados anteriormente, a $\mathrm{BH}$ é de grande eficácia na caracterização dinâmica de materiais. Atualmente, são muitos os trabalhos nos quais o conhecimento do comportamento do material, sob diferentes taxas de deformação, é adquirido com este equipamento (KAPOOR; NEMAT-NASSER, 1998; LEE; SHYU; CHIOU, 2000; NEMAT-NASSER; GUO; KIHL, 2001; BORVIK et al., 2001a; LEE; KIM, 2003; CLAUSEN et al., 2004; BORVIK et al., 2005; EL-MAGD; ABOURIDOUANE, 2006; LEE; LIU, 2006; LEE; LIN; LIU, 2006).

\subsection{CORREÇÃO DOS EFEITOS DE ATRITO NOS TESTES DINÂMICOS}

A adoção de um corpo de prova em formato de anel, no teste dinâmico com a BH, é proposta como alternativa à utilização de lubrificante na interface com as barras, principalmente para corpos de prova de pequeno comprimento, e.g. quando da caracterização de chapas finas. O objetivo é diminuir os efeitos de atrito, além de equilibrar a relação entre as inércias radial e axial.

Além do que já foi exposto acerca do uso de lubrificante, este, que não consta na modelagem da $\mathrm{BH}$, ainda pode se comportar como um terceiro material na interface das barras e do corpo de prova, modificando a propagação das ondas mecânicas. Salienta-se, portanto, que a utilização de lubrificantes nos testes de caracterização mecânica na BH requer estudos específicos para avaliação de sua influência.

A razão $L_{0} / D_{0}$ dos discos utilizados na caracterização convencional resulta nos valores 0,08 para o material M1 e 0,16 para o material M2, muito distantes do ponto ótimo indicado por Davies (Equação (5.2)), de 0,48. Isto indica um desequilíbrio entre as inércias radiais e axiais neste corpo de prova. A opção pelo formato anelar corresponde à retirada de material do centro do disco, diminuindo sua inércia radial, de modo a aproximá-la da axial. Nota-se que a inércia axial, neste caso, não pode ser alterada, pois está relacionada com a espessura das chapas laminadas. 


\subsubsection{Análise numérica inicial}

Um estudo numérico inicial foi realizado pelo autor (MICHELI; ALVES; GALLINA, 2004), englobando apectos geométricos do corpo de prova e atrito. Desconsiderou-se a interferência da dispersão dos pulsos nos resultados. Salienta-se que a razão entre o comprimento e o diâmetro das barras da $\mathrm{BH}$ disponível é considerada suficiente (barras delgadas) para satisfazer a condição de propagação unidimensional (MENG; LI, 2003b).

A BH foi modelada com elementos finitos axissimétricos CAX4R, no programa ABAQUS, totalizando 2265 elementos (15 radialmente e 151 no comprimento) em cada barra. Os valores geométricos utilizados para o corpo de prova são apresentados na Tabela 5.1. A discretização deste ocorreu com 20 elementos CAX4R ao longo do seu comprimento. O número de elementos na direção radial dependeu da geometria, seguindo o valor de 0,083mm por elemento. Representou-se a ação do impactador por um pulso de deformação aplicado na barra de entrada. Estudou-se a influência do atrito no nível de tensão e no valor de taxa de deformação média do teste, em função dos diâmetros do anel, $d_{0}$ e $D_{0}$, indicados na Figura 3.13.

O procedimento numérico foi adaptado do utilizado em Meng e Li (2003a), o qual foi baseado no trabalho de Bertholf e Karnes (1975), onde é atribuído ao material do corpo de prova um comportamento independente da taxa de deformação. O teste é simulado e os pulsos de deformação, $\varepsilon_{i}, \varepsilon_{r}$ e $\varepsilon_{t}$ são obtidos de elementos finitos existentes na mesma posição dos extensômetros da BH real. A curva tensão versus deformação é então reconstruída com o auxílio das Equações (4.4) e (4.9) e comparada com a usada na simulação numérica. Como o material hipotético utilizado independe da taxa de deformação, os principais erros obtidos podem ser atribuídos somente à existência de um estado não uniforme de tensão e deformação, que por sua vez, tem sua causa maior no atrito presente na interface barra-corpo de prova e nos efeitos de inércia deste.

A curva de entrada utilizada para representar esse material hipotético é apresentada na Figura 5.1. Segundo Gallina, Birch e Alves (2003), a amplitude do pulso de tensão a ser aplicado na barra de entrada, $\sigma_{p}$, pode ser calculado a partir do nível de tensão, $\sigma_{E}$, e da taxa de deformação, $\dot{\varepsilon}_{E}$, aos quais se deseja submeter o corpo de prova,

$$
\sigma_{p}=\frac{A_{0}}{A_{b}} \sigma_{E}+\frac{E_{b} L_{0}}{2 c_{b}} \dot{\varepsilon}_{E}
$$

O nível de tensão escolhido para o corpo de prova foi a própria tensão de escoamento do corpo de prova, 350MPa, hipoteticamente selecionada, e apresentada na Figura 5.1. 


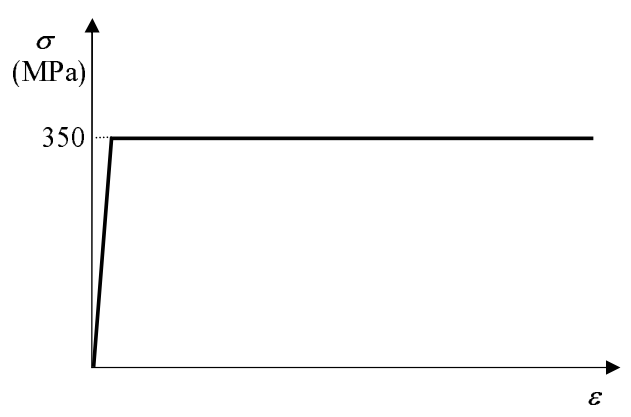

Figura 5.1: Curva de entrada do material insensível à taxa de deformação.

A taxa de deformação e as amplitudes do pulso de tensão utilizados nas simulações são descritos na Tabela 5.1. Observe que, na simulação NS1, tem-se um corpo de prova na forma de um disco $\left(d_{0}=0\right)$.

Tabela 5.1: Valores dos parâmetros utilizados nas simulações do teste de caracterização dinâmica.

\begin{tabular}{|c|ccccccc|}
\hline N. Simulação & $\dot{\boldsymbol{\varepsilon}}_{E}\left(\mathrm{~s}^{-1}\right)$ & $\boldsymbol{D}_{0}(\mathrm{~mm})$ & $\boldsymbol{d}_{0}(\mathrm{~mm})$ & $\boldsymbol{d}_{0} / \boldsymbol{D}_{0}$ & $\boldsymbol{L}_{0}(\mathrm{~mm})$ & $\boldsymbol{L}_{0} / \boldsymbol{D}_{0}$ & $\boldsymbol{\sigma}_{p}(\mathrm{MPa})$ \\
\hline \hline$N S 1$ & 2500,0 & 19,6 & 0,0 & 0,00 & 4,0 & 0,204 & 411,7 \\
$N S 2$ & 2500,0 & 19,6 & 1,0 & 0,05 & 4,0 & 0,204 & 409,5 \\
$N S 3$ & 2500,0 & 19,6 & 9,8 & 0,50 & 4,0 & 0,204 & 359,6 \\
$N S 4$ & 2500,0 & 19,6 & 17,1 & 0,87 & 4,0 & 0,204 & 253,0 \\
\hline
\end{tabular}

De forma a ilustrar como o atrito exerce uma influência diferente em anéis e discos, as curvas reconstruídas a partir das simulações NS1(disco) e NS4(anel de parede fina), em conjunto com a curva de entrada, são apresentadas na Figura 5.2 (a) e (b), respectivamente, para diversos valores de coeficiente de atrito de Coulomb. Percebe-se que, para ambos os casos, a metodologia da $\mathrm{BH}$ não é precisa para pequenas deformações, pois o equilíbrio entre as extremidades do corpo de prova depende da passagem de várias reflexões das ondas, o que não ocorre instantaneamente. Após certo nível de deformação, em torno de $2 \%$, pode-se observar claramente a diferença de comportamento frente ao aumento do coeficiente de atrito. No caso do anel, ocorre uma saturação do nível de tensão, limitando o efeito do atrito, o que não ocorre com o disco.

Essa saturação do nível de tensão foi avaliada em função do diâmetro interno normalizado do anel, $d_{0} / D_{0}$, e os resultados são mostrados na Figura 5.3. Esta apresenta a diferença percentual no nível médio de tensão em relação ao nível correto de $350 \mathrm{MPa}$, a uma deformação de 4\%. Observa-se, nos discos (pontos de abscissa zero), que a influência do atrito eleva o erro no nível de tensão de praticamente zero para quase $80 \%$ com o aumento do 


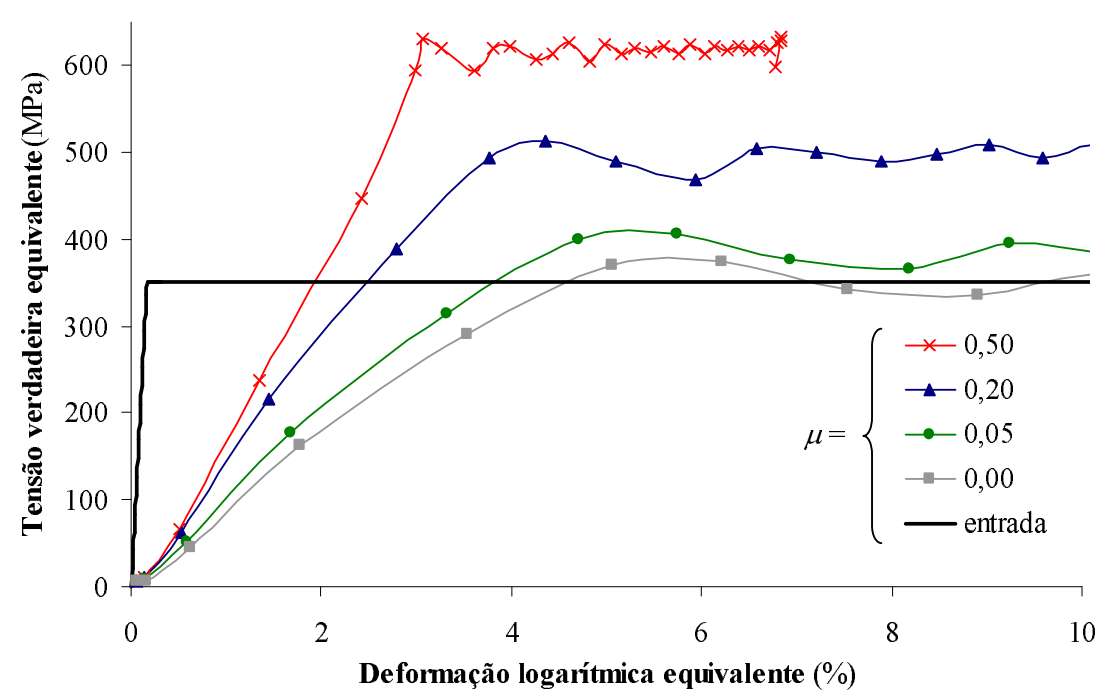

(a)

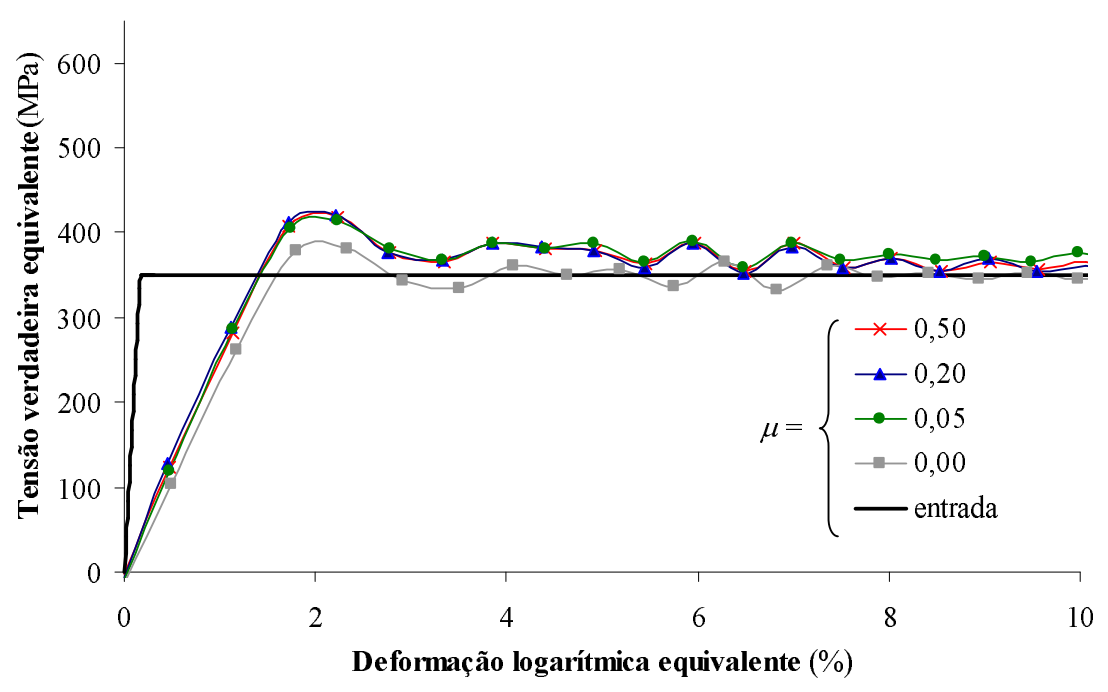

(b)

Figura 5.2: Curvas de entrada e reconstruídas de (a) discos e (b) anéis frente à variação do atrito.

coeficiente de atrito de 0,0 para 0,5. Entretanto, no caso do anel de parede mais delgada $\left(d_{0} / D_{0}=0,87\right)$, os erros ficam restritos a aproximadamente $15 \%$.

A taxa de deformação obtida com a Equação (4.5) também foi comparada à taxa de deformação nominal, imposta no cálculo da amplitude do pulso de deformação (Equação (5.3)), para diferentes valores do diâmetro interno normalizado do corpo de prova, Figura 5.4. O mesmo comportamento foi encontrado, ou seja, os erros diminuíram com o aumento do diâmetro do furo interno do anel.

Esses resultados motivaram um estudo analítico mais detalhado acerca do comportamento 


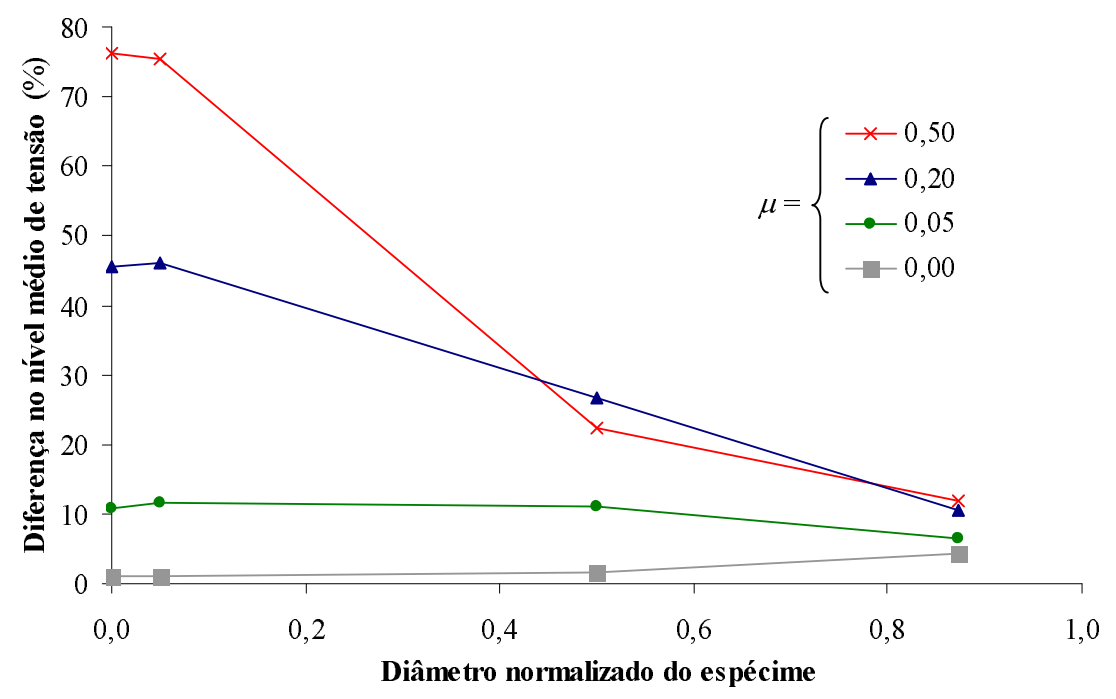

Figura 5.3: Erro no nível de tensão em função do diâmetro interno normalizado do corpo de prova.

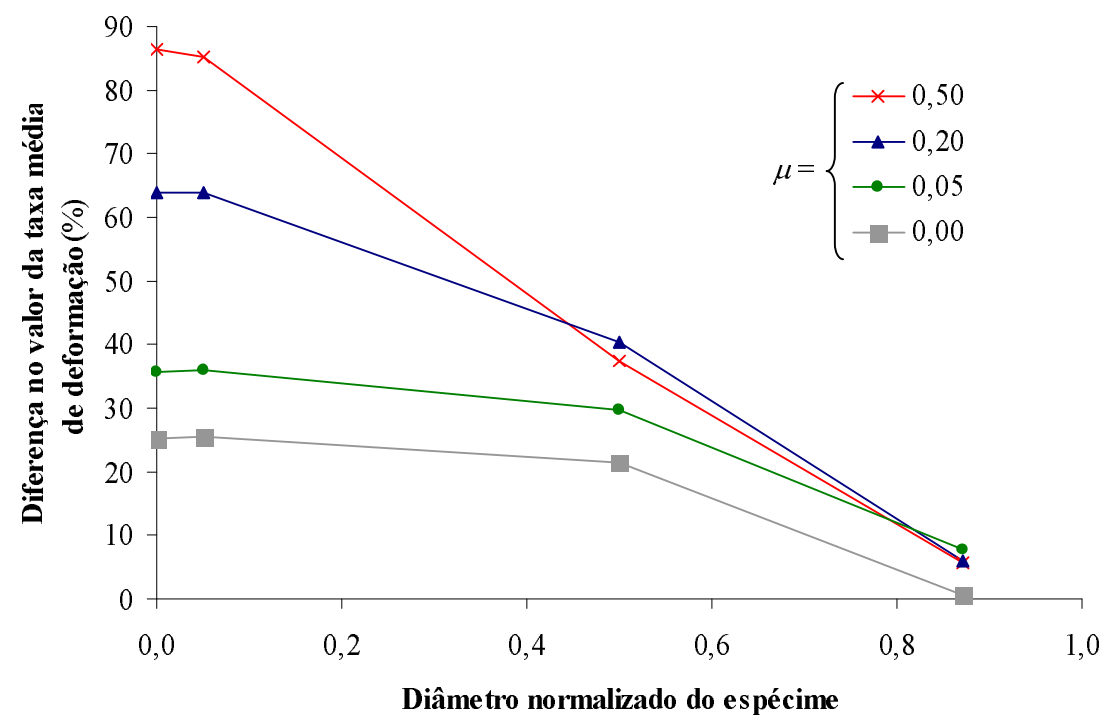

Figura 5.4: Erro na taxa de deformação em função do diâmetro interno normalizado do corpo de prova.

de anéis em compressão, pois sua validação implica numa solução simples para o importante problema de atrito associado ao teste de caracterização dinâmica com uma $\mathrm{BH}$.

\subsubsection{Modelagem analítica}

A compreensão dos resultados parciais obtidos, que apontaram vantagens em se utilizar anéis na caracterização dinâmica por compressão, exigiu um estudo mais aprofundado de 
como ocorre a deformação deste corpo de prova durante o teste.

Com o auxílio da Figura 5.5, pretende-se analisar o comportamento de um anel em compressão dinâmica, de acordo com o proposto por Alves e Karagiozova (2007). Esta análise é feita em função da razão geométrica entre o comprimento do anel e a diferença entre os raios externo, $R_{0}$, e interno, $r_{0}$.

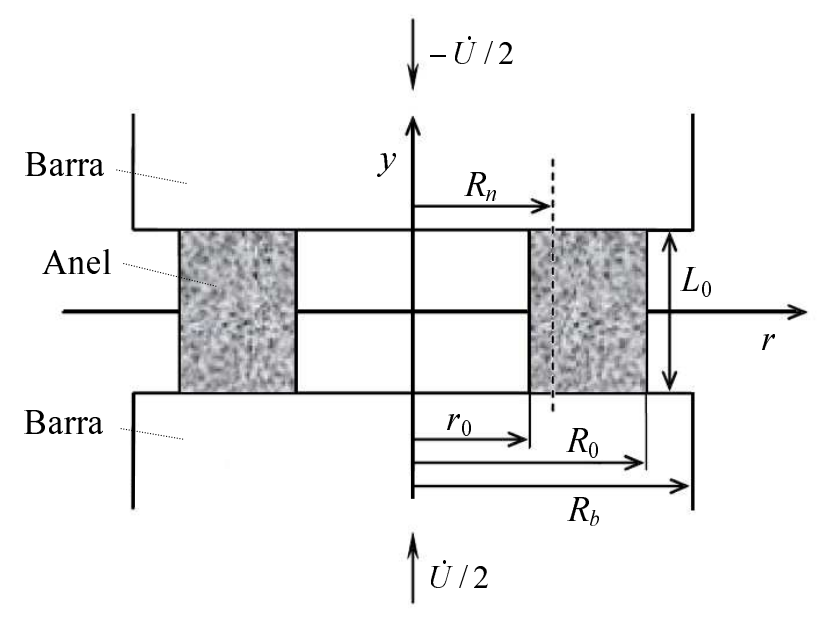

Figura 5.5: Sistema de coordenadas para um anel sob compressão (ALVES; KARAGIOZOVA, 2007).

A compressão axial do anel, sem a existência de atrito com as superfícies das barras, ocorre de modo que a razão $r_{0} / R_{0}$, permanece constante. Neste caso, os diâmetros interno e externo aumentam na mesma proporção, como ocorre com um disco sólido, e o únicos pontos com velocidade nula estão sobre o eixo de simetria axial.

A existência de atrito tende a restringir o movimento de expansão do anel, fazendo com que a parede interna assuma uma velocidade radial inferior à velocidade da parede externa. Aumentando-se o atrito, o raio $R_{n}$, no qual a velocidade radial é nula, adentra a parede interna do anel. $\mathrm{O}$ material que se encontra dentro do semi-espaço definido por este raio tenta se expandir, mas é forçado a se movimentar no sentido do centro do anel, permanecendo imóvel. Isto diminui a energia dissipada na fricção. Numa condição extrema, grande parte da face do anel em contato com as barras permanece imóvel, e a energia que era dissipada com a movimentação por atrito fica estagnada, i.e. o efeito causado pelo atrito atinge uma saturação, dando significado aos resultados apresentados anteriormente. É preciso então relacionar esta mínima dissipação de energia por atrito com a razão geométrica citada, $L_{0} /\left(R_{0}-r_{0}\right)$, e determinar de que modo é possível corrigir as curvas 
tensão versus deformação obtidas no teste com a BH.

A tensão média do corpo de prova transmitida para a barra pode ser obtida pela minimização da variação de energia no tempo, dada por

$$
\dot{W}=\dot{W}_{i}+\dot{W}_{f},
$$

onde $\dot{W}$ é a potência externa, $\dot{W}_{i}$ é a variação temporal da energia interna de deformação, ou potência interna, e $\dot{W}_{f}$ é a potência devido ao atrito na interface.

A simetria na geometria apresentada na Figura 5.5 propicia a consideração de somente metade do anel, $0<y<L_{S} / 2$. O movimento das interfaces é assumido simétrico em relação ao eixo $r$, i.e. cada barra se move com velocidade de igual amplitude e direção, $\dot{u} / 2$, porém com sentido contrário, sendo que $\dot{u}=\dot{u}_{1}-\dot{u}_{2}$, onde $\dot{u}_{1}$ e $\dot{u}_{2}$ são as velocidades axiais das barras de entrada e saída, respectivamente.

A tensão de cisalhamento, $\tau_{r y}$, e a taxa de deformação equivalente, $\dot{\varepsilon}$, podem ser expressas, no sistema cilíndrico, por

$$
\tau_{r y}=\frac{2 \sigma_{E}}{3 \dot{\varepsilon}} \dot{\varepsilon}_{r y}
$$

e

$$
\dot{\varepsilon}=\sqrt{2\left(\dot{\varepsilon}_{r}^{2}+\dot{\varepsilon}_{y}^{2}+\dot{\varepsilon}_{\theta}^{2}+2 \dot{\varepsilon}_{r y}^{2}\right) / 3}
$$

onde $\sigma_{E}$ é obtido pela Equação (4.9) com as componentes da taxa de deformação dadas por

$$
\dot{\varepsilon}_{r}=\frac{\partial V_{r}}{\partial r}, \quad \dot{\varepsilon}_{\theta}=\frac{V_{r}}{r}, \quad \dot{\varepsilon}_{y}=\frac{\partial V_{y}}{\partial y}, \quad \dot{\varepsilon}_{r y}=\frac{1}{2}\left(\frac{\partial V_{r}}{\partial y}+\frac{\partial V_{y}}{\partial r}\right),
$$

sendo $V_{r}$ e $V_{y}$ as componentes da velocidade nas direções $r$ e $y$, respectivamente. Da condição de incompressibilidade no regime plástico, a taxa de deformação volumétrica vale

$$
\dot{\varepsilon}_{r}+\dot{\varepsilon}_{\theta}+\dot{\varepsilon}_{y}=0
$$

ou

$$
\frac{\partial V_{r}}{\partial r}+\frac{V_{r}}{r}=-\frac{\partial V_{y}}{\partial y}
$$

Assumindo que $V_{r}=f(r) \frac{\partial V_{y}}{\partial y}$ e que $V_{r}$ e $V_{y}$ são independentes de $r$ na interface $y=L_{S} / 2$, então, de acordo com Wang (2001),

$$
V_{r}=-\frac{r}{2}\left(1-\frac{R_{n}^{2}}{r^{2}}\right) \frac{\partial V_{y}}{\partial y}
$$




$$
\begin{gathered}
\dot{\varepsilon}_{r}=-\frac{1}{2}\left(1+\frac{R_{n}^{2}}{r^{2}}\right) \frac{\partial V_{y}}{\partial y}, \\
\dot{\varepsilon}_{\theta}=-\frac{1}{2}\left(1-\frac{R_{n}^{2}}{r^{2}}\right) \frac{\partial V_{y}}{\partial y}, \\
\dot{\varepsilon}_{y}=\frac{\partial V_{y}}{\partial y}, \\
\dot{\varepsilon}_{r y}=-\frac{r}{4}\left(1-\frac{R_{n}^{2}}{r^{2}}\right) \frac{\partial^{2} V_{y}}{\partial y^{2}} .
\end{gathered}
$$

O abaulamento do anel durante a compressão pode ser considerado através da dependência exponencial desenvolvida por Avitzur (1980). Assume-se que $V_{y}=V_{y}(y)$ e que a taxa de deformação na direção axial pode ser expressa como uma função do parâmetro de abaulamento $b$,

$$
\dot{\varepsilon}_{y}=-2 a_{2} \frac{\dot{u}}{L_{s}} e^{-b y / L_{s}}
$$

Integrando a Equação (5.15) segue que

$$
V_{y}=-2 \dot{u} \frac{a_{2}}{b} e^{-b y / L_{s}}+a_{1}
$$

com as constantes $a_{1}$ e $a_{2}$ obtidas das condições $\left.V_{y}\right|_{y=L_{s} / 2}=\dot{u} / 2$ e $\left.V_{y}\right|_{y=0}=0$, resultando em

$$
a_{1}=-\frac{\dot{u}}{2}\left(1-4 \frac{c_{2}}{b} e^{b / 2}\right)
$$

$\mathrm{e}$

$$
a_{2}=-\frac{b}{4\left(e^{-b / 2}-1\right)} .
$$

As taxas de deformação definidas pelas Equações (5.11 - 5.14) tornam-se

$$
\begin{gathered}
\dot{\varepsilon}_{r}=\frac{\dot{u}}{4 L_{s}} \frac{b}{\left(e^{-b / 2}-1\right)}\left(1-\frac{R_{n}^{2}}{r^{2}}\right) e^{-b y / L_{s}}, \\
\dot{\varepsilon}_{\theta}=\frac{\dot{u}}{4 L_{s}} \frac{b}{\left(e^{-b / 2}-1\right)}\left(1+\frac{R_{n}^{2}}{r^{2}}\right) e^{-b y / L_{s}}, \\
\dot{\varepsilon}_{y}=\frac{\dot{u}}{2 L_{s}} \frac{b}{\left(e^{-b / 2}-1\right)} e^{-b y / L_{s}}
\end{gathered}
$$

$\mathrm{e}$

$$
\dot{\varepsilon}_{r y}=\frac{\dot{u}}{8} \frac{b^{2}}{L_{s}^{2}} \frac{1}{\left(e^{-b / 2}-1\right)}\left(r-\frac{R_{n}^{2}}{r}\right) e^{-b y / L_{s}} .
$$


A potência interna de deformação é dada por

$$
\dot{W}_{i}=\sigma_{E} \int_{V} \sqrt{\frac{2}{3} \dot{\varepsilon}_{i j} \dot{\varepsilon}_{i j}} d V
$$

ou, usando as Equações (5.19) a (5.22) e $d V=2 \pi r d r d y$,

$$
\dot{W}_{i}=\dot{u} \frac{\sigma_{E} \pi \sqrt{2}}{\sqrt{3}} \int_{r_{s}}^{R_{s}}\left\{4 r^{2}+\frac{\left(r^{2}+r_{s}^{2}\right)^{2}+\left(r^{2}-r_{s}^{2}\right)^{2}}{r^{2}}+\frac{b^{2}\left(r^{2}-r_{s}^{2}\right)^{2}}{2 L_{s}^{2}}\right\}^{1 / 2} d r
$$

onde $r_{s}$ e $R_{s}$ se referem aos valores médios dos raios interno e externo do anel, respectivamente,

$$
r_{s}=r_{0} \pm \Delta R, \quad R_{s}=R_{0}+\Delta R
$$

com "+"associado à expansão do anel $\left(R_{n}<r_{0}\right)$ e "-"relacionado ao abaulamento $\left(R_{n}>\right.$ $\left.r_{0}\right)$. Além disso, $\Delta R=1 / 2\left(L_{0} / L_{s}-1\right)\left(R_{0} \pm r_{0}\right)$, quando satisfeita a relação $A_{0} L_{0}=A_{s} L_{s}$, $\operatorname{com} A_{s}$ representando a área atual média da seção transversal do anel.

A perda por atrito é expressa por

$$
\dot{W}_{f}=-\left.4 \pi m \frac{\sigma_{E}}{\sqrt{3}} \int_{r_{s}}^{R_{s}} V_{r}\right|_{y=L_{s} / 2} r d r
$$

onde $m$ é um fator de atrito associado a $\mu$ através da relação

$$
m=\sqrt{3} \mu
$$

A potência externa é expressa por

$$
\dot{W}=\pi\left[\left(R_{S}\right)^{2}-\left(r_{s}\right)^{2}\right] P_{a v} \dot{u}
$$

onde $P_{a v}$ é a pressão por unidade de área, i.e. a tensão média na interface.

Igualando a potência externa com a potência interna de deformação somada à taxa temporal de perda de energia por atrito, obtém-se

$$
P_{a v}=\sigma_{E} \frac{G_{1}\left(R_{s}, r_{s}, R_{n}, b\right)+G_{2}\left(R_{s}, r_{s}, R_{n}, b, m\right)}{\left(R_{0}^{2}-r_{0}^{2}\right)}
$$

onde

$$
G_{1}=\frac{1}{\pi} \sqrt{\frac{2}{3}} \int_{r_{s}}^{R_{S}}\left\{4 r^{2}+\frac{\left(r^{2}+r_{s}^{2}\right)^{2}+\left(r^{2}-r_{s}^{2}\right)^{2}}{r^{2}}+\frac{b^{2}\left(r^{2}-r_{s}^{2}\right)^{2}}{2 L_{s}^{2}}\right\}^{1 / 2} d r
$$


e

$$
G_{2}=\frac{m b}{3 \pi L_{s} \sqrt{3}} \frac{e^{-b / 2}}{\left(e^{-b / 2}-1\right)}\left\{R_{s}\left(R_{s}^{2}-3 R_{n}^{2}\right)+2 R_{n}^{3}+r_{s}\left(r_{s}^{2}-3 R_{n}^{2}\right)+2 r_{s}^{3}\right\}
$$

Na minimização de $P_{a v}$, os valores ótimos para $b, R_{S}, r_{s}$ and $R_{n}$ devem ser obtidos para cada parâmetro de atrito $m$. Nos testes com a BH, o diâmetro externo do anel é limitado ao diâmetro da barra, $R_{0}<R_{b}$. Na presente análise paramétrica, assume-se $R_{0}=10 \mathrm{~mm}$, i.e. $R_{0}=0.7874 R_{b}$ (ALVES; KARAGIOZOVA, 2007). Assim, a tensão média no corpo de prova, $\sigma_{a v}$, é obtida para valores discretos de $m$ e $\left(R_{0}-r_{0}\right)$ por

$$
\sigma_{a v}=\frac{\sigma_{E}}{\left(R_{s}^{2}-r_{s}^{2}\right)} \min _{\left(R_{n}, b\right)}\left\{G_{1}\left(R_{n}, b\right)+G_{2}\left(R_{n}, b, m\right)\right\}
$$

Defini-se o coeficiente de correção, $\beta$, como

$$
\beta=\frac{\max _{(m)}\left\{\sigma_{a v}\right\}}{\sigma_{E}}
$$

As equações (5.32) e (5.33) são usadas para obter a tensão equivalente em função da tensão média, de características geométricas e do atrito, em um anel sob compressão. Em Alves e Karagiozova (2007) são construídas curvas de $\beta$ em função de $m$ e da razão $L_{0} /\left(R_{0}-r_{0}\right)$ para diferentes valores de $L_{0}$ e $r_{0}$. Dentro da faixa de $1,5 \mathrm{~mm}$ a $5,0 \mathrm{~mm}$, para o comprimento do corpo de prova, e de 1,5 a 2,5 para a razão deste comprimento pela espessura do anel $\left(L_{0} /\left(R_{0}-r_{0}\right)\right)$, chega-se a um valor médio de $\beta=1,17$ para $m$ variando de 0,15 a $0,25(0,087<\mu<0,15)$. Isto implica na necessidade de uma modificação na equação do cálculo da tensão no corpo de prova da BH, de modo que a Equação (4.9) torna-se

$$
\sigma_{E}^{\prime}(t)=\frac{1}{\beta} \sigma_{E}(t)=0,85 E_{b} \frac{A_{b}}{2 A_{s}}\left[\varepsilon_{i}(t)+\varepsilon_{r}(t)+\varepsilon_{t}(t)\right]
$$

Interessante notar que a aplicação deste coeficiente de correção está de acordo com as curvas da Figura 5.3, que apontaram um erro constante nos níveis de tensão, calculados pela modelagem da $\mathrm{BH}$, em torno de $10 \%$ a $15 \%$.

\subsection{TESTES EXPERIMENTAIS}

Anéis de mesma geometria que a apresentada na Tabela 3.7 foram utilizados na caracterização dinâmica dos materiais M1 e M2 com a BH. Da mesma forma que os discos, os comprimentos (espessuras) dos anéis seguem as espessuras das chapas das quais eles 
foram retirados. O diâmetro externo é o mesmo utilizado nos discos. O diâmetro interno foi definido de modo a garantir $L_{0} /\left(R_{0}-r_{0}\right)=2$, que trata-se do valor central na região apresentada na modelagem analítica, possibilitando assim, a utilização do fator de correção $1 / \beta=0,85$.

Nesta nova metodologia, o corpo de prova é colocado entre as barras sem lubrificante. Todo o processo de obtenção e posterior processamento dos sinais no computador são os mesmos descritos no Capítulo 4. A diferença ocorre apenas da multiplicação, neste caso, do nível de tensão pelo fator $1 / \beta$.

O equilíbrio de forças entre as extremidades do corpo de prova pode ser averiguado através da Equação (4.10), que é graficamente avaliada na Figura 5.6 a qual pode ser comparada com a Figura 4.6. Observa-se que, neste caso, os formatos das curvas se aproximam, indicando o estabelecimento de um estado mais próximo do equilíbrio. A diferença no nível de deformação, num mesmo instante, é atribuído à perda de energia que ocorre na interface com o corpo de prova e à atenuação das ondas mecânicas entre os extensômetros e esta interface, fatores não tratados aqui.

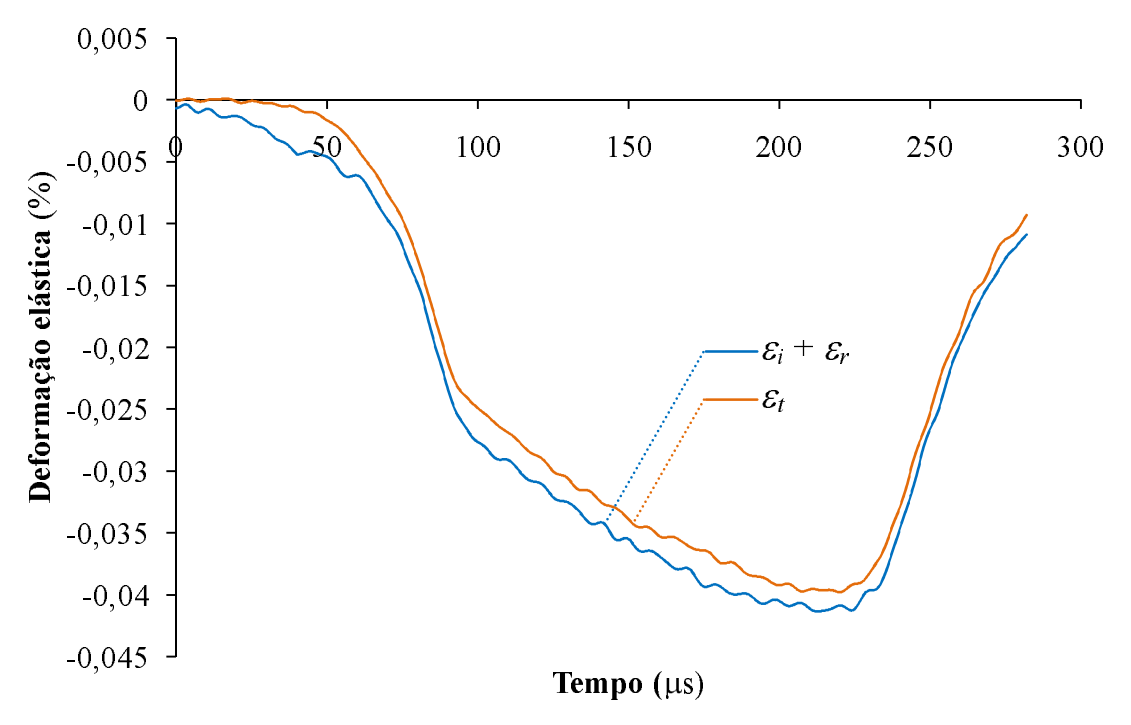

Figura 5.6: Equilíbrio de forças avaliado pela relação entre os pulsos de deformação na BH. Corpo de prova: anel.

Uma verificação mais evidente da melhora na substituição do disco por um anel, como corpo de prova da $\mathrm{BH}$, pode ser feita na comparação da curva do histórico de deformação equivalente. A Figura 5.7 apresenta esta curva para um teste com o material M1, mas que representa, em geral, os resultados de todos os testes com anéis. Pode-se observar que 
existe uma região evidentemente linear, indicando que o corpo de prova se deformou de uma maneira constante, i.e. os estados de deformação e tensão no corpo de prova foram mais uniformes que no teste com discos, Figura 4.10. Adicionalmente, atribuir um único valor de taxa de deformação para este teste, como a modelagem exige, é mais coerente quando utilizado o anel.

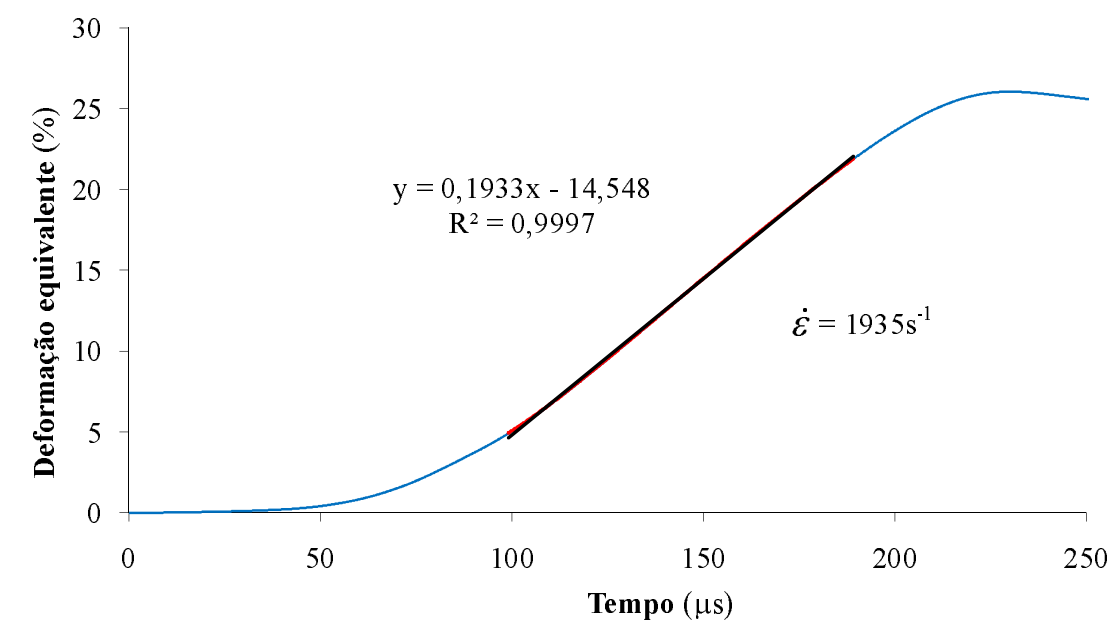

Figura 5.7: Taxa de deformação média (teste M1T1A). Corpo de prova: anel.

Os testes com os anéis e as correspondentes taxas de deformação, calculadas por regressão linear na curva de deformação equivalente versus tempo, são descritos na Tabela 5.2. Novamente três testes de cada material foram selecionados para representação de seu comportamento dinâmico. Observa-se que as taxas de deformação alcançadas são bem maiores que no teste com disco, onde a pressão máxima de disparo foi utilizada. Esta se tornou outra vantagem do teste com anel. Para uma mesma energia, consegue-se uma deformação e uma taxa de deformação maiores, possibilitando testes numa faixa de valores mais ampla.

Tabela 5.2: Taxas de deformação utilizadas na caracterização dinâmica na BH. Corpos de prova: anéis.

\begin{tabular}{|c|c|c|}
\hline Material & Teste & Taxa de deformação $\left(\mathbf{s}^{-1}\right)$ \\
\hline \hline \multirow{3}{*}{ M1 } & $M 1 T 1 A$ & 1935 \\
& $M 1 T 2 A$ & 4845 \\
& $M 1 T 3 A$ & 5050 \\
\hline \multirow{3}{*}{ M2 } & $M 2 T 1 A$ & 1315 \\
& $M 2 T 2 A$ & 2765 \\
& $M 2 T 3 A$ & 4405 \\
\hline
\end{tabular}


As curvas tensão versus deformação equivalentes foram calculadas do mesmo modo descrito no Capítulo 4. Nas Figuras 5.8 e 5.9, para os materias M1 e M2, têm-se as curvas dinâmicas apresentadas até uma deformação de 25\%, suficiente para a obtenção dos parâmetros envolvidos. Nota-se que as oscilações no início das curvas se estabilizam antes do que nos testes com os discos, considerando-se valores próximos das taxas de deformação.

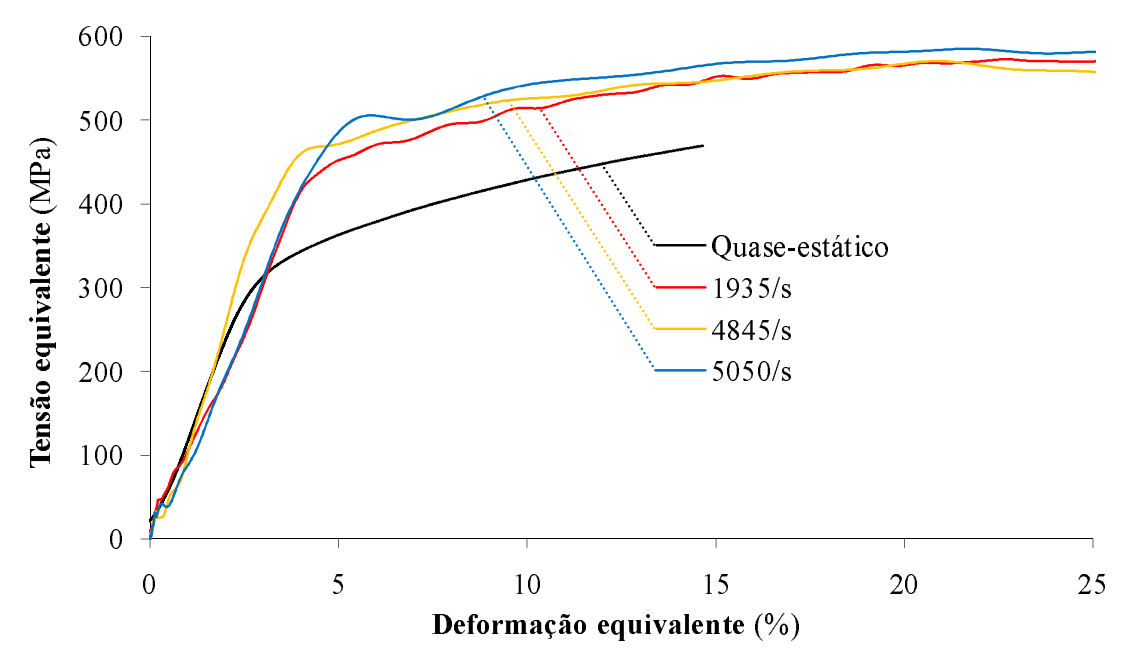

Figura 5.8: Comportamento quase-estático e dinâmico do material M1. Corpos de prova: anéis.

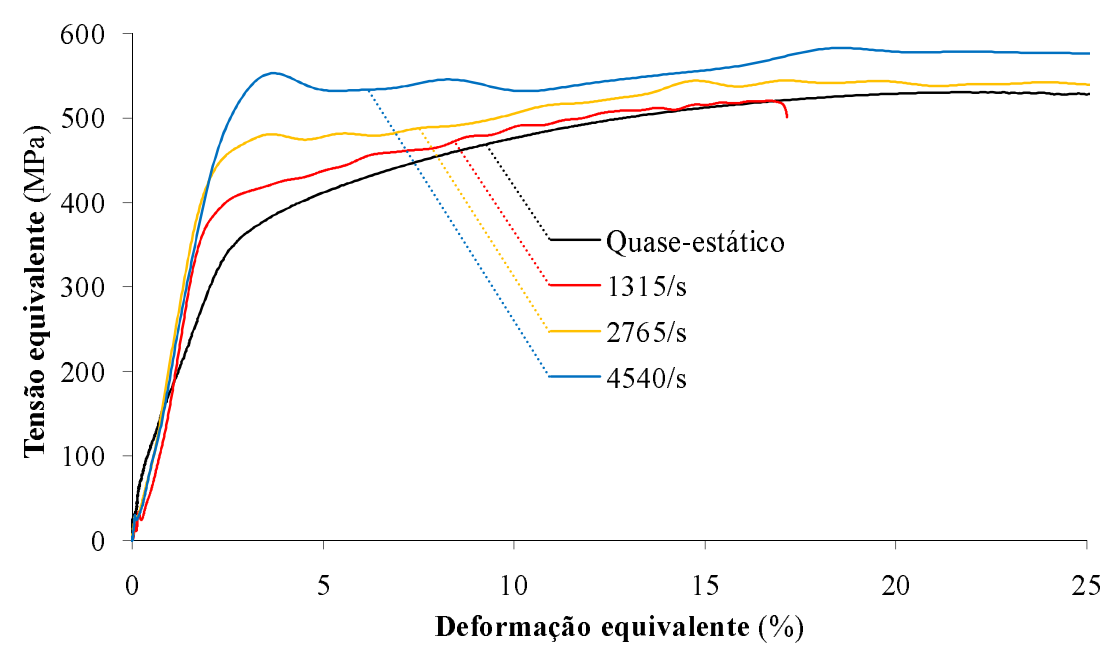

Figura 5.9: Comportamento quase-estático e dinâmico do material M2. Corpos de prova: anéis.

O mesmo critério para o início de deformação plástica equivalente foi utilizado, baseado na máxima deformação elástica do teste quase-estático. A região plástica selecionada 
das curvas para a obtenção dos parâmetros dinâmicos são apresentadas nas Figuras 5.10 e 5.11 para os materiais M1 e M2, respectivamente. A ocorrência, em menor tempo, da estabilização das oscilações nas curvas com os anéis possibilitou a seleção de uma região plástica em níveis de deformação menores que no caso com os discos, dentro da faixa de deformações dos testes de tração, diminuindo possíveis erros de extrapolação.

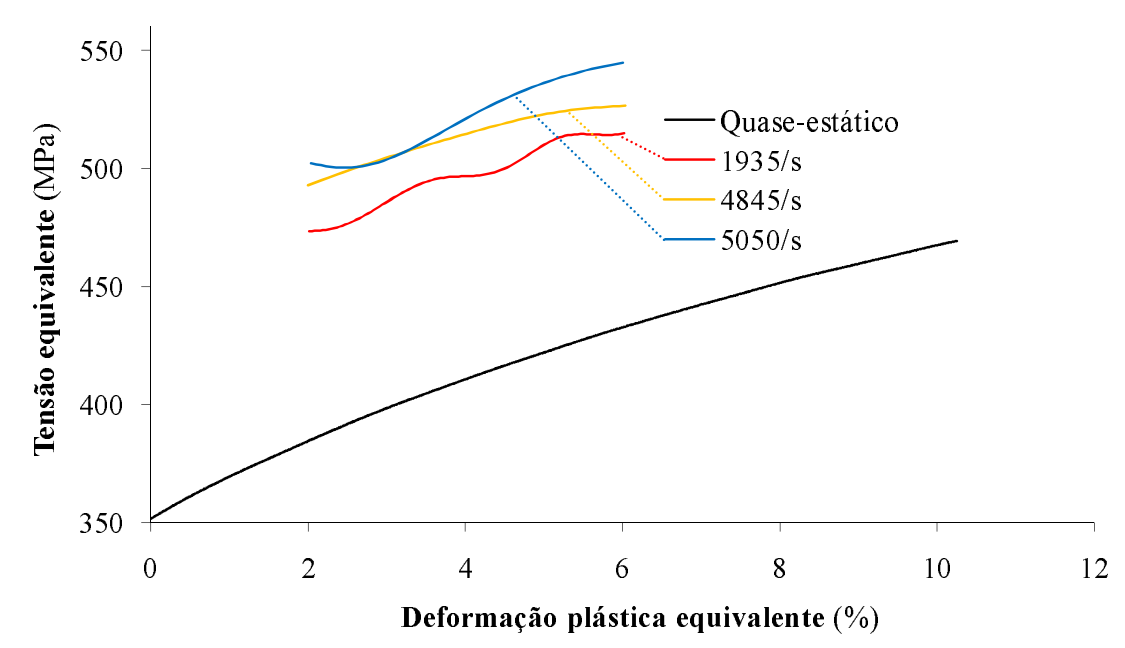

Figura 5.10: Região selecionada das curvas dinâmicas para ajuste dos parâmetros do material M1. Corpos de prova: anéis.

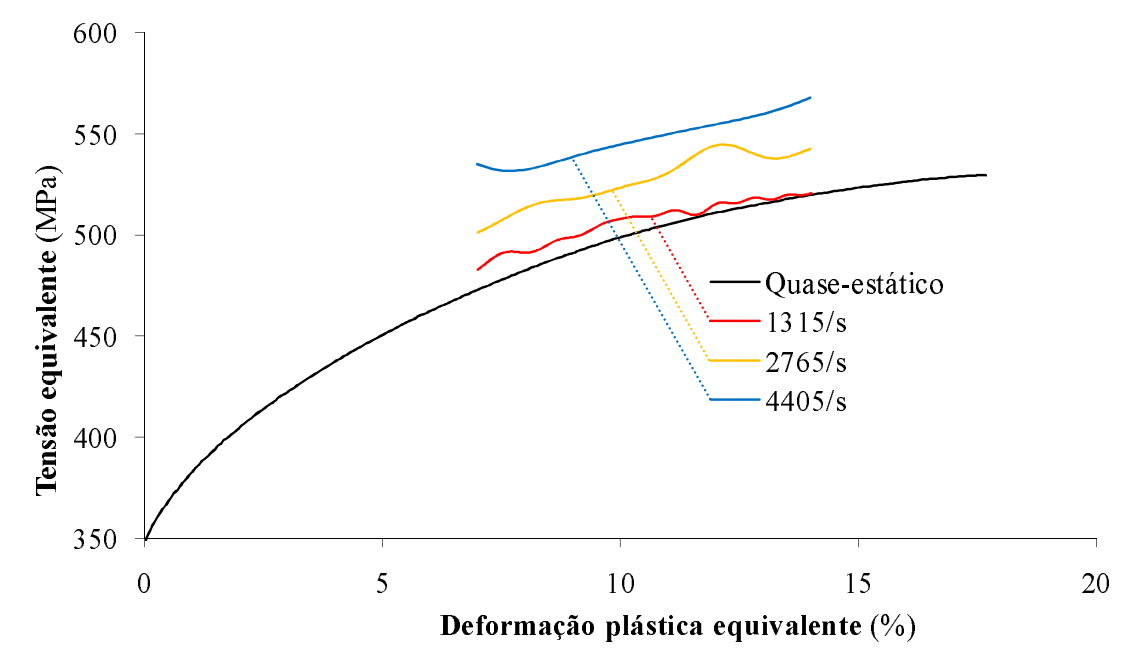

Figura 5.11: Região selecionada das curvas dinâmicas para ajuste dos parâmetros do material M2. Corpos de prova: anéis.

Selecionadas as regiões, foi realizado o ajuste das curvas dinâmicas com os parâmetros do modelo estático de Lemaitre, a menos da tensão de escoamento. As Figuras 5.12 e 5.13 
apresentam as curvas experimentais e os modelos ajustados, para os materiais M1 e M2, respectivamente.

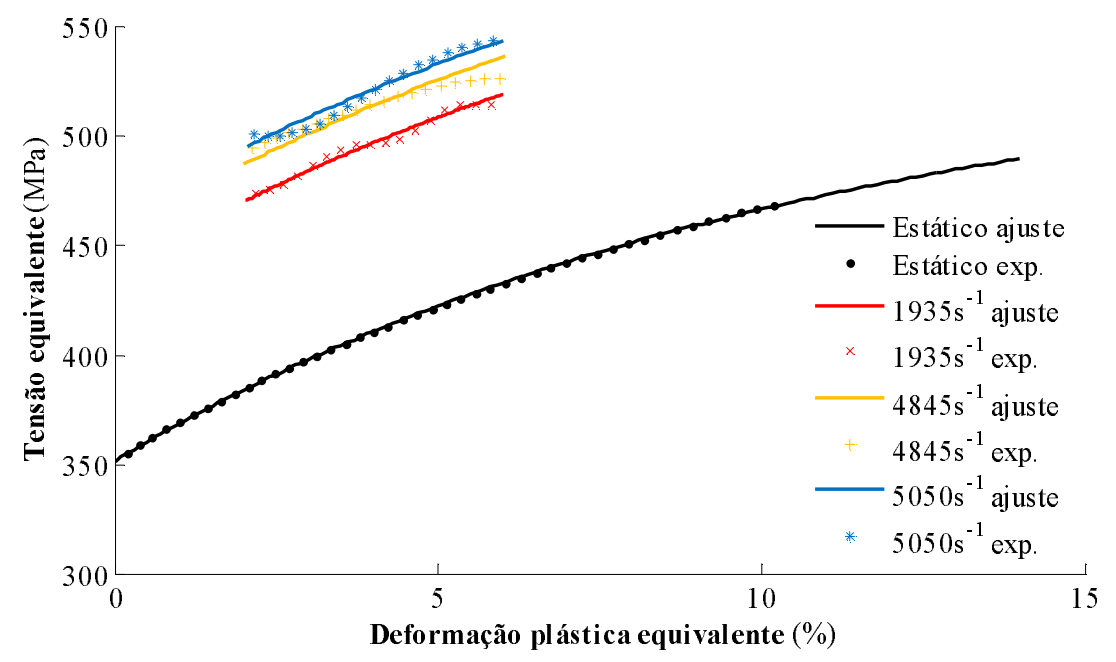

Figura 5.12: Ajuste das curvas dinâmicas com parâmetros do modelo estático do material M1. Corpos de prova: anéis.

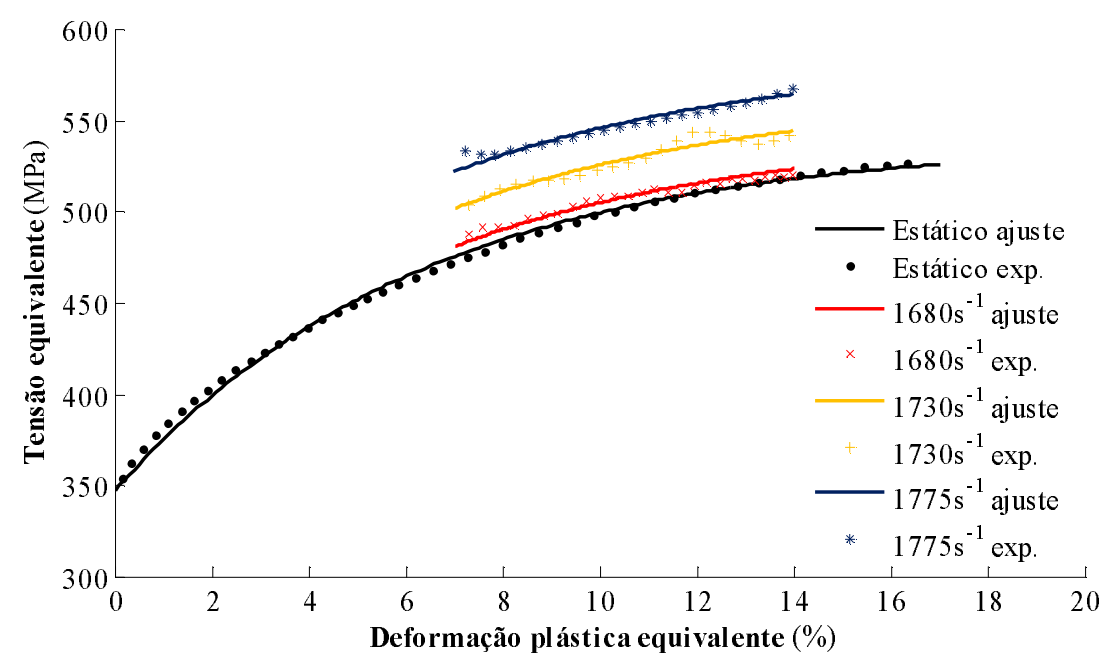

Figura 5.13: Ajuste das curvas dinâmicas com parâmetros do modelo estático do material M2. Corpos de prova: anéis.

\subsection{IDENTIFICAÇÃO DOS PARÂMETROS DO MODELO DE JOHNSON-COOK (JC)}

A calibração do parâmetro $C$ do modelo de JC, Equação (4.13), ocorreu pela construção da curva da Equação (4.14), apresentada nas Figuras 5.14 e 5.15, para os materiais M1 
e M2, respectivamente. Observa-se que o ajuste por este modelo não representou adequadamente os pontos, assim como no caso da caracterização com discos. Os valores do parâmetro $C$ são os coeficientes angulares das curvas e estão explícitos na Tabela 5.3.

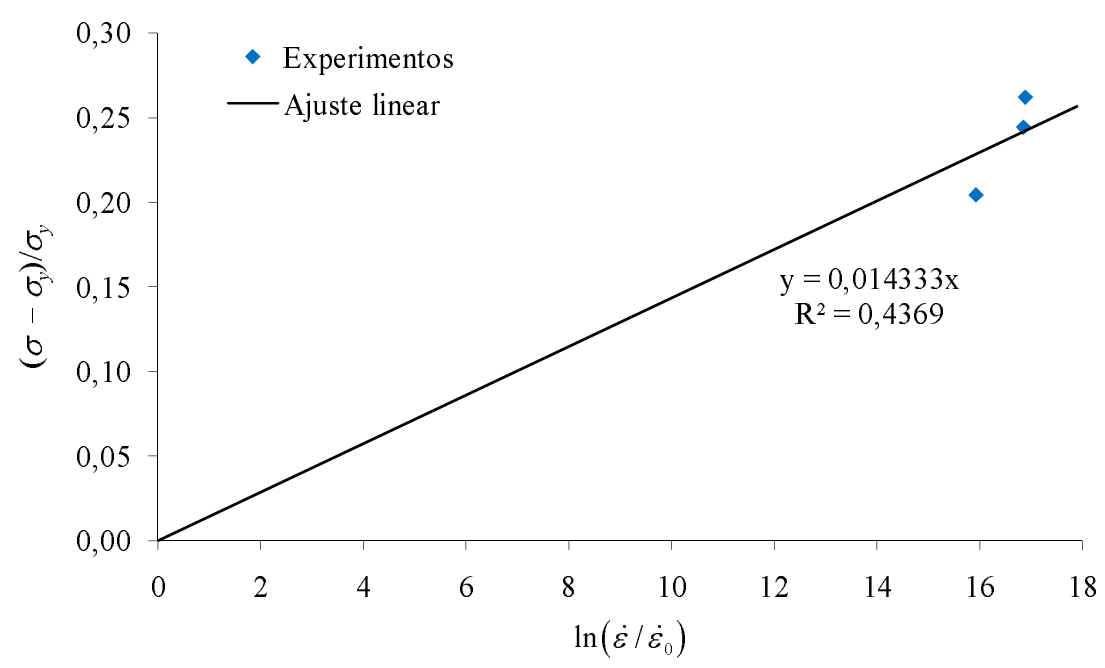

Figura 5.14: Ajuste do parâmetro de JC para o material M1. Corpos de prova: anéis.

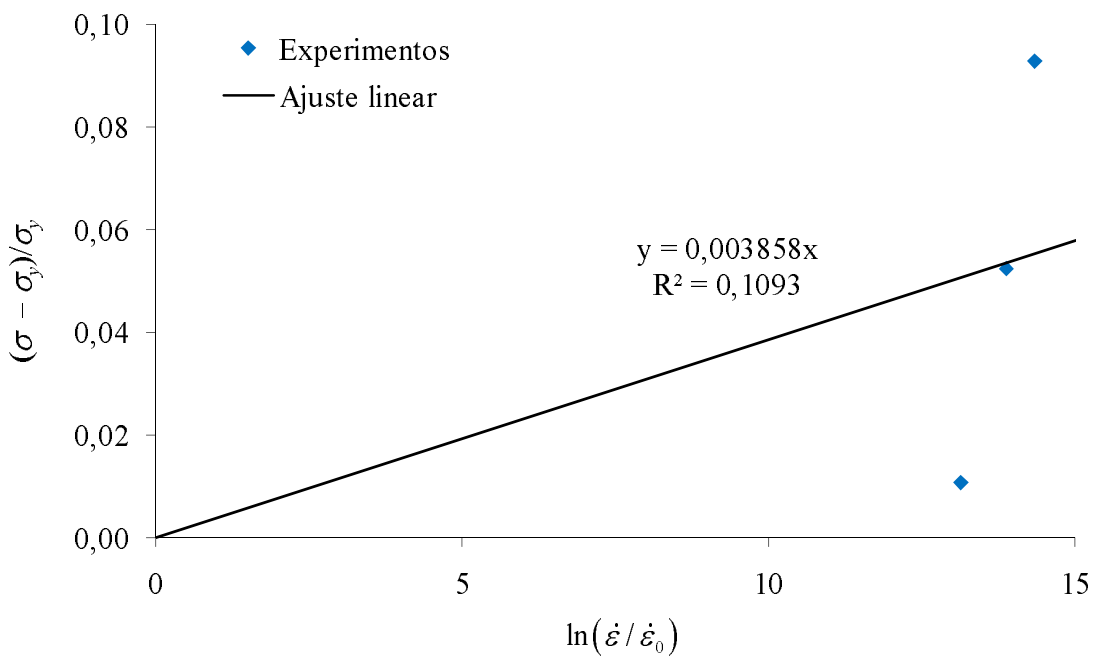

Figura 5.15: Ajuste do parâmetro de JC para o material M2. Corpos de prova: anéis.

\subsection{IDENTIFICAÇÃO DOS PARÂMETROS DO MODELO DE COWPER-SYMONDS (CS)}

O modelo de CS segue a Equação (4.17) que é manipulada para resultar na Equação linear (4.18). Os pontos experimentais encontrados são apresentados nas Figuras 5.16 e 5.17 para os materiais M1 e M2, respectivamente, em conjunto com o ajuste linear obtido. 
Observa-se nas Figuras 5.16 e 5.17 que o modelo de CS se ajustou bem aos dados experimentais. Os valores do coeficiente de determinação $R^{2}$, próximos da unidade, comprovam quantitativamente esta constatação. Nota-se ainda, comparando estas curvas com as das Figuras 4.19 e 4.20 , que o modelo se ajustou melhor que no caso da caracterização com discos.

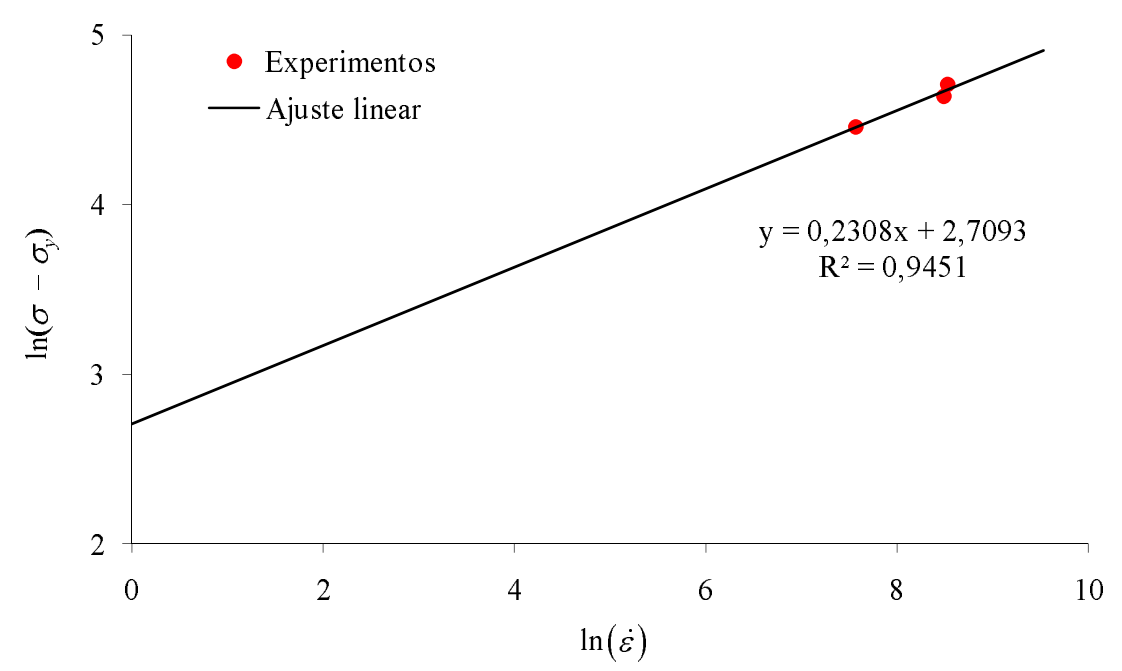

Figura 5.16: Ajuste dos parâmetros de CS para o material M1. Corpos de prova: anéis.

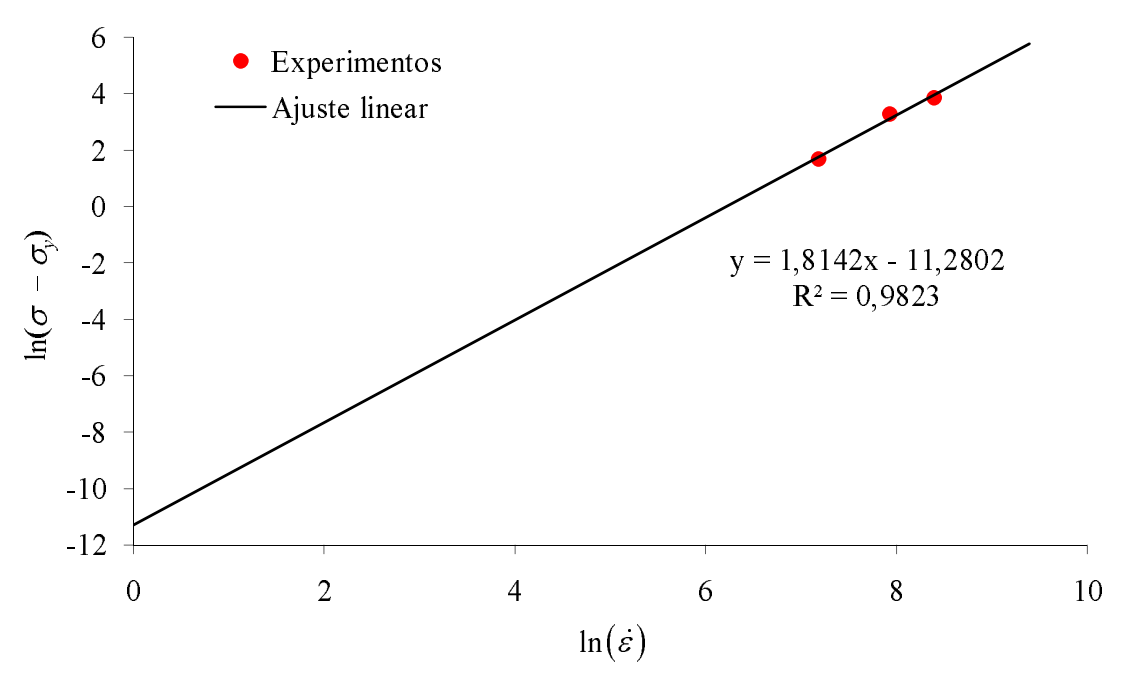

Figura 5.17: Ajuste dos parâmetros de CS para o material M2. Corpos de prova: anéis.

Os valores dos coeficientes de CS, $V_{k}$ e $V_{m}$, são apresentados na Tabela 5.3. 
Tabela 5.3: Parâmetros dos modelos de Johnson-Cook (JC) e Cowper-Symonds (CS). Corpos de prova: anéis.

\begin{tabular}{|c|c|cccc|}
\hline Material & JC & \multicolumn{4}{|c|}{ CS } \\
& $\boldsymbol{C}$ & $\boldsymbol{V}_{k}(\mathrm{MPa} \cdot \mathrm{s})$ & $\boldsymbol{V}_{m}$ & $\boldsymbol{Q}\left(\mathrm{s}^{-1}\right)$ & $\boldsymbol{p}$ \\
\hline \hline M1 & 0,014333 & 15,0187 & 0,2308 & $1,8990 \cdot 10^{6}$ & 4,3324 \\
M2 & 0,003858 & $1,2620 \cdot 10^{-5}$ & 1,8142 & $1,5412 \cdot 10^{4}$ & 0,5512 \\
\hline
\end{tabular}

\subsection{COMPARAÇÃO ENTRE OS MODELOS DINÂMICOS}

Na seleção do melhor modelo para representar o comportamento dinâmico dos materiais, a reconstrução das curvas com os parâmetros obtidos é de muito auxílio. Desta maneira, para o material M1, as Figuras 5.18 e 5.19 apresentam as curvas dos dois modelos utilizados.

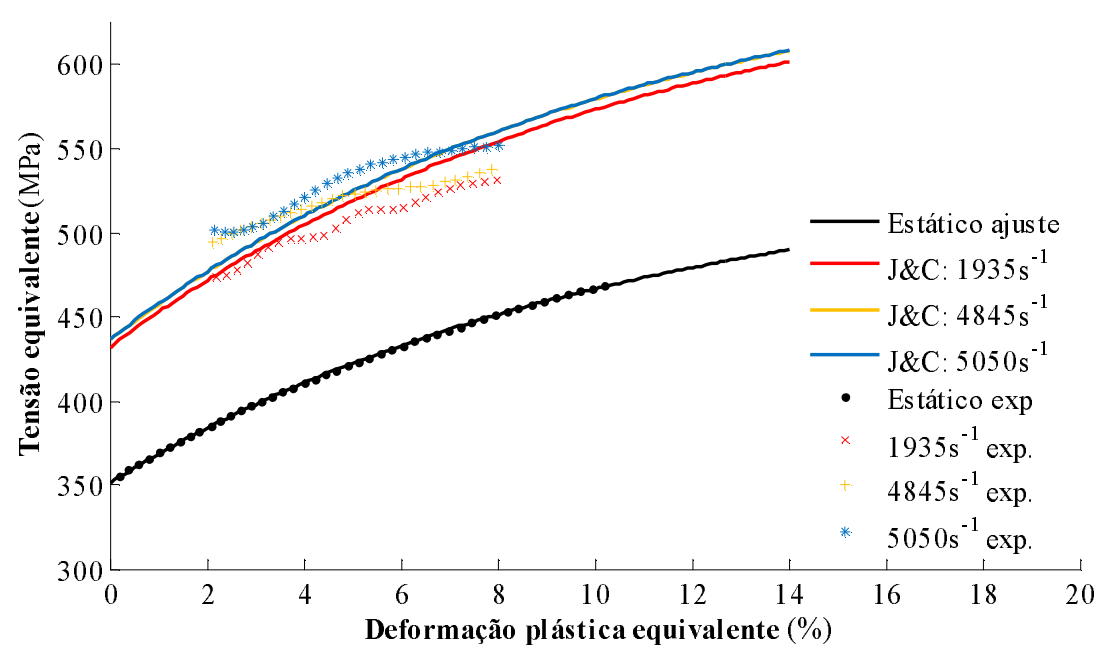

Figura 5.18: Curvas reconstruídas pelo modelo de JC para o material M1. Corpos de prova: anéis.

Nas Figuras 5.20 e 5.21 são reconstruídas as curvas para o material M2 dos modelos de JC e CS, respectivamente.

Analisando as curvas, percebe-se que o modelo de CS, para ambos os materiais, se adequou melhor aos dados experimentais. O modelo de JC proporcionou um incremento quase que constante, independentemente da taxa de deformação, o que não ocorreu de maneira tão rigorosa nos testes experimentais. Acredita-se que, numa caracterização com taxas de deformação variando de uma ou duas ordens de grandeza, seja mais adequada a utilização do modelo de JC, devido ao termo logarítmico empregado na variável $\dot{\varepsilon}$. 


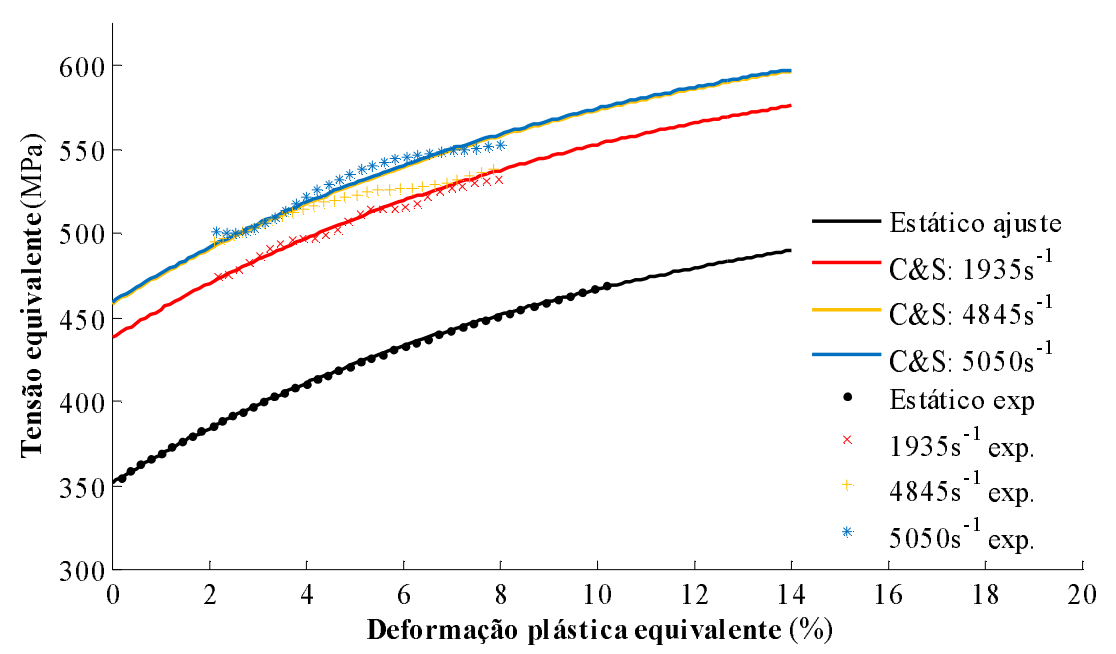

Figura 5.19: Curvas reconstruídas pelo modelo de CS para o material M1. Corpos de prova: anéis.

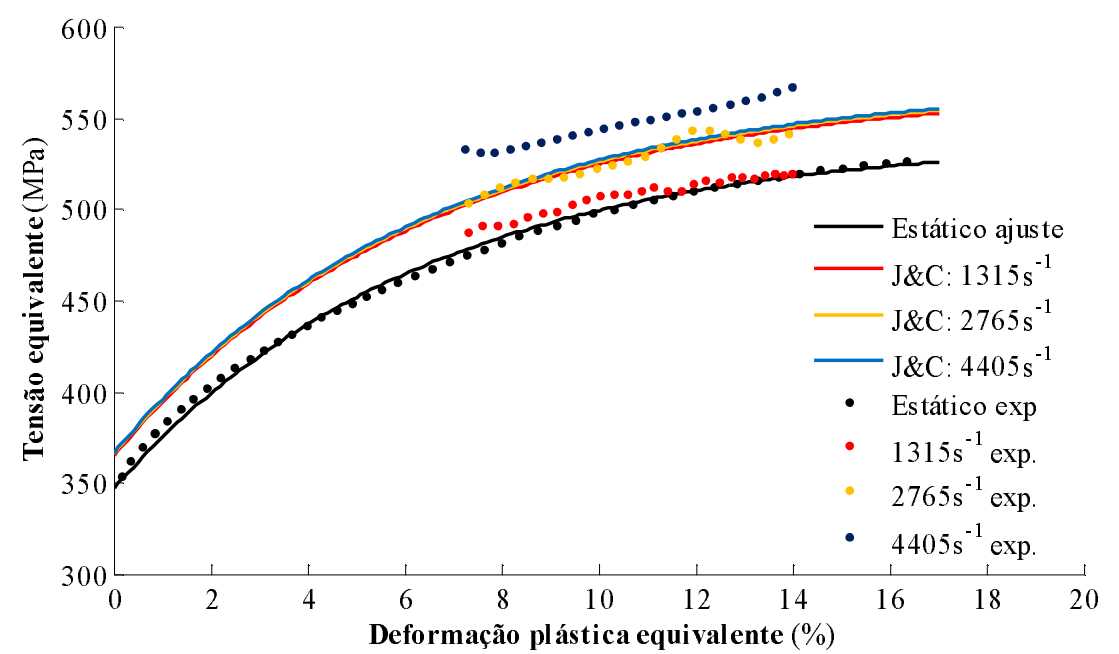

Figura 5.20: Curvas reconstruídas pelo modelo de JC para o material M2. Corpos de prova: anéis. 


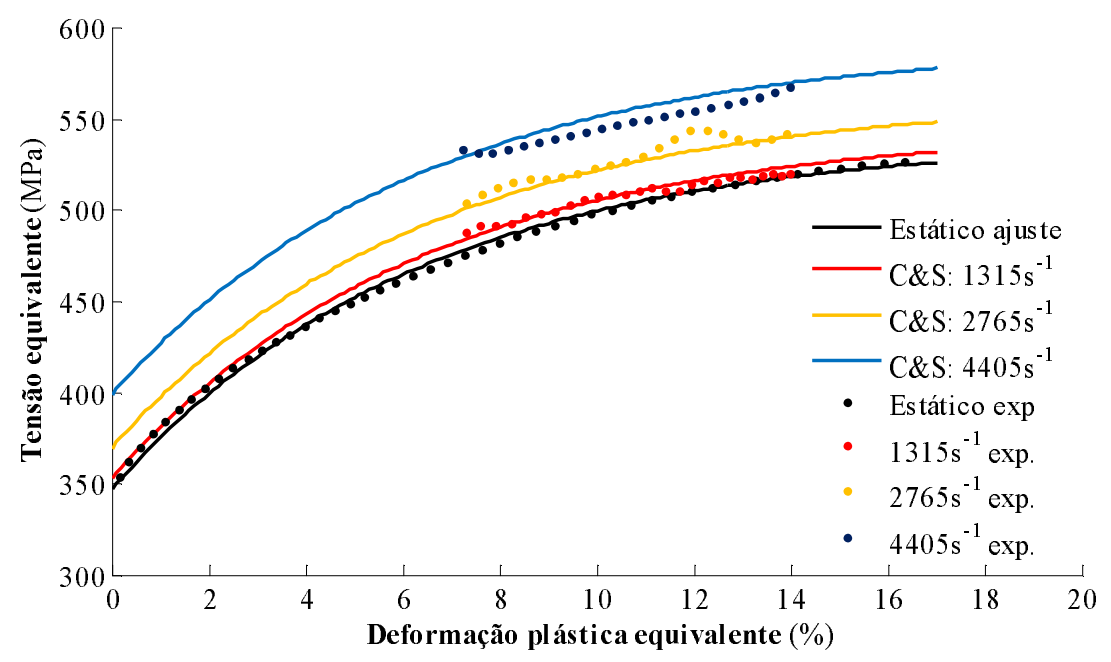

Figura 5.21: Curvas reconstruídas pelo modelo de CS para o material M2. Corpos de prova: anéis. 


\section{IMPACTO EM CHAPAS}

O impacto em estruturas é um fenômeno que compreende uma ampla gama de conceitos não triviais, como não-linearidades, efeitos de inércia, contato, efeitos de taxa de deformação do material, flambagem e propagação de ondas elásticas e plásticas.

Adicionando-se os aspectos de falha do material e penetração, tem-se a conjuntura na qual os testes experimentais realizados neste trabalho se inserem. Podendo, aparentemente, ser visto com um problema simples, o estudo do impacto de uma esfera rígida contra uma chapa fina circular e engastada revela a presença de um inter-relacionamento dos fatores acima, o que se torna evidente quando da etapa de representação numérica do fenômeno.

O objetivo de se realizar os testes de impacto em chapas de ligas de alumínio aeronáuticas foi estudar os fatores envolvidos na perfuração destas estruturas, de ampla empregabilidade na aviação e, portanto, de grande relevância na sociedade atual. Adiciona-se a isto a necessidade de se obter dados de referência para avaliação da importância da caracterização dinâmica do material, na representação numérica do fenômeno. O interesse na utilização de ligas de alumínio em estruturas leves de proteção é cada vez maior e a quantidade de investigações experimentais e numéricas ainda é pequena (Borvik et al. (2005)). De forma a se quantificar os parâmetros de comparação entre as metodologias de caracterização mecânica, duas grandezas foram escolhidas: primeiro, a velocidade balística, ou seja, a velocidade de transição entre a perfuração parcial, onde a chapa falha, mas a esfera ricocheteia, e a perfuração total, na qual a esfera atravessa completamente a chapa; e posteriormente, o deslocamento máximo permanente sofrido pela chapa após o impacto sem falha de material, portanto sem perfuração.

Este capítulo apresenta a parte experimental do estudo do impacto de chapas, que consiste, inicialmente, de um teste para captação de suas freqüências naturais e do amortecimento estrutural, necessários para determinação de parâmetros para a análise numérica. $\mathrm{Na}$ etapa de obtenção da velocidade balística, vários testes experimentais necessitaram ser realizados de forma a buscar a transição entre perfuração parcial e total. Finalizando os testes experimentais, têm-se os casos de não perfuração, que consistem em realizar o experimento físico e medir o deslocamento máximo obtido na região do impacto, após verificação da não ocorrência de fratura na chapa.

De modo a facilitar a compreensão do assunto, a Revisão Bibliográfica apresentada aqui engloba não somente a área de experimentos físicos, como também aspectos das simu- 
lações numéricas do Capítulo 7, visto que, normalmente, o problema é atacado das duas formas nos trabalhos encontrados na literatura.

\subsection{REVISÃO BIBLIOGRÁFICA}

Presente em todo contexto relacionado à segurança estrutural de aeronaves e veículos blindados, o impacto em chapas é um tema ainda não compreendido em sua plenitude. Conforme afirmam Gupta, Iqbal e Sekhon (2006), resultados obtidos por pesquisadores, a partir de configurações pouco diferentes, têm se verificado conflitantes. Isto evidencia que o impacto em chapas metálicas é extremamente sensível à variação dos parâmetros envolvidos, tais como condições de contorno, material, geometrias do projétil e chapaalvo e velocidade de impacto. Essa sensibilidade se intensifica na representação numérica do fenômeno, onde a dependência da malha é claramente observada nos resultados computacionais.

Em estudo numérico e experimental, Gupta, Iqbal e Sekhon (2006) analisaram a influência da forma do projétil no impacto de chapas de alumínio de $1 \mathrm{~mm}$ de espessura. Projéteis cilíndricos de ponta plana apresentaram menor velocidade balística que os de ponta hemisférica. A velocidade residual, ou seja, a velocidade do projétil após perfuração total, também foi analisada e os resultados mostraram que, para velocidades de impacto acima de $100 \mathrm{~m} / \mathrm{s}$, não há diferenças significativas entre os dois formatos de ponta. Nas simulações com o programa ABAQUS 6.3, os resultados obtidos para a predição das velocidades residuais ficaram de acordo com os testes experimentais. Entretanto, na determinação da velocidade balística, os resultados numéricos se distanciaram de 8,2\% a 10\%, nos caso de ponta hemisférica e plana, respectivamente, o que foi considerado bom pelos autores.

Esse percentual de discrepância para as velocidades balísticas também foi o obtido por Borvik et al. (1999) trabalhando com painéis de aço Weldox 460 E e projéteis cilíndricos de ponta plana. Os autores formularam e implementaram, no programa LS-DYNA, um modelo constitutivo acoplado de visco-plasticidade e dano, com o propósito de melhor representar os fenômenos envolvidos durante a penetração de chapas metálicas. Um programa completo de caracterização do material foi realizado, envolvendo a busca não somente das curvas tensão-deformação para grandes deformações, altas taxas de deformação e temperaturas, mas também do dano acumulado e do modo de falha. Uma série de experimentos foi conduzida, determinando a curva limite balístico da chapa de aço de $12 \mathrm{~mm}$ de espessura. Essa curva representa a variação da velocidade residual com a velocidade de impacto e tem seu início a partir da velocidade balística. A curva numérica 
se aproximou mais da experimental, à medida que a velocidade de impacto aumentou, se afastando da velocidade balística. Os autores ainda salientaram a necessidade da avaliação da sensibilidade dos resultados numéricos, frente a variações em constantes do material e tamanho de malha, e dos resultados experimentais, quando da mudança na espessura da chapa e na geometria da ponta do projétil.

Testes com projéteis de pontas hemisférica e cônica foram adicionados ao estudo anterior em Borvik et al. (2002), com chapas de mesmo material e espessura. Neste trabalho experimental, foi evidenciado que a forma da ponta do projétil afeta significantemente o mecanismo de absorção de energia e o modo de falha da chapa durante a penetração. Uma menor velocidade balística foi encontrada para projéteis de ponta plana que para os outros formatos, entre os quais não houve diferença. A curva velocidade residual versus velocidade de impacto também é influenciada pelo formato do projétil, conforme pode ser observado na Figura 6.1. Quando se aumenta a velocidade de impacto acima da balística, as curvas da velocidade residual do projétil para pontas hemisférica e plana se aproximam, seguindo uma mesma tendência. Por outro lado, a curva do projétil de ponta cônica excede as outras duas.

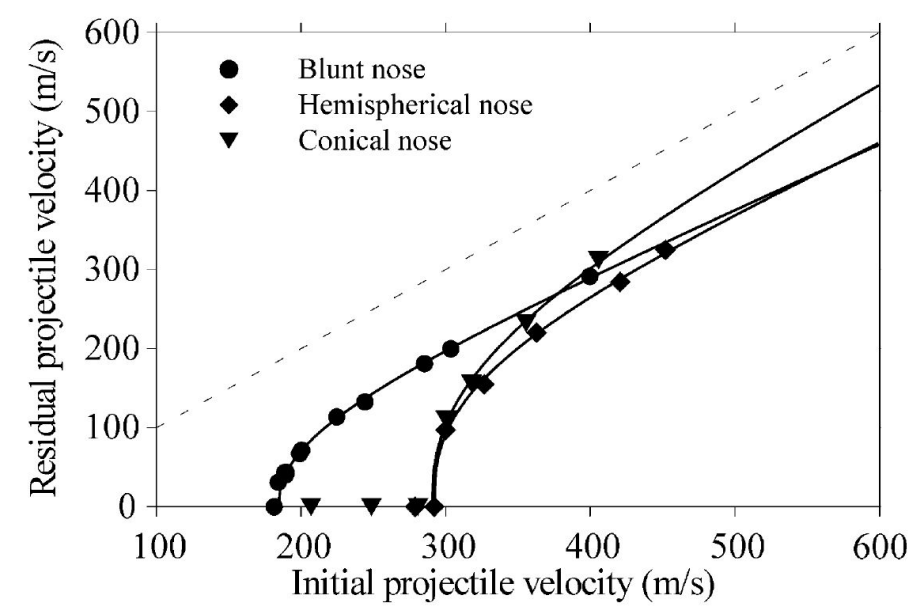

Figura 6.1: Curvas de velocidade residual para projéteis com diferentes tipos de ponta (BORVIK et al., 2002).

Utilizando o programa LS-DYNA, Borvik et al. (2002) simularam esses testes com chapas de aço e boas correlações foram encontradas entre os resultados numéricos e experimentais, $10 \%$ e $2 \%$ para os projéteis de ponta plana e hemisférica, respectivamente. Apenas após a inclusão de uma malha adaptativa é que foi possível obter bons resultados numéricos (4\% de diferença), com projéteis de ponta cônica. 
Sciuva, Frola e Salvano (2003) estudaram o comportamento à penetração de painéis de ligas de níquel IN718, impactados a baixas $(6-7 \mathrm{~m} / \mathrm{s})$ e altas velocidades $(250-550 \mathrm{~m} / \mathrm{s})$. Um projétil de aço de ponta esférica, no caso de velocidades baixas, impactou chapas de 170 x 170mm, com espessuras de 5,5mm e 11,95mm, fixadas por quatro pontos de solda. Sinais de deformação foram adquiridos por extensômetros colados nas chapas e os correspondentes numéricos indicaram uma boa correlação, principalmente no início do impacto. Os pesquisadores concluíram que, devido à diferença de inércia dos dois corpos envolvidos, a penetração do identador ocorre através de pequenos impactos, uma vez que evidenciaram numericamente pequenos intervalos de tempo com força de contato nula. Várias espessuras de chapa foram utilizadas na busca da menor espessura que, sob o impacto de uma determinada energia cinética, a altas velocidades, impedisse a penetração do projétil cilíndrico de ponta plana. A curva experimental da mínima espessura versus a energia cinética de impacto foi então construída para a liga de níquel IN718. Neste caso de altas velocidades, as chapas foram simplesmente apoiadas e a representação numérica contou com elementos sólidos e de casca. Qualitativamente, as simulações numéricas com elementos sólidos apresentaram melhores resultados.

Ligas de níquel são comumente utilizadas como reforço em estruturas de material cerâmico que revestem palhetas e a parte interna de turbinas, onde é constante a ocorrência de impactos de fragmentos do rotor. A resistência de painéis das ligas NiAl monocristalina e eutética ao impacto de esferas de alumínio de diâmetro variando de 1,6mm a 3,2mm foi estudada experimentalmente por Walston, Darolia e Demania (1997). Os testes foram conduzidos à temperatura de $980^{\circ} \mathrm{C}$, com e sem revestimento térmico no painel. Os resultados indicaram que estas camadas de revestimento não interferem no processo de absorção de energia de impacto. A faixa de velocidades balísticas encontrada mostrou que a liga NiAl testada pode ser aplicada em partes fixas da turbina, onde a velocidade dos fragmentos é menor, determinada apenas pelo fluxo do gás.

Materiais compostos de alta relação resistência/peso têm sido analisados experimental (HORSFALL; AUSTIN; BISHOP, 2000; JOVICIC; ZAVALIANGOS; KO, 2000; OKAFOR et al., 2001) e numericamente (THOMSON; SCOTT, 2000; ARIAS et al., 2003; MEO et al., 2003; JOHNSON; HOLZAPFEL, 2003; BOSSAK; KACZKOWSKI, 2003), com o objetivo de substituir a utilização de metais, porém suas propriedades mecânicas podem se degradar severamente na presença de dano. O trabalho de Okafor et al. (2001) apresenta uma técnica multi-sensorial para se avaliar o dano em tempo real e poder prever com antecedência a falha em chapas de materiais compostos. Horsfall, Austin e Bishop (2000) propõem um sistema estrutural de proteção para uso aeronáutico, principalmente 
em aeronaves militares. Segundo os autores, a estrutura existente nestes veículos, composta de fibra de vidro e aramida sobre uma armação de, por exemplo, compensado, tem sua resistência à flexão triplicada e à perfuração aumentada de uma ordem de grandeza, com a adição de uma camada de fibra de carbono. A necessidade de se representar numericamente o comportamento de materiais compostos levou Hayhurst et al. (2001) a implementarem, no programa AUTODYN, um modelo de material desenvolvido para os materiais Nextel e Kevlar-epoxy, dentro de um projeto da Agência Espacial Européia (ESA). Este objetivo também foi devidamente explorado por Johnson, Pickett e Rozycki (2001) no desenvolvimento de um modelo de dano contínuo para simulação da falha, tanto da manta como na delaminação das camadas.

O interesse na utilização de ligas de alumínio em estruturas de proteção de baixo peso é cada vez maior, e a quantidade de investigações experimentais e numéricas ainda é pequena. Isto motivou o trabalho experimental descrito em (BORVIK et al., 2004) sobre a perfuração de chapas da liga de alumínio AA5083-H116 com espessura entre 15mm e 30mm. Os resultados indicaram uma relação quase linear da velocidade balística com a espessura, dentro dessa faixa utilizada, resultado este também encontrado por Riddle et al. (1996). O modelo de Recht-Ipson (IPSON, 1963) para a curva limite balístico, que exprime uma predição para a velocidade balística a partir da medição de velocidades residuais, foi aplicado e se ajustou adequadamente aos pontos experimentais. Uma comparação realizada com outros materiais testados por estes autores (BORVIK et al., 2002, 2002), indicou que, sob as condições de impacto testadas e levando-se em conta o fator massa, o alumínio é melhor absorvedor de energia cinética que o aço e muito melhor que o concreto.

O alumínio também está presente no trabalho de Palmieri et al. (2001) sobre a perfuração de estruturas espaciais por meteoritos e fragmentos orbitais. Utilizando os programas AUTODYN-2D e PAMSHOCK-3D, que permitem acoplar o método SPH (Smoothed Particles Hydrodynamics) com a malha Lagrangiana, os autores simularam testes de impacto contra painéis de dupla camada de alumínio Whipple, com velocidades de até $15 \mathrm{~km} / \mathrm{s}$. Os resultados se aproximaram das curvas balísticas experimentais obtidas pela NASA ( $\mathrm{Na}$ tional Aeronautics and Space Administration). Outros trabalhos na literatura (ADLER, 1999; LANDGRAF et al., 2004) também dão ênfase ao impacto de estruturas aeroespaciais durante a interação com meteoritos e, até mesmo, gotas de chuva.

Uma estrutura um pouco mais complexa foi utilizada em Borvik et al. (2005) na perfuração por projéteis cilíndricos de ponta ogival. Tratam-se de painéis extrudados de alumínio 
AA6005-T6, compostos por duas chapas de $6 \mathrm{~mm}$ espaçadas de $130 \mathrm{~mm}$ por um perfil $\mathrm{W}$ com almas de $3 \mathrm{~mm}$ de espessura. Velocidades próximas à mínima de penetração foram utilizadas, de modo a se levantar a curva balística da estrutura. A perfuração ocorreu pela formação de pétalas e pelo alargamento do furo nas três chapas (anterior, alma e posterior), de forma que não se evidenciou a formação de plugues. A velocidade do projétil foi monitorada por equipamentos ópticos, e uma câmera de alta velocidade fotografou a penetração. Elementos 3D foram utilizados nas simulações com o programa LS-DYNA. O erro numérico-experimental encontrado para a velocidade balística foi de apenas $3 \%$. Foi verificado também que, em comparação com uma chapa sólida de mesma capacidade de absorção de impacto, estes painéis possuem o dobro da densidade superficial e só se tornariam viáveis utilizando material de enchimento entre as almas. Atenção foi dada à comparação do comportamento ao impacto entre uma chapa única e uma estrutura formada de várias chapas sobrepostas, considerando outros trabalhos da literatura, e a conclusão é que os benefícios da substituição do bloco monolítico ainda não estão claros.

Segundo Zukas e Scheffler (2001), para chapas finas e médias $(T / D<10$, onde T é a espessura da chapa e D é o diâmetro do projétil), a divisão em camadas facilitou a perfuração das mesmas. Resultado semelhante foi encontrado por Roeder e Sun (2001) investigando experimentalmente a perfuração de estruturas laminadas de alumina/alumínio. Conforme se diminuía a espessura das lâminas, aumentava-se a profundidade de perfuração. Por outro lado, Riddle et al. (1996) não encontraram diferenças na utilização de várias camadas ou um único monobloco.

Uma das configurações exibidas por chapas submetidas a testes balísticos, principalmente quando usados projéteis de ponta cônica ou hemisférica, é a presença de pétalas que se formam a partir de rompimentos radiais que se originam da falha do material no ponto de perfuração. Um modelo analítico de representação deste fenômeno foi proposto por Wierzbicki (1999), onde a energia total absorvida, o número de pétalas e a forma final deformada da chapa puderam ser previstos a partir de parâmetros de geometria, material e carregamento. Comparando-se as predições com resultados experimentais da literatura, boas correlações foram encontradas. Outro tipo de falha, comum para projéteis de ponta plana, é o rompimento da chapa ao redor da aresta da face impactante do projétil, o que provoca a formação de um plugue que se destaca da chapa. Baseado no interesse neste tipo de falha, foi desenvolvido e implementado no LS-DYNA um modelo de material acoplado de visco-plasticidade e dano (BORVIK et al., 1999, 2001a). Simulações (BORVIK et al., 2001b) indicaram importante influência de parâmetros como tamanho do elemento e efeitos de taxa de deformação e temperatura no modelo de material. Em relação aos 
resultados de testes experimentais, o modelo proposto foi o que obteve melhores resultados comparando-se com outros testados, nos quais se suprimia algum efeito, como dano, temperatura ou taxa de deformação.

A análise dos efeitos da escolha de parâmetros de malha foi o ponto abordado em Zukas e Scheffler (2000). Os autores afirmaram que, inerentes à transformação de um problema físico em um modelo discreto, resolvido em computadores com precisão limitada, erros devido ao arredondamento e truncamento numéricos e aproximações do método de elementos finitos, incluindo modelo matemático do material, podem ser identificados e não contribuem com mais de $5 \%$ do total do erro da solução encontrada. Esta, entretanto, pode ser totalmente invalidada por erros na escolha da malha, pela falha na descrição constitutiva de aspectos físicos (tanto na escolha do modelo, quanto na obtenção de seus parâmetros), no reconhecimento de instabilidades ou de efeitos de contato das superfícies nas soluções numéricas.

Aspectos relativos à modelagem da interação que ocorre na interface entre dois materiais em contato foi o tema tratado no trabalho de Scheffler e Zukas (2000). A eliminação (erosion) de um elemento finito, que atinge determinado grau de danificação, foi apresentada como o fator fundamental na capacidade de malhas Lagrangianas de representar problemas envolvendo penetração profunda e outras situações onde o dano é altamente localizado. Porém, é ressaltado que esta técnica deve ser utilizada com cautela, pois não há conservação de energia na interface. Perdas de $4-10 \%$ em cálculos de contato foram apresentadas como valores toleráveis para a maioria dos problemas de impacto a altas velocidades.

O momento da eliminação do elemento depende do valor crítico de uma variável específica do modelo de falha utilizado. A avaliação de seis modelos de falha, em problemas de penetração a altas velocidades, foi realizada por Teng e Wierzbicki (2006), através da implementação de rotinas no programa ABAQUS/Explicit. Atenção foi dada à necessidade de uma adequada calibração dos parâmetros dos modelos escolhidos, realizada num trabalho anterior (WIERZBICKI et al., 2005). Uma malha de elementos axissimétricos, com integração reduzida, foi utilizada para representar as chapas. Os modelos de Johnson-Cook e Bao-Wierzbicki, formulados no espaço de triaxialidade de tensões, foram os únicos capazes de predizer corretamente padrões de falha e velocidades residuais.

Uma alternativa à eliminação de elementos foi avaliada por Knight et al. (2000), interessado em representar a perfuração da fuselagem de aeronaves causada pelo desprendimento de fragmentos da turbina. Trata-se do método TNWF (tied-nodes-with-failure), 
onde nós coincidentes são criados na malha, um para cada elemento, e unidos por uma relação de restrição, a qual se extingue quando a deformação plástica efetiva, ponderada pelo volume, dos elementos que compartilham a restrição atinge um valor crítico. Deste modo é representada a iniciação de uma trinca, fratura ou penetração. Chapas quadradas de alumínio com $1 \mathrm{~mm}$ de espessura foram então modeladas com elementos de casca Belytschko-Lin-Tsay e método TNWF, e com elementos hexaédricos juntamente com o método de eliminação do elemento, para comparação de resultados. O mecanismo de fixação das chapas também foi modelado. Através das simulações com o programa LS-DYNA, o método TNWF se mostrou mais adequado à representação da falha com formação de pétalas, porém a partir de um esforço maior de pré-processamento e análise computacional. Constatou-se a necessidade de uma malha bem refinada na região do impacto, chegando-se a valores máximos para o tamanho de elemento da chapa de $20 \%$ a $25 \%$ da menor dimensão da aresta de contato do projétil.

Por ser um processo de alta velocidade, no impacto balístico os corpos se deformam rapidamente, fazendo com que o calor gerado a partir da energia plástica não consiga se dissipar durante o tempo de ocorrência do fenômeno. Trata-se, então, de um processo adiabático onde a temperatura aumenta localmente, podendo até atingir a temperatura de fusão dos materiais envolvidos, principalmente na interface destes. Em geral, este aumento de temperatura causa um amolecimento do material. A influência deste amolecimento por temperatura na penetração balística de metais foi estudada numericamente por Yadav et al. (2001) com projéteis de tungstênio e blocos de liga de alumínio 6061-T6. Segundo os autores, a utilização de um modelo de material que possua uma parcela de representação deste amolecimento é crucial na obtenção de resultados numéricos válidos. Esta conclusão é compartilhada por Kurtaran, Buyuk e Eskandarian (2003), num trabalho sobre perfuração de painéis para a blindagem de veículos militares. A influência da temperatura foi também considerada nos principais trabalhos apresentados aqui (RIDDLE et al., 1996; BORVIK et al., 1999, 2001b, 2002, 2005; GUPTA; IQBAL; SEKHON, 2006; TENG; WIERZBICKI, 2006).

\subsection{ANÁLISE MODAL E TRANSIENTE}

A resposta dinâmica transiente da chapa engastada foi realizada experimentalmente dentro do regime elástico. O objetivo foi identificar valores de variáveis que pudessem auxiliar na avaliação da posterior modelagem numérica, como o amortecimento e as freqüências naturais. 
A excitação dos modos de vibrar de uma estrutura pode ser realizada com a aplicação de um impulso, i.e. uma força aplicada num instante infinitesimal de tempo. Neste caso, um impulso foi gerado no centro da chapa através de uma leve pancada, insuficiente para causar deformação plástica, com o auxílio de um pequeno martelo de metal. O registro da vibração num determinado ponto da chapa foi obtido com a utilização de um vibrômetro POLYTEC OFV 3020, que possui um filtro analógico Bessel de 3a ordem, ajustado na freqüência de corte de $50 \mathrm{kHz}$. Os dados foram digitalizados através de uma placa de aquisição de 12bits da National Instrument para um PC. As Figuras 6.2 e 6.3 apresentam as curvas do deslocamento em função do tempo adquiridas a $750 \mathrm{kHz}$ e $100 \mathrm{MHz}$, respectivamente, onde percebe-se a atenuação da amplitude da vibração devido ao amortecimento inerente à estrutura.

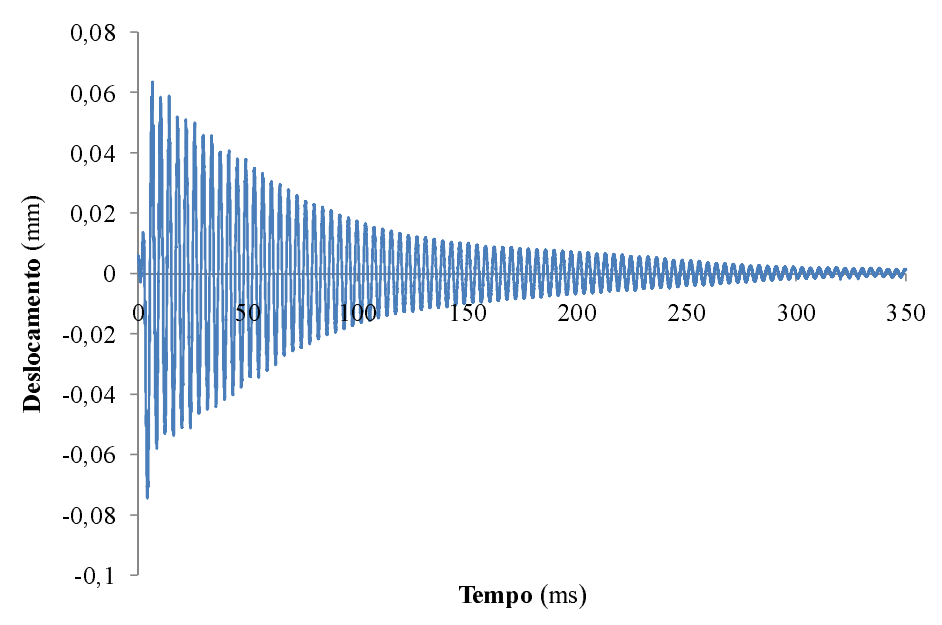

Figura 6.2: Resposta impulsiva da chapa do material M1.

As freqüências naturais desta estrutura podem ser identificadas através do cálculo da transformada de Fourier (FFT) das curvas obtidas, que permite a observação da amplitude de cada componente frequiêncial, como é mostrado nas Figuras 6.4 e 6.5. Os picos nos gráficos resultantes indicam as componentes de frequiência de maior significância. Os valores encontrados para a primeira freqüência natural amortecida, $f_{d}$, foram $263,22 \mathrm{~Hz}$ para a chapa do material M1 e 450,15Hz para a do material M2.

Para o cálculo da primeira freqüência natural, $f_{n}$, necessita-se conhecer o amortecimento da estrutura, o qual é determinado também através do histórico de deslocamento, $x(t)$, apresentado nas Figuras 6.2 e 6.3 .

O decaimento da amplitude do deslocamento segue uma função exponencial (THOMSON, 1993), de modo que o histórico deste deslocamento, $x(t)$, pode ser escrito como 


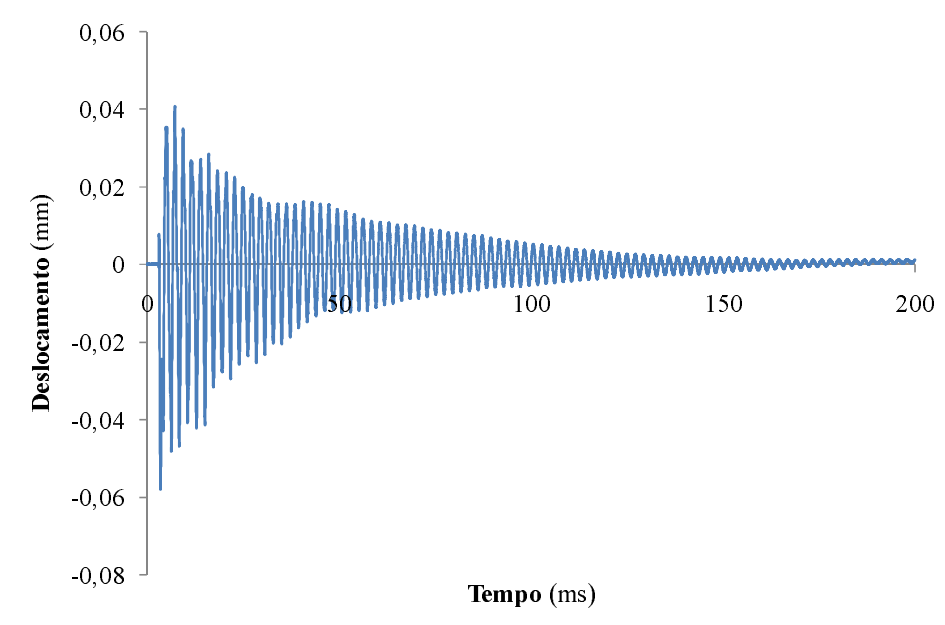

Figura 6.3: Resposta impulsiva da chapa do material M2.

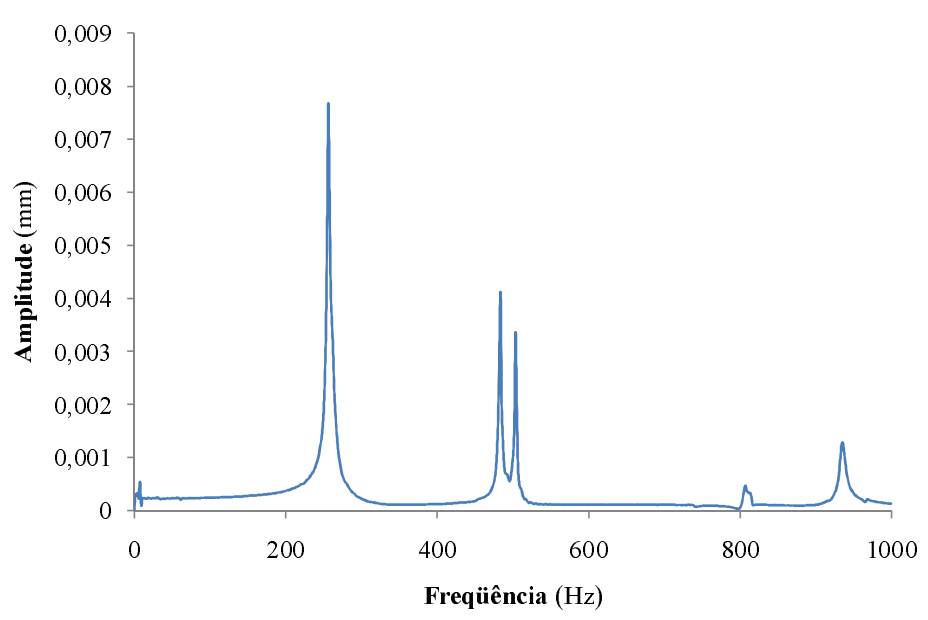

Figura 6.4: Amplitude da vibração em função da frequiência para a chapa do material M1.

$$
x(t)=X e^{-\zeta \omega_{n} t} \sin \left(\sqrt{1-\zeta^{2}} \omega_{n} t+\phi\right),
$$

onde $X$ é a amplitude máxima no instante inicial, $\omega_{n}$ é a primeira frequiência natural em radianos por segundo, $\phi$ é o ângulo de defasagem e $\zeta$ é a razão entre o coeficiente de amortecimento da estrutura, $c$, e o coeficiente de amortecimento crítico, $c_{c r i t}$. O coeficiente de amortecimento é o fator de proporcionalidade existente entre a força de amortecimento viscoso e a velocidade. Introduzindo um termo denominado decremento logarítmico, $\delta$, definido como

$$
\delta=\ln \frac{x_{1}}{x_{2}}=\ln \frac{e^{-\zeta \omega_{n} t_{1}}}{e^{-\zeta \omega_{n}\left(t_{1}+\tau_{d}\right)}}
$$




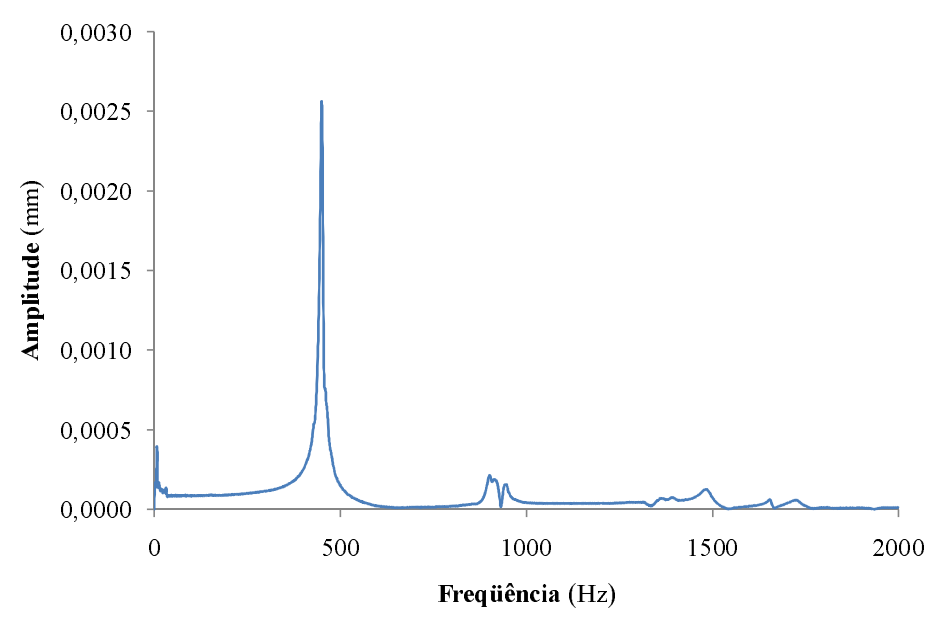

Figura 6.5: Amplitude da vibração em função da freqüência para a chapa do material M2.

que estabelece uma relação entre dois picos consecutivos, $x_{1}$ e $x_{2}$, separados pelo período $\tau_{d}=2 \pi / \omega_{n} \sqrt{1-\zeta^{2}}$, como mostra a Figura 6.6. Manipulando-se a Equação (6.2), obtémse

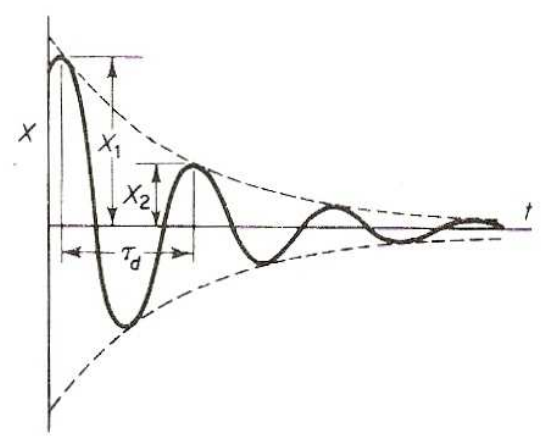

Figura 6.6: Decaimento exponencial da amplitude de vibração de uma estrutura amortecida (THOMSON, 1993).

$$
\delta=\zeta \omega_{n} \tau_{d}=\frac{2 \pi \zeta}{\sqrt{1-\zeta^{2}}}
$$

Isolando $\zeta$ na Equação (6.3) e admitindo que o amortecimento é pequeno, comum em estruturas metálicas, obtém-se

$$
\zeta \cong \frac{\delta}{2 \pi}
$$

resultando em $\zeta=0,046$ para a chapa do material M1 e $\zeta=0,074$ para a do material M2. Torna-se possível então, obter os valores das freqüências naturais, 


$$
f_{n}=\frac{f_{d}}{\sqrt{1-\zeta^{2}}},
$$

implicando em $f_{n}=263,50 \mathrm{~Hz}$ para a chapa do material M1 e $f_{n}=451,39 \mathrm{~Hz}$ para a do material M2.

\subsection{TESTES DE IMPACTO}

Os testes de impacto contra chapas de alumínio foram realizados num equipamento construído no laboratório do GMSIE-USP, com a participação do autor. Este equipamento compreende um lançador de projéteis, Figura 6.7(a), e um anteparo de grande inércia para sustentar a chapa alvo, Figura 6.7(b).

O lançador de projéteis é composto, por sua vez, de um reservatório de ar comprimido, que é alimentado por um compressor, de uma válvula de disparo, de um tubo de PVC que guia o projétil e de um módulo de controle. Esferas de aço de $20 \mathrm{~mm}$ de diâmetro e $32 \mathrm{~g}$ de massa foram aceleradas até a faixa de velocidades de $80 \mathrm{~m} / \mathrm{s}$ a 140/ms, com o auxílio de um cartucho de nylon (Figura 6.8(a)), variando-se a pressão no reservatório de ar comprimido.

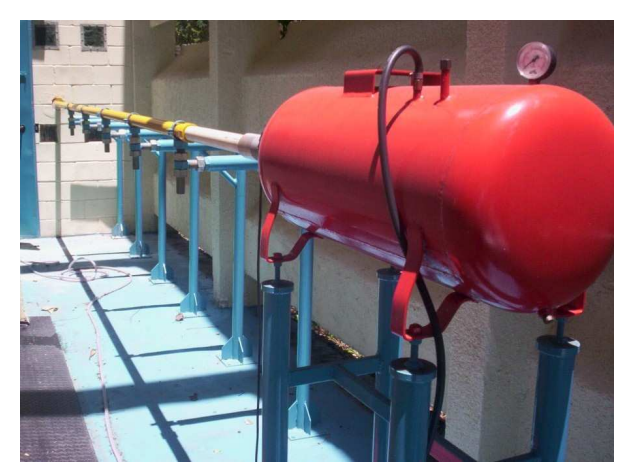

(a)

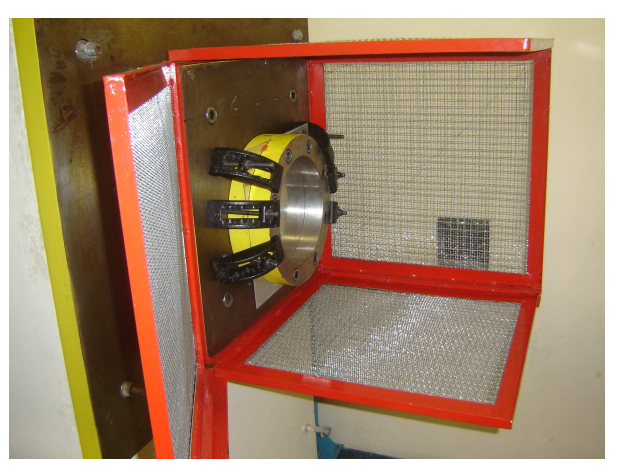

(b)

Figura 6.7: (a) Lançador de projéteis (b) e anteparo-alvo pertencentes ao GMSIE-USP.

A velocidade da esfera é controlada pela pressão do reservatório de disparo, porém, para uma medição direta e mais precisa, um cronoscópio foi instalado a um metro e meio da saída do tubo, Figura 6.8(b). Neste ponto, há um dispositivo que retém o cartucho e libera a esfera, que, somente sob a ação da força gravitacional, atinge a chapa, cerca de meio metro depois. 


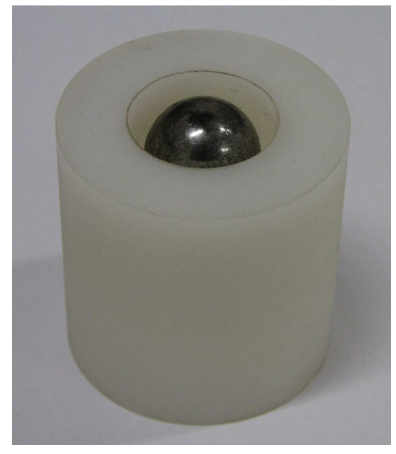

(a)

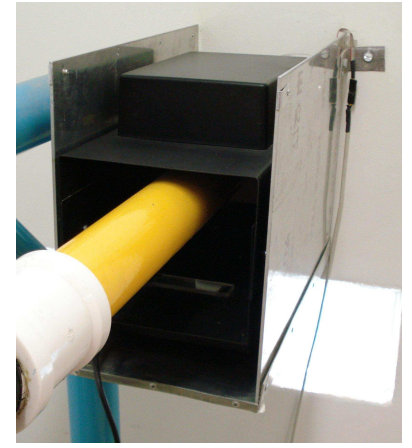

(b)

Figura 6.8: (a) Conjunto esfera e cartucho de disparo e (b) cronoscópio para medição da velocidade de impacto.

O arranjo de fixação das chapas, responsável pela condição de contorno das mesmas, é composto por dois anéis de aço, de $250 \mathrm{~mm}$ de diâmetro interno e $350 \mathrm{~mm}$ externo, que comprimem chapas quadradas de $350 \mathrm{~mm}$ de lado, Figura 6.9. Oito parafusos, apertados com uma parafusadeira pneumática a $600 \mathrm{kPa}$ (6bar), são os responsáveis pela restrição do movimento da chapa, a qual assume o comportamento de uma chapa circular engastada de $250 \mathrm{~mm}$ de diâmetro. O conjunto é preso por presilhas num anteparo de altas rigidez e inércia.

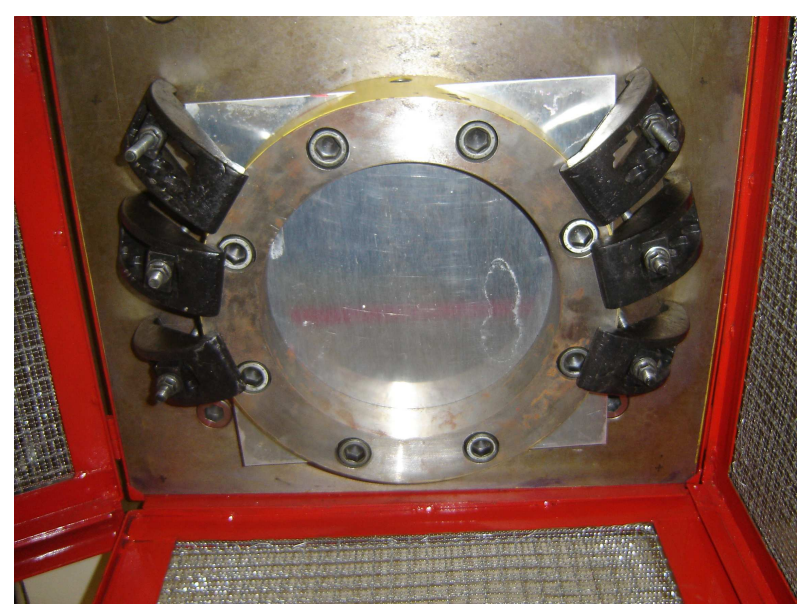

Figura 6.9: Arranjo para fixação das chapas alvo.

Uma câmera de alta velocidade também foi utilizada, porém apenas com o objetivo de se analisar qualitativamente os fenômenos e métodos empregados, principalmente no que se refere ao funcionamento do lançador de projéteis. 


\section{VELOCIDADE BALÍSTICA}

Vários testes foram realizados na busca das velocidades de início de falha e de perfuração total (velocidade balística). As Figuras 6.10 e 6.11 mostram as faixas de velocidades encontradas para cada um dos três tipos de respostas da estrutura: a primeira região, onde o impacto causa apenas deformação plástica na chapa; a região intermediária, onde ocorre falha de material, mas não o suficiente para a esfera atravessar completamente a chapa; e a terceira região, onde ocorre a perfuração total da chapa pela esfera.

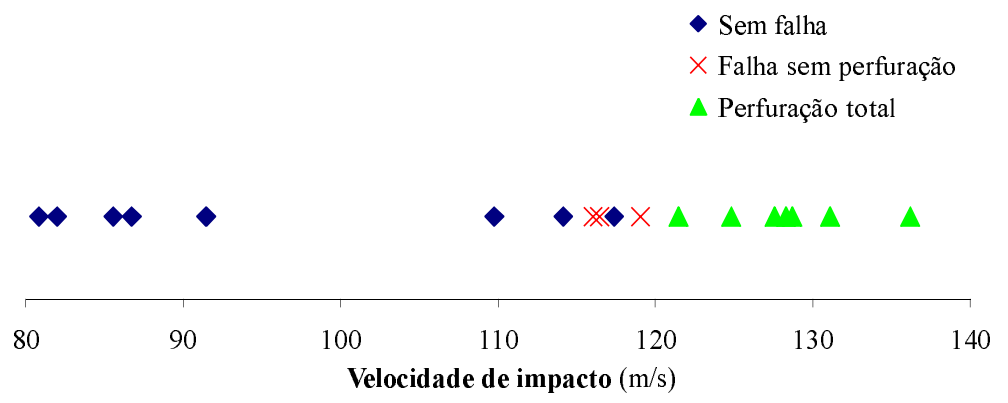

Figura 6.10: Faixa de velocidades para os três tipos de resposta estrutural, para o material M1.

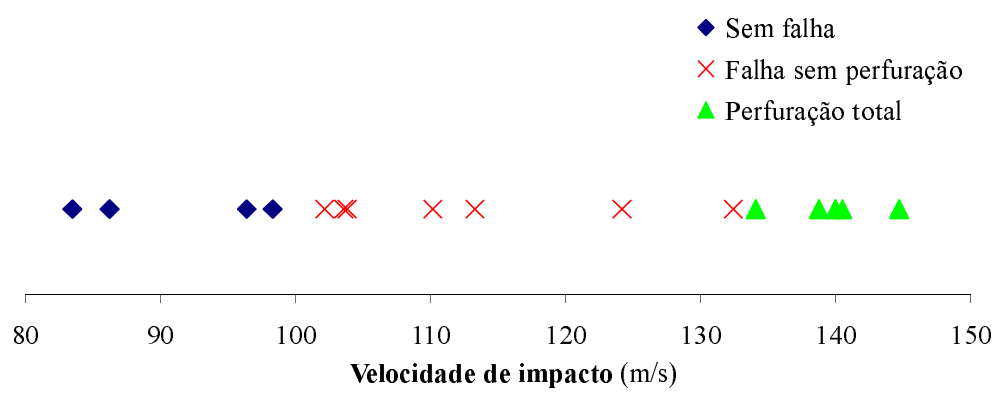

Figura 6.11: Faixa de velocidades para os três tipos de resposta estrutural, para o material M2.

Com base nos dados encontrados, pode-se definir a velocidade balística como a média entre a maior velocidade sem penetração e a menor velocidade com penetração total encontradas. A Tabela 6.1 apresenta os valores encontrados para ambos os materiais.

A falha do material é caracterizada, neste texto, pelo surgimento de uma ruptura macroscópica na região de impacto, como pode ser visto no teste de uma chapa M1 apresentado na Figura 6.12 (a) e (b). Na faixa de velocidades em que ocorre este tipo de falha, há 
Tabela 6.1: Velocidades balísticas experimentais.

\begin{tabular}{|c|c|}
\hline Material & Velocidade balística $(\mathrm{m} / \mathrm{s})$ \\
\hline \hline M1 & 120,23 \\
M2 & 133,26 \\
\hline
\end{tabular}

deformação ao longo de toda a chapa, o que é evidenciado pela flexão da mesma, que é grande na região do impacto e diminui de modo tênue até o engaste. Observou-se ser constante também, a formação de uma calota de formato esférico e de diâmetro menor que a esfera-projétil, na face anterior da chapa, ao redor do ponto central de contato (Figura $6.12(\mathrm{a}))$.

Conforme se aumenta a velocidade de impacto, a ruptura observada torna-se maior, na forma de uma trinca que se propaga circunferencialmente, até o ponto em que uma grande pétala é formada e a esfera consegue atravessar a chapa, resultando na configuração mostrada na Figura 6.12(c) e (d), típica para o material M1.

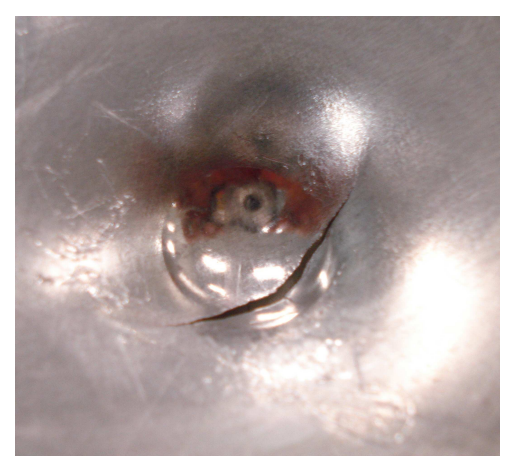

(a)

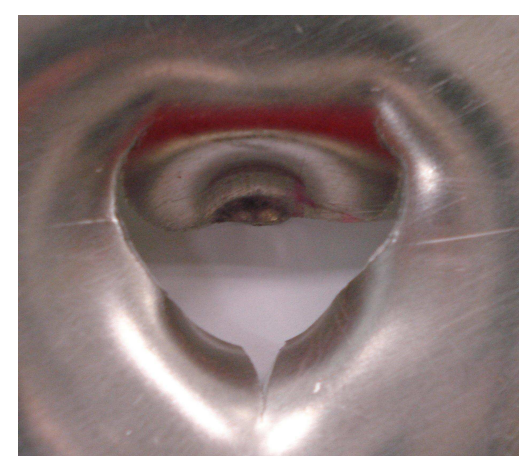

(c)

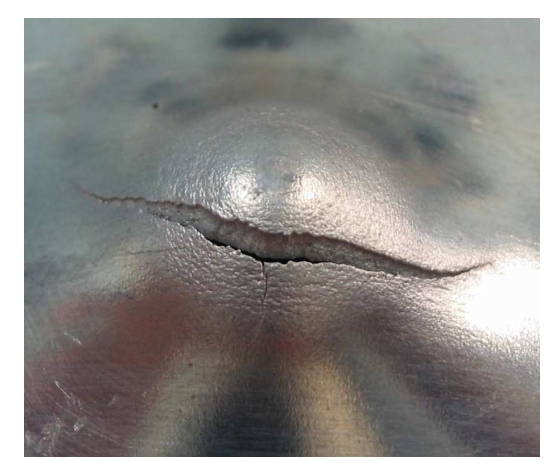

(b)

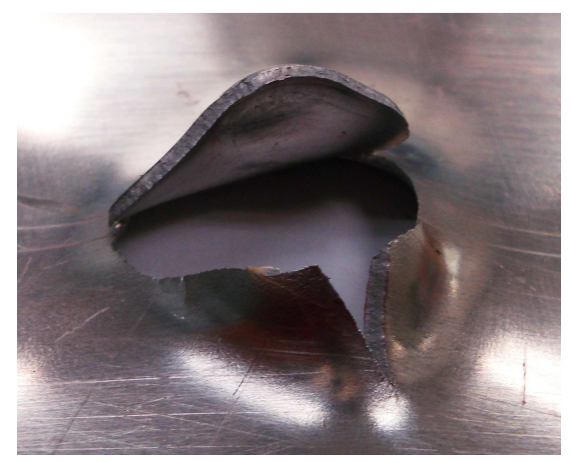

(d)

Figura 6.12: Detalhe da região de falha do material M1: falha sem perfuração a 116,0m/s, (a) vista anterior e (b) posterior; e perfuração total a $128,7 \mathrm{~m} / \mathrm{s}$, (c) vista anterior e (d) posterior. 
A falha no material M2 se deu de forma bastante similar ao M1, no caso de velocidades abaixo da balística, conforme Figura 6.13(a) e (b), a menos de uma nítida ruptura circular na parte posterior da chapa, ao redor do ponto de impacto e oposta à calota espelhada, e de uma deformação mais localizada na região de impacto. Essa ruptura circunferencial é causada pela ocorrência de bandas de cisalhamento na deformação ao longo da espessura da chapa. Considerando que as ligas testadas possuem propriedades muito próximas, pode-se então afirmar que, além do formato do projétil, a espessura das chapas também influencia no modo de falha sob impacto destas estruturas.

Nos casos de perfuração total do material M2, as bandas de cisalhamento se tornam dominantes na deformação da chapa e o rompimento circunferencial é total, proporcionando a liberação de um plugue circular na região de impacto. $\mathrm{O}$ diâmetro dos plugues obtidos foi aproximadamente constante, e o valor corresponde à metade do diâmetro da esfera. Observa-se, neste tipo de falha, uma maior concentração da deformação no local do impacto, diferentemente da falha do material M1, que apresenta uma significativa flexão de toda a chapa. Constatou-se também a presença de várias fraturas radiais, indicando o início de formação das pétalas, como apresentado na Figura 6.13(c) e (d).

Estes resultados diferenciam-se daqueles obtidos por Gupta, Iqbal e Sekhon (2006) para projéteis cilíndricos com ponta hemisférica, onde fora constatada a formação de um plugue, porém este ficava preso a uma das pétalas que se formavam. Neste trabalho, com chapas de alumínio de $1 \mathrm{~mm}$ de espessura, a liberação do plugue fora constatada apenas nos casos de projéteis com ponta plana. Entretanto, no trabalho de Borvik et al. (2002), tanto na utilização de projéteis cilíndricos de ponta hemisférica quanto de ponta plana, para chapas de aço de $12 \mathrm{~mm}$ de espessura, foi reportada a formação e liberação de plugues.

O formato do plugue encontrado por Borvik et al. (1999), um tronco de cone, cuja base maior situa-se na face posterior da chapa, não foi o observado aqui. Os plugues circulares expelidos quando da penetração das esferas no material M2 possuem formato invertido, a parte posterior apresenta um diâmetro menor que a anterior, onde há o contato com a esfera.

A ocorrência de um grande retorno elástico local foi constatada a partir dos testes de perfuração total, em acordo com os resultados de Borvik et al. (1999). Os furos deixados pelas esferas são menores do que seu diâmetro, cerca de 15\%. Deformações elásticas também foram identificadas numa forma mais globalmente distribuída, através do vídeo 
realizado com uma câmera de alta velocidade, onde se percebe uma grande vibração da chapa após o impacto.

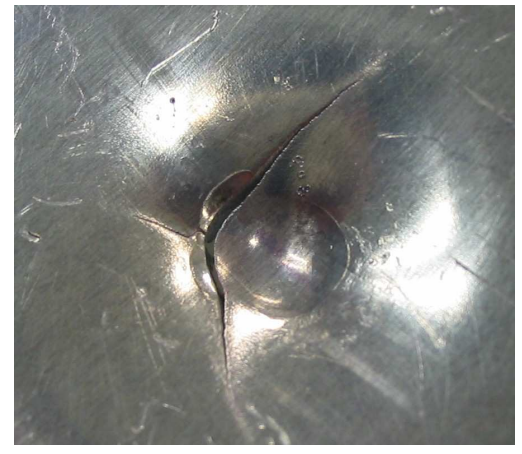

(a)

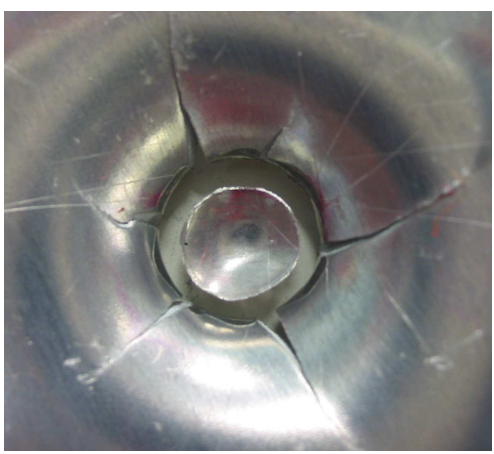

(c)

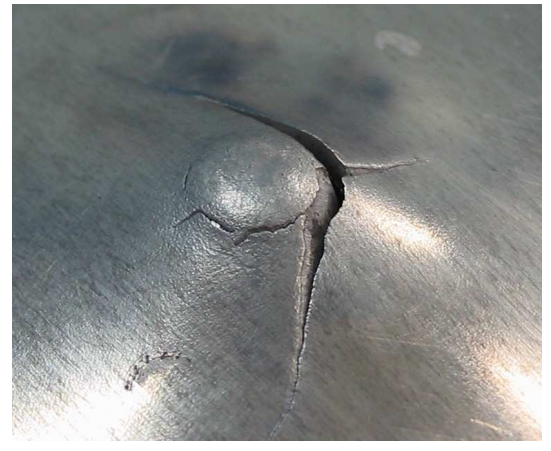

(b)

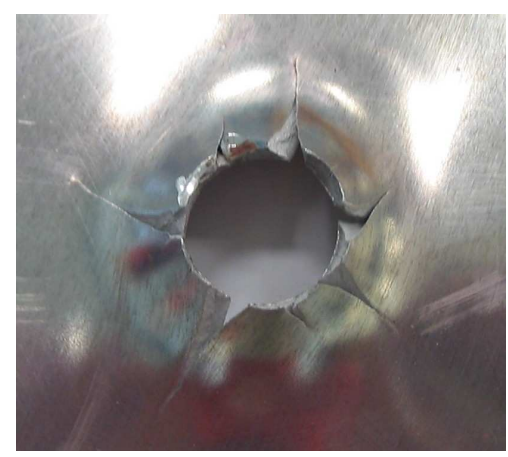

(d)

Figura 6.13: Detalhe da região de falha do material M2: falha sem perfuração a $110,2 \mathrm{~m} / \mathrm{s}$, (a) vista anterior e (b) posterior ; e perfuração total a 140,0m/s, (c) vista anterior e (d) posterior.

A formação do plugue foi uma falha típica para as chapas do material M2, mas também ocorreu uma única vez para as chapas do material M1, à velocidade de 127,5m/s, Figura 6.14. Deste modo, a predominância na deformação das bandas de cisalhamento deve ainda estar associada a outros fatores, como a velocidade de perfuração, verificando-se assim a extrema sensibilidade aos parâmetros envolvidos. É importante salientar que não houve deformação permanente nas esferas-projétil em nenhum dos testes realizados.

\section{DESLOCAMENTO MÁXIMO PERMANENTE}

Chapas testadas a velocidades próximas de $80 \mathrm{~m} / \mathrm{s}$ foram escolhidas para obtenção do deslocamento máximo permanente atingido pela chapa. Nesta faixa de velocidades, a esfera apenas causa deformação plástica, sem ocorrer falha do material, conforme pode ser observado nas Figuras 6.15 e 6.16. Esta deformação plástica ocorre com maior intensidade 


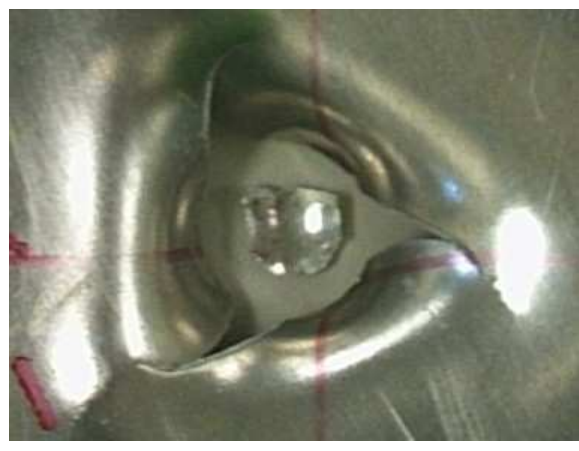

(a)

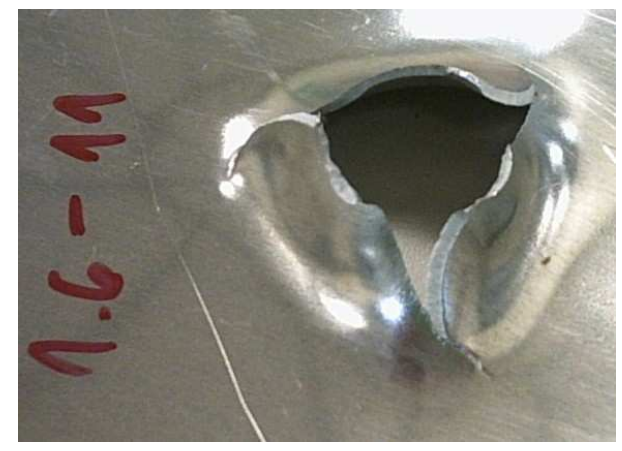

(b)

Figura 6.14: Detalhe da formação do tampão no material M1 a 127,5m/s com perfuração total, (a) vista anterior e (b) posterior.

na região de impacto, formando uma pequena calota côncava na parte anterior da chapa. Esta calota é tanto maior quanto maior a velocidade e é mais pronunciada no material M1, lembrando-se que este material compõe a chapa de menor espessura.

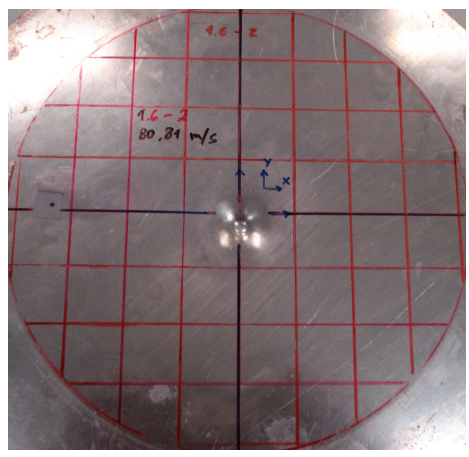

(a)

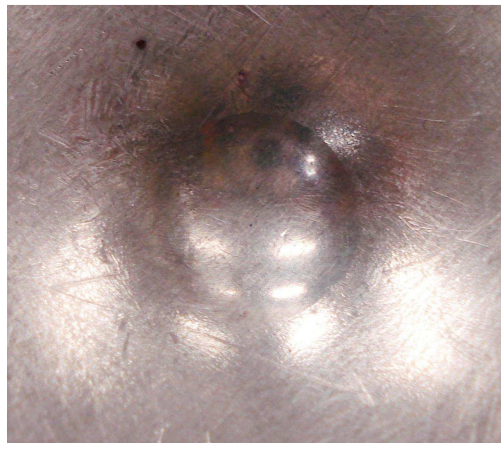

(b)

Figura 6.15: Chapa M1 testada a 80,81m/s: (a) visão geral e (b) detalhe da região impactada.

Os deslocamentos máximos foram medidos através de um relógio comparador de $0,01 \mathrm{~mm}$ de resolução, instalado numa fresadora de topo. As medições foram realizadas nos dois lados das chapas e a média dos valores foi utilizada. Os resultados encontrados de quatro testes para o material M1 e três testes para o material M2, podem ser vistos nas Figuras 6.17 e 6.18 , respectivamente. O deslocamento normalizado é composto pela divisão do deslocamento máximo pela espessura da chapa e a velocidade de impacto é normalizada pela velocidade balística obtida.

Observa-se que os pontos se ajustam bem por curvas lineares, como demonstra os valores 


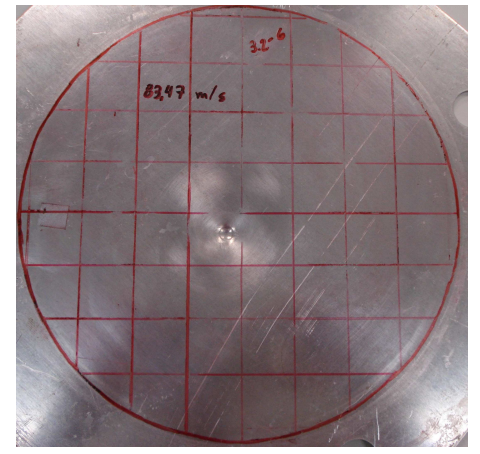

(a)

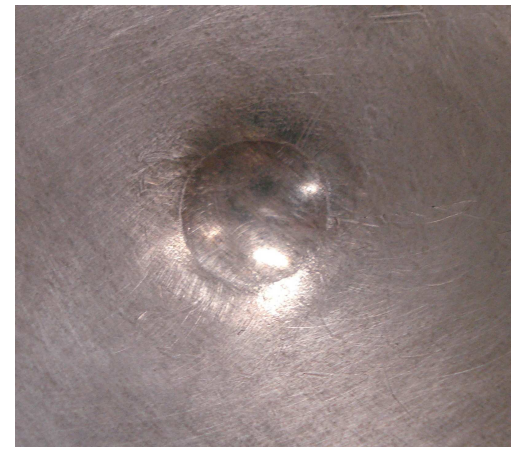

(b)

Figura 6.16: Chapa M2 testada a 83,47m/s: (a) visão geral e (b) detalhe da região impactada.

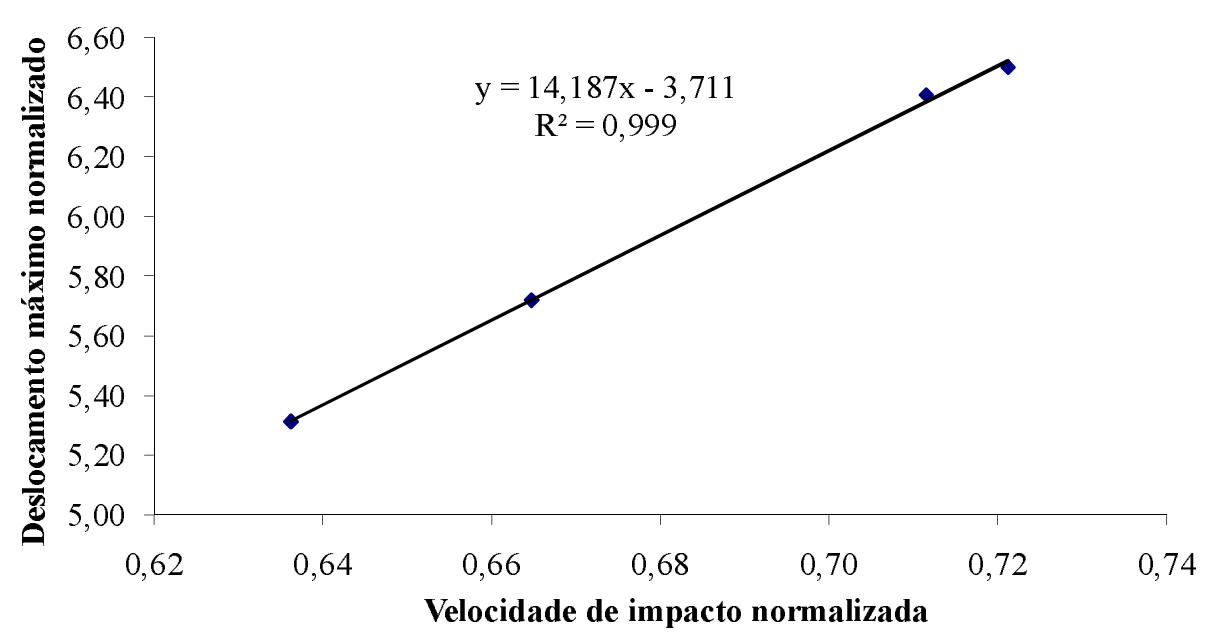

Figura 6.17: Deslocamentos máximos obtidos nos testes sem perfuração do material M1.

próximos da unidade do coeficiente de determinação da regressão linear, $R^{2}$, mostrados nas Figuras 6.17 e 6.18. Interessante notar que a posição do impacto na chapa variou entre os testes realizados, com diferenças de até $30 \mathrm{~mm}$. 


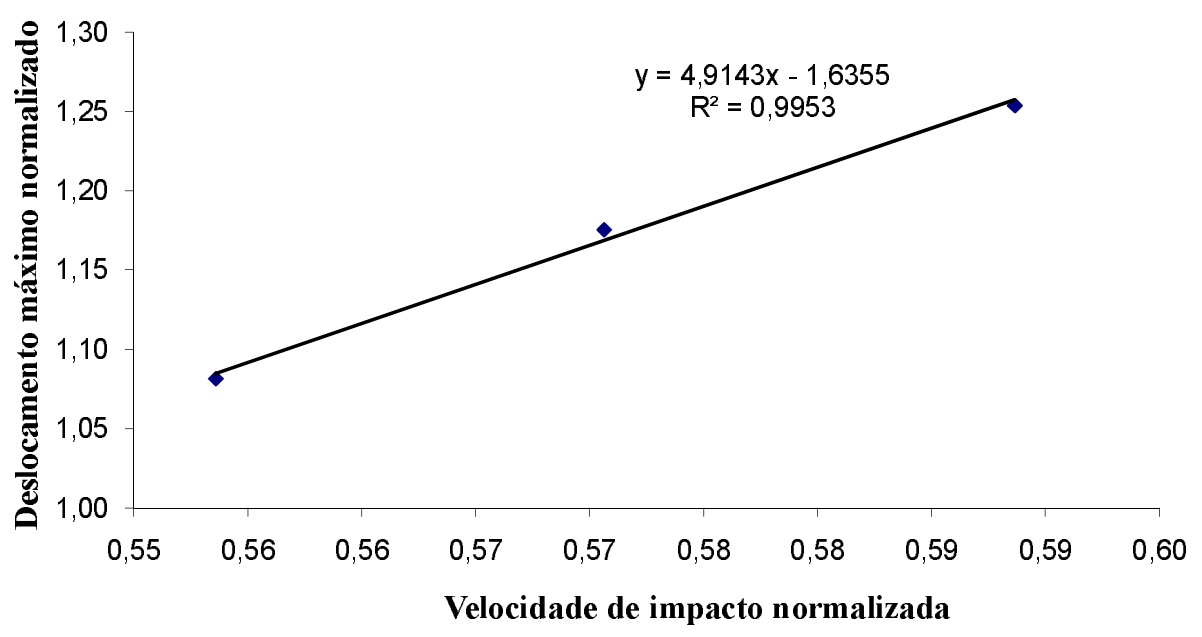

Figura 6.18: Deslocamentos máximos obtidos nos testes sem perfuração do material M2. 


\section{SIMULAÇÕES NUMÉRICAS}

A representação numérica dos testes de impacto foi realizada em elementos finitos. $\mathrm{O}$ objetivo nesta etapa foi estabelecer um modelo que se assemelhasse, da melhor forma possível, ao caso real. Deste modo, buscou-se avaliar a influência dos parâmetros do material na determinação da velocidade balística e do deslocamento máximo permanente sem fratura da chapa. Adicionalmente, a performance dos elementos de casca, axissimétricos e hexaédricos foi confrontada frente à capacidade de representação do fenômeno. O programa de elementos finitos utilizado foi o LS-DYNA em conjunto com o pré-processador HYPERMESH e com o pós-processador HYPERVIEW.

A busca da velocidade balística numérica, para cada um dos materiais, foi realizada variando-se a velocidade inicial da esfera e verificando-se, após o impacto da mesma contra a chapa, a ocorrência ou não de penetração total. No caso dos testes sem falha do material, três velocidades iniciais para cada material foram escolhidas, dentro da faixa de valores testados experimentalmente. A simulação durava até o fim da vibração da chapa, tornando possível a avaliação de seu deslocamento máximo final.

Sabe-se que a construção do modelo numérico é determinante na eficácia de se predizer o comportamento de estruturas. Buscou-se desenvolver uma modelagem adequada ao fenômeno de impacto em questão, considerando as limitações presentes no código computacional escolhido. A determinação dos parâmetros para simulação do impacto das chapas envolveu aspectos físicos, simulações preliminares e informações da literatura. Propriedades relativas aos mecanismos de vibração das chapas foram obtidas através de medições realizadas com um vibrômetro a laser, detalhadas no Capítulo 6. Parâmetros da modelagem do contato e efeitos do refinamento de malha foram obtidos na análise qualitativa e quantitativa de resultados de simulações prévias e da experiência de outros pesquisadores, relatadas em artigos científicos.

\subsection{MODELAGEM EM ELEMENTOS FINITOS}

\subsubsection{Malha}

Uma preocupação especial esteve presente em relação à dependência do tamanho dos elementos finitos nos resultados, tanto na busca da velocidade balística quanto nas simulações sem perfuração. As primeiras malhas foram criadas desconsiderando a simetria geométrica no teste, do que resultou uma análise tridimensional do fenômeno. Foram 
utilizados elementos de casca 2D, e sólidos 3D (hexaedros), para representar as chapas. A esfera impactante foi representada por uma superfície analítica. Após a definição das malhas das chapas com estes elementos e a execução de testes preliminares, optou-se por adicionar um modelo com simetria axial, através do uso de elementos finitos axissimétricos, tanto para a chapa quanto para a esfera.

Os elementos de casca foram construídos apenas com quadriláteros, de modo que, a partir de uma simples extrusão, gerou-se uma malha correspondente de elementos sólidos. A primeira e principal malha, com a qual se realizaram todos os testes preliminares, foi composta por uma região central quadriculada e outra periférica responsável pela adequação ao formato circular da borda. O refinamento desta malha na região do impacto gerou a formação de faixas de elementos de tamanhos diferentes. O número de faixas criadas definiu o nome do refinamento pela qual a malha é referenciada neste texto, e.g., uma malha com três faixas recebeu o nome de ref3. Salienta-se que, no caso tridimensional, uma equação representa a esfera, não sendo necessária sua discretização em elementos finitos.

Os dados relativos às malhas de elementos de casca utilizadas, como o tamanho de uma aresta dos elementos na região mais refinada e o número total de elementos e nós, podem ser vistos na Tabela 7.1. Esta tabela apresenta também o número de elementos na região de impacto por unidade de área do plano da chapa. A Figura 7.1 apresenta uma vista anterior das malhas ref3 e ref4.

As malhas sólidas 3D foram então construídas com a extrusão dos elementos de casca, procurando-se garantir a razão geométrica unitária para os hexaedros gerados na região mais refinada. Assim, o número de elementos ao longo da espessura ficou definido pela dimensão dos elementos 2D nesta região e pela espessura da chapa modelada. A Tabela 7.2 apresenta os dados das malhas geradas para cada um dos materiais/espessuras usadas. Utilizando uma malha com 8 elementos sólidos na espessura de 1,6mm (ref6) não foi possível obter resultados com o programa LS-DYNA, provavelmente devido à grande quantidade de elementos e nós e às limitações dos computadores disponíveis.

A partir das malhas criadas com o programa HYPERMESH, simulações preliminares testaram a influência do tamanho do elemento na determinação da velocidade balística, ou seja, da velocidade de transição entre a ocorrência ou não de perfuração. Utilizando intervalos de $5 \mathrm{~m} / \mathrm{s}$, com muitos parâmetros ainda não definitivos, foram determinadas as duas velocidades que definem a região de início da perfuração total, a menor representando a 
Tabela 7.1: Dados das malhas de elementos de casca usadas na modelagem das chapas.

\begin{tabular}{|c|cccc|}
\hline Malha & $\begin{array}{c}\text { Tamanho } \\
\text { do elemento } \\
(\mathrm{mm})\end{array}$ & $\begin{array}{c}\text { Número } \\
\text { total de } \\
\text { elementos }\end{array}$ & $\begin{array}{c}\text { Número de } \\
\text { elementos } \\
\text { por } \mathrm{mm}^{2}\end{array}$ & $\begin{array}{c}\text { Número } \\
\text { total } \\
\text { de nós }\end{array}$ \\
\hline \hline ref3 & 2,08 & 3678 & 0,23 & 3728 \\
ref4 & 1,04 & 7006 & 0,92 & 7056 \\
ref5 & 0,52 & 15534 & 3,70 & 15585 \\
ref6 & 0,26 & 41662 & 14,79 & 41712 \\
\hline
\end{tabular}

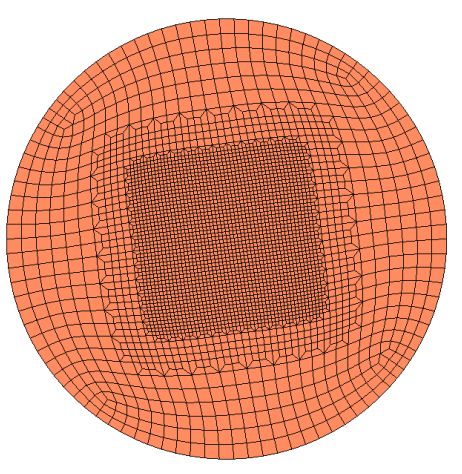

(a)

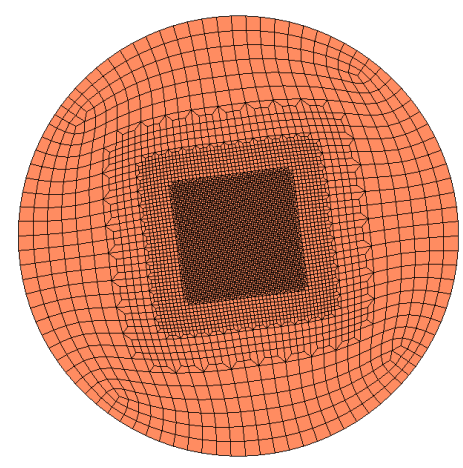

(b)

Figura 7.1: Malhas de elementos quadriláteros (a) ref3 e (b) ref4.

Tabela 7.2: Dados das malhas de elementos sólidos usadas na modelagem das chapas.

\begin{tabular}{|c|c|ccccc|}
\hline $\begin{array}{c}\text { Espessura } \\
\text { da chapa } \\
(\mathrm{mm})\end{array}$ & Malha & $\begin{array}{c}\text { Número de } \\
\text { elementos na } \\
\text { espessura }\end{array}$ & $\begin{array}{c}\text { Tamanho } \\
\text { do elemento } \\
(\mathrm{mm})\end{array}$ & $\begin{array}{c}\text { Número } \\
\text { total de } \\
\text { elementos }\end{array}$ & $\begin{array}{c}\text { Número de } \\
\text { elementos } \\
\text { por } \text { mm }^{3}\end{array}$ & $\begin{array}{c}\text { Número } \\
\text { total } \\
\text { de nós }\end{array}$ \\
\hline \hline \multirow{3}{*}{1,6} & ref3 & 1 & 2,08 & 3678 & 0,11 & 7455 \\
& ref4 & 2 & 1,04 & 14012 & 0,89 & 21166 \\
& ref5 & 4 & 0,52 & 62136 & 7,11 & 77916 \\
\hline \multirow{2}{*}{3,2} & ref3 & 2 & 2,08 & 7356 & 0,11 & 11182 \\
& ref4 & 4 & 1,04 & 28024 & 0,89 & 35276 \\
& ref5 & 8 & 0,52 & 124272 & 7,11 & 140248 \\
\hline
\end{tabular}

máxima velocidade sem perfuração e a maior representando a mínima velocidade com perfuração total. A velocidade balística é definida como a média destes dois valores. Os resultados são apresentados nas curvas da Figura 7.2, em função do número de elementos por unidade de área, no caso dos elementos de casca, e em função do número de elementos por unidade de volume, no caso dos elementos sólidos.

A comparação das velocidades balísticas presentes nas curvas da Figura 7.2 com os valores obtidos nos testes de impacto é ainda inoportuna pois, como citado, estes são resul- 


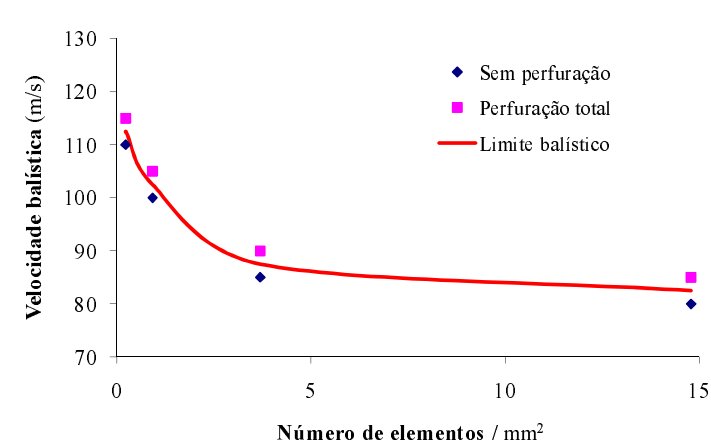

(a)

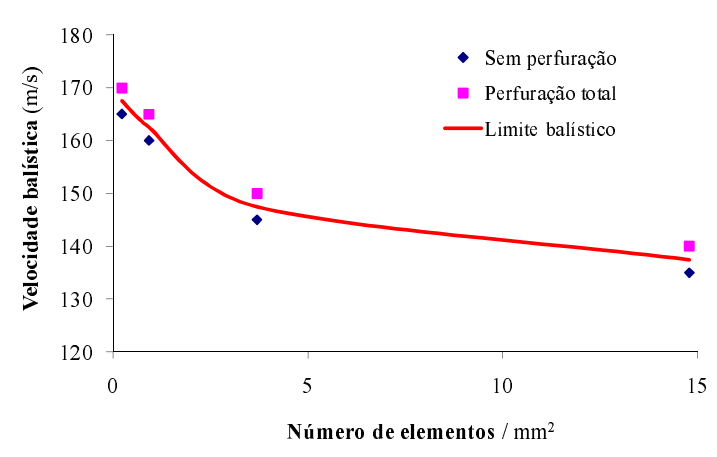

(c)

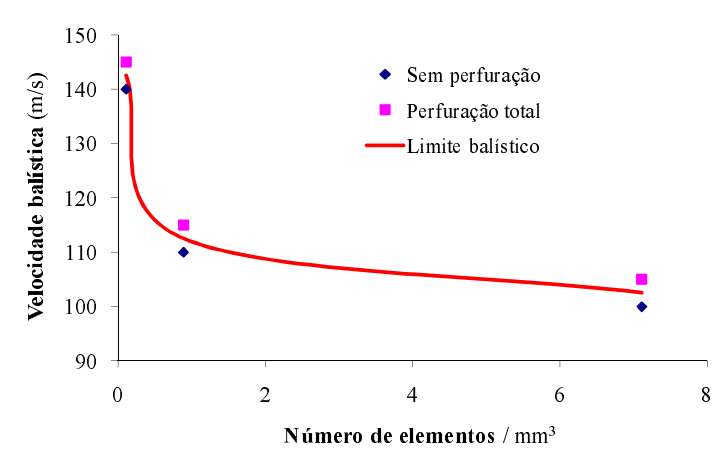

(b)

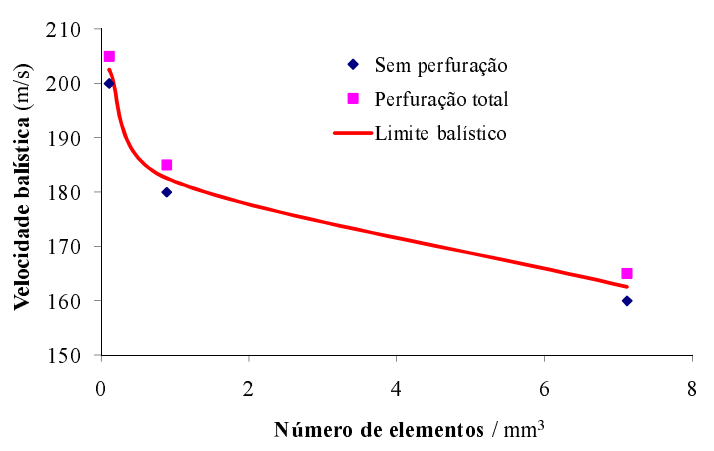

(d)

Figura 7.2: Variação da velocidade balística com o refinamento da malha. Material M1 com elementos (a) de casca e (b) sólido, e M2 com elementos (c) de casca e (d) sólido.

tados preliminares. Contudo, relativamente, pode-se observar claramente a dependência da velocidade balística com o tamanho do elemento. Adicionalmente, a modelagem por elementos 2D e 3D apresentaram resultados distintos, e.g. 18\%(M1) e 10\%(M2) de diferença entre eles na velocidade balística para a malha ref5.

A estabilização da velocidade balística com o refinamento da malha ocorreu de forma mais acentuada para o material M1 e para os elementos de casca, notando-se que não foi possível simular a malha ref6 com elementos sólidos. A malha ref5 se mostrou, então, como a mais coerente para comparação dos resultados entre estes dois tipos de elementos. Porém, em virtude da estabilização não ocorrer de forma clara em todos os casos, optouse por utilizar também a malha ref4 na simulação da velocidade balística, após a obtenção definitiva de todos os parâmetros de simulação.

A mesma análise preliminar foi realizada nas simulações sem consideração da falha do material.

Observando os gráficos da Figura 7.3, onde não há falha, o deslocamento máximo permanente, previsto com elementos de casca, praticamente independe da malha utilizada. 


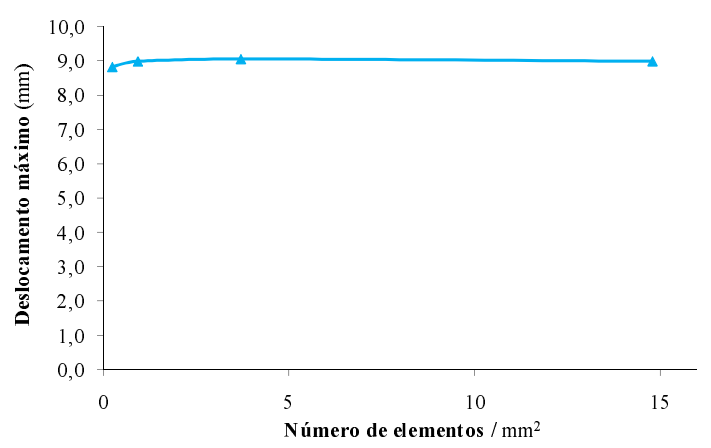

(a)

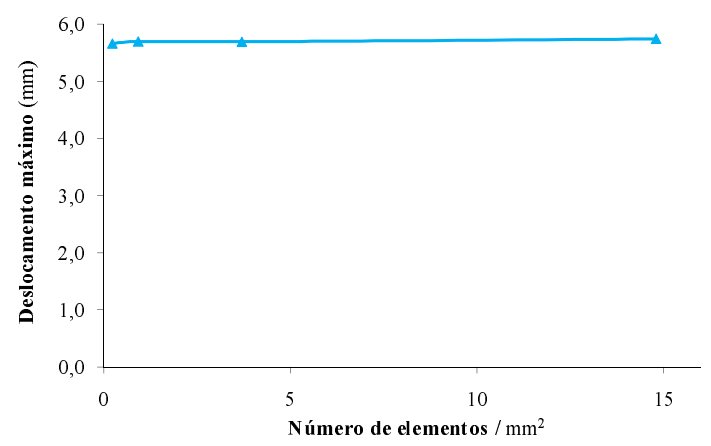

(c)

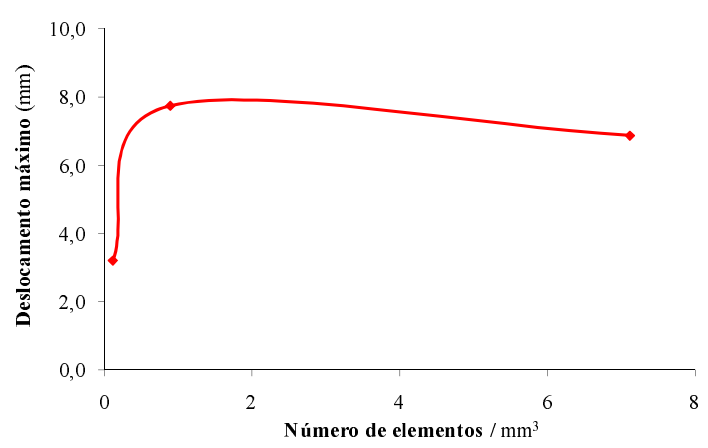

(b)

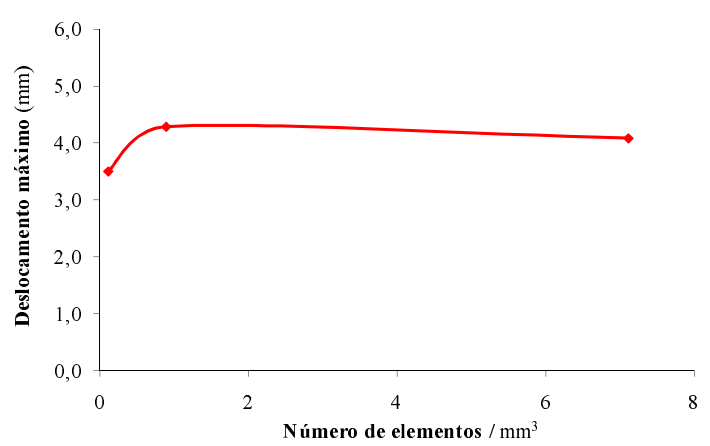

(d)

Figura 7.3: Variação do deslocamento máximo permanente com o refinamento da malha. Material M1 com elementos (a) de casca e (b) sólido, e M2 com elementos (c) de casca e (d) sólido.

Mesmo no caso de representação por elementos 3D, as diferenças entre as malhas ref4 e ref5 não foram grandes, resultando em 11,3\% e 4,7\% de diferença entre estes refinamentos, para os materiais M1 e M2, respectivamente. Deste modo, na determinação numérica do deslocamento máximo permanente da chapa sem perfuração, que corresponde à simulação que demanda maior tempo de processamento, apenas a malha ref5 será utilizada.

Realizada esta análise inicial da influência do tamanho do elemento na velocidade balística, na representação tridimensional do impacto, optou-se por averiguar a resposta de uma malha construída assumindo-se uma simetria axial do problema. Uma representação bidimensional do fenômeno foi então criada com a geração de uma malha de elementos axissimétricos cujo tamanho destes se aproximou ao da malha ref6. A Tabela 7.3 apresenta as características deste modelo, cuja configuração é apresentada na Figura 7.4(a) para a chapa do material M1 e na Figura 7.4(b) para o material M2.

Observa-se que, diferentemente dos outros casos, a malha é construída sobre uma geometria correspondente à vista lateral em corte da esfera e da chapa. Portanto, a quinta coluna da Tabela 7.3 apresenta a quantidade de elementos por unidade de área na seção 
transversal e não no plano da chapa, como nos elementos de casca. Na região do impacto, o tamanho do elemento é fixo, conforme o apresentado na Tabela 7.3, e à medida que se aproxima da borda, a aresta axial do elemento aumenta linearmente. A esfera foi modelada com elementos rígidos, num total de 122 nós e 170 elementos, com a única preocupação de que os elementos da superfície de contato tivessem seu tamanho próximo ao dos elementos da chapa para evitar problemas de contato.

Tabela 7.3: Dados da malha de elementos axissimétricos usada na modelagem das chapas.

\begin{tabular}{|c|c|cccc|}
\hline $\begin{array}{c}\text { Espessura } \\
\text { da chapa } \\
(\mathrm{mm})\end{array}$ & Malha & $\begin{array}{c}\text { Tamanho } \\
\text { do elemento } \\
(\mathrm{mm})\end{array}$ & $\begin{array}{c}\text { Número } \\
\text { total de } \\
\text { elementos }\end{array}$ & $\begin{array}{c}\text { Número de } \\
\text { elementos } \\
\text { por } \mathrm{mm}^{2}\end{array}$ & $\begin{array}{c}\text { Número } \\
\text { total } \\
\text { de nós }\end{array}$ \\
\hline \hline 1,6 & ref6 & 0,2 & 1360 & 25 & 1539 \\
3,2 & ref6 & 0,2 & 2720 & 25 & 2907 \\
\hline
\end{tabular}

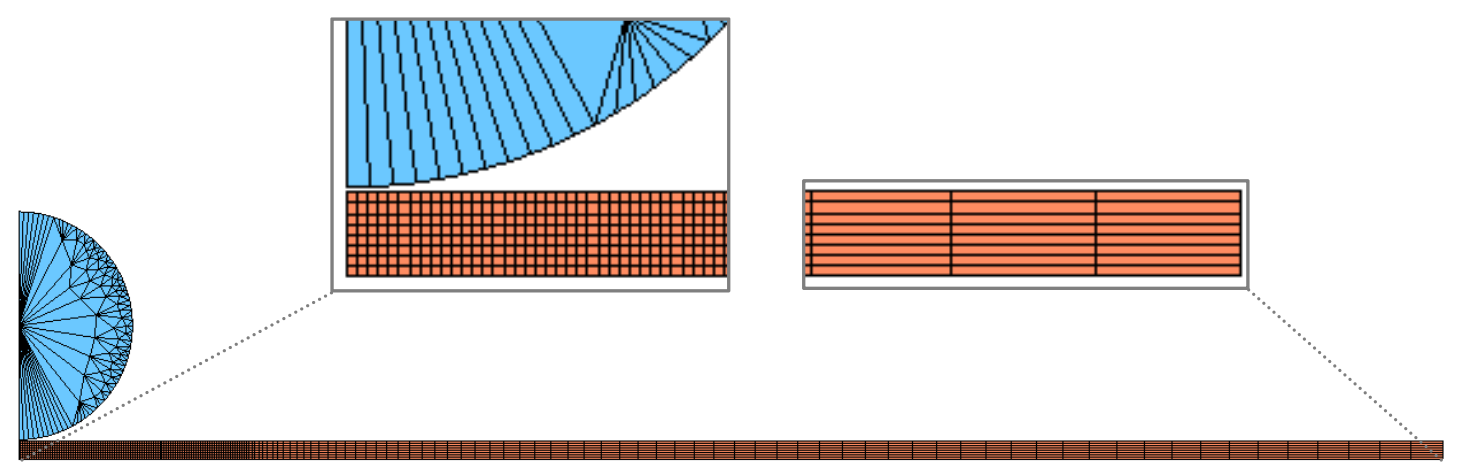

(a)

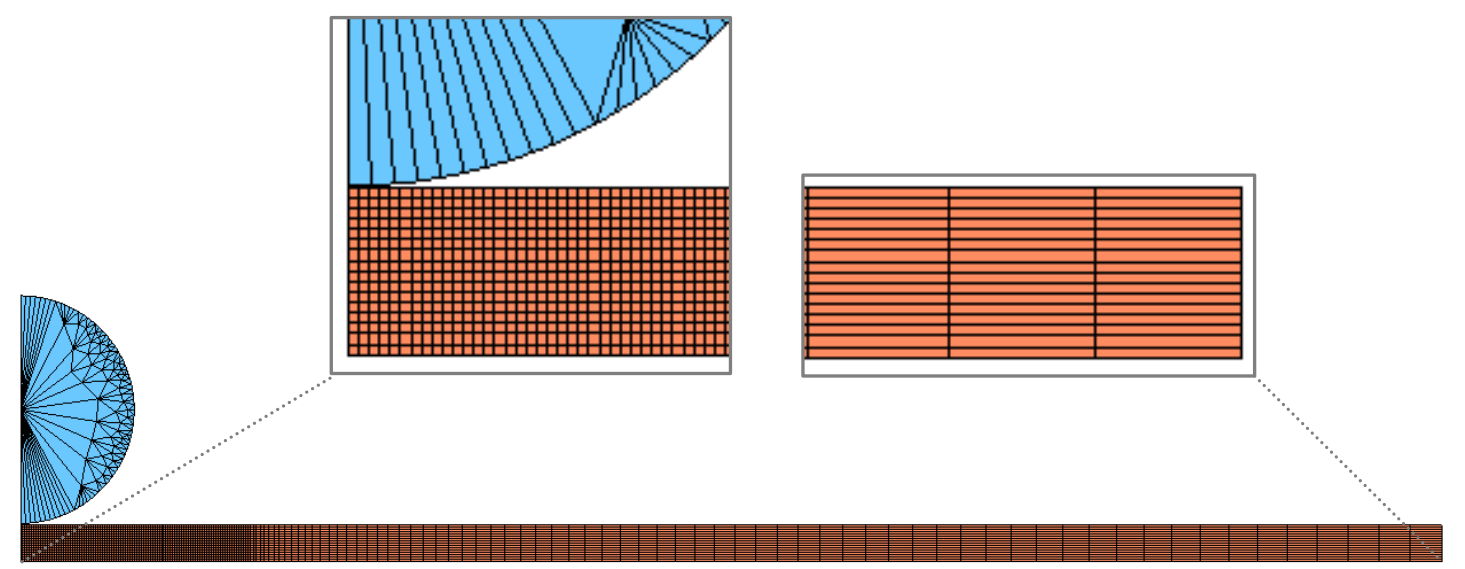

(b)

Figura 7.4: Malhas de elementos axissimétricos para as chapas do material (a) M1 e (b) M2. 


\subsubsection{Definição de parâmetros}

Elementos de casca Belytschko-Leviathan (elform-8), elementos sólidos de tensão constante (elform-1) e elementos axissimétricos de Galerkin (elform-15) foram utilizados na representação das chapas, com o objetivo de se avaliar a eficiência dos mesmos frente aos resultados experimentais.

Na literatura, encontra-se uma grande empregabilidade de elementos axissimétricos (ROEDER; SUN, 2001; YADAV et al., 2001; BORVIK et al., 2002; TENG; WIERZBICKI, 2006). Nota-se que estes elementos podem prever a velocidade balística com fidelidade a um custo computacional menor, mas não conseguem representar a formação das pétalas encontradas no impacto do projétil esférico, o que vem a ser uma de suas limitações.

Diferentes formulações de elementos de casca foram testadas em simulações preliminares, nas quais os valores definitivos de outros parâmetros numéricos ainda não estavam estabelecidos. Qualitativamente, avaliou-se o comportamento dos elementos, na região do impacto, durante a penetração da esfera. A Figura 7.5 apresenta configurações das malhas após o impacto para as diferentes formulações.

Os melhores resultados foram os encontrados através do elemento de integração total elform-16 do LS-DYNA (Hu-Washizu) (HALLQUIST, 2006) e do elemento de BelytschkoLeviathan. Segundo consta em ANSYS (1998), este último é similar à formulação de Belytschko-Wong-Chiang, porém usa controle físico de modos espúrios, o que inibe a necessidade de inserção destes parâmetros pelo usuário. Charoenphan (2002) afirma que este controle de modos espúrios permite ao elemento produzir melhores resultados para deformações por flexão e torção.

Algumas simulações de determinação da velocidade balística foram realizadas com as duas formulações e os resultados não apresentaram significativas diferenças, a menos do tempo de processamento, que chegou a triplicar no caso do elemento com integração total em relação ao elemento de Belytschko-Leviathan. Com base nisto, o elemento de Belytschko-Leviathan, com cinco pontos de integração ao longo da espessura, foi escolhido como elemento de casca para representação das chapas. No caso do elemento sólido 3D, foi escolhido o hexaedro com um ponto de integração. Seguindo a sugestão apresentada em Hallquist (2006), para análises estruturais axissimétricas, o elemento de Galerkin (volume-ponderado) foi empregado.

Na representação tridimensional do fenômeno, a esfera foi modelada como uma entidade matemática, ou seja, com uma equação de superfície esférica, método propiciado pelo 


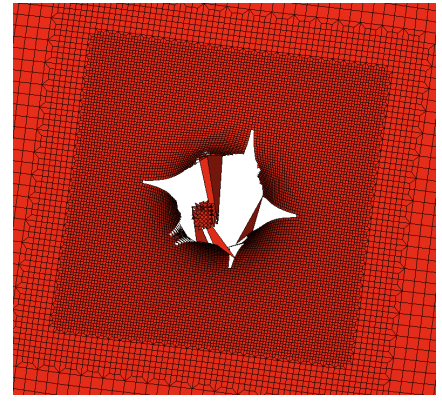

(a)

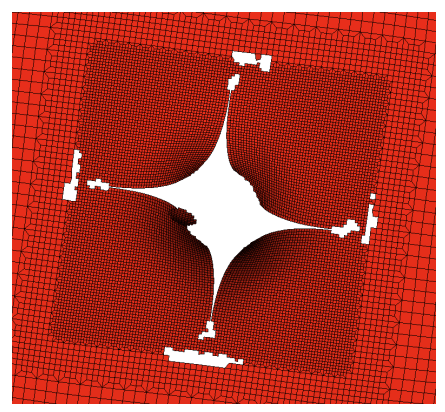

(c)

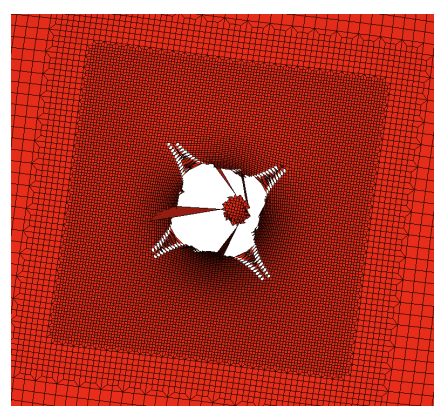

(e)

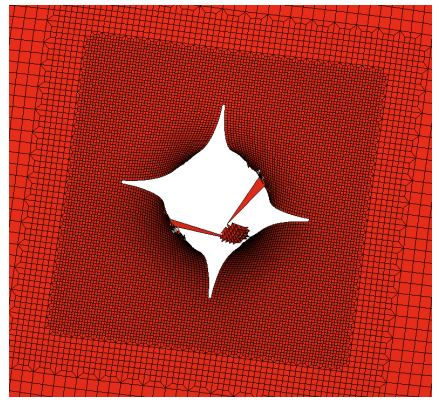

(b)

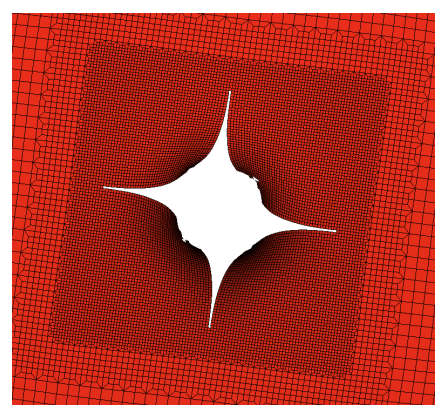

(d)

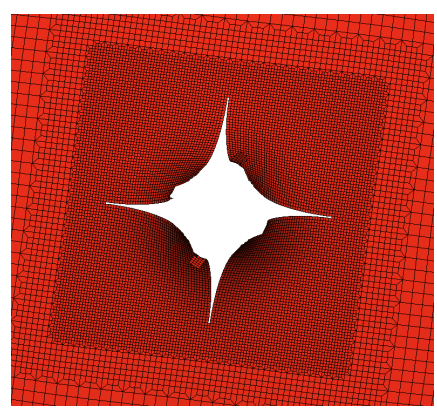

(f)

Figura 7.5: Detalhe da malha de elementos de casca durante a penetração da esfera, utilizando as formulações: (a) Hughes-Liu; (b) Belytschko-Tsay; (c) S/R Hughes-Liu; (d) Belytschko-Leviathan; (e) Belytschko-Wong-Chiang; (f) integração total.

cartão CONTACT_ENTITY do LS-DYNA para uma superfície master. Deste modo, não houve discretização em elementos finitos do projétil, sendo considerado como um corpo rígido, o que está de acordo com o observado experimentalmente e também com o utilizado por outros trabalhos (BORVIK et al., 2004; TENG; WIERZBICKI, 2006).

Neste tipo de modelagem do contato, baseada na formulação de rigidez por penalização, dois parâmetros foram alterados a partir da configuração padrão: o coeficiente de atrito e a ordem de integração.

Os efeitos causados pelo atrito são normalmente desprezados em problemas de impacto 
(TENG; WIERZBICKI, 2006). Num caso citado por Borvik et al. (2002), onde o atrito deveria ser considerado, o diâmetro do furo criado, provocado na chapa por um projétil cilíndrico de ponta cônica, era menor que o diâmetro do cilindro, indicando que, durante todo o processo de penetração, ocorreu contato entre a lateral do projétil e a parede do furo. De acordo com Borvik et al. (2005), isto pode ser estendido aos projéteis de ponta esférica, porém, não ocorre com projéteis cilíndricos de ponta plana, onde o furo gerado é maior que o diâmetro do cilindro. Segundo Ravid e Bodner (1983) um valor de coeficiente de atrito menor que 0,10 deve ser usado na interação dinâmica entre metais a altas velocidades e temperaturas, sendo indicado um coeficiente de 0,05. No impacto balístico envolvendo superfícies metálicas, um coeficiente de 0,01 é sugerido por Borvik et al. (2002). Nos experimentos de perfuração de Forrestal, Okajima e Luk (1988), foi observada a formação, durante a penetração, de uma camada de material fundido entre o bloco de alumínio testado e os projéteis cilíndricos de aço, implicando na existência de um atrito praticamente nulo entre a lateral do projétil e as paredes da cavidade criada.

Analisando os resultados desses trabalhos, a preocupação com o atrito está mais ligado ao contato da lateral de projéteis longos com faces criadas ao longo da espessura do alvo. Considerando que o alvo aqui é uma chapa fina e que o projétil tem um comprimento relativamente pequeno (igual ao seu diâmetro), pode-se concluir que este parâmetro não exerce uma grande influência nos resultados. Nas simulações realizadas, utilizou-se o valor de 0,02 para o coeficiente de atrito e, em algumas simulações, de modo a se confirmar esta baixa sensibilidade, empregou-se o valor de 0,1 , não se evidenciando mudanças nos valores de velocidade balística, dentro da precisão utilizada.

A ordem de integração na modelagem tridimensional do contato indica, na superfície slave, quantos pontos, além dos nós, são utilizados na verificação da ocorrência de penetração da superfície master (LSTC, 2003). Os seis valores possíveis, de 0 a 5 , foram testados num caso de perfuração, tanto para os elementos de casca quanto para os elementos sólidos. Utilizando elementos sólidos, independentemente do número de pontos utilizados, os resultados não apresentaram diferenças. Entretanto, a configuração da malha de elementos de casca, durante a penetração da esfera, diferenciou-se muito de acordo com a ordem utilizada, conforme apresenta a Figura 7.6. A ordem de integração 3 foi escolhida, com base nas figuras apresentadas, por tratar-se da configuração mais simétrica obtida. Esta simetria, embora não ocorra nos casos reais, foi considerada coerente com a modelagem utilizada. Além disso, a menos do grau 5 de integração, que se mostrou fisicamente inválido, não foi constatada influência relevante deste parâmetro na velocidade balística. No caso da representação bidimensional (axissimétrica) aplicou-se o contato 
com o cartão CONTACT_2D_AUTOMATIC_SURFACE_TO_SURFACE, que não possui este parâmetro de configuração.

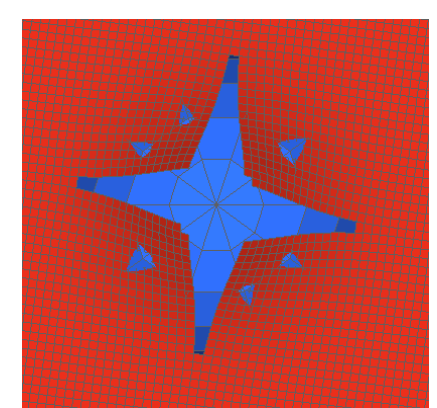

(a)

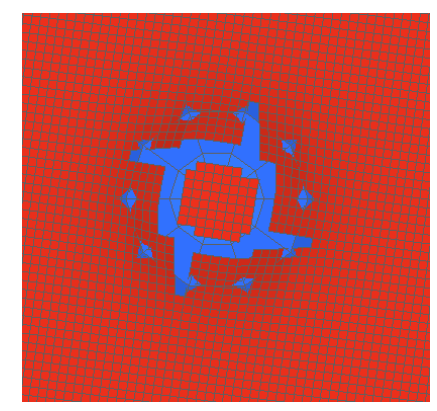

(c)

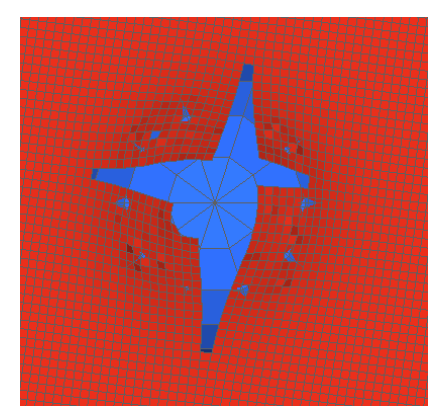

(e)

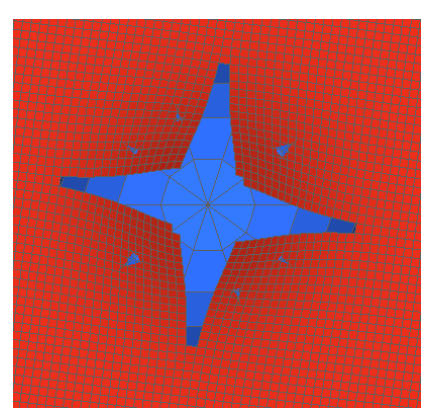

(b)

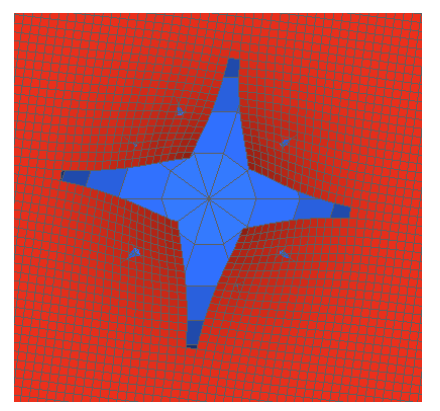

(d)

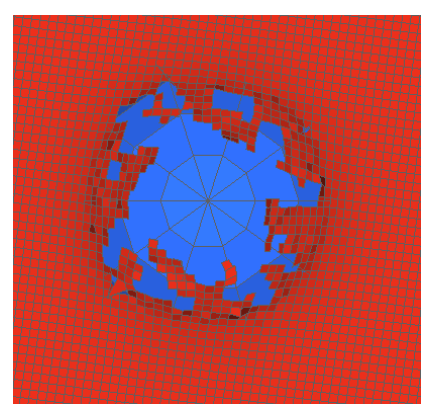

(f)

Figura 7.6: Configuração da malha de elementos de casca (em vermelho) durante a penetração da esfera (azul) para diferentes valores de ordem de integração do contato: (a) 0 ; (b) 1 ; (c) 2; (d) 3; (e) 4; (f) 5 .

Um parâmetro importante quando se lida com grandes deformações é o controle de modos espúrios. No caso dos elementos de casca, a formulação utilizada possui um controle automático, como foi apresentado. Porém, na malha de elementos sólidos, houve a necessidade de se avaliar as diferenças entre os tipos de controle disponíveis no código utilizado, principalmente pelo uso de apenas um ponto de integração. Novamente, a seleção foi feita com base na análise qualitativa da deformação da malha durante o 
contato com a esfera, como ilustra a Figura 7.7. Os três primeiros controles, com formulação baseada na viscosidade (Flanagan-Belytschko), apresentaram alguns elementos com grande distorção. A formulação co-rotacional, baseada na rigidez de BelytschkoBindeman, proporcionou uma flexibilidade exacerbada da malha. A forma rígida da integração de Flanagan-Belytschko proporcionou os melhores resultados, juntamente com a opção de integração volumétrica exata, a qual foi escolhida por não apresentar acréscimo de tempo de simulação significativo. No caso dos elementos axissimétricos, resultados idênticos foram encontrados para qualquer uma das formas rígidas presentes no programa LS-DYNA.

No manual do programa LS-DYNA (LSTC, 2003) é especificado que nenhum amortecimento está presente na formulação dos elementos finitos, sendo altamente recomendada sua inserção pelo cartão DAMPING_PART_MASS. O parâmetro principal deste cartão é uma constante de amortecimento, $D_{s}$, que é a razão entre o coeficiente de amortecimento e a massa do sistema. É sugerido ainda atribuir um valor para $D_{s}$ assumindo amortecimento crítico, que implica em

$$
D_{s}=2 \omega_{n}
$$

Simulações preliminares indicaram que, nestas condições, o amortecimento é muito alto, influindo muito no resultado, de forma que toda a energia cinética da esfera era dissipada no impacto, não importando seu valor inicial. Alternativamente, optou-se por inserir a razão de amortecimento definida na análise transiente apresentada no Capítulo 6, resultando em

$$
D_{s}=2 \zeta \omega_{n}
$$

Utilizando este parâmetro de amortecimento, por outro lado, não foi possível obter um valor para o deslocamento máximo permanente, visto que a malha vibrava sem cessar. Uma solução empírica utilizada foi aumentar essa constante e avaliar o tempo necessário para o amortecimento, ponderando, de um lado, o tempo encontrado nas curvas das Figuras 6.4 e 6.5 e, de outro, a viabilidade do tempo de processamento. Desta forma, multiplicou-se o lado direito da Equação (7.2) pelo fator $2 \pi$, resultando nos valores de $D_{s}$ igual a 150 para a simulação com o material M1 e 490 para o material M2. 


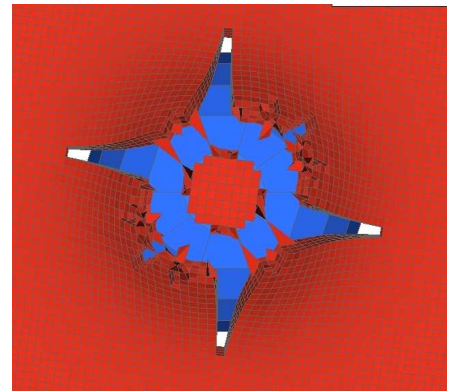

(a)

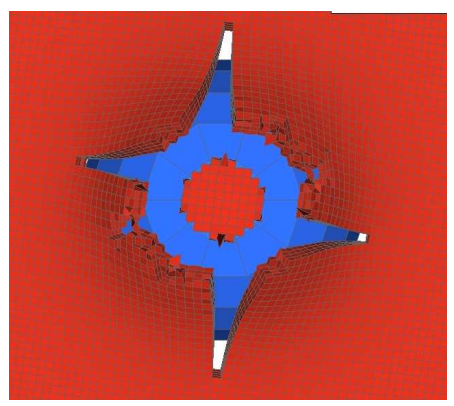

(c)

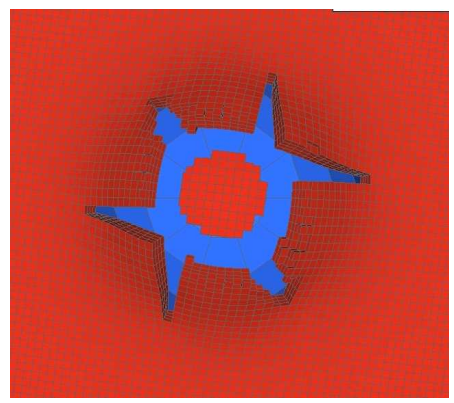

(e)

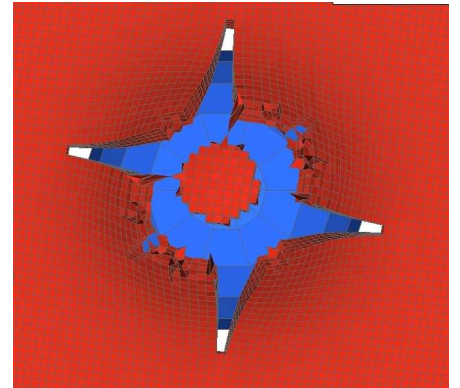

(b)

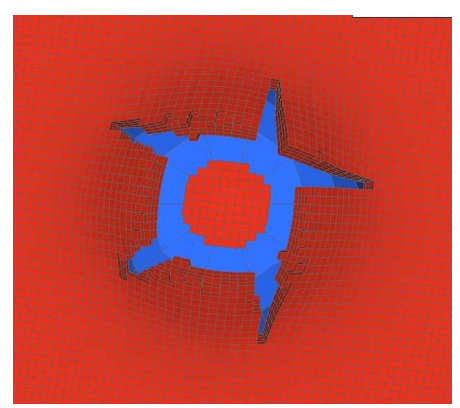

(d)

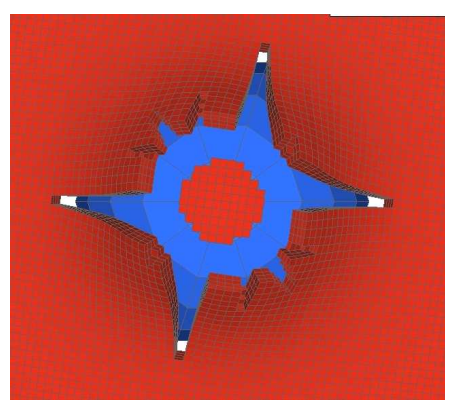

(f)

Figura 7.7: Configuração da malha de elementos sólidos (em vermelho) durante a penetração da esfera (azul) para diferentes tipos de controle de modos espúrios: (a) padrão do LS-DYNA; (b) integração de Flanagan-Belytschko; (c) integração volumétrica exata de Flanagan-Belytschko; (d) forma rígida da integração de Flanagan-Belytschko; (e) forma rígida da integração volumétrica exata de Flanagan-Belytschko; (f) forma rígida co-rotacional de Belytschko-Bindeman.

\subsection{RESULTADOS}

\subsubsection{Análise modal}

A extração dos modos e freqüências naturais da chapas circulares engastadas foi escolhida como um primeiro procedimento de avaliação da modelagem computacional. O experimento físico que possibilitou a medição dessas freqüências foi detalhado no Capítulo 6, Figuras 6.4 e 6.5 . 
Por se tratar de uma estrutura relativamente simples, uma análise modal analítica pôde ser realizada (ROARK; YOUNG, 1975). Para uma chapa circular engastada, de raio $r_{p}$, de espessura constante $t_{p}$, módulo elástico $E$, densidade $\rho$ e coeficiente de Poisson $v$, a freqüência fundamental é calculada por

$$
f_{n}=\frac{5,1}{\pi} \sqrt{\frac{E t_{p}^{2}}{12\left(1-v^{2}\right) \rho r_{p}^{4}}} .
$$

Substituindo os valores referentes aos materiais, obtém-se as freqüências apresentadas na Tabela 7.4, que ainda apresenta a diferença percentual em relação ao valor experimental.

Utilizando o programa ANSYS versão 10, a extração dos modos e frequiências foi realizada com as malhas ref4 e ref5, tanto com elementos sólidos quanto de casca, provendo resultados para a primeira análise comparativa dessas malhas. A Tabela 7.4 apresenta os resultados numéricos encontrados e as diferenças percentuais em relação aos dados experimentais.

Tabela 7.4: Avaliação da modelagem através da Análise Modal. Os valores percentuais representam a diferença em relação aos experimentos.

\begin{tabular}{|c|c|c|c|c|c|c|c|}
\hline \multirow[t]{2}{*}{ Material } & \multirow{2}{*}{$\begin{array}{c}\text { Experimental } \\
(\mathrm{Hz})\end{array}$} & \multicolumn{2}{|c|}{ Analítico } & \multicolumn{4}{|c|}{ Numérico } \\
\hline & & & $(\%)$ & & & $(\mathrm{Hz})$ & $(\%)$ \\
\hline \multirow{4}{*}{ M1 } & \multirow{4}{*}{263,2} & \multirow{4}{*}{265,9} & \multirow{4}{*}{1,03} & \multirow[b]{2}{*}{ casca } & ref4 & 259,2 & 1,52 \\
\hline & & & & & ref5 & 259.2 & 1.52 \\
\hline & & & & \multirow{2}{*}{ sólido } & ref4 & 263,6 & 0,15 \\
\hline & & & & & ref5 & 263,8 & 0,23 \\
\hline \multirow{4}{*}{ M2 } & \multirow{4}{*}{450,2} & \multirow{4}{*}{527,0} & \multirow{4}{*}{17,06} & \multirow{2}{*}{ casca } & ref4 & 516,7 & 14,77 \\
\hline & & & & & ref5 & 516,7 & 14,77 \\
\hline & & & & \multirow[t]{2}{*}{ sólido } & ref4 & 521,3 & 15,79 \\
\hline & & & & & refs & 521,4 & 15,82 \\
\hline
\end{tabular}

Percebe-se nitidamente, observando os resultados apresentados na Tabela 7.4, que as estimativas numérica e analítica da frequiência natural foram muito eficazes no caso do material M1, com diferenças menores que 2\%. Trata-se de um indício inicial de uma coerente representação da chapa e sua condição de contorno. Porém, os valores se distanciaram para o material M2, o que indica uma modelagem menos representativa. Possivelmente, isto deve estar relacionado à condição de contorno da chapa que, no caso real, se afasta da condição de engastamento, à medida que se utilizam espessuras maiores.

Por outro lado, existe outra explicação. Os dados da chapa M1 foram adquiridos com taxas de $100 \mathrm{kHz}, 500 \mathrm{kHz}$ e $750 \mathrm{kHz}$, sendo desta última extraídos os resultados apresentados. Como não houve diferenças significativas, e para aumentar o tempo de aquisição, 
utilizou-se a taxa de $100 \mathrm{kHz}$ para o material M2. Este valor, entretanto, está no limite inferior das taxas possíveis, segundo o teorema de aquisição de Nyquist, quando do uso de um filtro de $50 \mathrm{kHz}$, o que pode ter causado alguma alteração nos valores das freqüências das componentes do sinal digitalizado.

Em geral, uma boa representatividade foi encontrada no modelo. Porém, as influências tanto do tipo quanto do tamanho do elemento se mostraram mínimas, indicando que o uso da análise modal pode não ser um método adequado para este tipo de estudo.

\subsubsection{Velocidade balística}

A busca pela velocidade de transição entre as perfurações parcial e total da chapa ocorreu com a utilização das malhas ref4 e ref5 com elementos de casca e sólidos, e da malha ref6 com elementos axissimétricos. O modelo de Lemaitre foi escolhido para representação do comportamento do material, com suas leis de escoamento e de evolução do dano, em conjunto com o método numérico de eliminação de elemento.

A parcela de energia que é retirada do sistema devido à eliminação dos elementos, ao longo de toda a simulação, é apresentada na Figura 7.5, para cada tipo de elemento testado. Percebe-se que a representação da perfuração no caso axissimétrico implica numa perda maior de energia que nos outros casos, que se assemelham.

Tabela 7.5: Energia perdida na eliminação dos elementos em relação à energia total.

\begin{tabular}{|c|ccc|}
\hline \multirow{2}{*}{ Material } & \multicolumn{3}{|c|}{ Elemento } \\
& $\begin{array}{c}\text { axissimétrico } \\
(\%)\end{array}$ & $\begin{array}{c}\text { casca } \\
(\%)\end{array}$ & $\begin{array}{c}\text { sólido } \\
(\%)\end{array}$ \\
\hline \hline M1 & 28 & 14 & 11 \\
M2 & 32 & 9 & 13 \\
\hline
\end{tabular}

Quanto à representação dos efeitos da taxa de deformação, três situações foram avaliadas: a não consideração desses efeitos (apenas curva tensão versus deformação quaseestática); o modelo de CS com parâmetros obtidos com a metodologia convencional; o modelo de CS com parâmetros obtidos com a metodologia de caracterização modificada. Todos estes parâmetros foram apresentados nas Tabelas 4.3 e 5.3. Utilizando-se intervalos de $2,5 \mathrm{~m} / \mathrm{s}$ e precisão de 64 bits, a predição da velocidade balística foi encontrada nas três situações descritas, para cada um dos materiais.

Os valores de velocidade balística resultantes da representação das chapas do material M1 com o modelo sem efeitos da taxa de deformação são apresentados na Figura 7.8. 
A Figura 7.9 apresenta os resultados da inclusão destes efeitos a partir da metodologia convencional de caracterização mecânica dinâmica, e a Figura 7.10 a partir da nova metodologia proposta. Nestas figuras, as colunas indicam as diferenças em relação ao valor experimental (Tabela 6.1), definido pela linha horizontal espessa em cada gráfico.

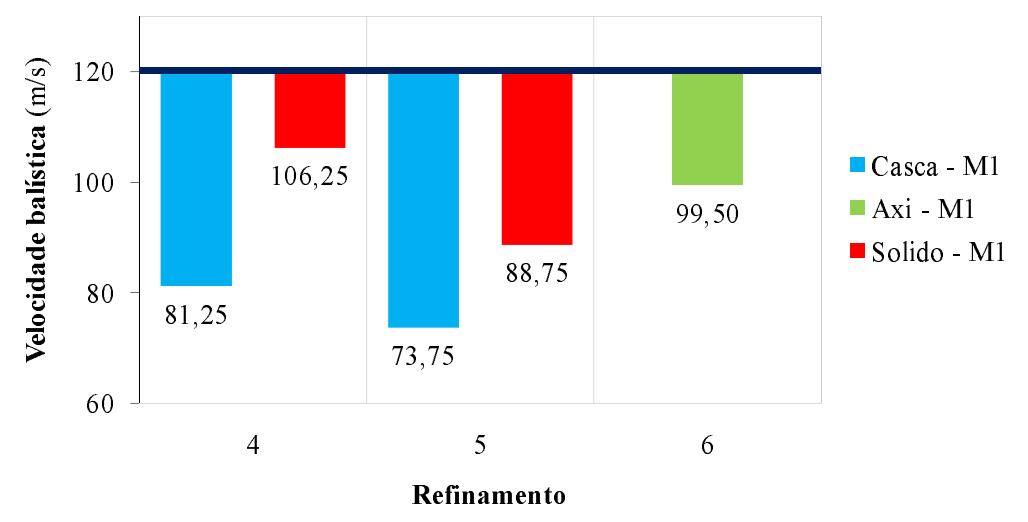

Figura 7.8: Comparação dos valores de velocidades balísticas numéricas e experimentais. Caracterização mecânica do material M1 sem taxa de deformação (estático).

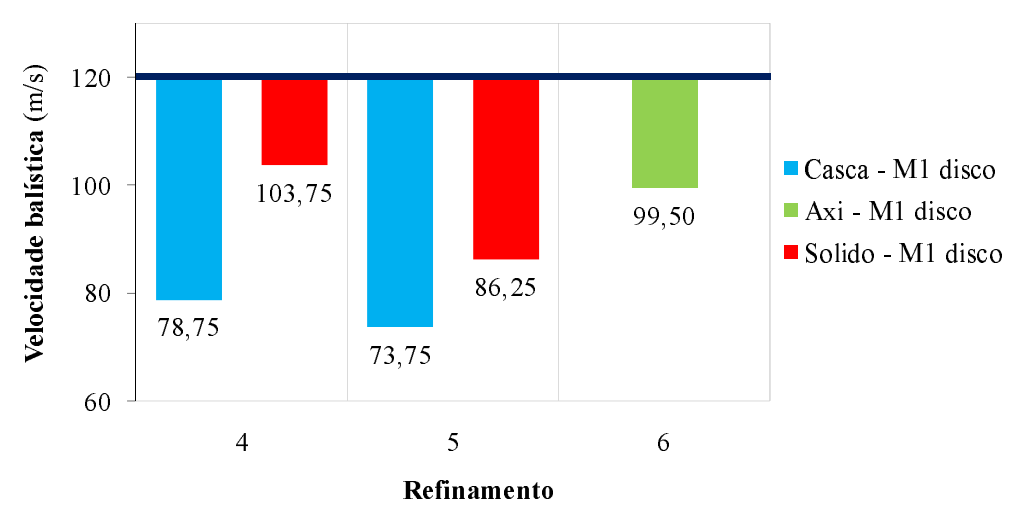

Figura 7.9: Comparação dos valores de velocidades balísticas numéricas e experimentais. Caracterização mecânica do material M1 com a metodologia convencional.

Em todas as simulações da chapa do material M1, a predição da velocidade balística se mostrou bem conservadora, ficando abaixo do valor experimental, da ordem de 20 a $40 \%$ menor. Observando-se as diferenças entre os refinamentos ref4 e ref5, nas Figuras 7.8, 7.9 e 7.10, percebe-se que uma malha mais refinada implicou numa estrutura menos resistente à perfuração.

Admitindo a malha ref5 como a mais coerente na modelagem tridimensional (Figura 7.2), pode-se dizer que o modelo com elementos axissimétricos apresenta uma maior resistên- 


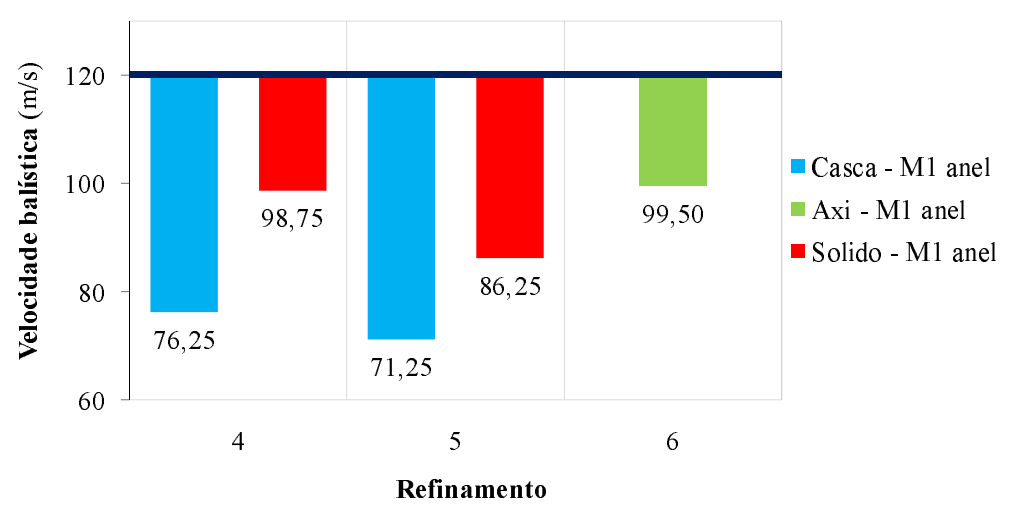

Figura 7.10: Comparação dos valores de velocidades balísticas numéricas e experimentais. Caracterização mecânica do material M1 com a nova metodologia.

cia à perfuração que o modelo com elementos sólidos, que por sua vez, é mais resistente que a representação por elementos de casca. Segue esta mesma ordem, portanto, a proximidade com o resultado experimental, de forma que a malha de elementos axissimétricos apresentou a melhor predição.

$\mathrm{Na}$ simulação da chapa do material M2, ocorreram erros no algoritmo do modelo do material, quando utilizados os parâmetros obtidos com a metodologia convencional de caracterização dinâmica da BH. Alterações em outros parâmetros foram feitas, como a diminuição do incremento de tempo, mas não foi possível obter a convergência do modelo, dentro da faixa de velocidades testadas, para nenhum tipo de malha e elemento utilizados neste trabalho. Assim, para o material M2, as predições da velocidade balística encontradas com a nova metodologia, Figura 7.12, foram confrontadas apenas com os dados experimentais e com os resultados da representação sem efeitos da taxa de deformação, Figura 7.11.

Observando-se as Figuras 7.11 e 7.12, percebe-se que as predições da velocidade balística das chapas do material M2 com a malha de elementos de casca ficaram abaixo do valor experimental, entre 5,3\% e 13,7\% de diferença. As outras malhas resultaram em predições acima do resultado experimental, variando de 3,2\% a 15,4\% com elementos sólidos, e de $8,8 \%$ a $9,6 \%$ com elementos axissimétricos. Comparativamente ao material M1, as predições para a chapa do material M2 ficaram mais próximas ao resultado experimental.

De maneira similar ao ocorrido com o material M1, a malha de elementos de casca foi a que apresentou menor resistência ao impacto, considerando o refinamento ref5, seguida da malha de elementos sólidos e da axissimétrica, nesta ordem. A modelagem por elementos 


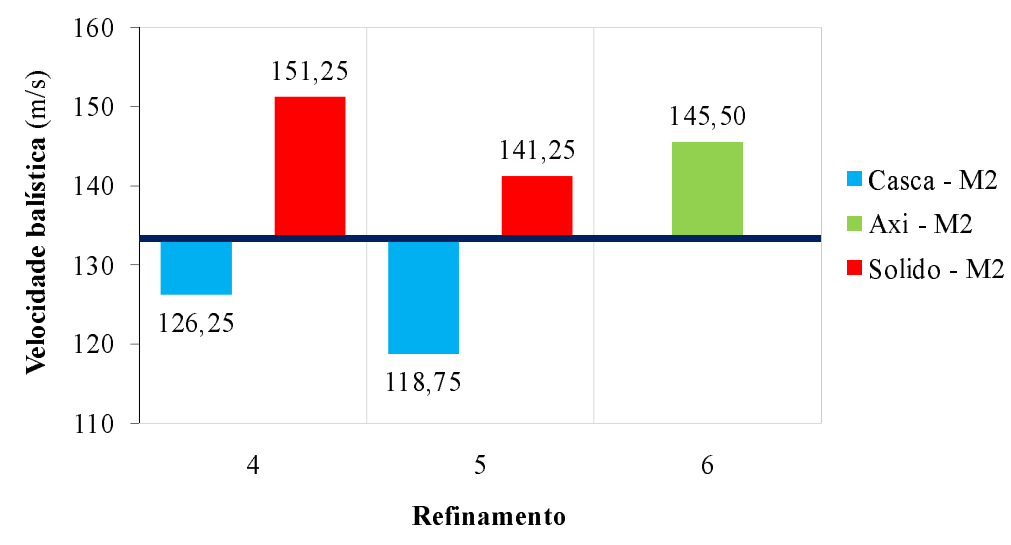

Figura 7.11: Comparação dos valores de velocidades balísticas numéricas e experimentais. Caracterização mecânica do material M2 sem taxa de deformação (estático).

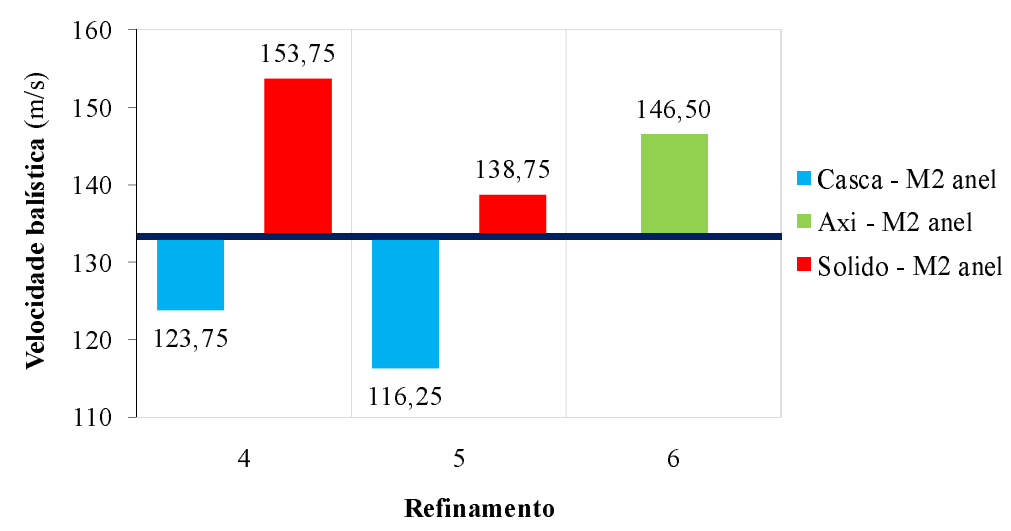

Figura 7.12: Comparação dos valores de velocidades balísticas numéricas e experimentais. Caracterização mecânica do material M2 com a nova metodologia.

sólidos apresentou a melhor predição da velocidade balística para o material M2, com uma diferença de $3,2 \%$, quando utilizados os parâmetros obtidos com a metodologia de caracterização proposta neste trabalho.

Uma melhor avaliação da influência dos parâmetros do modelo de material pode ser feita utilizando-se as curvas das Figuras 7.13 e 7.14 relativas aos materiais M1 e M2, respectivamente. Nestas figuras, são apresentadas as diferenças percentuais entre os dados numéricos e experimentais, em função da metodologia de caracterização mecânica do material empregada.

Observa-se na Figura 7.13 que utilizando a malha de elementos axissimétricos, nenhuma diferença foi encontrada na predição da velocidade balística para a chapa do material M1, ao variar-se o método de caracterização dinâmica, mesmo diminuindo-se a precisão de 


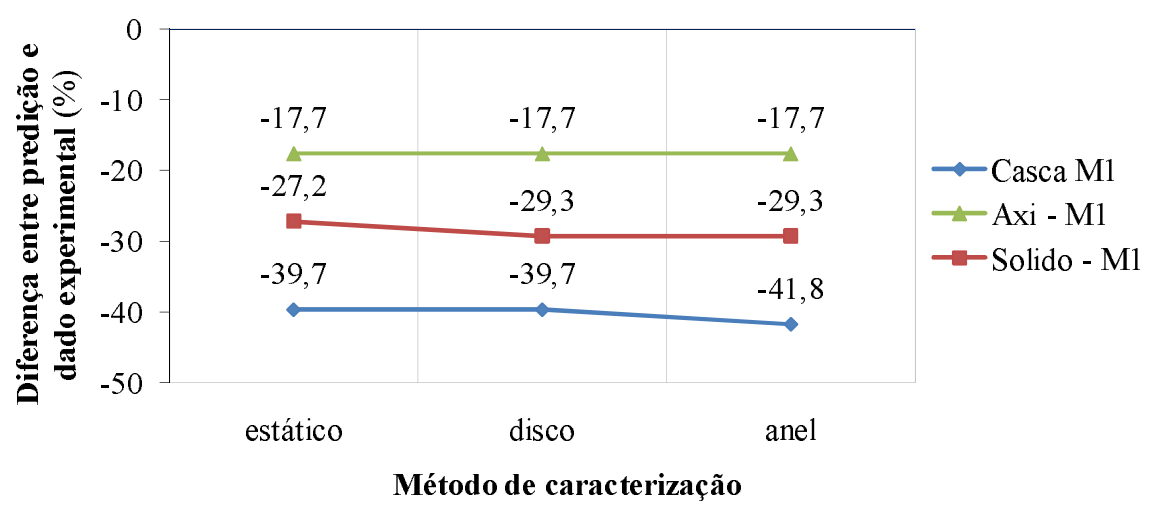

Figura 7.13: Diferença em relação à velocidade balística experimental, em função da metodologia de caracterização mecânica do material M1.

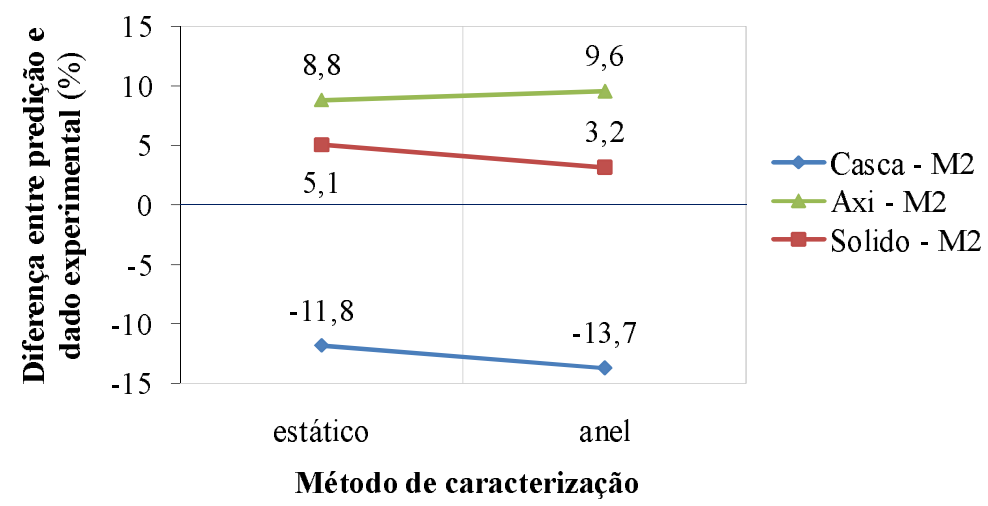

Figura 7.14: Diferença em relação à velocidade balística experimental, em função da metodologia de caracterização mecânica do material M2.

$1,25 \mathrm{~m} / \mathrm{s}$ (intervalos de $2,5 \mathrm{~m} / \mathrm{s}$ no incremento de velocidade de uma simulação para outra) para $0,5 \mathrm{~m} / \mathrm{s}$ (intervalos de $1,0 \mathrm{~m} / \mathrm{s}$ ). Esta resposta diverge das obtidas com os outros dois tipos de malhas, que mostraram algum tipo de variação frente aos parâmetros dinâmicos adotados. No caso dos elementos de casca, a predição não se alterou ao se incluir efeitos de taxa de deformação pela metodologia convencional ao modelo quase-estático, e diminui 3,4\% ao utilizar-se a metodologia de caracterização dinâmica modificada. Na simulação com elementos sólidos, a resposta, considerando os efeitos de taxa de deformação, foi $2,8 \%$ menor que a quase-estática, não importando a metodologia de caracterização adotada.

A Figura 7.14 apresenta as diferenças percentuais entre as predições numéricas e a velocidade balística experimental do material M2, confrontando a modelagem sem e com efeitos da taxa de deformação. Devido à impossibilidade de se simular a chapa do ma- 
terial M2 com os parâmetros da metodologia convencional, a modelagem dos efeitos de taxa de deformação é representada pela nova metodologia proposta. Diferentemente do caso do material M1, ocorreu variação em todas as predições ao se incluir os efeitos dinâmicos, ainda que essa variação, no caso axissimétrico, tenha sido de somente $0,7 \%$. Ao se considerar os efeitos da taxa de deformação, o resultado para o elemento sólido se aproximou do valor experimental, numa variação de 1,8\%, e no caso dos elementos de casca, se distanciou, variando $2,1 \%$.

A influência do modelo do material na variação da predição balística obtida entre as malhas ref4 e ref5, para os elementos de casca e sólidos, pode ser avaliada através da Tabela 7.6.

A primeira linha de resultados da Tabela 7.6, material M1 e elementos de casca, mostra que a variação dos resultados entre os refinamentos das malhas diminuiu, de maneira significativa, com a inclusão dos efeitos de taxa de deformação. Pouca diferença foi encontrada entre os dois tipos de caracterização dinâmica. Nos resultados com elementos sólidos (segunda linha da Tabela 7.6), porém, houve pouca diferença na variação dos resultados entre os refinamentos quando foram considerados os efeitos da taxa de deformação pela caracterização convencional, e uma diminuição sensível quando utilizada a caracterização modificada.

Tabela 7.6: Diferenças percentuais entre as predições das velocidades balísticas dos refinamentos ref4 e ref5.

\begin{tabular}{|c|c|ccc|}
\hline Material & Elemento & $\begin{array}{c}\text { estática } \\
(\%)\end{array}$ & $\begin{array}{c}\text { convencional } \\
(\%)\end{array}$ & $\begin{array}{c}\text { modificada } \\
(\%)\end{array}$ \\
\hline \hline \multirow{2}{*}{ M1 } & casca & 9,2 & 6,3 & 6,6 \\
& sólido & 16,5 & 16,9 & 12,7 \\
\hline \multirow{2}{*}{ M2 } & casca & 5,9 & - & 6,1 \\
& sólido & 6,6 & - & 9,8 \\
\hline
\end{tabular}

Analisando-se os resultados da Tabela 7.6 para o material M2, percebe-se que, tanto com elementos de casca quanto com os sólidos, houve um comportamento diferente do material M1, com a variação entre os resultados dos refinamentos aumentando com a inclusão dos efeitos dinâmicos.

Um dos objetivos de se utilizar elementos de casca 2D e sólidos 3D foi a tentativa de representação da configuração final das chapas, após o impacto do projétil. Na Figura 7.15, é possível observar a configuração de uma chapa perfurada totalmente pela esfera e 
de suas representações tridimensionais, com elementos de casca e sólidos. A configuração correspondente obtida através da análise axissimétrica pode ser vista na Figura 7.16, onde, para facilitar o entendimento, a malha é rebatida segundo o eixo de simetria.
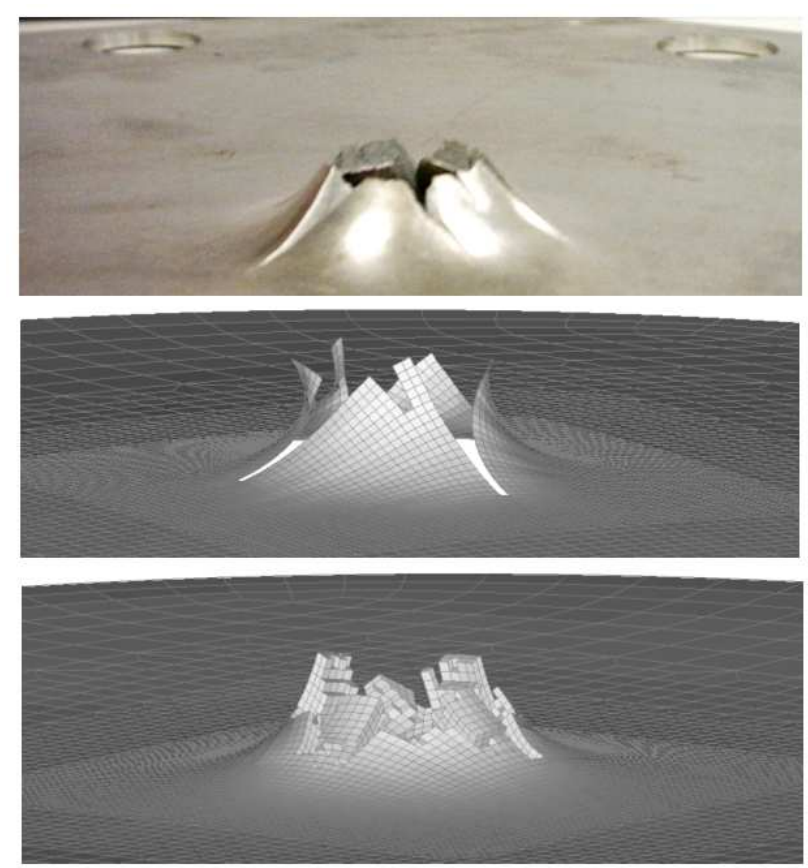

Figura 7.15: Comparação da configuração após penetração total entre os casos real, casca e sólido, para o material M2.

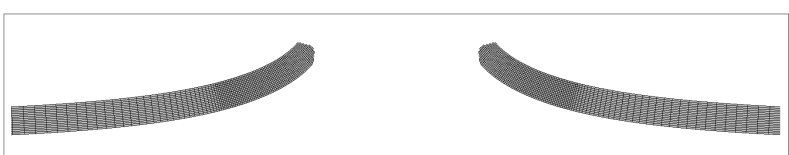

Figura 7.16: Configuração final da malha de elementos axissimétricos, para o material M2.

Nas análises numéricas, o tempo de processamento torna-se uma variável importante que pondera a decisão pelo melhor método de representação do fenômeno. Tomandose como referência um computador com dois processadores AMD Opterom(tm) Dual Core de 2,21GHz e 4GB de memória RAM DDR 400MHz, os tempos para simulação de $2,5 \mathrm{~ms}$ de teste (suficiente para averiguar a ocorrência de penetração total da esfera) são apresentados na Tabela 7.7, para cada malha, refinamento e material.

Observa-se na Tabela 7.7 que o tempo para realizar a simulação do impacto da esfera na chapa é muito menor quando utilizados elementos axissimétricos. Para os elementos 
Tabela 7.7: Tempo de processamento para predição da velocidade balística.

\begin{tabular}{|c|c|cl|}
\hline \multirow{2}{*}{ Elemento } & \multirow{2}{*}{ Refinamento } & \multicolumn{2}{|c|}{ Material } \\
& & M1 & M2 \\
\hline \hline \multirow{2}{*}{ casca } & ref4 & $10 \mathrm{~min} 19 \mathrm{seg}$ & $09 \mathrm{~min} 51 \mathrm{seg}$ \\
& ref5 & $46 \mathrm{~min} 54 \mathrm{seg}$ & $49 \mathrm{~min} 17 \mathrm{seg}$ \\
\hline \multirow{2}{*}{ sólido } & ref4 & $28 \mathrm{~min} 52 \mathrm{seg}$ & $21 \mathrm{~min} 23 \mathrm{seg}$ \\
& ref5 & $2 \mathrm{~h} 47 \mathrm{~min}$ & $3 \mathrm{~h} 38 \mathrm{~min}$ \\
\hline axissimétrico & ref6 & $1 \mathrm{~min} 58 \mathrm{seg}$ & $3 \mathrm{~min} 31 \mathrm{seg}$ \\
\hline
\end{tabular}

sólidos, o tempo de processamento é da ordem de três vezes o tempo com elementos de casca e oitenta e cinco vezes o tempo com elementos axissimétricos. A variação deste parâmetro entre os materiais M1 e M2 ocorre principalmente onde o número de elementos aumenta com a espessura da chapa, nas malhas de elementos sólidos e axissimétricos.

\subsubsection{Deslocamento máximo permanente}

O segundo conjunto de simulações numéricas engloba os testes experimentais onde não ocorreu falha do material da chapa, ou seja, os testes a velocidades abaixo da balística, onde o impacto da esfera não foi suficiente para criar uma fissura na chapa. A representação numérica destes testes é importante na avaliação da influência da modelagem do comportamento dinâmico do material, pois exclui efeitos do modelo de dano e perfuração nos resultados.

O mesmo modelo de material da simulação de velocidade balística foi utilizado, apenas o parâmetro $\varepsilon_{D}^{p}$, que indica o início do processo de danificação foi alterado para um valor incapaz de ser alcançado $\left(\varepsilon_{D}^{p}=100\right)$. Diferentemente dos testes experimentais, o local do impacto da esfera, nas simulações, foi sempre o centro da chapa. Devido à maior proximidade da convergência (Figura 7.2) e ao elevado tempo de processamento numérico, apenas as malhas ref5 foram utilizadas nas representações tridimensionais.

A Figura 7.17 apresenta os valores de deslocamento máximo permanente encontrados através das simulações numéricas de três velocidades de impacto, 78, 81 e $84 \mathrm{~m} / \mathrm{s}$, para o material M1. Nesta figura, o deslocamento máximo permanente é adimensionalizado pela espessura da chapa e a velocidade de impacto pela velocidade balística experimental.

De um modo geral, as predições do deslocamento máximo permanente variaram linearmente com a velocidade de impacto, similarmente ao que ocorreu nos experimentos. A tabela 7.8 apresenta os valores do coeficiente de determinação, $R^{2}$, para regressões lineares realizadas nos conjuntos de três pontos de cada tipo de malha e modelo dinâmico do 


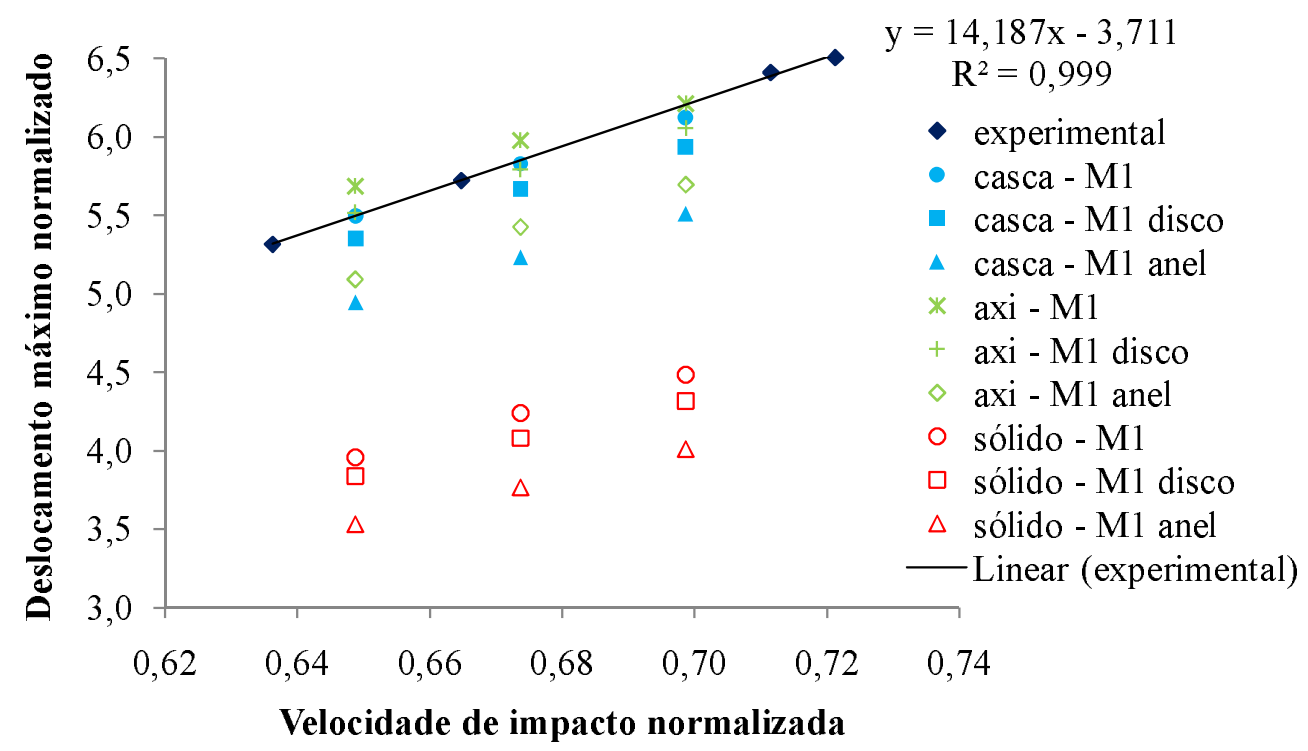

Figura 7.17: Deslocamentos máximos encontrados com as diversas malhas, para o material M1.

material M1.

Tabela 7.8: Valores dos coeficientes angulares, lineares e de determinação das regressões lineares aplicadas nos resultados do material M1.

\begin{tabular}{|c|c|ccc|}
\hline Elemento & $\begin{array}{c}\text { Modelagem } \\
\text { dinâmica }\end{array}$ & $\begin{array}{c}\text { coeficiente } \\
\text { angular }\end{array}$ & $\begin{array}{c}\text { coeficiente } \\
\text { linear }\end{array}$ & $\boldsymbol{R}^{2}$ \\
\hline \hline \multirow{3}{*}{ casca } & estático & 12,54 & $-2,63$ & 0,9988 \\
& disco & 11,68 & $-2,22$ & 0,9976 \\
& anel & 11,28 & $-2,37$ & 0,9998 \\
\hline \multirow{3}{*}{ sólido } & estático & 10,62 & $-2,93$ & 0,9984 \\
& disco & 9,57 & $-2,37$ & 1,0000 \\
& anel & 9,64 & $-2,72$ & 0,9999 \\
\hline \multirow{3}{*}{ axissimétrico } & estático & 10,54 & $-1,15$ & 0,9961 \\
& disco & 10,81 & $-1,50$ & 0,9998 \\
& anel & 12,01 & $-2,69$ & 0,9962 \\
\hline
\end{tabular}

Observando a Figura 7.17, constata-se que as predições com elementos axissimétricos se aproximaram melhor dos resultados experimentais das chapas do material M1, seguidas das predições com elementos de casca. A representação por elementos sólidos apresentou uma rigidez bem acima da encontrada nos testes físicos.

Problemas de convergência da rotina do material no programa LS-DYNA com o material M2 também foram encontradas nas simulações sem o modelo de dano. As predições de deslocamento máximo permanente das chapas deste material são apresentadas na Figura 
7.18, para três valores de velocidade de impacto, 74,76 e $78 \mathrm{~m} / \mathrm{s}$.

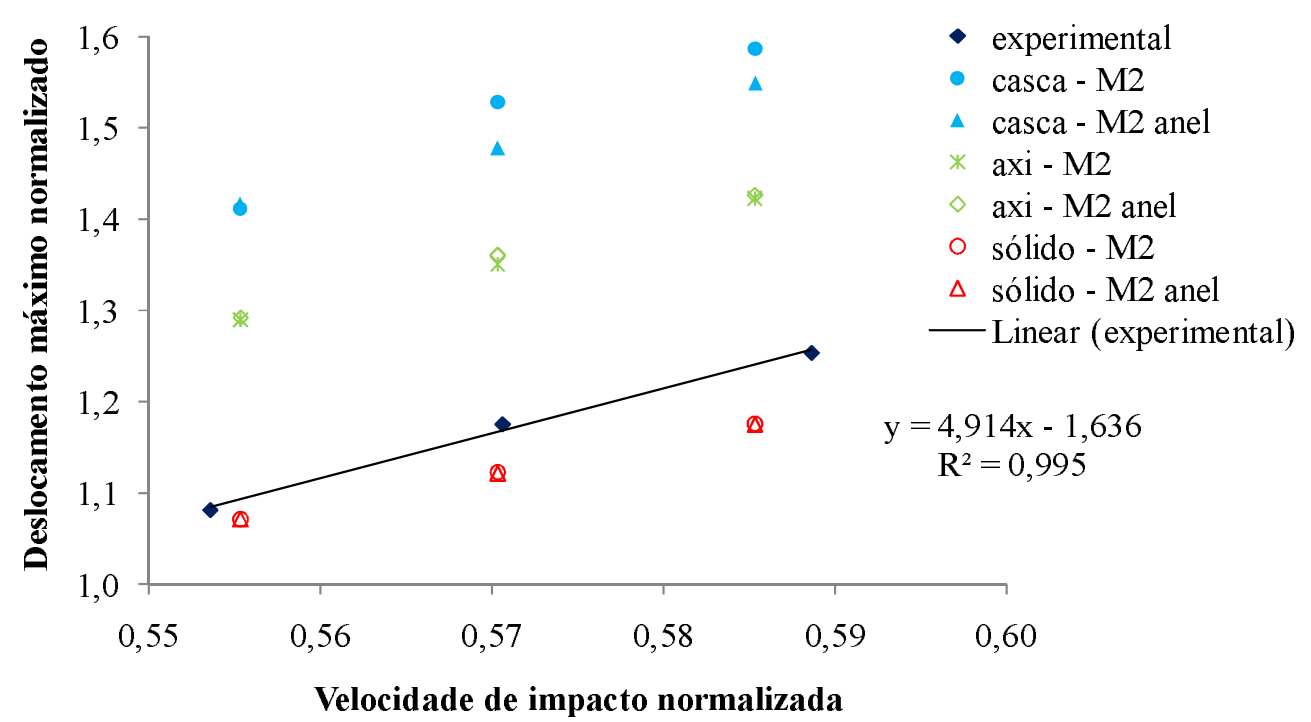

Figura 7.18: Deslocamentos máximos encontrados com as diversas malhas, para o material M2.

Aplicando-se regressões lineares para cada tipo de modelagem e averiguando o valor de $R^{2}$ resultante, Tabela 7.9, percebe-se que os resultados da predição de deslocamento máximo permanente do material M2 também se aproximaram de uma curva linear, como nos testes experimentais.

Tabela 7.9: Valores dos coeficientes angulares, lineares e de determinação das regressões lineares aplicadas nos resultados do material M2.

\begin{tabular}{|c|c|ccc|}
\hline Elemento & $\begin{array}{c}\text { Modelagem } \\
\text { dinâmica }\end{array}$ & $\begin{array}{c}\text { coeficiente } \\
\text { angular }\end{array}$ & $\begin{array}{c}\text { coeficiente } \\
\text { linear }\end{array}$ & $\boldsymbol{R}^{2}$ \\
\hline \hline & estático & 5,83 & $-1,81$ & 0,9638 \\
casca & anel & 4,43 & $-1,04$ & 0,9982 \\
\hline \multirow{2}{*}{ sólido } & estático & 3,47 & $-0,86$ & 0,9999 \\
\hline \multirow{2}{*}{ axissimétrico } & anel & 3,46 & $-0,85$ & 0,9997 \\
\hline & estático & 4,43 & $-1,17$ & 0,9975 \\
& anel & 4,49 & $-1,20$ & 0,9999 \\
\hline
\end{tabular}

A avaliação da influência da modelagem dinâmica do material nos resultados encontrados pode ser feita com o auxílio das Figuras 7.19 e 7.20, que apresentam as diferenças percentuais das predições do deslocamento máximo permanente das simulações, para os materiais M1 e M2, em relação aos dados experimentais. Os valores representam a média aritmética das diferenças dos três pontos obtidos para cada tipo de representação numérica, os quais foram apresentados nas Figuras 7.17 e 7.18. 


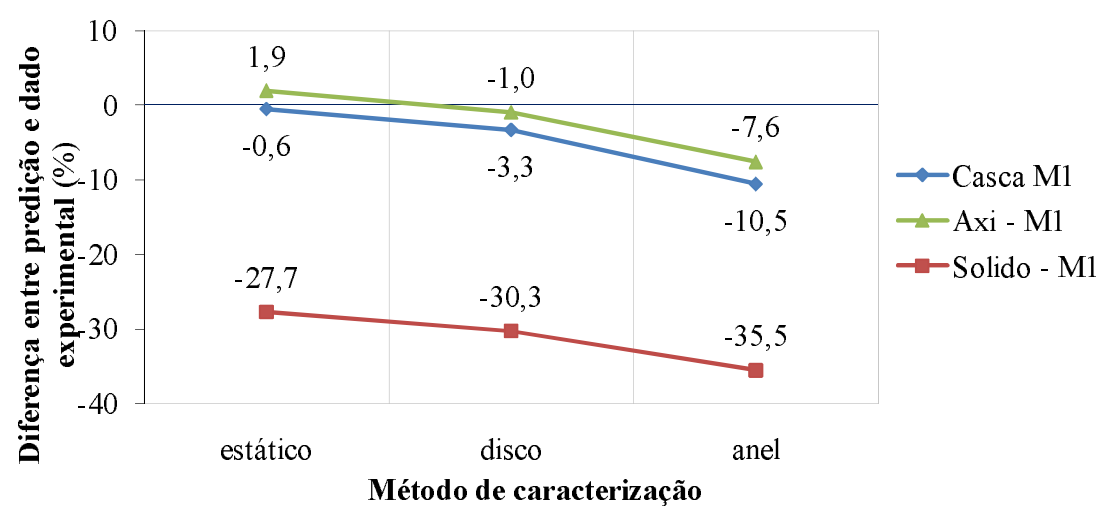

Figura 7.19: Diferença em relação ao deslocamento máximo permanente experimental, em função da metodologia de caracterização mecânica do material M1.

Observa-se na Figura 7.19 que a variação das predições com a mudança da modelagem do comportamento dinâmico é praticamente a mesma para todas as malhas simuladas. Há um aumento de rigidez da chapa com a inclusão dos efeitos de taxa de deformação do material e esse aumento é maior na metodologia de caracterização proposta que na convencional.

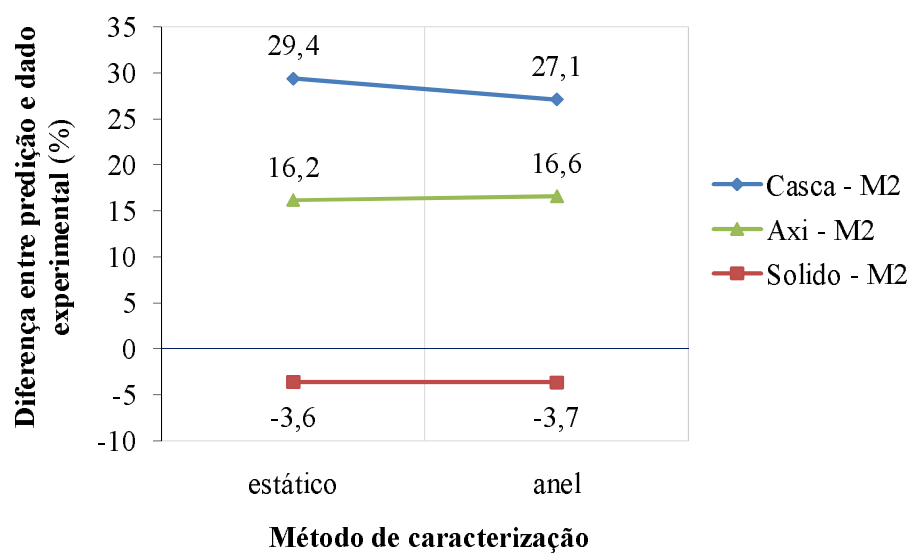

Figura 7.20: Diferença em relação ao deslocamento máximo permanente experimental, em função da metodologia de caracterização mecânica do material M2.

A inclusão dos efeitos dinâmicos na modelagem do comportamento do material M2 não implicou em uma grande variação nos valores das predições de deslocamento máximo permanente da chapa. Uma variação perceptível foi encontrada com elementos de casca, mas com elementos sólidos e axissimétricos as variações foram praticamente imperceptíveis. 
A obtenção dos valores numéricos do deslocamento máximo permanente das chapas exigiu a simulação de $40 \mathrm{~ms}$ de teste, um tempo 16 vezes o simulado para determinação da velocidade balística, pois as distâncias só podem ser mensuradas após a minimização da vibração da chapa. Os tempos de processamento estão apresentados na Tabela 7.10. A simulação com elementos de casca chega a ser 22 vezes menor que quando usada a malha de elementos sólidos.

Tabela 7.10: Tempo de processamento para predição do deslocamento máximo permanente.

\begin{tabular}{|c|c|cl|}
\hline \multirow{2}{*}{ Elemento } & \multirow{2}{*}{ Refinamento } & \multicolumn{2}{|c|}{ Material } \\
& & M1 & M2 \\
\hline \hline casca & ref5 & $2 \mathrm{~h} 43 \mathrm{~min}$ & $2 \mathrm{~h} 44 \mathrm{~min}$ \\
sólido & ref5 & $10 \mathrm{~h} 59 \mathrm{~min}$ & $12 \mathrm{~h} 31 \mathrm{~min}$ \\
axissimétrico & ref6 & $30 \mathrm{~min} 32 \mathrm{seg}$ & $50 \mathrm{~min} 41 \mathrm{seg}$ \\
\hline
\end{tabular}

\subsection{DISCUSSÃO DOS RESULTADOS}

As simulações numéricas realizadas para determinação do deslocamento máximo permanente e da velocidade balística apresentaram, em geral, resultados satisfatórios, com as predições sendo mais ou menos eficazes dependendo do material e da configuração utilizada na representação. As avaliações foram agrupadas de acordo com os dois fatores de influência da representação em elementos finitos estudados: malha e comportamento do material.

\subsubsection{Influência da malha}

A sensível variação das predições das velocidades balísticas com o refinamento da malha, identificada nas simulações preliminares (Figura 7.2), também ocorreu nas simulações finais com os parâmetros definitivos (Tabela 7.6). Comparativamente às predições de deslocamento máximo permanente, sem falha do material (Figura 7.3), as diferenças encontradas entre os refinamentos são maiores no caso balístico onde há falha do material. Esta dependência do tamanho dos elementos da malha pode então ser atribuída, em parte, à utilização do método de eliminação do elemento finito para representação da propagação de trincas, conclusão semelhante à apresentada em Teng e Wierzbicki (2006). Segundo Knight et al. (2000), mesmo para o método TNWF, a dependência da malha é maior nos casos que incluem falha do material que nos casos sem perfuração.

Apesar da variação encontrada entre os refinamentos, que ocorre principalmente entre as malhas mais grossas na Figura 7.2, há uma tendência de convergência dos resultados com 
a diminuição do tamanho dos elementos, ou seja, a dependência não é patológica. Isto também foi observado por Borvik et al. (2002), para uma malha de elementos axissimétricos.

Apesar da malha ref4 ser a melhor predição da velocidade balística do material M1 (Figuras 7.8 a 7.10), quando utilizados elementos sólidos, e uma das melhores também do material M2, quando com elementos de casca (Figuras 7.11 e 7.12), ela não deve ser considerada como predição válida. As diferenças encontradas com relação à malha ref5, tanto nas simulações preliminares quanto nas definitivas, indicam que ainda não se atingiu a convergência dos resultados no refinamento ref4.

A modelagem da chapa com elementos sólidos apresentou uma influência mais acentuada do refinamento que a modelagem com elementos de casca. Melhores resultados foram encontrados na representação da chapa do material M2. Isto está relacionado ao número de elementos utilizados na espessura, que é maior no caso da chapa mais espessa (pois manteve-se o mesmo tamanho de elemento da malha do material M1), e à possibilidade de representação, com estes elementos, de efeitos de cisalhamento, que são maiores na chapa M2 de maior espessura. Assim, o tamanho e o tipo do elemento implicam diretamente na qualidade da representação da chapa ao longo de sua espessura e, conseqüentemente, na acurácia dos resultados. Knight et al. (2000) indicaram a necessidade da utilização de, no mínimo, 3 elementos sólidos na espessura de uma chapa e propuseram que esse número deve aumentar quanto maior for a flexão da mesma.

A resistência relativa das malhas ao impacto, em função do tipo de elemento utilizado, pode ser avaliada, inicialmente, pela comparação das predições de deslocamento máximo permanente. As diferenças em relação aos resultados experimentais estão presentes nas Figuras 7.19 e 7.20, onde a distância entre as curvas de cada tipo de elemento indica a diferença de rigidez entre as malhas. Quanto mais rígida a malha, mais abaixo estará a curva nestas figuras. Nota-se que há diferenças na resistência relativa (ordem das curvas) entre os materiais M1 e M2, as quais se devem principalmente à alterações nas malhas quando da mudança de espessura. As malhas axissimétrica e hexaédrica dobram seu número de elementos na representação do material M2, aumentando o número de graus de liberdade, o que tende a torná-las mais flexíveis, enquanto a malha de elementos de casca tem apenas um parâmetro alterado, a própria espessura do elemento.

Adicionado os modelos de dano e falha, observa-se que houve alterações nas resistências relativas para os dois materiais, como pode ser observado nas Figuras 7.13 e 7.14. Esta 
nova ordem das curvas pode ser explicada pela grande influência do método de representação da fratura do material. Em síntese, a resistência relativa aumenta quanto mais elementos necessitam ser eliminados para transposição da chapa pela esfera.

Nessa modelagem da fratura do material, que possibilita a representação da penetração da esfera, a energia dos elementos eliminados se perde, implicando na não conservação da energia total. No caso do elemento axissimétrico, para haver perfuração total, toda uma região circular, de diâmetro praticamente igual ao da esfera, necessita ser eliminada para possibilitar a passagem desta. Este processo exige uma energia maior que nos outros casos, como pode ser observado na Tabela 7.5, nos quais há a eliminação de apenas quatro linhas axiais de elementos num formato de cruz no plano da chapa, e.g. (Figura 7.6(d)). Isto permite a flexão das regiões delimitadas nos quatro quadrantes criados, que se dobram como pétalas, possibilitando a passagem da esfera, com uma parcela menor da energia eliminada. Adicionalmente, o critério de eliminação de um elemento está indiretamente relacionado às suas variáveis, como tamanho e forma, pois o nível de danificação depende das tensões e deformações cujos cálculos estão associados a sua formulação.

A determinação da velocidade balística numérica da chapa do material M1 (Figuras 7.8 a 7.10) foi o único caso em que as predições de todos os tipos de malha se distanciaram mais de $8 \%$ dos resultados experimentais. Os erros associados à assunção de um comportamento isotrópico numa chapa laminada muito fina poderiam explicar as diferenças, contudo, as predições de deslocamento máximo permanente foram bem eficazes. A causa se concentra, então, na possível falta de exatidão dos parâmetros do modelo de falha de material empregados.

A maioria dos trabalhos citados da literatura utiliza, como comparação, a curva limite balístico, ou seja, velocidade residual versus velocidade de impacto, e boas correlações, inclusive com modelos analíticos, são encontradas. Porém, na região próxima à velocidade balística, ocorrem erros significativos (BORVIK et al., 1999, 2001b, 2002, 2005; GUPTA; IQBAL; SEKHON, 2006). Deste modo, os erros de pouco menos de 20\%, encontrados com elementos axissimétricos, na predição da velocidade balística do material M1, não devem ser considerados suficientemente grandes na determinação de velocidades balísticas, a ponto de se rejeitar a representação utilizada.

Qualitativamente, as modelagens tridimensionais, tanto com elementos de casca quanto sólidos, se mostraram mais semelhantes aos resultados experimentais, possibilitando uma adequada representação da penetração e formação das pétalas, como visto na Figura 7.15. 
Como esperado, a utilização de simetria axial no problema, impediu este tipo de representação, Figura 7.16.

Considerando-se resultados quantitativos, a melhor representação da chapa do material M1 foi a malha de elementos axissimétricos, independente da presença ou não do modelo de falha de material, ao passo que a configuração com elementos sólidos se mostrou mais eficaz para o material M2. Porém, quando considerado o custo computacional na avaliação da melhor representação, o elemento axissimétrico é exageradamente mais eficiente (Tabelas 7.7 e 7.10). Esse tempo é tão menor, que diminui sensivelmente a importância tanto de vantagens dos outros tipos de elemento quanto de possíveis fragilidades deste tipo de representação, como a não variação de resultados frente à inclusão dos efeitos dinâmicos do material (Figura 7.13). Esse baixo custo computacional é certamente a principal razão pela qual o elemento axissimétrico, como citado anteriormente, é amplamente utilizado em simulações balísticas na literatura.

\subsubsection{Efeitos dinâmicos}

A avaliação da inclusão dos efeitos da taxa de deformação no comportamento do material da chapa é aqui realizada com o auxílio das Figuras 7.13 e 7.19, para o material M1, e das Figuras 7.14 e 7.20, para o material M2.

De um modo geral, a inclusão dos efeitos dinâmicos proporcionou um aumento da resistência do material implicando no aumento da rigidez da estrutura, como pode ser evidenciado claramente na Figura 7.19, onde a predição do deslocamento diminui com a inclusão do modelo dinâmico. Esta constatação, porém, não foi unânime e, no caso da malha de elementos axissimétricos e sólidos, do material M2, ocorreu um ligeiro aumento da flexibilidade da estrutura (Figura 7.20).

Interessante notar que, ao se incluir o modelo de dano e falha, os efeitos dinâmicos, em geral, provocaram uma queda na resistência ao impacto da chapa, que pode ser verificada através da observação da queda no valor das velocidades balísticas, para os elementos sólidos e de casca, nas Figuras 7.13 e 7.14. É difícil explicar a causa dessa ocorrência, visto que existe uma combinação de fatores que podem ter levado a esses resultados, principalmente fatores associados ao modelo de dano, o qual não considera efeitos dinâmicos nem triaxilidade, por exemplo. Salienta-se a importância desta constatação, principalmente, pela comum assunção de que não se considerar efeitos dinâmicos implica numa resposta numérica mais conservativa. 
Conforme apresentado anteriormente, as melhores predições para a chapa do material M2 ocorreram com a utilização de elementos sólidos, com erros menores que 5,1\%, que ainda diminuíram com a inclusão dos efeitos dinâmicos pela nova metodologia, tanto na busca da velocidade balística quanto do deslocamento máximo permanente. Este resultado, entretanto, não se repetiu da mesma maneira uniforme entre os outros tipos de malha.

Todas estas variações obtidas com a inclusão dos efeitos dinâmicos, para cada uma das metodologias, demonstram a complexidade da inter-relação entre os fatores envolvidos, como o tamanho e tipo de elemento da malha, modelo constitutivo, de dano e de falha de material, da modelagem da penetração, entre outros. Isto indica o grau de atenção necessária ao se tentar prever resultados, tanto numéricos quanto experimentais. 



\section{CONCLUSÃO}

O impacto de uma esfera de aço contra chapas de duas ligas de alumínio foi estudado numérica e experimentalmente, visando a representação do impacto de pequenos fragmentos contra a fuselagem de aviões. Aspectos de caracterização do material e análise numérica foram abordados de maneira ampla. A partir dos estudos de caracterização dinâmica com a Barra de Hopkinson, foi proposta uma modificação na metodologia convencional usada nos testes com este equipamento, que se mostrou promissora. Avaliou-se a influência de possíveis erros na seleção dos parâmetros de simulação, relacionados ao contato, amortecimento estrutural e principalmente ao material, através de análises de sensibilidade, que indicaram a relevância de uma correta modelagem computacional. Predições numéricas tanto para o deslocamento máximo permanente das chapas, frente ao impacto a baixas velocidades, quanto para as velocidades balísticas, em testes de perfuração total, foram realizadas através do programa LS-DYNA. Confrontados com dados experimentais, estes resultados indicaram boas correlações comparativamente ao já apresentado na literatura.

Nos testes estáticos de tração, evidenciou-se certa anisotropia do material M2, que foi desconsiderada devido à utilização de um modelo de material mais simples. Acredita-se, à luz dos vários testes realizados, que as diferenças estão dentro da variabilidade encontrada em cada direção, de modo que não se justificou a utilização de um modelo anisotrópico. Os parâmetros do modelo de dano de Lemaitre foram retirados da literatura. Uma verificação mais detalhada da obtenção destes parâmetros, através, por exemplo, de um programa de otimização que minimizasse os erros entre as curvas numéricas e experimentais do teste de tração, provavelmente implicaria em valores mais precisos que auxiliariam numa melhor predição das velocidades balísticas.

Testes de compressão a baixas velocidades foram realizados de forma a se obter curvas quase-estáticas dos materiais, na mesma direção que a usada nos testes dinâmicos. Neste tipo de teste, constatou-se muita dependência da geometria do corpo de prova. O paralelismo das faces que entram em contato com os pratos da máquina e a cilindricidade do corpo de prova são essenciais na produção de um estado uniaxial de tensão. Dificuldades foram encontradas na obtenção de corpos de prova com estas características, principalmente no caso da chapa mais fina, a do material M1.

Na determinação do parâmetro do modelo de Johnson-Cook, relacionado à taxa de deformação, as curvas lineares ajustadas apresentaram baixas correlações com os dados 
experimentais. Atribuiu-se este fato à não adequação desse modelo aos materiais, dentro da faixa de valores de taxa de deformação testados. O modelo de Cowper-Symonds foi escolhido, então, para representação dinâmica, mostrando-se bem adequado no ajuste dos dados experimentais.

Testes na Barra de Hopkinson comprovaram a validade da metodologia proposta, a qual elimina a necessidade de utilização de lubrificante, restringindo os efeitos danosos do atrito e equilibrando a relação das inércias axial e radial em corpos de prova de pequeno comprimento. A principal verificação desta eficácia foi a averiguação da ocorrência de taxas constantes de deformação do corpo de prova ao longo do teste. As dificuldades referentes à lubrificação, no teste convencional, foram apontadas e, tanto numérica como analiticamente, evidenciaram-se as vantagens da utilização de um corpo de prova na forma de um anel.

Um opulento conjunto de dados foi colhido nos testes de impacto, o que permitiu a observação e o entendimento dos diversos fenômenos presentes na interação entre a esfera e a chapa. Valores de deslocamentos permanentes, velocidades balísticas, ricochete, restituição elástica, métodos de absorção de energia, modos de propagação de trincas e modos de fratura são alguns dos fatores que puderam ser observados, e que estão associados ao que se consideraria, leigamente, um simples impacto de uma esfera contra uma chapa engastada.

A não consideração, na análise numérica dos testes de impacto, dos efeitos causados pelo aquecimento adiabático, evidenciada na escolha de um modelo que não leva em conta a temperatura, faz com que o amolecimento do material seja gerado apenas através do modelo de dano. Nos testes onde há perfuração, os quais seriam os mais críticos com relação à dependência da temperatura, o material falha em tração, modo este que apresenta uma deformação de ruptura da ordem de $10 \%$ a $20 \%$, insuficiente para geração de calor considerável.

A dependência dos resultados das simulações com a malha, principalmente tamanho de elemento, é apontada como fator crítico nos casos de determinação de velocidade balística. A obtenção da configuração final das chapas pelas simulações foi uma etapa cumprida com sucesso ao se utilizar elementos de casca e sólidos, porém a um custo computacional extremamente alto se comparado ao caso de elementos axi-simétricos.

Os resultados da consideração dos efeitos de taxa de deformação e a variação entre cada metodologia mostraram que há alternância na obtenção da melhor predição entre as três 
situações testadas. Esse resultado é coerente, pois os materiais testados possuem pouca influência da taxa de deformação e outros parâmetros relacionados à simulação e às hipóteses adotadas (isotropia, processo isotérmico, convergência dos refinamentos utilizados, modelo de falha, etc.) podem, através de uma variação simples, aproximar ou distanciar os resultados da resposta experimental.

Trabalhos futuros devem focar na possibilidade de utilização de um remalhamento automático na região do impacto da esfera, a fim de se averiguar o refinamento necessário calculado pelo programa. A repetição de toda o processo descrito neste trabalho, com um material mais sensível à taxa de deformação, confirmaria justificativas apresentadas, exemplificando, de uma maneira quantitativamente mais clara, as diferenças na representação dos efeitos dinâmicos no material com cada metodologia de caracterização. 



\section{REFERÊNCIAS BIBLIOGRÁFICAS}

ADLER, W. F. Rain impact retrospective and vision for the future. WEAR, v. 233-235, p. 25-38, 1999.

AIROLDI, A.; CACCHIONE, B. Modelling of impact forces and pressures in lagrangian bird strike analyses. International Journal of Impact Engineering, v. 32, p. 1651-1677, 2006.

ALVES, M.; CHAVES, C. E.; BIRCH, R. S. Impact on aircraft. In: COBEM 2003. São Paulo: ABCM, 2003.

ALVES, M.; DRIEMEIER, L.; MICHELI, G. B. Impact behaviour of aeronautical materials and structures. São Paulo, Julho 2006. (Relatório Técnico, Grupo de Mecânica dos Sólidos e Impacto em Estruturas).

ALVES, M.; KARAGIOZOVA, D. Correction of frictional effects on Hopkinson pressure bar compression tests. Bochum: The University Press Bochum, 2007. 175-182 p. ISBN 978-3-89966-365-5.

ANSYS. ANSYS Elements Reference. Release 5.5. USA, 1998.

ARIAS, A.; ZAERA, R.; LóPEZ-PUENTE, J.; NAVARRO, C. Numerical modeling of the impact behavior of new particulate-loaded composite materials. Composite Structures, v. 61, p. 151-159, 2003.

ASHBY, M. F.; JONES, D. R. H. Engineering materials 1. $2^{\text {nd }}$. ed. Great Britain: Butterworth Heinemann, 1996. 306 p.

ASITEVEO.COM. Boeing 737-800 de China Airlines se incendio en Okinawa. Agosto 2007. Disponível em: <http://www.youtube.com/watch?v=CzKZP6Si-20>. Acessado em: 20 fev. 2008.

AVITZUR, B. Metal forming: The application of limit analysis. New York: Marcel Dekker, 1980. 208 p.

BERTHOLF, L. D.; KARNES, C. H. Two dimensional analysis of the split Hopkinson pressure bar system. Journal of Mechanis and Physics of Solids, v. 23, p. 1-19, 1975.

BICKFORD, W. B. Advanced Mechanics of Materials. $1^{\text {st }}$. ed. California: Addison Wesley Longman, 1998. 460 p.

BOIS, P. A. D.; KOLLING, S.; KOESTERS, M.; FRANK, T. Material behaviour of polymers under impact loading. International Journal of Impact Engineering, v. 32, p. 725-740, 2006.

BORESI, A. P.; SCHMIDT, R. J.; SIDEBOTTOM, O. M. Advanced Mechanics of Materials. $5^{\text {th }}$. ed. USA: John Wiley and Sons, 1993. 817 p.

BORVIK, T.; CLAUSEN, A. H.; ERIKSSON, M.; BERSTAD, T.; HOPPERSTAD, O. S.; LANGSETH, M. Experimental and numerical study on the perforation of AA6005-T6 panels. International Journal of Impact Engineering, v. 32, p. 35-64, 2005. 
BORVIK, T.; CLAUSEN, A. H.; HOPPERSTAD, O. S.; LANGSETH, M. Perforation of AA5083-H116 aluminium plates with conical-nose steel projectiles-experimental study. International Journal of Impact Engineering, v. 30, p. 367-384, 2004.

BORVIK, T.; HOPPERSTAD, O. S.; BERSTAD, T.; LANGSETH, M. A computational model of viscoplasticity and ductile damage for impact and penetration. European Journal of Mechanics. A. Solids., v. 20, p. 685-712, 2001.

BORVIK, T.; HOPPERSTAD, O. S.; BERSTAD, T.; LANGSETH, M. Numerical simulation of plugging failure in ballistic penetration. International Journal of Solids and Structures, v. 38, p. 6241-6264, 2001.

BORVIK, T.; HOPPERSTAD, O. S.; BERSTAD, T.; LANGSETH, M. Perforation of $12 \mathrm{~mm}$ thick steel plates by $20 \mathrm{~mm}$ diameter projectiles with flat, hemispherical and conical noses. Part II: numerical simulations. International Journal of Impact Engineering, v. 27, p. 37-64, 2002.

BORVIK, T.; LANGSETH, M.; HOPPERSTAD, O. S.; MALO, K. A. Ballistic penetration of steel plates. International Journal of Impact Engineering, v. 22, p. 855-886, 1999.

BORVIK, T.; LANGSETH, M.; HOPPERSTAD, O. S.; MALO, K. A. Perforation of $12 \mathrm{~mm}$ thick steel plates by $20 \mathrm{~mm}$ diameter projectiles with flat, hemispherical and conical noses. Part I: experimental study. International Journal of Impact Engineering, v. 27, p. 19-35, 2002.

BOSSAK, M.; KACZKOWSKI, J. Global/local analysis of composite light aircraft crash landing. Composite Structures, v. 81, p. 503-514, 2003.

BRAGOV, A. M.; LOMUNOV, A. K. Methodological aspects of studying dynamic material properties using the kolsky method. International Journal of Impact Engineering, v. 16, n. 2, p. 321-330, 1995.

CADY, C. M.; GRAY, G. T. Influence of strain rate on the deformation and fracture response of a 6061-T6 Al-50 vol.\% $\mathrm{Al}_{2} \mathrm{O}_{3}$ continuous-reinforced composite. Materials Science and Engineering A, v. 298, p. 56-62, 2001.

CASEM, D. T.; FOURNEY, W. L.; CHANG, P. A polymeric split Hopkinson pressure bar instrumented with velocity gages. Experimental Mechanics, v. 43, p. 420-427, 2003.

CHAROENPHAN, S. Computer methods for modeling the progressive damage of composite material plates and tubes. $168 \mathrm{p}$. Tese (Doutorado) - UNIVERSITY OF WISCONSIN-MADISON, 2002.

CHEN, W.; SONG, B.; FREW, D. J.; FORRESTAL, M. J. Dynamic small strain measurements of a metal specimen with a split Hopkinson pressure bar. Experimental Mechanics, v. 43, p. 20-23, 2003.

CLAUSEN, A. H.; BORVIK, T.; HOPPERSTAD, O. S.; BENALLAL, A. Flow and fracture characteristics of aluminium alloy AA5083-H116 as function of strain rate, temperature and triaxiality. Materials Science and Engineering A, v. 364, p. 260-272, 2004. 
DAVIES, E. D. H.; HUNTER, S. C. The dynamic compression testing of solids by the method of the split Hopkinson bar. Journal of Mechanis and Physics of Solids, v. 11, p. 155-179, 1963.

DIETER, G. E. Mechanical metallurgy. $3^{\text {rd }}$. ed. New York: McGraw Hill, 1986. 751 p.

DONGSHIN ENGINEERING CORP. Aluminum Honeycomb Panel. Junho 2008. Disponível em: <http://rollin75.en.ec21.com>. Acessado em: 20 jun. 2008.

DUFFY, J.; CAMPBELL, J. D.; HAWLEY, R. H. On the use of a torsional split Hopkinson bar to study rate effects in 1100-0 aluminium. Journal of Applied Mechanics, v. 38, p. 83-91, 1971.

EL-MAGD, E.; ABOURIDOUANE, M. Characterization, modelling and simulation of deformation and fracture behaviour of the light-weight wrought alloys under high strain rate loading. International Journal of Impact Engineering, v. 32, p. 741-758, 2006.

ELLWOOD, S.; GRIFFITHS, L. J.; PARRY, D. J. Materials testing at high constant strain. Journal of Physics E: Scientific Instruments, v. 15, p. 280-282, 1982.

ESPINOSA, H. D.; PATANELLA, A.; FISCHER, M. A novel dynamic friction experiment using a modified Kolsky bar apparatus. Experimental Mechanics, v. 40, n. 2 , p. 138-153, June 2000 .

FORRESTAL, M. J.; OKAJIMA, K.; LUK, V. K. Penetration of 6061-T651 aluminum targets with rigid long rods. Journal of Applied Mechanics, v. 55, n. 4, p. 755-760, December 1988.

FREW, D. J.; FORRESTAL, M. J.; CHEN. Pulse shaping techniques for testing elastic-plastic materials with a split Hopkinson pressure bar. Experimental Mechanics, v. 45, n. 2, p. 186-195, April 2005.

GALLINA, F.; BIRCH, R. S.; ALVES, M. Design of a split Hopkinson pressure bar. In: ABCM. 17th International Congress of Mechanical Engineering. São Paulo, Brasil, 2003.

GOLDSMITH, W. Non-ideal projectile impact on targets. International Journal of Impact Engineering, v. 22, p. 95-395, 1999.

GORHAM, D. A. A numerical method for the correction of dispersion in pressure bar signals. Journal of Physics E: Scientific Instruments, v. 16, p. 477-479, 1983.

GUPTA, N. K.; IQBAL, M. A.; SEKHON, G. S. Experimental and numerical studies on the behavior of thin aluminum plates subjected to impact by blunt- and hemispherical-nosed projectiles. International Journal of Impact Engineering, v. 32, p. 1921-1944, 2006.

HADDADI, H.; BOUVIER, S.; BANU, M.; MAIER, C.; TEODOSIU, C. Towards an accurate description of the anisotropic behaviour of sheet metals under large plastic deformations: Modelling, numerical analysis and identification. Internation Journal of Plasticity, v. 22, p. 2226-2271, 2006. 
HALL, I. W.; GUDEN, M. Split Hopkinson pressure bar compression testing of an aluminum alloy: effect of lubricant type. Journal of Materials Science Letters, v. 22, p. 1533-1535, 2003.

HALLQUIST, J. O. LS-DYNA theory manual. California, March 2006.

HARDING, J.; WOOD, E. D.; CAMPBELL, J. D. Tensile testing of materials at impact rates of strain. Journal of Mechanical Engineering Science, v. 2, p. 88-96, 1960.

HAYHURST, C. J.; LIVINGSTONE, I. H. G.; CLEGG, R. A.; DESTEFANIS, R.; FARAUD, M. Ballistic limit evaluation of advanced shielding using numerical simulations. International Journal of Impact Engineering, v. 26, p. 309-320, 2001.

HAZIZAN, M. A.; CANTWELL, W. J. The low velocity impact response of an aluminium honeycomb sandwich structure. Composites PartB: Engineering, v. 34, p. 679-687, 2003.

HORSFALL, I.; AUSTIN, S. J.; BISHOP, W. Structural ballistic armour for transport aircraft. Material \& Design, v. 21, p. 19-25, 2000.

IPSON, R. F. R. e T. W. Ballistic perforation dynamics. Journal of Applied Mechanics, v. 30, p. 384-390, 1963.

JOHNSON, A. F.; HOLZAPFEL, M. Modelling soft body impact on composite structures. Composite Structures, v. 61, p. 103-113, 2003.

JOHNSON, A. F.; PICKETT, A. K.; ROZYCKI, P. Computacional methods for predicting impact damage in composite structures. Composites Science and Technology, v. 61, p. 2183-2192, 2001.

JOHNSON, G. R.; COOK, W. H. A constitutive model and data for metals subjected to large strains, high strain rates and high temperatures. In: Proceedings of the 7th International Symposium on Ballistics. Hague: [s.n.], 1983. p. 541-547.

JOVICIC, J.; ZAVALIANGOS, A.; KO, F. Modeling of the ballistic behavior of gradient design composite armors. Composites Part A: Applied Science and Manufacturing, v. 31, p. 773-784, 2000.

JUE, Z.; SHISHENG, H.; LILI, W. An analysis of stress uniformity for viscoelastic materials during SHPB tests. Latin American Journal of Solids and Structures, v. 3, n. 2, p. $125-148,2006$.

KAPOOR, R.; NEMAT-NASSER, S. Determination of temperature rise duriong high strain rate deformation. Mechanics of Materials, v. 27, p. 1-12, 1998.

KNIGHT, N. F.; JAUNKY, N.; LAWSON, R. E.; AMBUR, D. R. Penetration simulation for uncontained engine debris impact on fuselage-like panels using LS-Dyna. Finite Elements in Analysis and Design, v. 36, p. 99-133, 2000.

KURTARAN, H.; BUYUK, M.; ESKANDARIAN, A. Ballistic impact simulation of GT model vehicle door using finite element method. Theoretical and Applied Fracture Mechanics, p. 113-121, 2003. 
LANDGRAF, M.; JEHN, R.; FLURY, W.; DIKAREV, V. Hazards by meteoroid impacts onto operational spacecraft. Advances in Sace Research, v. 33, p. 1507-1510, 2004.

LEE, O. S.; KIM, M. S. Dynamic material property characterization by split Hopkinson pressure bar (SHPB) technique. Nuclear Engineering and Design, v. 226, p. 119-125, 2003.

LEE, W.; LIN, C.; LIU, T. Strain rate dependence of impact properties of sintered 316L stainless steel. Journal of Nuclear Materials, v. 359, p. 247-257, 2006.

LEE, W.; LIU, C. The effects of temperature and strain rate on the dynamic flow behaviour of different steels. Materials Science and Engineering A, v. 426, p. 101-113, 2006.

LEE, W.; SHYU, J.; CHIOU, S. Effect of strain rate on impact response and dislocation substructure of 6061-T6 aluminum alloy. Scripta Materialia, v. 42, p. 51-56, 2000.

LEMAITRE, J. A course on damage mechanics. Berlin: Springer-Verlag, 1992. 210 p.

LINDHOLM, U. S. Some experiments with the split Hopkinson pressure bar. Journal of Mechanis and Physics of Solids, v. 12, p. 317-335, 1964.

LSTC. LS-DYNA keyword user's manual. version 970. California, Abril 2003.

MALINOWSKI, J. Z.; KLEPACZKO, J. R. A unified analytic and numerical approach to specimen behaviour in the split-Hopkinson pressure bar. International Journal of Mechanical Sciences, v. 28, n. 6, p. 381-391, 1986.

MATWEB. Material Property Data. Fevereiro 2008. Disponível em: $<$ http://www.matweb.com/search/MaterialGroupSearch.aspx>. Acessado em: 18 fev. 2008 .

MENG, H.; LI, Q. M. Correlation between the accuracy of a shpb test and the stress uniformity based on numerical experiments. International Journal of Impact Engineering, v. 28, p. 537-555, 2003.

MENG, H.; LI, Q. M. An SHPB set-up with reduced time-shift and pressure bar lenght. International Journal of Impact Engineering, v. 28, p. 677-696, 2003.

MEO, M.; MORRIS, A. J.; VIGNJEVIC, R.; MARENGO, G. Numerical simulations of low-velocity impact on an aircraft sandwich panel. Composite Structures, v. 62, p. 353-360, 2003.

MICHELI, G. B.; ALVES, M.; GALLINA, F. Influence of friction and specimen geometry in a pressure pulse bar test for dynamic characterisation of materials. In: $X X V$ Iberian Latin American Congress on Computational Methods. Recife: UFPE, 2004.

MINISTERE de L'EQUIPEMENT DES TRANSPORTS ET DU LOGEMENT. Bureau d'Enquêtes et d'Analyses. Accident on 25 July 2000 at "La Patte d'Oie"in Gonesse (95) to the Concorde registered F-BTSC operated by Air France. Paris, julho 2001. (Interim report). 
MSNBC - Associated Press. Hole found in fuel tank of plane that exploded. Fevereiro 2007. Disponível em: <http://www.msnbc.msn.com/id/20373668/>. Acessado em: 20 fev. 2008.

NATIONAL TRANSPORTATION SAFETY BOARD. Uncontained Engine Failure Delta Air Lines Flight 1288, McDonnell Douglas MD-88, N927DA. Washington, D.C., 1998. (Aircraft Accident Report).

NEMAT-NASSER, S.; GUO, W.; KIHL, D. P. Thermomechanical response of AL-6XN stainless steel over a wide range of strain rates and temperatures. Journal of Mechanis and Physics of Solids, v. 49, p. 1823-1846, 2001.

NEMAT-NASSER, S.; ISAACS, J. B.; STARRETT, J. Hopkinson techniques for dynamic recovery experiments. In: Proceedings of the Royal Society A. London: Royal Society Publishing, 1991. A435, p. 371-391.

O POPULAR. Urubu choca-se contra pára-brisa de avião. Abril 2003. Disponível em: <http://www.geocities.com/away_to_fly/Acidentes/urubu.html>. Acessado em: $10 \mathrm{abr}$. 2007.

OKAFOR, A. C.; OTIENO, A. W.; DUTTA, A.; RAO, V. S. Detection and characterization of high-velocity impact damage in advanced composite plates using multi-sensing techniques. Composite Structures, v. 54, p. 289-297, 2001.

PALMIERI, D.; FARAUD, M.; DESTEFANIS, R.; MARCHETTI, M. Whipple shield ballistic limit at impact velocities higher than $7 \mathrm{Km} / \mathrm{s}$. International Journal of Impact Engineering, v. 26, p. 579-590, 2001.

POTEET, C. C.; BLOSSER, M. L. Improving metallic thermal protection system hypervelocity impact resistance through design of experiments approach. In: AIAA (Ed.). 40th Aerospace Sciences Meeting and Exibit. Reno, Nevada: American Institute of Aeronautics and Astronautics, 2002. p. 1-20.

RAVID, M.; BODNER, S. R. Dynamic perforation of viscoplastic plates by rigid projectiles. International Journal of Engineering Science, v. 21, n. 6, p. 577-591, 1983.

RIDDLE, R.; LESUER, D.; SYN, C.; GOGOLEWSKI, R.; CUNNINGHAM, B. Application of metal laminates to aircraft structures: Prediction of penetration performance. Finite Elements in Analysis and Design, v. 23, p. 173-192, 1996.

ROARK, R. J.; YOUNG, W. C. Formulas for Stress and Strain. $5^{\text {th }}$. ed. New York: McGraw-Hill, 1975. 624 p.

ROEDER, B. A.; SUN, C. T. Dynamic penetration of alumina/aluminum laminates: experiments and modeling. International Journal of Impact Engineering, v. 25, p. 169-185, 2001.

ROXBURGH, G. Concord accident pictures. Abril 2003. Disponível em: $<$ http://www.concordesst.com/accident/pictures.html>. Acessado em: $11 \mathrm{abr}$. 2007. 
SCHEFFLER, D. R.; ZUKAS, J. A. Practical aspects of numerical simulation of dynamic events: material interfaces. International Journal of Impact Engineering, v. 24, p. 821-842, 2000.

SCIUVA, M. D.; FROLA, C.; SALVANO, S. Low and high velocity impact on Inconel 718 casting plates: ballistic limit and numerical correlation. International Journal of Impact Engineering, v. 28, p. 849-876, 2003.

SEO, S.; MIN, O.; YANG, H. Constitutive equation for Ti-6Al-4V at high temperatures measured using the SHPB technique. International Journal of Impact Engineering, v. 31, p. 735-754, 2005.

SHAMES, I. H.; COZZARELLI, F. A. Elastic and Inelastic Stress Analysis. $1^{\text {st }}$. ed. New York: Prentice-Hall International, 1992. 722 p.

TENG, X.; WIERZBICKI, T. Evaluation of six fracture models in high velocity perforation. Engineering Fracture Mechanics, v. 73, p. 1653-1678, 2006.

THOMSON, R. S.; SCOTT, M. L. Experience with the finite element modelling of a full-scale test of a composite aircraft control surface. Composite Structures, v. 50, p. 331-345, 2000.

THOMSON, W. T. Theory of Vibration With Applications. $4^{\text {th }}$. ed. London: Chapman \& Hall, 1993. 546 p.

TRAUTMANN, A.; SIVIOUR, C. R.; WALLEY, S. M.; FIELD, J. E. Lubrication of polycarbonate at cryogenic temperatures in the split Hopkinson pressure bar. International Journal of Impact Engineering, v. 31, p. 523-544, 2005.

UEDA, K.; UMEDA, A. Dynamic response of strain gauges up to 300KHz. Experimental Mechanics, v. 32, n. 2, p. 93-98, 1998.

VALES, F.; MORAVKA, S.; BREPTA, R.; CERV, J. Wave propagation in a thick cylindrical bar due to longitudinal impact. International Journal Series A of The Japan Society of Mechanical Engineers, v. 39, p. 60-70, 1996.

WALSTON, W. S.; DAROLIA, R.; DEMANIA, D. A. Impact resistance of NiAl alloys. Material Science \& Engineering, A239-240, p. 353-361, 1997.

WANG, J. A new evaluation to friction analysis for the ring test. Machine Tools and Manufacture, v. 41, p. 311-324, 2001.

WIERZBICKI, T. Pettaling of plates under explosive and impact loading. International Journal of Impact Engineering, v. 22, p. 935-954, 1999.

WIERZBICKI, T.; BAO, Y.; LEE, Y. W.; BAI, Y. Calibration and evaluation of seven fracture models. International Journal of Impact Engineering, v. 47, p. 719-743, 2005.

YADAV, S.; REPETTO, E. A.; RAVICHANDRAN, G.; ORTIZ, M. A computacional study of the influence of thermal softening on ballistic penetration in metals. International Journal of Impact Engineering, v. 25, p. 787-803, 2001. 
YANG, L. M.; SHIM, V. P. W. An analysis os stress uniformity in split Hopkinson bar test specimens. International Journal of Impact Engineering, v. 31, p. 129-150, 2005.

ZHAO, H.; GARY, G. On the use of SHPB techniques to determine the dynamic behavior of materials in the range of small strain. International Journal of Solids and Structures, v. 33, n. 23, p. 3363-3375, 1996.

ZUKAS, J. A.; SCHEFFLER, D. R. Practical aspects of numerical simulation of dynamic events: effects of meshing. International Journal of Impact Engineering, v. 24, p. 925-945, 2000.

ZUKAS, J. A.; SCHEFFLER, D. R. Impact effects in multilayered plates. International Journal of Solids and Structures, v. 38, p. 3321-3328, 2001. 